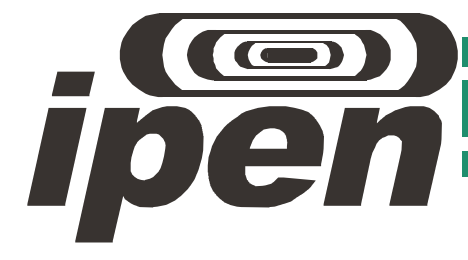

AUTARQUIA ASSOCIADA À UNIVERSIDADE DE SÃO PAULO

ESTUDO DOS POLUENTES ORGÂNICOS PERSISTENTES (POPS) EM REGIÕES INDUSTRIAIS DA GRANDE SÃO PAULO - VIA CROMATOGRAFIA A GÁS ACOPLADA A ESPECTROMETRIA DE MASSAS (GC-MS) E CAPTURA DE ELÉTRONS (GC-ECD)

Justine Paula Ramos de Oliveira

Dissertação apresentada como parte dos requisitos para obtenção do Grau de Mestre em Ciências na Área de Tecnologia Nuclear - Materiais

Orientador:

Prof. Dr. José Oscar Vega Bustillos 
"T rajidez da mudança e a velocidade com que novas
situaçoes säo criadas seguem o ritmo impetuoso e insensato da Fumanidade, e não o passo cauteloso da natureza. 



\title{
Estudo dos poluentes orgânicos persistentes (POPs) em regiões industriais da Grande São Paulo - via cromatografia a gás acoplada a espectrometria de massas (GC-MS) e captura de elétrons (GC-ECD)
}

\author{
Justine Paula Ramos de Oliveira
}

\section{RESUMO}

O estudo objetivou desenvolver e validar um método para identificar e quantificar poluentes orgânicos persistentes, conhecidos como POPs, em solo de regiões industriais dos municípios de Caieiras e Franco da Rocha - SP, via cromatografia a gás acoplada a Espectrometria de Massas (GC-MS) e Detector por Captura de Elétrons (ECD). Em observância ao Tratado de Estocolmo, patrocinado pela Organização das Nações Unidas - ONU, que prevê o banimento de pelo menos doze dos POPs, e no qual o Brasil é um dos 113 países signatários, o trabalho visou colaborar positivamente com essa questão ambiental tão importante. Estes compostos são tóxicos e altamente estáveis no ambiente e em organismos vivos, dentre os quais, são abordados nesse trabalho o clordano cis/trans $\left(\mathrm{C}_{10} \mathrm{H}_{6} \mathrm{Cl}_{8}\right)$, o heptacloro $\left(\mathrm{C}_{10} \mathrm{H}_{5} \mathrm{Cl}_{7}\right)$, o heptacloro epóxido cis/trans $\left(\mathrm{C}_{10} \mathrm{H}_{5} \mathrm{Cl}_{7}\right)$ e os isômeros $\alpha-, \beta-, \gamma-$ e $\delta-B H C\left(C_{6} \mathrm{Cl}_{6}\right)$. Para garantir a confiabilidade das análises realizadas, foram realizados ensaios de Validação da metodologia, com base nas diretrizes do INMETRO. A técnica de extração utilizada foi o QuEChERS, obtendo resultados de recuperação na faixa de 70 a $120 \%$ para a maioria dos compostos estudados, considerados aceitáveis para matrizes complexas. Os limites de detecção e quantificação do método compreenderam a faixa de 0,0002 e 0,01 $\mu \mathrm{g} . \mathrm{g}^{1}$, respectivamente. As amostras analisadas apresentaram contaminação pelos compostos hexaclorobenzeno $\alpha-, \beta-, \gamma^{-}$e $\delta-$, muitas das quais estão acima dos limites máximos permissíveis, de acordo com as legislações nacionais e internacionais vigentes. 


\title{
Study of persistent organic pollutants (POPs) in industrial areas of Greater São Paulo - via gas chromatography-mass spectrometry (GC-MS) and electron capture (GC-ECD)
}

\author{
Justine Paula Ramos de Oliveira
}

\section{ABSTRACT}

The study aimed to develop and validate a method to identify and quantify persistent organic pollutants, known as POPs in soil of industrial regions Caieiras and Franco da Rocha municipalities in São Paulo, via gas chromatography coupled with Mass Spectrometry (GC-MS) and Electron Capture Detector (ECD). In compliance with the Treaty of Stockholm, sponsored by the United Nations - UN, which provides for a ban of at least twelve POPs, in which Brazil is one of the 113 signatory countries, the work aims to contribute positively to the environmental issue as important. These compounds are highly toxic and stable in the environment and living organisms, among which are address in this work chlordane cis / trans $\left(\mathrm{C}_{10} \mathrm{H}_{6} \mathrm{Cl}_{8}\right)$, heptachlor $\left(\mathrm{C}_{10} \mathrm{H}_{5} \mathrm{Cl}_{7}\right)$, heptachlor epoxide the cis / trans $\left(\mathrm{C}_{10} \mathrm{H}_{5} \mathrm{Cl}_{7}\right)$ and the isomers $\alpha-, \beta-, \mathrm{Y}$-and $\delta$ - $\mathrm{BHC}\left(\mathrm{C}_{6} \mathrm{Cl}_{6}\right)$. To ensure reliability of the analysis carried out, tests were carried out validation method, based on the guidelines of INMETRO. The extraction technique was used QuEChERS, achieving recovery in the range 70 to $120 \%$ for the most of compounds, acceptable for complex matrices. The limits of detection and quantification of the method comprises the range of 0.0002 and $0.01 \mu \mathrm{g} . \mathrm{g}^{-1}$, respectively. The samples analyzed were contaminated by compounds hexachlorobenzene- $\alpha, \beta-, \gamma$-and $\delta-$, many of which are above the maximum allowable in accordance with national legislation and international law. 


\section{AGRADECIMENTOS}

A Deus por me presentear com a capacidade de raciocinar e evoluir. Pela saúde, força, perseverança e, por tudo que conquistei nessa jornada que se finaliza, como as várias pessoas que conheci, pessoas muito queridas que foram cruciais para o desenvolvimento desse trabalho. Por ter estabelecido muitas relações, por ter feito muitas amizades e pela oportunidade de crescer com todas elas.

Ao meu esposo Ricardo por seu amor, cumplicidade, apoio e paciência em todos os momentos. Você é o meu maior presente.

A minha família, especialmente meus pais Ana Maria e José Gilson, aos meus irmãos Giulia e Paulo, minha avó Luiza e a minha sogrinha Rita, amo vocês.

Ao Dr. José Oscar Vega Bustillos pela inestimável orientação, pela amizade, apoio e estímulo no desenvolvimento do trabalho e ao amor à ciência.

Ao meu co-orientador, Daniel Temponi Lebre, por suas valiosas dicas e contribuições no desenvolvimento do trabalho.

A Dra. Elâine Arantes Jardim Martins, pelas preciosas contribuições em todo o desenvolvimento da parte experimental do trabalho e validação de método.

Ao Dr. Jorge Vaz por sempre despertar em mim, um olhar mais analítico, em nossas discussões a respeito do meu trabalho.

Ao Dr. Lainetti por sua parceria e disponibilização do equipamento GC-ECD, para realizar as análises, e aos seus alunos, Victor e Guilherme, pela colaboração e amizade.

Ao Dr. Hélio Akira Furusawa, pela inestimável contribuição com relação à planilha de Validação de Ensaios Químicos.

Ao Instituto de Pesquisas Energéticas e Nucleares, IPEN-CNEN/SP e ao Centro de Química e Meio Ambiente, CQMA, pela oportunidade de desenvolver este trabalho. A UNIEMP pela bolsa concedida e ao Centro de Espectrometria de Massas Aplicada - CEMSA, pelo apoio financeiro e infra-estrutura disponibilizada. 
À Tereza Kussumi, do Instituto Adolfo Lutz, por viabilizar este trabalho, de diversas formas, tais como a doação dos padrões de pesticidas, por nos apresentar à equipe da VGS e por estar sempre disposta a discutir sobre o trabalho, me dando muitas dicas.

À Dra. Vera e ao Instituto Adolfo Lutz por todo apoio e parceria firmada.

À VGS - Vigilância Sanitária do estado de São Paulo pela parceria e colaboração no projeto de pesquisa, aos funcionários Sra. Cristiana e Sres. Arnaldo e Mário e a toda equipe pela parceria firmada e disponibilização dos locais de coleta.

Aos meus amigos Renato L. Romano e Helena Miho, Liana Key Nakamura e Henrique pelos bons momentos de descontração, por toda ajuda e apoio, pela amizade e companheirismo, adoro vocês.

Aos amigos do laboratório, Caroline, Jéssica, Tereza, Paulinha, Eloisa, Débora, Clarissa, Leonardo, Sandra, Beth e todos os amigos do laboratório, por fazer meus dias mais leves e divertidos. Muito bom almoçar com vocês.

Aos amigos do CQMA Takeshi e João, pela fabulosa contribuição com o desenvolvimento do coletor de amostras, e aos corajosos Valdelei, Valdeci e Sergio, pela imensa ajuda com a coleta das amostras. Foram, sem dúvidas, muito guerreiros. 


\section{Sumário}

1 INTRODUÇÃO

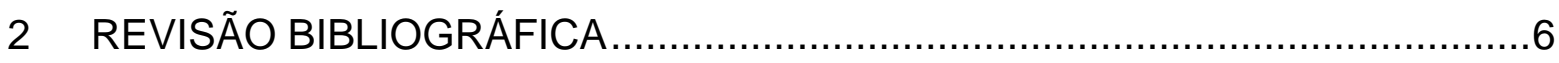

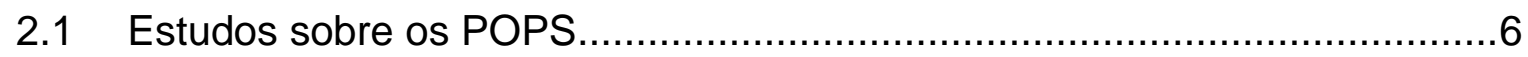

2.2 Histórico sobre análise de POPS em solo no Brasil...................................

2.3 Poluentes orgânicos persistentes …………………..........................11

2.3.1 Breve histórico dos poluentes orgânicos persistentes ........................14

2.3.2 Exposição aos POPs, toxicidade e sintomas....................................16

2.3.3 Legislação a cerca dos POPs......................................................17

2.3.4 Propriedades dos compostos estudados .........................................19

2.3.5 Propriedades Físico-Químicas...................................................22

2.4 Legislações nacionais e internacionais sobre os organoclorados em solo 25

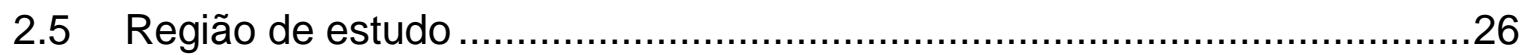

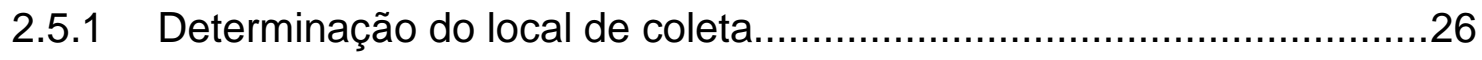

2.5.2 Caracterização da área de estudo...............................................27

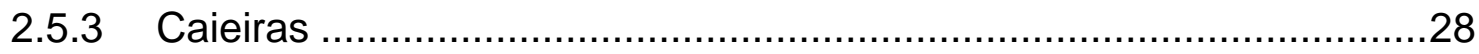

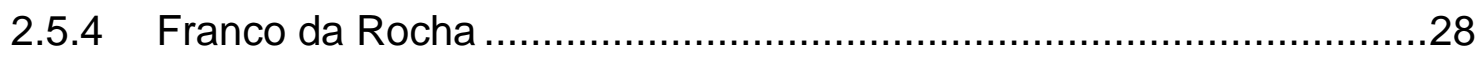

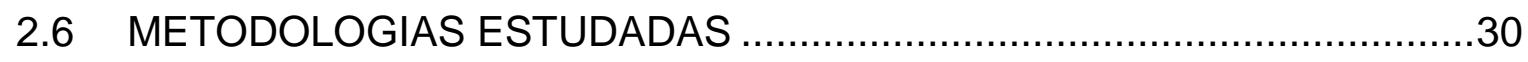

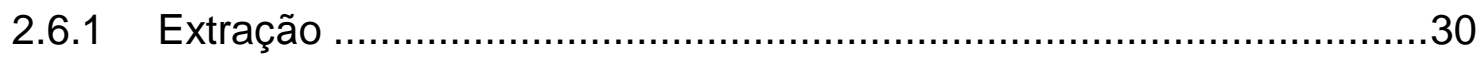

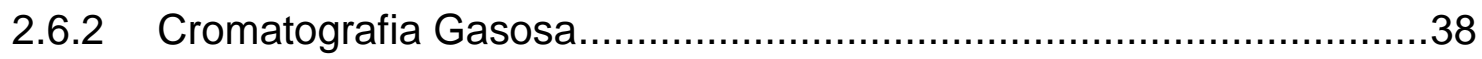

2.6.3 Deteç̧ão por captura eletrônica (ECD) ……….............................43

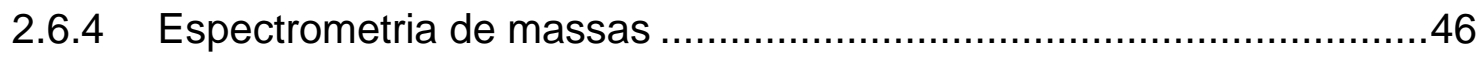

2.6.5 Validação de Método .....................................................................

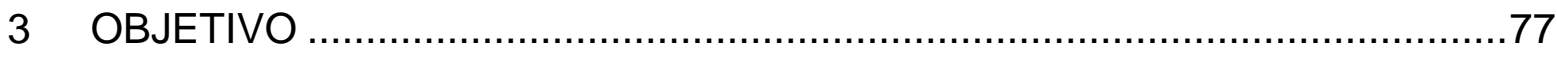

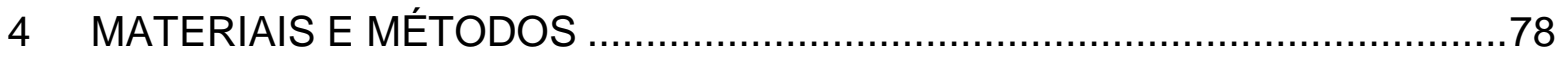

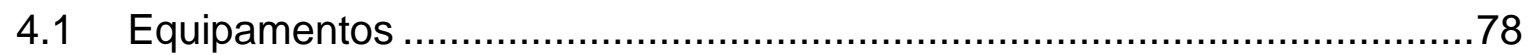




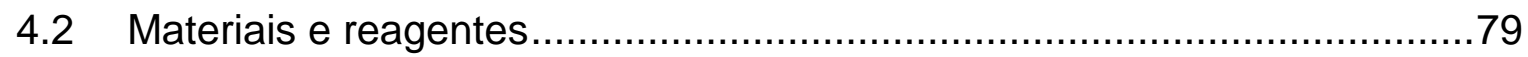

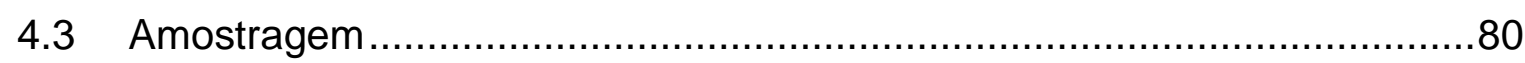

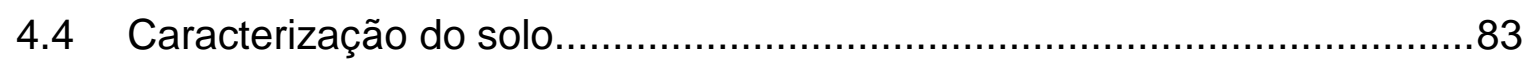

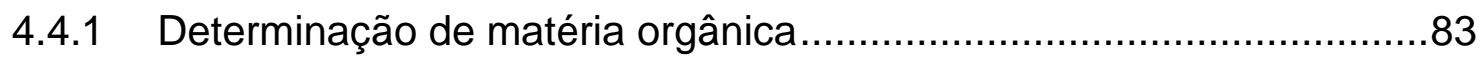

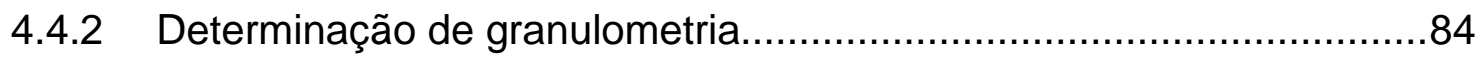

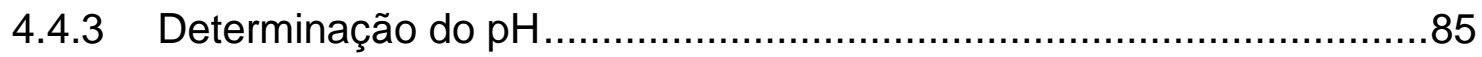

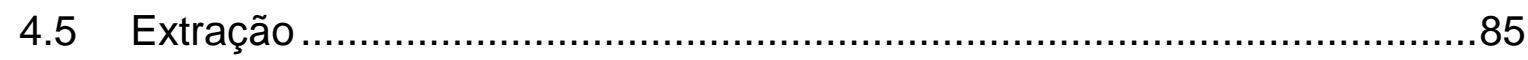

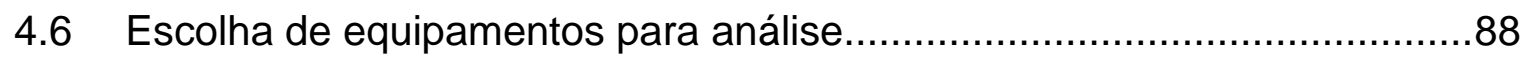

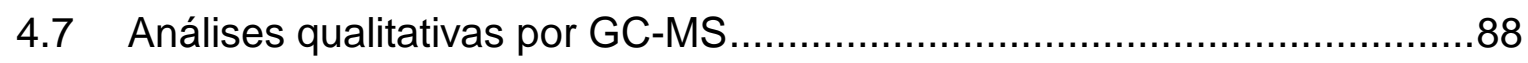

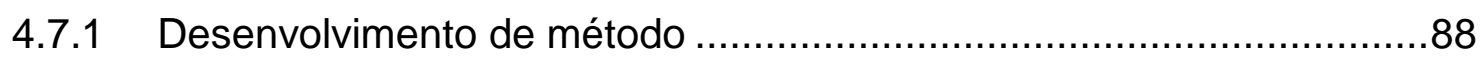

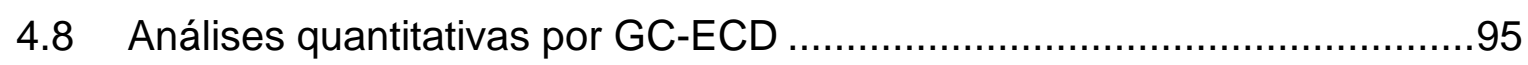

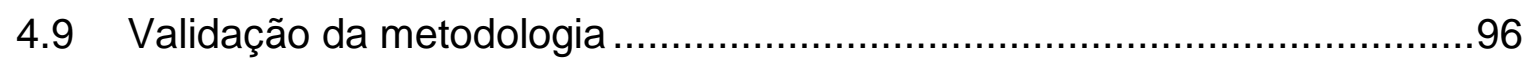

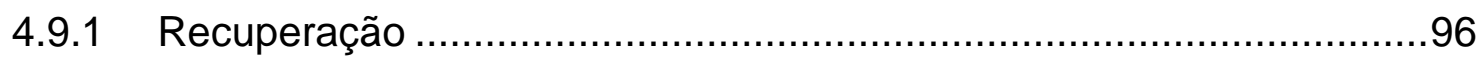

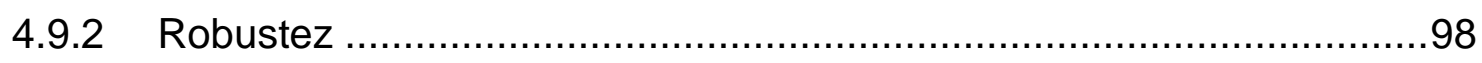

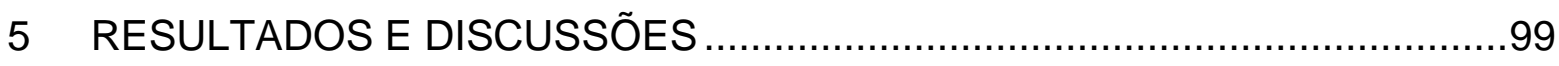

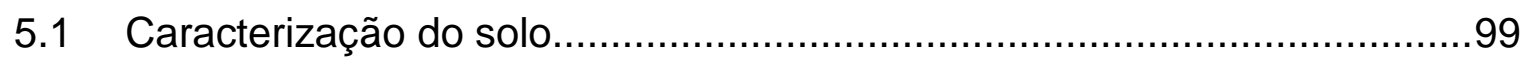

5.1.1 Determinação de Matéria Orgânica (M.O.) .......................................99

5.1.2 Determinação da Granulometria.....................................................99

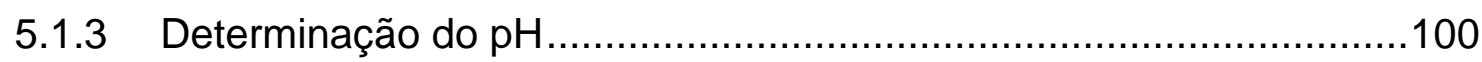

5.2 Resultados de validação .................................................................100

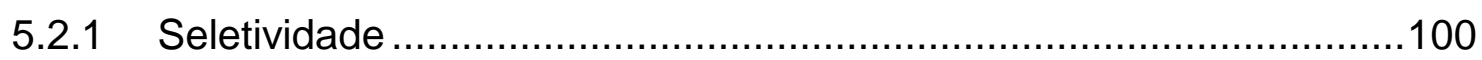

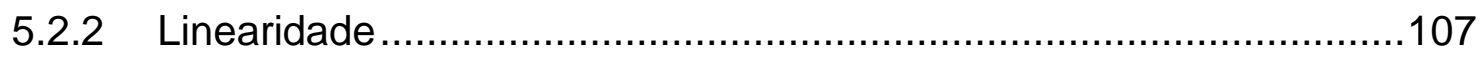

5.2.3 Limites de Detecção (LD) e Quantificação (LQ) ..............................124

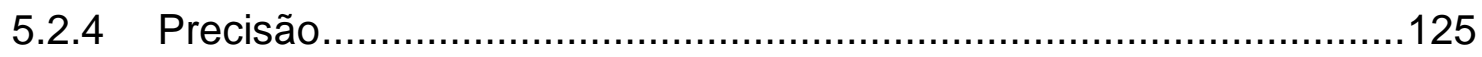

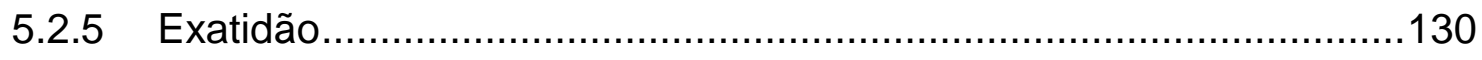

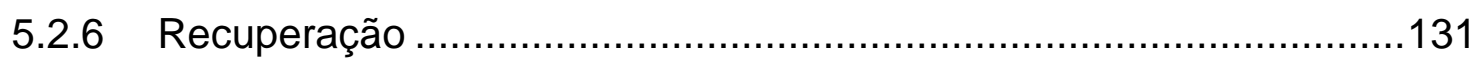


5.2.7 Robustez

5.2.8 Cálculo de incertezas 139

5.3 Resultados das amostras. 144

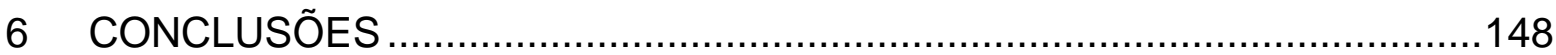

7 CONSIDERAÇÕES E PERSPECTIVAS ................................................150

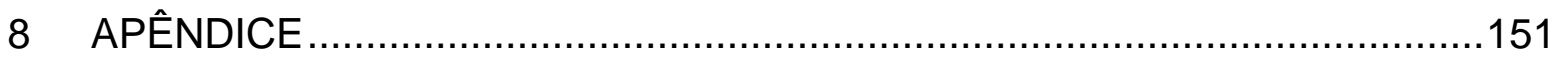

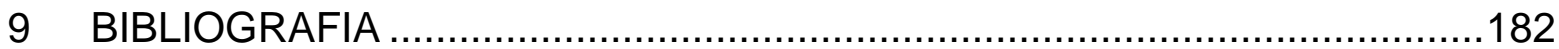




\section{LISTA DE FIGURAS}

Figura 1. Uma criança sendo pulverizada por DDT, na Alemanha, $2^{a}$ Guerra Mundial (Challoner, 2010)

Figura 2. Fórmula Estrutural do (a) $\alpha-B H C,(b) \beta-B H C,(c) \gamma-B H C$ e (d) $\delta-B H C$..20

Figura 3. Fórmula Estrutural do Heptacloro $(\mathrm{C} 10 \mathrm{H} 5 \mathrm{Cl})$

Figura 4. Fórmula Estrutural do Heptacloro Epóxido (a) Cis e (b) trans (C10H5Cl7O)

Figura 5. Fórmula Estrutural do Clordano (a) Cis e (b) Trans $(\mathrm{C} 10 \mathrm{H} 6 \mathrm{Cl} 8) \ldots \ldots \ldots \ldots . . . .22$

Figura 6. Localização geográfica de Caieiras e Franco da Rocha no Brasil ..........28

Figura 7. Esquema ilustrativo de um cromatógrafo a gás .38

Figura 8. Interação entre analito e fase estacionária por (a) dipolo-induzido e (b) dipolo-permanente.

Figura 9. Interação entre analito e fase estacionária por (a) ponte de hidrogênio..41

Figura 10. Esquema de Detector por Captura Eletrônica (ECD) .44

Figura 11. $\mathrm{O} 1^{\circ}$ Espectrômetro de massas (Challoner, 2010). 47

Figura 12. Cromatógrafo a Gás acoplado a Espectrômetro de Massas . 48

Figura 13. Representação esquemática de fonte de íons por impacto de elétrons acoplada a um analisador de massas quadrupolar bidimensional.

Figura 14. Algumas reações de fragmentação na fonte de impacto de elétrons (Skoog et. al, 1998) .51

Figura 15. Curva Analítica Clássica. .68

Figura 16. Cromatógrafo a gás (esquerda) acoplado a um espectrômetro de massas (direita) .78

Figura 17. Cromatógrafo a gás (esquerda) acoplado a um detector por captura eletrônica (direita). .79

Figura 18. Coleta de amostras realizada em Caieiras - SP utilizando coletor de amostras de solo elaborado pela equipe técnica do CQMA .80

Figura 19. Plano de amostragem de solo circular .80 
Figura 20. Região de coleta - município de Caieiras

Figura 21. Região de coleta - município de Franco da Rocha.

Figura 22. Esquema de extração por QuEChERS.

Figura 23. Cromatograma obtido pelo método SCAN, com injeção de mistura de padrões em concentração de $5 \mu \mathrm{g} \cdot \mathrm{mL}-1$, onde os picos cromatográficos correspondem aos padrões de (1) Y-BHC, (2) pentaclorofenol e (3) heptacloro. ....89

Figura 24. Cromatograma obtido pelo metodo SCAN, com injeção de mistura de padrões em concentração de $5 \mu \mathrm{g} \cdot \mathrm{mL}-1$, onde os picos cromatográficos correspondem aos padrões de (1) Y-BHC, (2) pentaclorofenol, (3) heptacloro, (4) e (5) heptacloro epoxido cis/trans e (6) e (7) clordano trans e cis. .89

Figura 25. Cromatograma obtido pelo método SCAN, com injeção de mistura de padrões em concentração de $5 \mu \mathrm{g} \cdot \mathrm{mL}-1$, onde os picos cromatográficos correspondem aos padrões de (1) $\mathrm{Y}-\mathrm{BHC}$, (2) pentaclorofenol, (3) heptacloro, (4) e (5) heptacloro epoxido cis/trans e (6) e (7) clordano trans e cis. .90

Figura 26. Cromatograma obtido pelo método SIM, pela injeção de $1 \mu \mathrm{L}$ de uma solução mistura de padrões em concentração de $1 \mu \mathrm{g} \cdot \mathrm{mL}^{-1}$

Figura 27. Mecanismo de fragmentação do pentaclorofenol por clivagem indutiva.

Figura 28. Mecanismos de fragmentação do íon-molécula heptacloro, por retro Diels-Alder. .93

Figura 29. Mecanismos de fragmentação do íon-molécula clordano, por retro Diels-Alder.

Figura 30. Mecanismos de fragmentação do íon-molécula pentaclorofenol, por rearranjo.

Figura 31. Cromatograma de padrão misto de pesticidas em: (a) solvente e (b) matriz, em concentração $0,1 \mu \mathrm{g} / \mathrm{mL}$, obtido em GC-ECD.

Figura 32. Gráficos de seletividade representados pelas retas obtidas nos ensaios com solvente ( $A C N$ ), solo de Caieiras e de Franco da Rocha para os compostos $\alpha$ BHC e $\beta$-BHC, $y-B H C, \delta-B H C$, heptacloro, heptacloro epóxido cis. 106 
Figura 33. Gráficos de seletividade representados pelas retas obtidas nos ensaios com solvente (ACN), solo de Caieiras e de Franco da Rocha para os compostos heptacloro epóxido trans e clordano cis / trans.

Figura 34. Representação gráfica da linearidade para os compostos $\alpha-B H C, \beta-$ BHC, $y-B H C$ e $\delta-B H C$ estudados em matriz de Caieiras. 108

Figura 35. Representação gráfica da linearidade para todos os compostos estudados em matriz de Caieiras. 109

Figura 36. Representação gráfica da linearidade para todos os compostos, em matriz de Franco da Rocha. 110

Figura 37. Representação gráfica da linearidade para os compostos $\alpha-B H C, \beta-$ $\mathrm{BHC}, \mathrm{y}-\mathrm{BHC}, \delta-\mathrm{BHC}$, heptacloro e Heptacloro epóxido cis em matriz de Franco da Rocha.

Figura 38. Representação gráfica da linearidade para os compostos Heptacloro Epóxido Trans e Clordano Cis / Trans estudados em solvente (ACN). 112

Figura 39. Gráficos dos resíduos absolutos (a) e normalizados (b) para os compostos BHC $\alpha-, \beta-, \gamma^{-}, \delta$ - e heptacloro no ensaio com matriz de Caieiras. 116

Figura 40. Gráficos dos resíduos absolutos (a) e normalizados (b) para o Heptacloro Epóxido Cis/Trans e Clordano Cis/Trans no ensaio com matriz de Caieiras. 117

Figura 41. Gráficos dos resíduos absolutos (a) e normalizados (b) para os compostos BHC $\alpha$-, $\beta$ - e $\gamma$ - e $\delta$ - e Heptacloro ensaio com matriz de Franco da Rocha. 118

Figura 42. Gráficos dos resíduos absolutos (a) e normalizados (b) para o composto Heptacloro Epóxido Cis / Trans e Clordano Cis/ Trans no ensaio com matriz de Franco da Rocha. 119

Figura 43. Gráficos dos resíduos absolutos (a) e normalizados (b) para os compostos BHC $\alpha-, \beta-, \gamma-, \delta$ e Heptacloro no ensaio com solvente (ACN). 120

Figura 44. Gráficos dos resíduos absolutos (a) e normalizados (b) para o composto Heptacloro Epóxido Cis / Trans e Clordano Cis / Trans no ensaio com solvente $(\mathrm{ACN})$ 
Figura 45. Gráficos da faixa de intervalo de confiança no ensaio sem matriz para os compostos $\mathrm{BHC} \alpha-, \beta$-, $\gamma$ - e $\delta$-, estudado na faixa de trabalho considerada.....123

Figura 46. Gráficos da faixa de intervalo de confiança no ensaio sem matriz para o composto Clordano Trans estudado na faixa de trabalho considerada.

Figura 47. Gráficos para os compostos $\alpha-B H C, \beta-B H C, \gamma-B H C, \delta-B H C$, Heptacloro, Heptacloro Epóxido Cis representando teste de verificação de significância dos efeitos. 135

Figura 48. Gráficos para os compostos Heptacloro Epóxido Trans e Clordano Cis/ Trans, representando teste de verificação de significância dos efeitos. 136

Figura 49. Gráficos para os compostos $\alpha-B H C$ representando teste de verificação de significância dos efeitos 136

Figura 50. Gráficos para os compostos $\beta-B H C, y-B H C, \delta-B H C$, Heptacloro, representando teste de verificação de significância dos efeitos

Figura 51. Gráficos para os compostos Heptacloro Epóxido Cis / Trans e Clordano Cis / Trans, representando teste de verificação de significância dos efeitos. 138

Figura 52. Representações gráficas das incertezas individuais envolvidas na análise dos compostos $\mathrm{BHC} \alpha-, \beta-, \gamma$ - e $\delta$ - na matriz de Caieiras

Figura 53. Representações gráficas das incertezas individuais envolvidas na análise dos compostos heptacloro, heptacloro epóxido cis/trans e clordano cis/trans na matriz de Caieiras.

Figura 54. Representações gráficas das incertezas individuais envolvidas na análise dos compostos $\mathrm{BHC} \alpha-, \beta-, \gamma-$ e $\delta$ - na matriz de Franco da Rocha. 142

Figura 55. Representações gráficas das incertezas individuais envolvidas na análise dos compostos Heptacloro, Heptacloro Epóxido Cis/ Trans e Clordano Cis / Trans na matriz de Franco da Rocha.

Figura 56. Gráfico que representa os níveis de concentração dos contaminantes encontrados nas amostras referentes aos 15 pontos coletados no município de Caieiras - SP. 144

Figura 57. Esquema de amostragem da região de Caieiras. 145 
Figura 58. Gráfico que representa os níveis de concentração dos contaminantes encontrados nas amostras referentes aos 15 pontos coletados no município de Caieiras - SP. 146

Figura 59. Esquema de amostragem em região industrial no município de Franco da Rocha. 


\section{Lista de Tabelas}

Tabela 1. Os Poluentes Orgânicos Persistentes e suas Aplicações. 12

Tabela 2. Características físico-químicas dos organoclorados em estudo (Felix et al., 2007). .23

Tabela 3. Limites máximos permissíveis para os organoclorados em estudo, em solos residencial e industrial.

Tabela 4. Ordem cronológica dos principais métodos de análise de resíduos de pesticidas

Tabela 5. Eletroafinidade de alguns átomos e moléculas (Ševčík, 1976). .45

Tabela 6. Parâmetros de validação do INMETRO e ANVISA (Ribani et. al, 2004).55

Tabela 7. Matriz de fatores para a determinação da robustez do método. .70

Tabela 8. Coordenadas dos pontos de amostragem da primeira coleta realizada em torno do aterro.

Tabela 9. Coordenadas dos pontos de amostragem da segunda coleta realizada nos aterros e imediações.

Tabela 10. Programação de temperatura do forno do cromatográfico a gás (GC/MS).

Tabela 11. Programação de monitoramento de íons para o detector do espectrômetro de massas (GC/MS).

Tabela 12. Programação de temperatura do forno da coluna cromatográfica (GC/ECD). .96

Tabela 13. Parâmetros selecionados para os testes de robustez. .98

Tabela 14. Dados e resultados obtidos para o teste de determinação de Matéria Orgânica.

Tabela 15. Dados e resultados obtidos para o teste de determinação de Granulometria. 100

Tabela 16. Resultados da seletividade pela aplicação dos testes $F$ e $t$ para os compostos estudados, pela adição padrão somente no solvente e nas matrizes de solo de Caieiras e Franco da Rocha (teste $F$, considera o $n=7$, com 6 graus de 
liberdade; o teste $\mathrm{t}$ considera o $\mathrm{n}=14$, com 12 graus de liberdade e $95 \%$ de confiança). Tabela com os resultados dos valores calculados, considerando e Ftabelado $=4,28$ e ttabelado $=2,179$.

Tabela 17. Faixa de trabalho para cada composto, equação da reta e coeficiente de determinação (r2) obtidos pela adição padrão na matriz de Caieiras. 108

Tabela 18. Faixa de trabalho para cada composto, equação da reta e coeficiente de determinação (r2) obtidos pela adição padrão na matriz de Franco da Rocha.

Tabela 19. Faixa de trabalho para cada composto, equação da reta e coeficiente de determinação (r2) obtidos pela adição padrão em solvente (ACN).

Tabela 20. Valores de tcalculado obtidos pelo teste t Student para a verificação do desvio da linearidade de cada ponto da curva para os nove compostos estudados na matriz de Caieiras, onde o valor de ttabelado $=2,365$, considerando 7 graus de liberdade $(n-1)$ e $95 \%$ de confiança.

Tabela 21. Valores de tcalculado obtidos pelo teste t Student para a verificação do desvio da linearidade de cada ponto da curva para os nove compostos estudados na matriz de Franco da Rocha, onde o valor de ttabelado $=2,365$, considerando 7 graus de liberdade (n-1) e 95\% de confiança. 113

Tabela 22. Valores de tcalculado obtidos pelo teste t Student para a verificação do desvio da linearidade de cada ponto da curva para os nove compostos estudados na em solvente $(A C N)$, onde o valor de ttabelado $=2,365$, considerando 7 graus de liberdade $(n-1)$ e $95 \%$ de confiança.

Tabela 23. Resumo dos resultados da análise de variância (ANOVA) para os nove compostos estudados nas matrizes de Caieiras e Franco da Rocha. 122

Tabela 24. Limites de detecção e de quantificação para os compostos estudados. 125

Tabela 25. Coeficientes de variação (CV \%) para os compostos em três níveis de concentração nos ensaios com as matrizes de Caieiras (C) e Franco da Rocha $(\mathrm{FR})$.

Tabela 26. Valores do limite de repetitividade ( $r$ ) para os compostos em três níveis de concentração no ensaio com matriz de Caieiras. 126 
Tabela 27. Valores do limite de repetitividade ( $r$ ) para os compostos em três níveis de concentração no ensaio com matriz de Franco da Rocha.

Tabela 28. Resultados do limite de reprodutibilidade (R) para os compostos em três níveis de concentrações no ensaio com matriz de Caieiras

Tabela 29. Resultados do limite de reprodutibilidade (R) para os compostos em três níveis de concentrações no ensaio com matriz de Franco da Rocha.

Tabela 30. Resultados do z Score para os compostos estudados nos ensaios em matriz de Caieiras e Franco da Rocha.

Tabela 31. Teste de recuperação dos compostos estudados (médias de 3 resultados) 133

Tabela 32. Resultados para as Incertezas expandidas referente a um ponto intermediário das curvas analíticas nas matrizes de Caieiras (C) e Franco da Rocha (FR), considerando $k=1,96$ e $95 \%$ de confiança. 139

Tabela 33. Contribuição da incerteza de cada grandeza de entrada no cálculo do mensurando no ensaio com a matriz de Caieiras, considerando o ponto médio do intervalo de concentração das curvas analíticas dos compostos estudados. 140

Tabela 34. Contribuição da incerteza de cada grandeza de entrada no cálculo do mensurando no ensaio com a matriz de Franco da Rocha, considerando o ponto médio do intervalo de concentração das curvas analíticas dos compostos estudados. 142

Tabela 35. Resultados das análises das amostras coletadas em 2ª Campanha no município de Caieiras.

Tabela 36. Resultados das análises das amostras coletadas em 2 ${ }^{\mathrm{a}}$ Campanha no município de Franco da Rocha. 146 


\section{INTRODUÇÃO}

Com o avanço da ciência e tecnologia, a maior parte dos produtos utilizados em nosso cotidiano, de alguma forma se beneficia do uso de produtos químicos. A utilização desses produtos cada vez mais têm se tornado indispensável para o desenvolvimento da economia de muitos países. Contudo, o grande desafio é trazer não somente a comodidade em fazer uso destes produtos, como garantir que esses compostos sejam manejados com segurança, ou seja, protegendo a vida humana e o meio ambiente.

Os Poluentes Orgânicos Persistentes, conhecidos como POPs, são compostos altamente estáveis e que persistem no ambiente, resistindo à degradação química, fotolítica e biológica (Stockholm Declaration, 2001).

São tóxicos para os seres vivos, pois têm a capacidade de bioacumular-se em organismos vivos. Estes compostos são lipofílicos e distribuem-se no interior das membranas celulares e depósitos de gordura. Desta forma, organismos tais como algas, que vivem em águas poluídas com compostos orgânicos persistentes, acumulam estas substâncias na medida em que as mesmas possuem maior afinidade por lipídios biológicos do que pela água. Quando esses organismos são ingeridos por animais, tais como crustáceos, no próximo nível trófico, estes acumulam quantidades ainda maiores. Níveis tróficos mais altos na cadeia alimentar podem então adquirir e armazenar concentrações extremamente altas de poluentes, em torno de 100.000 vezes a concentração que ocorre na água.

Atuam negativamente também nos sistemas reprodutivo, imunológico e endócrino, sendo também apontados como cancerígenos. Outra característica muito importante é a lixiviação, ou seja, o fato de serem transportados a longas distâncias pela água, vento e até mesmo pelos animais (Cockerman, 1994).

No que se refere à concentração destes produtos em solo, há um fator preocupante que diz respeito à formação de resíduos de pesticidas não extraíveis ou ligados ao solo, que podem resultar em menor biodisponibilidade e menor lixiviação do pesticida (Malliaros, 1997). A contaminação do solo implica não somente a 
quantidade de pesticidas à qual uma pessoa está sujeita a exposição, mas dos contaminantes que possam ser removidos do mesmo, podendo, posteriormente adentrar o organismo humano via sistema digestivo, por contaminação de alimentos. Em função da complexidade da matriz orgânica e inorgânica do solo, diferentes tipos de compostos químicos comportam-se de maneiras distintas. Isto implica que o procedimento de extração a ser utilizado não quantificará a presença da totalidade dos pesticidas a serem considerados, mas sim quantificará os pesticidas não ligados (Nakagawa, 2000). Estes dados, por sua vez podem ser utilizados para o cálculo da bioacessibilidade destes compostos, sendo a bioacessibilidade definida como a fração máxima de contaminantes presentes no solo que podem ser recuperados de um modelo de composição fisiológica e condições de digestão do trato digestivo humano (Kramer, 2000).

A falta de especificidade de alguns destes pesticidas representa riscos para 0 homem e, em conseqüência, tem aumentado a preocupação no que concerne ao efeito destes compostos à saúde humana e ao meio ambiente, particularmente em países cujas atividades de vigilância, controle e gerenciamento são pouco desenvolvidos (Maroni, 2000).

Alguns dos POPs foram resultados de incinerações de resíduos. Os pesticidas começaram a ser usados em larga escala após a Segunda Guerra Mundial, utilizados tanto na proteção de culturas agrícolas como em prevenção de doenças como a malária.

O uso destes pesticidas salvou milhões de pessoas ao serem utilizados para liquidar insetos transmissores de doenças, como é o caso do mosquito da malária. No entanto o efeito negativo destes compostos na agricultura bem como no ambiente, começou a ser mais evidente a partir dos anos 50 .

Nesse sentido, a Declaração de Estocolmo, documento que insere no vocabulário mundial, conceitos como ecologia e educação ambiental, elaborado na Conferência ocorrida na Suécia, prestigiada por cerca de 113 países, incluindo o Brasil, em 1.972, patrocinada pela Organização das Nações Unidas - ONU vem a ser o primeiro instrumento global que obriga os governos a tomarem ações objetivando a eliminação desses poluentes no meio ambiente. A não observância dos requisitos da declaração acima citada implicará em sanções políticas e econômicas aos países signatários. O documento prevê a eliminação de doze POPs ( dioxinas, furanos, DDT, 
PCBs, Clordano, Heptacloro, Aldrina, Dieldrina, Endrina, Mirex, Toxafeno e hexaclorobenzeno), predominantemente aplicados como pesticidas e alguns obtidos também como subprodutos de processos industriais, como por exemplo, as dioxinas e os furanos (ESB, 2006).

Uma grande variedade de indústrias químicas está envolvida na produção de compostos orgânicos persistentes. Indústrias produtoras de pesticidas, ácidos, bases, fertilizantes, resinas sintéticas, fibras artificiais entre outras, produzem grandes quantidades de POPs, em função do tratamento do lixo produzido (Malliaros, 1997)

Estes compostos foram banidos, porém a política de recolhimento desses materiais e o respaldo por parte do governo no que se referia ao gerenciamento desses resíduos, foi muito precária, e por isso não apresentou estrutura suficiente para lidar com este novo quadro. Muitas empresas, portanto, procederam inadequadamente no descarte destes contaminantes, afetando diversas matrizes, como água, solo e até mesmo organismos vivos (Cavalcanti,1998).

Dados estatísticos de 1996 situavam os agrotóxicos, de uso agropecuário, entre os três principais agentes de óbitos por intoxicação em ambos os sexos, destacandose com $41 \%$ dos óbitos no sexo masculino (CICT/FIOCRUZ, 1996), enquanto que os dados estatísticos de 1999 situavam os agrotóxicos, de uso agrícola, como os responsáveis pela maior letalidade por intoxicações em ambos os sexos (CICT/FIOCRUZ 1999). Estudos indicam que a maioria dos casos de intoxicação por agrotóxicos ocorre, principalmente, devido ao descumprimento das normas de segurança para a sua aplicação, devido a irregularidades no armazenamento e na distribuição dos produtos, assim como a ausência de políticas públicas de controle (OPAS/OMS, 1991). Embora os dados estejam corretos, a localização do problema no nível dos usuários reflete um tipo de discussão que acaba isentando a responsabilidade das indústrias que lucram com esta situação (Peres, 1999).

No Brasil, existe um vasto mercado de agrotóxicos que compreende aproximadamente trezentos princípios ativos aplicados em duas mil fórmulas diferentes. Deste total, segundo o Manual de Vigilância da Saúde de Populações Expostas a Agrotóxicos (OPAS/OMS, 1996), somente 10\% das substâncias químicas foram efetivamente submetidas a uma avaliação completa de riscos e $38 \%$ jamais sofreram qualquer avaliação. 
O país apresenta algumas áreas com forte histórico de contaminação ambiental, como por exemplo, os municípios de Cubatão, Franco da Rocha, Caieiras, - SP, entre outros, todos contaminados por POPs. Algumas das empresas responsáveis pelos passivos, já procedem a remediação. Entretanto o acesso a estas áreas é geralmente restrito, exceto pelas áreas abandonadas, devido à declaração de falência das empresas responsáveis, como ocorreu nos municípios de Franco da Rocha e Caieiras. Segundo informação técnica da VGS, uma empresa de fabricação de detergente em pó, líquido e pastoso encerrou as suas atividades em 1992, deixando no terreno resíduos de $\mathrm{BHC}$ e de sais de níquel oriundos da produção na cidade de Caieiras. A CETESB também detectou, na água da região, contaminação por BHC. Os estudos realizados pela CETESB nos aterros industriais nos municípios de Caieiras e Franco da Rocha-SP, até o momento, não foram suficientes para gerar um planejamento de proteção de riscos à saúde.

Poluentes potencialmente perigosos, geralmente, estão presentes, mesmo em concentrações baixas, nos pontos onde foram processados, estocados ou utilizados, e isso é um dado importante na condução dos estudos efetivos do histórico do local. Desta forma, as concentrações determinadas nesses locais são comparadas aos valores orientadores para a definição da condição da qualidade do solo. Assim, é possível estabelecer critérios de avaliação da qualidade do solo.

A análise de POPs concentra-se basicamente em duas etapas: a extração e a detecção. As metodologias de extração de pesticidas são diversas, compreendendo desde a técnica de Soxhlet definida como clássica, que utilizada quantidade demasiadamente grande de solventes orgânicos (Dean, 2000), até as técnicas de micro-extração, como por exemplo, o QuEChERS (Quick, Easy, Cheap, Effective and Rugged), método introduzido por Michelangelo Anastassiades em 2003. Este método de extração multiresíduo de pesticidas foi inicialmente aplicado em alimentos. Esta técnica vem ganhando campo na extração de solo, por ser uma técnica rápida, seletiva, de bons níveis de recuperação, além de ser simples e econômica (PINTO, 2010). A técnica de cromatografia gasosa (GC, gas chromatography), usada na determinação de compostos voláteis, pode ser acoplada a diferentes detectores. $\mathrm{O}$ detector por espectrometria de massas (MS, mass spectrometry) se destaca por ser uma técnica multielementar e de alta confiabilidade. O detector por captura eletrônica (electron capture detector, ECD), entretanto, destaca-se por sua alta sensibilidade a 
compostos halogenados, constituindo uma ferramenta excelente na quantificação de pesticidas clorados (Skoog, 1998).

Contudo, não são suficientes apenas boas técnicas analíticas para garantir a qualidade dos dados gerados e a confiabilidade dos resultados. Visando atender as exigências de órgãos nacionais e internacionais o novo método deve passar pelo processo denominado de validação de ensaio químico. A validação busca demonstrar que a metodologia desenvolvida é adequada ao uso pretendido, além de assegurar a comparabilidade e rastreabilidade dos resultados. Apesar de não existir uma norma que padronize o processo de validação, no Brasil, as duas agências que regulamentam e fornecem guias para validar um ensaio são a ANVISA - Agência Nacional de Vigilância Sanitária e o INMETRO - Instituto Nacional de Metrologia e Qualidade Instrumental (Ribani et. al, 2004).

Este estudo objetivou determinar nove poluentes orgânicos persistentes, de origem industrial em amostra de solo de municípios de Caieiras e Franco da Rocha SP, utilizando a técnica de extração QuEChERS seguida de determinação qualitativa por cromatografia a gás com detecção por espectrometria de massas (GC/MS) (Bustillos, 2003), e por determinação quantitativa por detector por captura eletrônica (ECD).

A validação de um método analítico envolve inúmeros experimentos laboratoriais e cálculos estatísticos para demonstrar a qualidade das medidas intrumentais. Para análise dos resultados obtidos foi utilizada a planilha "Validação de Ensaios Químicos", desenvolvida por Furusawa (2007). 


\section{REVISÃO BIBLIOGRÁFICA}

\subsection{Estudos sobre os POPS}

Nas últimas décadas, estudos sobre POPs têm sido desenvolvidos em todo o mundo, nas mais diversas matrizes, objetivando a detecção e quantificação desses contaminantes, assim como o entendimento de seu comportamento, mobilidade e possíveis transformações (Flores et. al, 2004). Estes compostos atingem o solo, não só pela incorporação direta na superfície, como também pelo tratamento de sementes com fungicidas e inseticidas, no controle de fungos patogênicos no solo, ou pela eliminação de ervas daninhas por herbicidas. Esses compostos podem ainda atingir o solo de forma indireta, pela pulverização das partes verdes dos vegetais e pela queda de frutos ou folhas que receberam aplicação de agrotóxicos (Musumeci, 1992). Uma vez no solo, podem ser transportados em grandes quantidades, pelas águas das chuvas, que levam a cobertura vegetal e parte do solo, atingindo, principalmente, águas superficiais como rios e lagos. Os pesticidas podem também se infiltrar no solo, atingindo as águas subterrâneas e ser encontrados em poços utilizados para abastecimento de água para o uso doméstico ou para dessedentação de animais. A importância relativa dessas duas formas de transporte depende, em grande parte, do tipo de solo e do relevo da região (Rigitano e Barbosa, 1994; Moreira e Cruz, 1996).

Hoje, existem evidências de que consideráveis quantidades de pesticidas atingem o mar. Segundo a Academia de Ciências dos Estados Unidos, cerca de 25\% da produção mundial de organoclorados chega ao ecossistema (Flores et. al, 2004).

Cascaes (2009) realizou estudo do comportamento de organoclorados em ambiente marinho, usando tubarões como indicadores. Os compostos bifenilas policloradas (PCBs) foram encontrados em maior concentração. Foi constatada uma maior concentração em organismos dos machos maduros do que nas fêmeas maduras, indicando uma possível transferência do contaminante para os filhotes.

Pesquisadores analisaram 60 amostras de leite materno em mulheres egípcias. Os resultados indicaram a presença de DDE e lindado em praticamente todas as amostras. Outros organoclorados, como DDT, Endrina e Endossulfano também foram encontrados em níveis elevados em algumas amostras. A presença destes pesticidas 
foi atribuída à intensa atividade agrícola na região (Flores et. al, 2004; Saleh et. al, 1996).

Análises de amostras em leite materno têm fornecido dados alarmantes em várias partes do mundo. Uma pesquisa realizada na India revelou a presença de DDT e BHC em leite materno, foram coletadas cerca de 90 amostras. As voluntárias eram moradoras de regiões agrícolas, urbanas e de vilas de pescadores. As concentrações de BHC variaram na faixa de 400 a $4500 \mathrm{ng} \cdot \mathrm{g}^{-1}$ (Subramanian et. al, 2007).

No Brasil, Sassine (2002) realizou um estudo de determinação de pesticidas em leite bovino. Após 24 horas da aplicação do inseticida, foram detectados $0,168 \mathrm{mg} \cdot \mathrm{kg}^{-}$ ${ }^{1}$ de cipermetrina, concentração superior ao limite máximo permissível $\left(0,01 \mathrm{mg} \cdot \mathrm{kg}^{-1}\right)$.

Kim e Smith (2001) realizaram um estudo da distribuição de 18 pesticidas em solos de plantação de arroz e de regiões industriais, no sul da Coréia. Para a extração, utilizou-se o método de Ultrassonificação. As análises foram realizadas por GC-MS e na quantificação, fez-se uso de padrão interno, assim como para os testes de recuperação, nos quais foram obtidos resultados na faixa de 78 a $167 \%$. As amostras analisadas apresentaram contaminantes na faixa de 14 a $53 \mathrm{ng} \cdot \mathrm{g}^{-1}$.

Zhang et.al (2009) determinou a presença de 22 pesticidas em solo superficial de indústrias no sudeste da China. A extração foi realizada pelo método SPE e as análises, por GC-MS. O método cromatográfico obteve duração de 38 minutos. Fezse uso de padrão interno para a quantificação. O teste de recuperação foi realizado utilizando-se o padrão interno e obtiveram-se resultados entre 75 a 125\%. Os LD variaram entre 0,01 a $0,17 \mu \mathrm{g} \cdot \mathrm{kg}^{-1}$. Foi detectada a presença de vários organoclorados, como $\alpha, \beta, \gamma, \delta$-BHC quantificados em concentrações na faixa de 0,02 a $96,7 \mu \mathrm{g} \cdot \mathrm{kg}^{-1}$.

Ssebugere et. al (2010) realizou análises de 10 pesticidas em solo no sudeste de Uganda. As amostras foram extraídas empregando o método Åkerblom, considerado relativamente complexo, por envolver uma série de etapas na manipulação da amostra. Além de envolver um gasto significante de reagentes, se comparado a outros métodos de extração multirresíduo de pesticidas atuais. As técnicas de análise utilizadas foram GC-ECD e GC-MS. Os métodos cromatográficos adotados para GC-ECD e GC-MS obtiveram duração de 48 e 46 minutos, respectivamente. Os LD obtidos variaram de 0,05 a $0,2 \mu \mathrm{g} \cdot \mathrm{kg}^{-1}$. Os testes de 
recuperação variaram em seus resultados, obtendo o menor rendimento para aldrin (52 - 59\%) e o maior rendimento para endossulfano (79-89\%). Nas amostras de solo analisadas foi detectada a presença de DDT e de seus metabólitos entre outros organoclorados.

\subsection{Histórico sobre análise de POPS em solo no Brasil}

Dorigatti (1987) realizou um estudo de dissipação de herbicidas, da classe dos organoclorados, em solos brasileiros, dos tipos arenoso e argiloso, aplicando a técnica de extração sólido / líquido, na qual foram testados vários solventes, sendo a acetonitrila o solvente escolhido, por apresentar maior recuperação. Como técnica de análise, foi empregada a cromatografia a gás acoplada a sistema de detecção termiônico específico, que por apresentar alta sensibilidade, possibilitou a análise e acompanhamento da dissipação até um baixo nível do herbicida no solo. A faixa de trabalho estabelecida compreendeu de 0,05 a $1 \mu \mathrm{g} \cdot \mathrm{mL}^{-1}$. Os resultados obtidos para os testes de recuperação foram, em média, de 64,2\%.

O estudo do efeito da irrigação na movimentação no solo dos inseticidas Thiodcarb e Carbofuran usados em tratamento de sementes de milho, desenvolvido por Vieira (1996) utilizou como método de extração de Thiodcarb, uma adaptação de método para extração do analito em folhas. Procedeu-se uma extração sólido-líquido e posterior pré-concentração com evaporação a $45^{\circ} \mathrm{C}$ em evaporador rotatório. Os resultados obtidos para recuperação de Thiodcarb ficaram na faixa de 90 a 100\%. O método de extração do Carbofuran seguiu o procedimento usado para o Thiodcarb, porém, com algumas modificações, como temperatura de evaporação $\left(35^{\circ} \mathrm{C}\right)$ na etapa de pré-concentração e a utilização de banho-maria no processo de préconcentração. Os resultados de recuperação foram acima de 90\%. O método de análise foi cromatografia líquida (High Performance Liquid Chromatography, HPLC) acoplado a detector Ultravioleta Visível (UV). A faixa de trabalho adotada foi de 0,1 a $5 \mu \mathrm{g} \cdot \mathrm{mL}^{-1}$. As análises constataram uma maior retenção dos compostos nas camadas mais superficiais do solo, e que a lixiviação dos mesmos está diretamente relacionada a sua solubilidade em água.

Javaroni et. al (1999) estudou o comportamento dos herbicidas atrazina e alaclor aplicados em solo preparado para o cultivo de cana-de-açucar. Foram analisados 5 
grupos com 3 amostras, cada. Todas as amostras foram submetidas a três métodos de extração, dois deles, empregando extração por Soxhlet, variando-se as composições dos solventes. O último consiste em uma extração líquido-líquido. Os extratos obtidos foram eluídos por uma coluna Florisil ativado para retirada de impurezas. Os testes de recuperação foram realizados procedendo a adição de concentração conhecida dos padrões atrazina e alaclor em amostra-testemunha, obteve-se resultados de $96,90 \% \pm 1,6 \%$ para atrazina e $88,3 \% \pm 4,5 \%$ para alaclor. As análises foram realizadas empregando-se a técnica de Cromatografia a Gás acoplada detector de nitrogênio e fósforo (GC-NPD).

Dominguez (2001) determinou a presença de 4 isômeros, $\alpha-, \beta-, \gamma$ - e $\delta$ - do hexaclorocicloexano $(\mathrm{BHC})$. Os estudos foram realizados em solo de estrada, de um ponto suspeito de ter sido aterrado com BHC, e em 3 áreas destinadas a construção de moradias, na cidade dos Meninos situada em Duque de Caxias, RJ. O LD do método foi determinado em $1 \mu \mathrm{g} \cdot \mathrm{kg}^{-1}$. Foi usada extração sólido-líquido, envolvendo etapas de agitação, ultrassonificação, filtração e posterior pré-concentração. A análise foi realizada por GC-ECD. $O$ método cromatográfico obteve aproximadamente 31 minutos de duração. Os resultados dos testes de recuperação foram obtidos na faixa de 80 a $90 \%$. Foi detectada a presença de BHC em concentração de $8 \mathrm{mg} \cdot \mathrm{kg}-1$ no ponto suspeito de ter sido aterrado com o analito. $\mathrm{Na}$ estrada o ponto de maior concentração foi de $24 \mathrm{mg} \cdot \mathrm{kg}^{-1}$ de BHC, e nas áreas destinadas à moradia, foi detectado $\mathrm{BHC}$ na ordem de dezenas de $\mu \mathrm{g} \cdot \mathrm{kg}^{-1}$ de solo.

Cotta (2003) realizou um diagnóstico ambiental de solo e sedimento do parque estadual turístico do Alto Ribeira, quanto a presença de 6 organoclorados e metais pesados. O método Sohxlet foi empregado para extração. A técnica de análise utilizada para diagnóstico de organoclorados foi GC-ECD. Os LD variaram de 0,017 a $0,294 \mu \mathrm{g} \cdot \mathrm{kg}^{-1}$. Os resultados para os testes de recuperação variaram de 85,9 a $94,1 \%$. Foi detectada a presença de organoclorados em concentrações superiores aos limites máximos permissíveis.

Rissato et. al (2004) determinou 6 pesticidas organoclorados em água e solo, na região de Baurú (SP). Para a determinação de pesticidas em solo, utilizou-se o método de extração sólido-líquido, com o auxílio de agitador, centrífuga e rotaevaporador. As amostras foram analisadas por cromatógrafo a gás HP 5890 Séries II acoplado a detector por captura de elétrons (HRGC/ECD). O método 
cromatográfico adotado obteve duração de 45 minutos. Como parâmetros de validação adotados, foram apresentados a recuperação do método, com resultados em torno de 80 a $99 \%$ e limite de quantificação de $0,1 \mu \mathrm{g} \cdot \mathrm{L}^{-1}$. As concentrações de resíduos de pesticidas detectados em solo variaram de 0,06 a 1,4 $\mu \mathrm{g} \cdot \mathrm{kg}^{-1}$.

Buosi e Felfili (2004) realizaram estudos de recuperação de áreas contaminadas por pesticidas organoclorados, hexaclorobenzeno (BHC) e dicloro-difenil-tricloroetano (DDT), no município de Duque de Caxias, RJ, por monitoramento de solo e folhas de uma plantação das espécies $C$. citriadora e E. grandis. A técnica de extração e o método cromatográfico não foram discutidos no trabalho. Utilizou-se como técnica de análise, GC/MS. Comparou-se os resultados do estudo com resultados obtidos em análise anterior, realizada no ano de 1999, e constatou-se a redução na concentração dos isômeros de hexacloro-ciclo-hexano (BHC) em solo, da ordem de centenas de milhares de vezes.

Filho (2003) realizou estudo do grau de exposição interna a organoclorados em moradores cincunvizinhos de aterro a céu aberto em Cubatão, SP. Os teores médios sanguíneos foram de 4,66 $\mu \mathrm{g} \cdot \mathrm{L}^{-1}$ de $\mathrm{BHC}$ e $3,71 \mu \mathrm{g} \cdot \mathrm{L}^{-1}$ de DDT.

Quinete (2005) desenvolveu um estudo sobre a extração de 17 poluentes organoclorados persistentes em solo de fragmentos remanescentes da mata Atlântica. A extração das amostras foi realizada utilizando os métodos de Sohxlet, extração assistida por ultra-som e por radiação de microondas e a etapa de limpeza do extrato, por SPE com discos de $\mathrm{C}_{18}$ e coluna Florisil. A técnica de análise adotada foi GC-ECD. O método cromatográfico obteve duração de 17 minutos. Os LD do equipamento variaram de 0,2 a $6 \mu \mathrm{g} \cdot \mathrm{L}^{-1}$. Os resultados dos testes de recuperação para a técnica de extração Sohxlet variaram de 65 a 208\%, enquanto na extração com o auxílio de microondas os resultados foram na faixa de 111 a $234 \%$, e com extração assistida por microondas foram de 14 a 138\%. A partir dos resultados de concentração de pesticidas obtidos nas amostras estudadas, se comparados a outros trabalhos da literatura, demonstraram que as áreas avaliadas não podem ser consideradas impactadas.

Nakagawa e Andréa (2006) estudaram o efeito de alterações nas características do solo mediante a degradação do hexaclorobenzeno. A pesquisa compreendeu a adição de bagaço de cana de açúcar a fim de estimular a atividade microbiana para decomposição do BHC e essa possível decomposição foi monitorada por meio do 
tratamento do solo com ${ }^{14} \mathrm{C}-\mathrm{BHC}$. O método sólido líquido com auxílio de microondas foi adotado para extração das amostras. A técnica de análise foi GC-ECD. Constatou-se que as ações realizadas nas amostras não se mostraram efetivas para decomposição de BHC, uma vez que esta molécula é muito estável e os microorganismos utilizados em estudo deveriam ser comprovadamente capazes de degradá-la.

\subsection{Poluentes orgânicos persistentes}

Os Poluentes Orgânicos Persistentes, conhecidos como POPs, são compostos altamente estáveis e que persistem no ambiente, resistindo à degradação química, fotolítica e biológica (Stockholm Declaration, 2001). São tóxicos para os seres vivos, pois têm a capacidade de bio-acumular-se em organismos vivos. Estes compostos são lipofílicos e distribuem-se no interior das membranas celulares e depósitos de gordura (Cockerman, 1994). Uma grande variedade de indústrias químicas está envolvida na produção de produtos orgânicos persistentes. Indústrias produtoras de pesticidas, ácidos, bases, fertilizantes, resinas sintéticas, fibras artificiais entre outras, produzem grandes quantidades de POPs, em função do tratamento do lixo produzido (Malliaros, 1997). A Tabela 1 apresenta os POPs, bem como suas aplicações. 
Tabela 1. Os Poluentes Orgânicos Persistentes e suas Aplicações

\begin{tabular}{|c|c|c|}
\hline Sustância & Fórmula Estrutural & Aplicação \\
\hline Aldrina & $\mathrm{Cl}$ & $\begin{array}{l}\text { Produzido como pesticida } \\
\text { para controle de insetos } \\
\text { no solo. }\end{array}$ \\
\hline Endrina & & $\begin{array}{l}\text { Rodenticida e inseticida } \\
\text { usado nas culturas de } \\
\text { algodão, milho e arroz. }\end{array}$ \\
\hline Dieldrina & $\mathrm{Cl}$ & $\begin{array}{l}\text { Inseticida usado em } \\
\text { solo para cultura de } \\
\text { frutas e sementes. }\end{array}$ \\
\hline Clordano & $\mathrm{Cl}$ & $\begin{array}{l}\text { Inseticida usado no controle } \\
\text { de fungos, formigas e } \\
\text { em várias culturas. }\end{array}$ \\
\hline $\begin{array}{l}\text { Dicloro-Difenil- } \\
\text { Tricloroetano } \\
\text { (DDT) }\end{array}$ & & $\begin{array}{l}\text { Usado como inseticida no combate } \\
\text { aos mosquitos que transmitem a } \\
\text { malária e febre amarela e no } \\
\text { combate aos piolhos do tifo. }\end{array}$ \\
\hline
\end{tabular}


... Continuação Tabela 1.

\begin{tabular}{|c|c|c|}
\hline Sustância & Fórmula Estrutural & Aplicação \\
\hline Heptacloro & & $\begin{array}{l}\text { Utilizado como inseticida de contato } \\
\text { contra insetos do solo e formigas. }\end{array}$ \\
\hline $\begin{array}{l}\text { Hexacloroben- } \\
\text { zeno }(\mathrm{BHC})\end{array}$ & & $\begin{array}{l}\text { Fungicida, aparece também como } \\
\text { subproduto na indústria química. }\end{array}$ \\
\hline Mirex & & $\begin{array}{l}\text { Inseticida e retardador de chamas } \\
\text { em plástico, borrachas e } \\
\text { componentes elétricos }\end{array}$ \\
\hline Toxafeno & $\mathrm{Cl}$ & $\begin{array}{l}\text { Inseticida acarícidio, } \\
\text { especialmente utilizado contra } \\
\text { larvas e algodão. }\end{array}$ \\
\hline $\begin{array}{l}\text { Policorobifenilos } \\
\qquad \text { (PCBs) }\end{array}$ & & $\begin{array}{c}\text { Usado em condensadores, } \\
\text { transformadores e em líquidos } \\
\text { refrigeradores. }\end{array}$ \\
\hline Furanos & & $\begin{array}{l}\text { Subprodutos relacionados com } \\
\text { dioxinas. Usado como pesticida. }\end{array}$ \\
\hline
\end{tabular}


... Continuação Tabela 1.

\begin{tabular}{|c|c|c|}
\hline Substância & Fórmula Estrutural & $\begin{array}{c}\text { Aplicações } \\
\text { Dioxina }\end{array}$ \\
\hline Subproduto da combustão, \\
especialmente de plásticos; da \\
manufaturação de produtos com \\
cloro e de processos resultantes da \\
produção de papel e usado como \\
herbicida.
\end{tabular}

\subsubsection{Breve histórico dos poluentes orgânicos persistentes}

Em 1940, Paul Mueller, da companhia suíça GEISY, observou que o DDT sintetizado por Zeidler em 1874, era um potente inseticida. A sua pronunciada propriedade inseticida, aliada à baixa solubilidade em água, alta persistência e sua forma de ação, desconhecida até aquele momento, propiciou resultados verdadeiramente notáveis e seu uso rapidamente se expandiu. Durante a Segunda Guerra Mundial, na Itália, Alemanha, entre outros países da Europa, o DDT em pó foi pulverizado na pele da população para prevenir epidemias de tifo transmitidas por piolhos, que causavam alta mortalidade. A Figura 1 mostra uma criança na Alemanha, sendo pulverizada por DDT. 


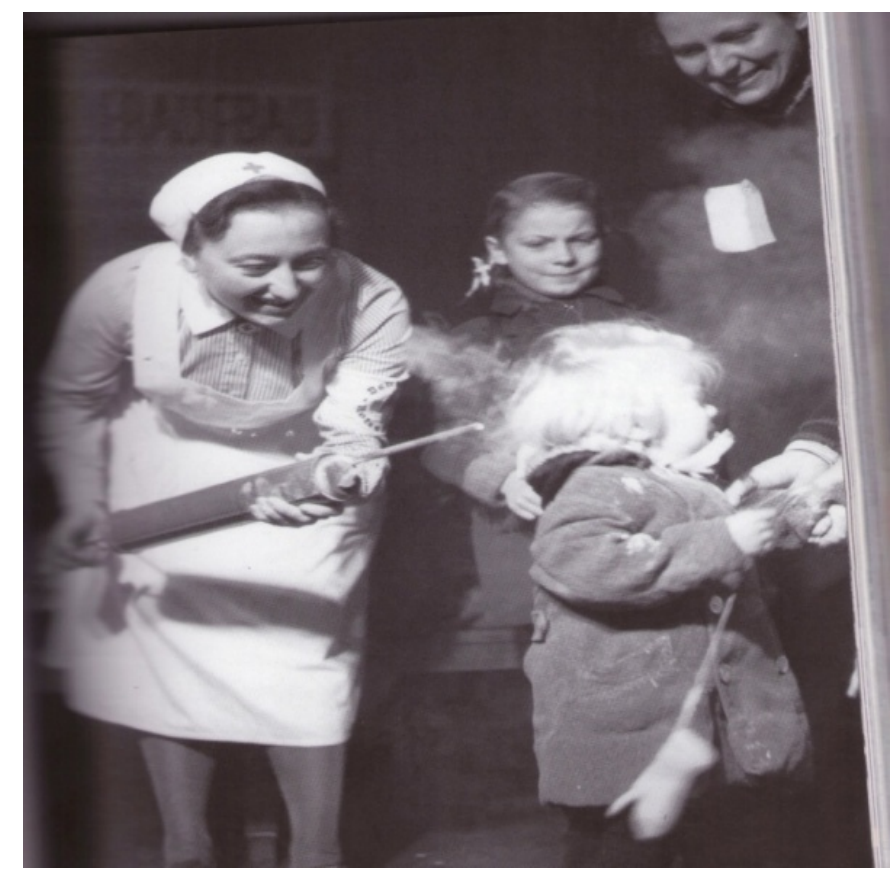

Figura 1. Uma criança sendo pulverizada por DDT, na Alemanha, 2ª Guerra Mundial (Challoner, 2010)

Ele foi usado, também, em grandes áreas do globo terrestre para eliminar o mosquito vetor da malária (Konradsen et. al, 2004). Mais tarde o DDT foi utilizado no controle de pragas da agricultura, particularmente em colheitas com alto rendimento econômico (Benn e McAuliffe, 1981; Ottaway, 1982; Mariconi, 1985; Flores et al., 2004).

Com o passar dos anos, no entanto, a promessa de estar livre de insetos foi quebrada, e o milagre químico, que tinha dado início à era dos pesticidas, não ocorreu (Turk, 1989; Flores et al., 2004). O poder residual considerado como de qualidade decididamente positiva desses compostos começou a ser encarado como sério incoveniente, o qual encerrava significado ecológico de extrema gravidade. A ação residual dos organoclorados era devida à sua estabilidade química, que lhes conferia prolongada persistência no ambiente. Resíduos de organoclorados haviam contaminado praticamente todos os ecossistemas, sendo detectados nos mais variados substratos e tendo provocado a inquietação dos estudiosos do assunto e da população em geral. Na segunda metade da década de 60, muitos países intensificaram as pesquisas relativas ao assunto e, ao mesmo tempo, tomaram medidas legais, restringindo ou proibindo seu emprego (Matuo et al., 1990; Flores et al., 2004). 
No Brasil, a partir de 1970, a produção agrícola sofreu grandes transformações. A política de estímulo do crédito agrícola, associada às novas tecnologias, impulsionou várias culturas, principalmente destinadas à exportação. Pacotes tecnológicos ligados ao financiamento bancário obrigavam os agricultores a adquirir insumos e equipamentos, muitas vezes desnecessários. Entre os insumos, estavam os pesticidas, que eram recomendados para o controle de pragas e doenças, como método de resguardar o potencial produtivo das culturas. Esse método obrigava aplicações sistemáticas de pesticidas, mesmo sem ocorrência das pragas, resultando em pulverizações excessivas e desnecessárias (Ruegg et al., 1991; Flores et al., 2004)

\subsubsection{Exposição aos POPs, toxicidade e sintomas}

Os pesticidas clorados podem ser introduzidos no organismo através das vias cutânea, digestiva e respiratória (Mariconi, 1985; Flores et al., 2004)

A eficiência da absorção dermal é variável. Os hexaclorobenzenos, os ciclodienos, como Aldrina, Dieldrina, Endrina e Endossulfano, são eficientemente absorvidos quando em contato com a pele. No entanto, a maior introdução no organismo de produtos, como o DDT e Dicofol, ocorre por meio dos alimentos, principalmente com os que contêm elevada quantidade de gordura. Além dos alimentos, a absorção dos pesticidas pode ocorrer através da via respiratória, que absorve as partículas de pó de pesticidas que estejam no ar (Fernícola, 1985; Flores et al., 2004).

As intoxicações do homem podem ocorrer de duas formas. Se o organismo absorve, numa única dose, elevada quantidade de pesticida, ele reage rapidamente, indicando os sintomas, que podem ser fatais ou permanecer por certo tempo. Dependendo do produto e da dose introduzida no organismo, o estado clínico pode ser reversível. Esse tipo de intoxicação é denominado intoxicação aguda. Outra forma de intoxicação é a crônica, a mais preocupante, pois não tem manifestação imediata e é resultante do acúmulo gradual do defensivo no organismo, sendo irreversível (Cavero, 1976; Flores et al., 2004).

Os inseticidas do grupo do DDT agem nos canais de sódio dos insetos, mantendo-os abertos por um período mais longo. Com isso, ações repetitivas são 
desencadeadas, uma vez que ocorre transmissão contínua do impulso nervoso. Os insetos eventualmente morrem devido à hiperexcitação (ETO, 1990; Guedes, 1999; Flores et al, 2004). Em aves, a assimilação destes inseticidas provoca diminuição na fertilidade, devido a alterações no metabolismo do cálcio e inibição da enzima anidrase carbônica, que atua na formação da casca de ovo, tornando-a fina e quebradiça (Pinheiro e Monteiro, 1992; Flores et al., 2004).

No homem, organoclorados atuam basicamente no sistema nervoso central e no sistema de defesa do organismo. Os organoclorados causam séries lesões hepáticas e renais. Alguns produtos desse grupo lesam o cérebro, outros, os músculos do coração, a medula óssea, o córtex da supra-renal, o DNA e etc. A atividade estrogênica, estimulando a testosterona e propiciando a puberdade precoce, foi comprovada para o DDT. Alguns estudos têm evidenciado a atividade imunossupressora de certos produtos desse grupo e as alterações na conduta dos indivíduos (Guerra e Sampaio, 1991; Pinheiro e Monteiro, 1992; Flores et al., 2004). Casos de câncer em órgãos do aparelho digestivo, pulmão e rim foram registrados em pessoas contaminadas com BHC (Oliveira e Adeodato, 1997). Estudos, realizados na Califórnia, indicaram que mulheres com altos níveis de DDE no corpo, possuem um risco quatro vezes maior de contrair câncer de mama (Falch et al, 1992; Wolff et al., 1993; Flores et al., 2004).

Os jovens, em fase de desenvolvimento, são particularmente sensíveis à exposição aos organoclorados. A exposição pré-natal a organoclorados persistentes, além de poder prejudicar o sistema reprodutivo, durante a fase de desenvolvimento, pode causar uma série de outros efeitos adversos à saúde, como: óbito fetal e aborto espontâneo, diminuição de peso e tamanho do recém-nascido, depressão do sistema imunológico e redução da resistência óssea (Flores, 2004).

\subsubsection{Legislação a cerca dos POPs}

É de grande importância o controle rigoroso dos efeitos não intencionais dos pesticidas sobre diversas formas de vida, incluindo o homem e o meio ambiente. Em vários países, foram fixados padrões e limites máximos permissíveis de tolerância desses resíduos (Dorigatti, 1987). No início da década de 70, os Estados Unidos, através da EPA (Environmental Protection Agency), proibiram o uso de alguns 
organoclorados como DDT, Aldrina, Heptacloro e Clordano (Hodges, 1977; Turk, 1989; Flores et al., 2004). Em Portugal, no ano de 1988, foram proibidos pela portaria $n^{\circ} 660 / 88$ os organoclorados Aldrina, Clordano, Dieldrina, DDT, Endrina, DDT, BHC, Heptacloro e Canfeno clorado (Flores et al., 2004). No Brasil, a comercialização, distribuição e uso desses produtos foram proibidos em 3 de setembro de 1985 (Brasil, 1985).

Nos últimos anos, uma série de órgãos internacionais tem se manifestado a respeito da contaminação com organoclorados. Em 1989, a Conferência Circumpolar fez um apelo internacional para o controle da contaminação tóxica do Ártico. Em 1992, a Comissão Mista dos Grandes Lagos, formada por cientistas dos Estados Unidos e Canadá, para tratar da contaminação dos lagos fronteiriços aos dois países, recomendou a seus governos a eliminação do cloro como matéria-prima industrial. Neste mesmo tempo, a Comissão de Paris, formada por 13 países da região do Atlântico Norte e da união Européia, concordaram em eliminar as descargas de substâncias tóxicas, persistentes e bioacumulativas, particularmente os organoclorados. No ano seguinte, em 1993, a Conferência do Mar do Norte, adotou o acordo da Comissão de Paris, assim como as metas prévias para a redução em 50\% de vários organoclorados. Ainda em 1993, a Conferência de Barcelona, que reuniu 21 nações do Mar Mediterrâneo, concordou em eliminar a descarga de substâncias tóxicas. Dois anos depois, em 1995, os países participantes da Conferência do Mar Norte reuniram-se mais uma vez com o objetivo de fechar um acordo para eliminar a descarga de substâncias perigosas no mar. No dia 06 de dezembro de 2000 o Greenpeace devolveu, na Argentina, parte do lixo tóxico para um indústria química. A ação da organização ambientalista faz parte da campanha mundial do Greenpeace contra a poluição tóxica. Os resíduos foram coletados no maior depósito de lixo do país, localizado num vilarejo com menos de 100 moradores, na província de Santiago Del Estero. Vinte ativistas do Greenpeace, incluindo voluntários da Argentina e Inglaterra, devolveram o lixo tóxico para a indústria, em San Lorenzo, exigindo que a empresa se responsabilizasse pelos resíduos tóxicos e descontaminasse a área. Análises de laboratório indicaram a presença de BHC, DDT, Aldrina, Dieldrina, Clordano e Heptacloro (Flores et al, 2004).

A Finlândia é um dos países que tem demonstrado preocupação com o meio ambiente e não tem poupado esforços para minimizar as descargas de produtos 
nocivos, como os organoclorados, para o Mar Báltico. Em abril de 2002, o governo finlandês aprovou um novo programa que visa o melhoramento do estado atual do Báltico e da sua vida marinha. Segundo este programa, as emissões de poluentes serão reduzidas à metade nos próximos 10 a 15 anos. Em maio de 2002, o World Wildlife Fund distinguiu o governo finlandês pelo seu programa de proteção do Báltico, com o distintivo Gift to the Earth, que é o mais alto reconhecimento concedido por este fundo internacional para a conservação da natureza (Flores et al., 2004).

\subsubsection{Propriedades dos compostos estudados}

Os poluentes orgânicos persistentes pertencem à classe dos organoclorados. Apresentam alta persistência e estabilidade molecular, além de serem altamente lipossolúveis, por isso são considerados prejudiciais ao seres vivos e ao meio ambiente. Dentre os organoclorados, destacam-se nove neste trabalho: os isômeros BHC $\alpha-, \beta-, \gamma-$ e $\delta$; heptacloro, heptacloro epóxido cis / trans, clordano cis / trans.

\subsubsection{Hexaclorobenzeno}

Segundo a IUPAC, o nome do hexaclorobenzeno (BHC) é hexachlorobenzene ou perchlorobenzene. Este composto é uma mistura de vários isômeros, incluindo a$\mathrm{BHC}(60-70 \%), \quad \beta-B H C \quad(5-12 \%)$ e $\mathrm{Y}-\mathrm{BHC}(10-15 \%)$ cujas estruturas estão representadas na Figura 2. Os BHC são menos bioacumulativos que outros organoclorados devido às suas baixas lipofilicidades, enquanto as altas pressões de vapor facilitam o transporte para longas distâncias na atmosfera. $\mathrm{O}(\mathrm{\gamma}-\mathrm{BHC})$, popularmente conhecido como lindano, é utilizado como pesticida e conservador de madeira, possui tempo de meia-vida $\left(\mathrm{t}_{1 / 2}\right)$ no solo superior a 1 ano e atua como interferente endócrino ( Felix et al., 2007; Almeida et. al, 2007; UNEP, 2010).

Historicamente, o $\mathrm{BHC}$ foi aplicado em diversos segmentos na indústria e na agricultura, como no tratamento de sementes de produtos agrícolas como trigo, cevada, aveia e centeio, para impedir o crescimento de fungos (Felix et al., 2007). 


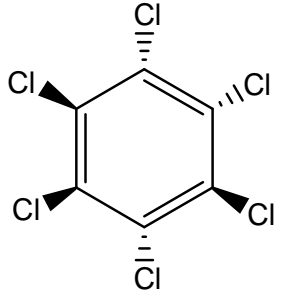

(a)

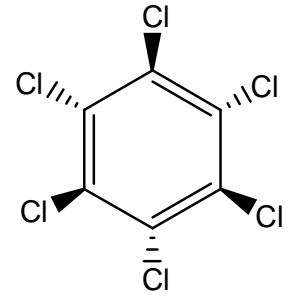

(b)

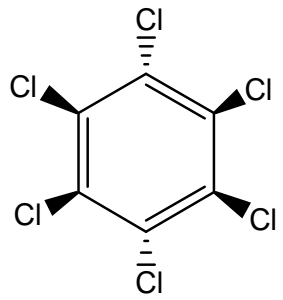

(c)<smiles>Cl[C]1[C](Cl)[C@](Cl)[C@](Cl)[C@](Cl)[C]1Cl</smiles>

(d)

Figura 2. Fórmula Estrutural do (a) $\alpha-B H C$, (b) $\beta-B H C$, (c) $\gamma-B H C$ e (d) $\delta-B H C$

\subsubsection{Heptacloro}

O nome do heptacloro é 1,4,5,6,7,8,8-heptachloro-3-alpha-4,7,7-alphatetrahydro-4,7-methanoindene, segundo a IUPAC. Este composto é persistente e relativamente estacionário no solo, porém pode desaparecer pela evaporação e pela oxidação lenta em heptacloro-epóxido (um produto ainda mais persistente). Suas propriedades físico-químicas de solubilidade baixa na água, estabilidade elevada e volatilidade parcial, tendem a favorecer o transporte a longas distâncias. O heptacloro foi detectado no ar, na água e nos organismos vivos do Ártico. Ele é considerado tóxico em ambiente aquático e perigoso para a vida selvagem (Felix et al., 2007).

O heptacloro foi isolado do clordano em 1946 e foi extensivamente usado, entre os anos de 1953 e 1974 no controle de pragas do solo, de sementes de milho, sorgo e outros pequenos grãos. Ele pode contaminar as águas superficiais e subterrâneas pelo escoamento superficial procedente de solos contaminados, ou de descargas de resíduos líquidos de procedência industrial. Quando liberado na água, adsorve-se fortemente a sedimentos suspensos e do fundo do corpo d'água (Felix et al., 2007).

Este composto orgânico pode permanecer em áreas contaminadas durante muitos anos. A meia vida do heptacloro em solo foi calculada entre 9 e 10 meses, quando usado de acordo com as doses recomendadas para a agricultura, e é pouco provável que se mobilize em um solo com alto conteúdo de matéria orgânica. Dados de regiões tropicais indicam que a dissipação do heptacloro do solo pode ser mais rápida em regiões tropicais do que em regiões temperadas (Almeida et. al, 2007; UNEP, 2010), sendo na última, seu $t_{1 / 2}$ de 0,7 a 2 anos (Felix et al., 2007). Sua estrutura molecular pode ser observada na Figura 3. 


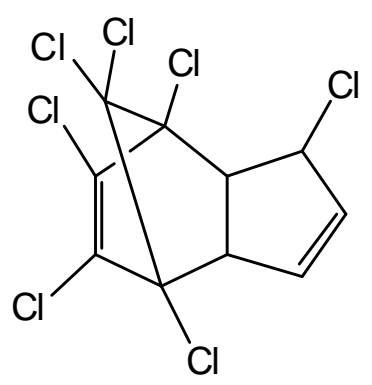

Figura 3. Fórmula Estrutural do Heptacloro $(\mathrm{C} 10 \mathrm{H} 5 \mathrm{Cl})$

\subsubsection{Heptacloro epóxido Cis / Trans}

O heptacloro epóxido é um pó branco dificilmente inflamável. Ao contrário do heptacloro, não foi usado como pesticida. O heptacloro epóxido é obtido por meio de reações produzidas por bactérias e animais, que saturam a molécula de heptacloro, quebrando sua dupla ligação e incorporando um oxigênio em sua estrutura. Aproximadamente $20 \%$ do heptacloro é convertido em heptacloro epóxido no meio ambiente e em organismos, em poucas horas (ATSDR, 2007).

O heptacloro ou heptacloro epóxido podem ser detectados em solo ou no ar de casas tratadas para controle de cupins. Pode ser detectado também dissolvido em águas superficiais ou subterrâneas ou ar próximo de locais onde se concentram resíduos perigosos, ou acumulados em animais que vivam próximos a estes locais contaminados. Seu uso é proibido atualmente para o controle de insetos em culturas ou em casas e prédios, no entanto, a EPA (Environmental Protection Agency) ainda permite o uso de heptacloro para matar formigas em transformadores subterrâneos, embora não esteja claro se ainda é utilizado para este fim nos Estados Unidos (ATSDR, 2007). As estruturas moleculares dos isômeros do heptacloro epóxido podem ser observadas na Figura 4.

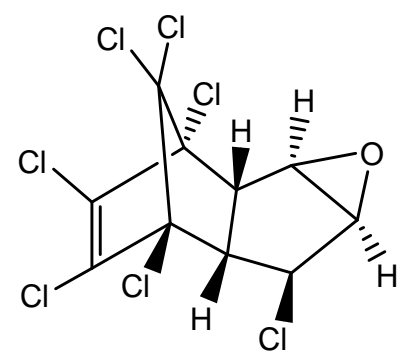

(a)

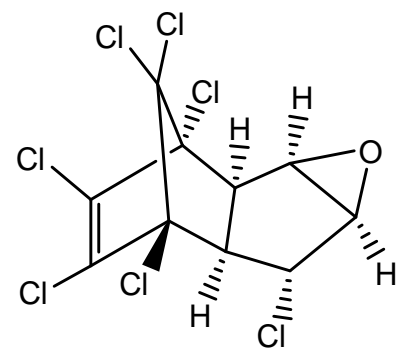

(b)

Figura 4. Fórmula Estrutural do Heptacloro Epóxido (a) Cis e (b) trans (C10H5Cl7O) 


\subsubsection{Clordano Cis / Trans}

O clordano é oficialmente chamado de octachloro-2,3,3-alpha-4,7,7-alphahexahydro-4,7-methanoindene, segundo a IUPAC. Trata-se de um inseticida utilizado em culturas de arroz, sementes oleaginosas, cana de açúcar e em frutíferas e as estruturas dos isômeros cis e trans estão representadas na Figura 5. É uma substância tóxica, persistente, bioacumulativa e que pode ser transportada, na atmosfera, a grandes distâncias (Felix et al., 2007), além de contaminar os alimentos, quando aplicado em plantas, também atinge o solo, sendo por este, absorvido devido rápida adsorção às partículas do solo. Apesar das inúmeras restrições, ainda é aplicado em muitos países do mundo (Felix et al., 2007).

A elevação em nível da toxicidade do clordano em solo é um indicador para o risco ambiental. Devido ao clordano não sofrer lixiviação no solo, é pouco provável que atinja águas subterrâneas, contudo, pode atingir corpos d'água pelo escoamento superficial em solos urbanos e agrícolas, podendo causar efeitos letais específicos em peixes e pássaros que se alimentam de peixes contaminados (Felix et al., 2007).

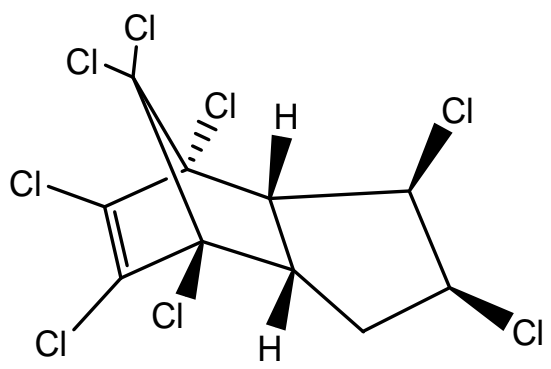

(a)

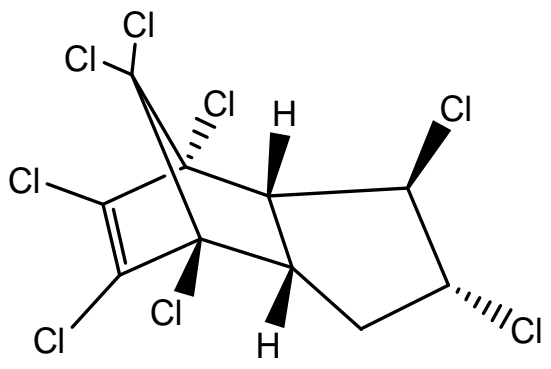

(b)

Figura 5. Fórmula Estrutural do Clordano (a) Cis e (b) Trans (C10H6Cl8)

\subsubsection{Propriedades Físico-Químicas}

No que se refere à qualidade do solo em relação a pesticidas, os indicadores e coeficientes expressam as propriedades físico-químicas destes poluentes, as quais estão relacionadas ao seu comportamento ambiental e determinam à afinidade natural das substâncias por um ou por outro compartimento do ambiente (Felix et al., 2007; Prata, 2002). O conhecimento de tais propriedades ajuda a entender, por exemplo, por que a concentrações, surpreendentemente altas, de produtos químicos 
tóxicos e persistentes como PCBs, DDT e toxafeno se concentram em maiores quantidades nas regiões mais frias do planeta, próximo aos pólos, onde nunca foram utilizados. Os critérios da Environmental Protection Agency - EPA apontam o coeficiente de adsorção, a meia-vida no solo e a solubilidade em água como sendo as mais relevantes no resultado final para sua classificação em relação à contaminação das águas (Felix et al., 2007; Ferracini et al., 2001).

Na Tabela 2, são apresentados os valores de pressão de vapor, solubilidade, Coeficiente de Partição octanol / água (log Kow), Coeficiente de Partição Orgânica (log Koc) e tempo de meia-vida, que são as principais características de alguns POPs encontradas na literatura.

Tabela 2. Características físico-químicas dos organoclorados em estudo (Felix et al., 2007).

\begin{tabular}{|c|c|c|c|c|c|c|}
\hline Composto & $\begin{array}{c}\text { Massa } \\
\text { Molar } \\
\left(\mathrm{g} \cdot \mathrm{mol}^{-1}\right)\end{array}$ & Solubilidade & Pressão de Vapor & Log Kow & $\log K_{o c}$ & $\begin{array}{c}\text { Meia- } \\
\text { vida } \\
\text { (dias) }\end{array}$ \\
\hline Heptacloro & 373,5 & $180 \mu \mathrm{g} \cdot \mathrm{L}^{-1}\left(25^{\circ} \mathrm{C}\right)$ & $3 \mathrm{e}-4 \mathrm{~mm} \mathrm{Hg}\left(20^{\circ} \mathrm{C}\right)$ & 5,44 & 4,34 & $>730$ \\
\hline $\mathrm{BCH}$ & 284,79 & $0,005 \mathrm{mg} \cdot \mathrm{L}^{-1}\left(25^{\circ} \mathrm{C}\right)$ & $1,73 e-8\left(25^{\circ} \mathrm{C}\right)$ & 5,73 & 6,08 & $\begin{array}{r}365 a \\
7305\end{array}$ \\
\hline $\begin{array}{l}\text { Heptacloro } \\
\text { Epóxido } \\
\text { Cis/Trans }\end{array}$ & 389,2 & - & - & - & - & - \\
\hline $\begin{array}{l}\text { Clordano } \\
\text { Cis/Trans }\end{array}$ & 409,77 & $0,056 \mathrm{mg} \cdot \mathrm{L}^{-1}\left(20^{\circ} \mathrm{C}\right)$ & $2,2 \mathrm{e} 5$ a $2,9 \mathrm{e} 5\left(25^{\circ} \mathrm{C}\right)$ & 5,54 a 6 & $\begin{array}{c}3,49 a \\
5,57\end{array}$ & $\begin{array}{r}730 a \\
5479\end{array}$ \\
\hline
\end{tabular}

\subsubsection{Pressão de Vapor}

Pressão de vapor (p) é definida como sendo a pressão exercida pela substância ou composto em um sistema fechado e em equilíbrio. É uma medida da tendência de volatilização em seu estado puro em função direta da temperatura, não expressa diretamente a taxa de volatilização de um ingrediente ativo. É a principal propriedade na determinação do potencial de volatilização de um composto. Quanto maior a pressão de vapor, maior a tendência de o contaminante estar no estado gasoso (Felix et al., 2007). A pressão de vapor de um determinado composto ou substância é a medida de quão rapidamente este irá evaporar (Felix et al., 2007). Este dado é importante, pois relacionado a outros dados, auxilia na compreensão do 
comportamento de um determinado contaminante, a pressão de vapor mostra a tendência que o composto tem em volatilizar, seu estado puro, de acordo com a temperatura (Felix et al., 2007). É possível entender, portanto, que compostos apresentam alta pressão de vapor, são voláteis e, portanto, não tendem a ter grande fixação em matriz.

\subsubsection{Partição}

A partição do contaminante entre as fases líquida e gasosa do solo é determinada pela pressão de vapor da substância e sua solubilidade em água. Das três fases constituintes do solo, a líquida e a gasosa são móveis e, portanto determinam à mobilidade do poluente (Felix et al., 2007). Os POPs, por serem semivoláteis, podem ser transportados pelos ventos na forma gasosa por milhares de quilômetros, até encontrarem temperaturas mais baixas (Duarte, 2002). Quando isto ocorre, são condensados diretamente na superfície do solo ou nas partículas presentes em aerossóis, que serão depositadas posteriormente por intermédio da neve ou das chuvas. A sua semi-volatilidade favorece o seu aparecimento em fase gasosa e a sua adsorção em partículas atmosféricas (Felix et al., 2007).

A pressão de vapor e a solubilidade, em geral, diminuem com aumento da massa molecular. Tais propriedades vão indicar que alguns poluentes podem ser encontrados tanto na fase gasosa do ar quanto sorvido em partículas orgânicas sólidas ou partículas contendo carbono orgânico em suspensão no ar. Essa propriedade é importante por indicar o potencial de volatilização de um poluente. O clordano, com pressão de vapor entre $2,2 \times 10^{5}$ a $2,9 \times 10^{5} \mathrm{mmHg}$ a $25^{\circ} \mathrm{C}$, é o mais volátil de todos POPs. Assim, quanto maior a pressão de vapor, maior a tendência desse poluente encontrar-se no estado gasoso, ou seja, o quão rapidamente ele irá evapora do solo.

\subsubsection{Solubilidade}

Solubilidade em Água (Sw) é a medida do quanto uma determinada substância irá se dissolver na água. É expressa como sendo a quantidade máxima de um composto ou substância que irá se dissolver completamente em um litro de água. 
Quanto maior o valor, mais solúvel em água (Felix et al., 2007). A solubilidade está relacionada à capacidade do composto em ser lixiviado, então quanto maior a solubilidade, mais facilmente será carreado pela água.

\subsection{Legislações nacionais e internacionais sobre os organoclorados em solo}

Em âmbito internacional, a Declaração de Estocolmo, elaborada em Conferência ocorrida na Suécia, patrocinada pela Organização das Nações Unidas ONU, prestigiada por cerca de 113 países, incluindo o Brasil, em 1.972, foi o primeiro instrumento global que obriga os governos a tomarem ações objetivando a eliminação desses poluentes no meio ambiente. A não observância dos requisitos da declaração acima citada implica em sanções políticas e econômicas aos países signatários (ICH, 1995). O documento prevê a eliminação de doze POPs, mencionados na Tabela 1 , no item 2.3.

A Holanda, em 1994, publicou uma nova proposta de valores de qualidade de solo e da água subterrânea, em atendimento a lei de proteção ao solo criada em 1987 pelo governo federal holandês. A característica principal dessa proposta foi a criação de três valores distintos (STI) de qualidade para os compartimentos ambientais citados, sendo o standard "S" o valor de referência, que indica um nível de qualidade que permite considerá-los "limpos". O "l" é o valor de intervenção, indicativo de riscos à saúde humana e para o ambiente, havendo a necessidade de implementação de medidas de remediação da área avaliada. O "T" é o valor de alerta, um valor médio entre $S$ e I. Dentre os pesticidas organoclorados em estudo, encontram-se especificados os compostos $\alpha$-BHC; $\beta$-BHC E $\gamma$-BHC que apresentam somente valores para "S" iguais a 0,0005; 0,0002 e 0,00001 mg.kg ${ }^{-1}$, e ainda, valores de "T" e "l" para a soma dos isômeros BHC, quais sejam 0,2 e 0,4 mg.kg-1, respectivamente (CETESB, 1999a).

A CETESB (1999a) e o CONAMA (2009) utilizam critérios nos moldes holandeses, para os quais os "STI" correspondem aos valores de Referência de Qualidade (VRQ), de Prevenção (VP) e de Intervenção (VI). Dentre os pesticidas organoclorados em estudo, encontram-se especificados somente os $\beta$-BHC e $y$-BHC 
com valores para VRQ, VP e VI iguais a 0,$011 ; 0,03 ; 0,1$ e 0,$001 ; 0,02$ e $0,07 \mathrm{mg}^{\mathrm{kg}}{ }^{-1}$, respectivamente (CETESB, 1999a).

A Lista Regional de Triagem de Níveis de Contaminantes - Regional Screening Levels for Chemical Contaminants at Superfund Sites americana estabelecida em 2008 reúne, dentre outros dados, os limites máximos permissíveis de várias classes de contaminantes, em solo industrial e residencial, baseada em dados da Integrated Risk Information System (IRIS), Provisional Peer Reviewed Toxicity Values (PPRTV), Agency for Toxic Substances \& Disease Registry (ATSDR), Health Effects Assessment Summary (HEAST) e World Health Organization (WHO) (EPA, 2010). Esta lista é utilizada como referência neste trabalho, por abranger praticamente todos os compostos estudados, exceto o $\delta$-BHC. A Tabela 3 apresenta os limites máximos permissíveis para os compostos estudados em solos residencial e industrial.

Tabela 3. Limites máximos permissíveis para os organoclorados em estudo, em solos residencial e industrial.

\begin{tabular}{|c|c|c|}
\hline Composto & $\begin{array}{l}\text { Solo Residencial } \\
\left(\mathrm{mg} \cdot \mathrm{kg}^{-1}\right)\end{array}$ & $\begin{array}{l}\text { Solo Industrial } \\
\left(\mathrm{mg}^{\prime} \mathrm{kg}^{-1}\right)\end{array}$ \\
\hline$\alpha-\mathrm{BHC}$ & 0,077 & 0,27 \\
\hline$\beta-\mathrm{BHC}$ & 0,27 & 0,96 \\
\hline $\mathrm{Y}-\mathrm{BHC}$ & 0,52 & 2,1 \\
\hline$\delta-\mathrm{BHC}$ & - & - \\
\hline BHC (técnico) & 0,27 & 0,96 \\
\hline Clordano cis / trans & 1,6 & 6,5 \\
\hline Heptacloro & 0,11 & 0,38 \\
\hline Heptacloro Epóxido Cis / Trans & 0,053 & 0,19 \\
\hline
\end{tabular}

\subsection{Região de estudo}

\subsubsection{Determinação do local de coleta}

Os municípios de Caieiras, Franco da Rocha, Cubatão e São Vicente - SP apresentam histórico de contaminação por POPs. Dentre estes locais, optou-se por realizar a coleta de amostras em Caieiras e Franco da Rocha, devido a uma parceria firmada com a Vigilância Sanitária do Estado de São Paulo e dos referidos municípios, que apresentaram grande interesse nessas análises, pelo fato de 0 aterro industrial estar localizado num ponto central a uma comunidade carente. Há uma 
grande preocupação quanto à defesa da saúde pública no que diz respeito à exposição desses moradores às áreas contaminadas.

\subsubsection{Caracterização da área de estudo}

Em 2002, a CETESB divulgou o primeiro cadastro então elaborado no Brasil de áreas contaminadas. Eram naquele momento, 225 áreas cadastradas, contabilizando passivos ambientais ainda não enumerados e apontando para uma mudança no interesse da sociedade em conhecer mais profundamente o problema, que remete aos vínculos entre crescimento urbano, impactos ambientais e qualidade de vida (Valentim, 2010).

Em 2003, a CETESB, em parceria com a Vigilância Sanitária (VGS) dos municípios de Caieiras e Franco da Rocha iniciaram um trabalho de pesquisa em água e solo das regiões mencionadas. Estes órgãos encontravam-se ante a um problema de contaminação por BHC. A empresa responsável declarou falência, e descartou seus rejeitos indevidamente, causando a contaminação do solo da região que usavam como aterro e, fatalmente, as imediações. É sabido que parte destes contaminantes foi levada para descarte em um terreno isolado, no qual se localizava o galpão de marcenaria, de um familiar do dono desta empresa. Houve histórico de contaminação por parte dos trabalhadores desse galpão (CETESB, 2009a).

As análises realizadas em água pela CETESB determinaram a presença de BHC em água, porém o estudo não foi conclusivo em solo. Desde então a população se encontra em exposição a estes contaminantes e até o momento não havia sido realizado um estudo efetivo em solo nas regiões mencionadas (CETESB, 2009).

Os municípios de Caieiras e Franco da Rocha podem ser claramente observados pela localização geográfica exposta na Figura 6. 


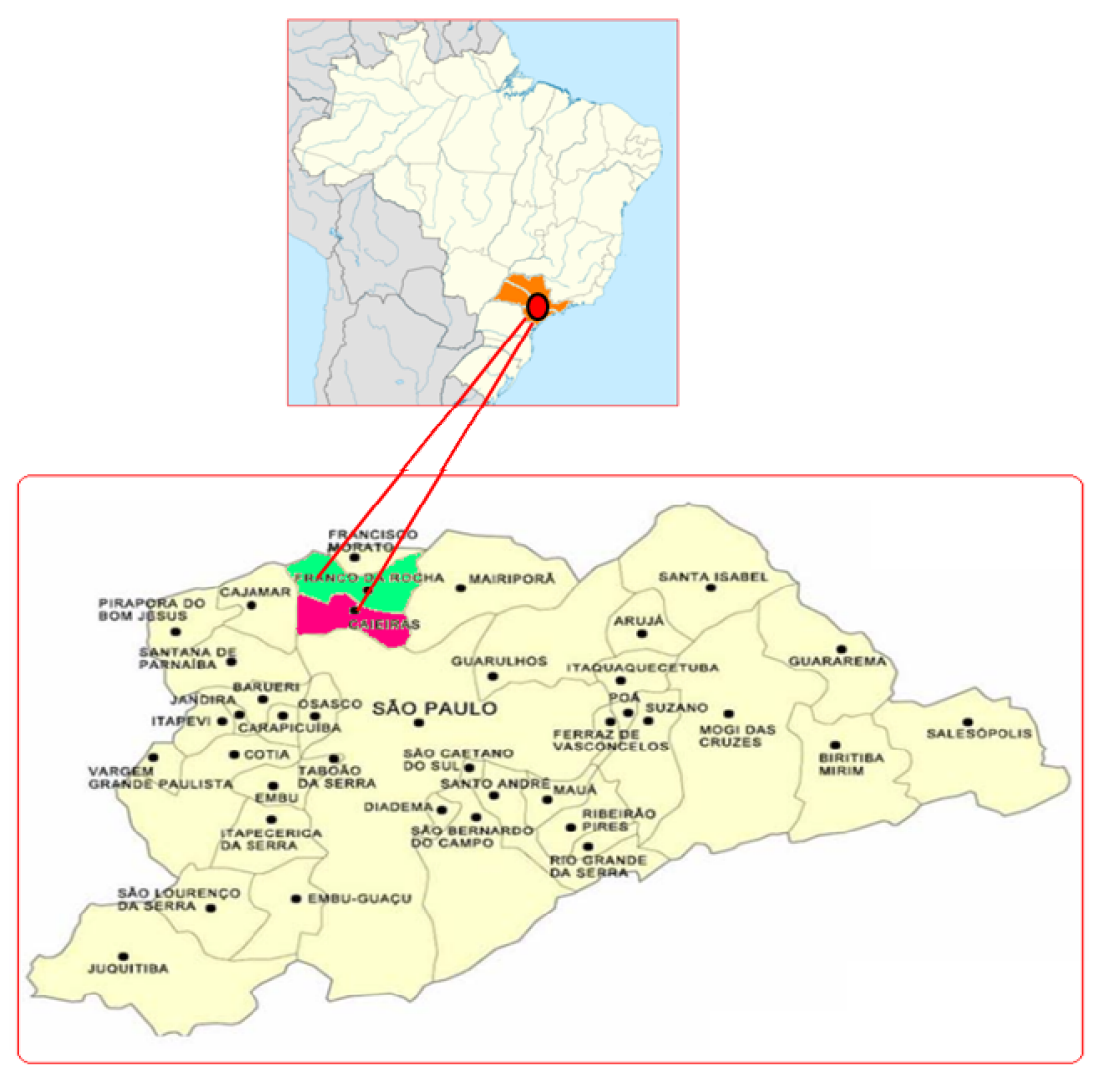

Figura 6. Localização geográfica de Caieiras e Franco da Rocha no Brasil

\subsubsection{Caieiras}

O município de Caieiras possui 81.163 mil habitantes, em seus $96 \mathrm{Km}^{2}$ de área territorial. Conhecida como a "cidade dos pinheirais", por possuir uma grande área florestal preenchida principalmente por pinheiros, Caieiras tem um PIB - produto interno bruto, per capita de $\mathrm{R} \$ 11.711,00$ (onze mil setecentos e setenta e um reais (IBGE, 2010). A cidade tem recebido inúmeras empresas ao longo dos anos. Seu cadastro central de empresas possui 1.577 unidades locais, que empregam 17.388 pessoas (IBGE, 2010). Seus limites são Franco da Rocha a norte, Mairiporã a leste, a capital a sul e Cajamar a oeste. Caieiras situa-se a uma altitude média de 785 metros.

\subsubsection{Franco da Rocha}

Franco da Rocha é um município do estado de São Paulo localizado na região metropolitana da capital paulista e microrregião a que dá nome. A população 
estimada em 2009 era de 131366 habitantes e a área é de 133,9 km², o que resulta numa densidade demográfica de 931,9 hab/km² (IBGE, 2010).

O que é hoje o município de Franco da Rocha originou-se principalmente do desenvolvimento em torno da estação de Juquery (atual Mairiporã), inaugurada na Estrada de Ferro Santos a Jundiaí em 1867. Como a estação ficava no município de Juquery, recebeu o nome do mesmo, embora estivesse a mais de dez quilômetros da sede municipal. $O$ estabelecimento de um hospital psiquiátrico próximo à estação ajudou no desenvolvimento do povoado (IBGE, 2010). 


\subsection{METODOLOGIAS ESTUDADAS}

\subsubsection{Extração}

Tradicionalmente, as extrações de pesticidas em solo eram realizadas usando o método Soxhlet (Lesueur et. al, 2008) uma técnica de extração exaustiva. Para realizar este tipo de extração, se utiliza um aparato extrator Soxhlet, no qual o solvente orgânico é automaticamente destilado, condensado e forçado a passar continuamente através de uma camada aquosa. Assim, o equivalente a várias centenas de extrações com o solvente fresco são realizadas com um equipamento que não requer atenção constante (Dean, 2000; Kramer, 2000).

Esta técnica, entretanto, tem caído em desuso, devido à grande demanda de solventes, muitos dos quais apresentam alta toxicidade, tempo e custo envolvidos. Nos últimos anos vem ocorrendo um desenvolvimento muito rápido de novos métodos analíticos ambientalmente favoráveis, que têm como pilar a não utilização de solventes ou a redução dos mesmos no processo de extração, objetivando alcançar o que chamam de "química analítica verde". Outros aspectos, como o toxicológico e econômico são observados (Prestes et al., 2011). A Tabela 4 demonstra em ordem cronológica os principais métodos de análise de resíduos de pesticidas (Prestes et al., 2011). 
Tabela 4. Ordem cronológica dos principais métodos de análise de resíduos de pesticidas

\begin{tabular}{lll}
\hline Método / & Extração e limpeza & Características \\
(Década) & O método baseia-se em uma extração com & \\
\hline & acetonitrila sendo utilizada basicamente na A extração é seguida por uma extração
\end{tabular}

Organoclora-

dos, Utiliza acetona na etapa de extração. Seguido de organofosfo- uma partição líquido-líquido utilizando rados e diclorometano ou mistura de diclorometano e éter nitrogena- de petróleo, a fim de remover a água. A etapa de dos limpeza é realizada com carvão ativado.

Este foi o primeiro método em que uma solução de cloreto de sódio foi adicionada ao extrato para promover o efeito salting out

(1970)

A extração de pesticidas é realizada com acetona.

Adiciona-se cloreto de sódio para saturar a fase

Luke aquosa, resultando maiores valores de

(1970) recuperação dos compostos polares. A etapa de limpeza, quando realizada, é feita com coluna Este método e suas modificações ainda são utilizados em análises de resíduos de pesticidas.

florisil. 


\section{Método /}

(Década)

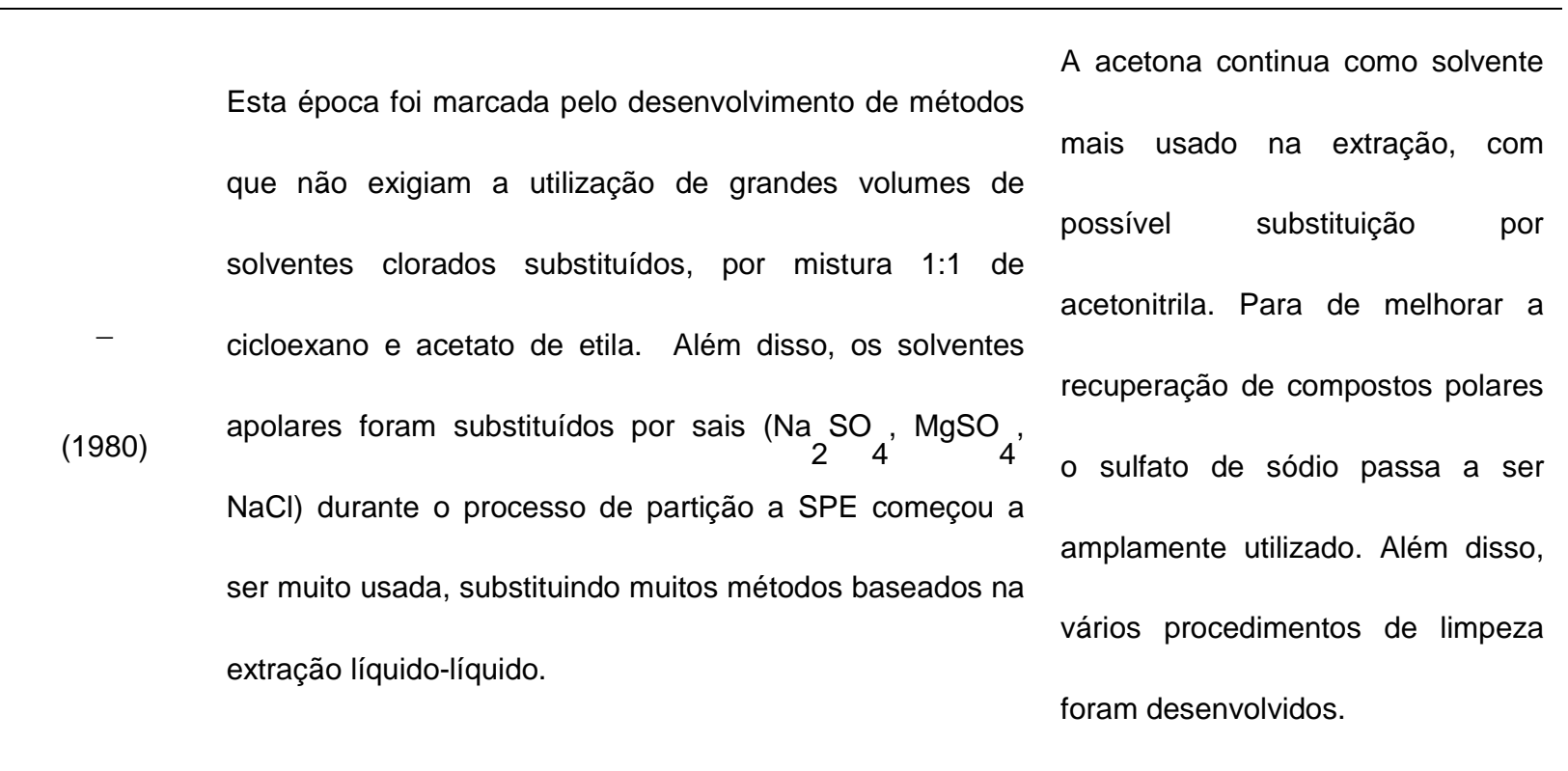

Os avanços da Química Analítica em consonância com o 1990 - atual conceito de sustentabilidade levaram ao desenvolvimento Rapidez na execução das análises, miniaturização, automatização. de várias técnicas alternativas de extração.

Desde o início da década de 90, vêm ocorrendo um grande desenvolvimento de métodos alternativos de extração baseados na redução do volume de solvente utilizado, dentre os quais, destacam-se Extração em Fase sólida (Solid Phase Extraction, SPE), a qual também tem sido empregada com frequência na etapa de limpeza do extrato para amostras de alimentos (Prestes et al., 2011).

Outros métodos foram desenvolvidos no mesmo período, e tinham como objetivo a simplificação de etapas como, por exemplo, Dispersão da Matriz em Fase Sólida (Matrix Solid Phase Dispersion, MSPD) que apresenta as vantagens de utilização de equipamentos simples, consumo moderado de solventes e simplicidade no preparo da amostra. Este método apresenta porem, algumas desvantagens, tais como a não adequação às amostras secas ou com alto teor de lipídeos, o alto 
consumo de solventes e a necessidade, em alguns casos, de etapa de limpeza adicional (Ramos et. al, 2002; Barker, 2000).

A Microextração em Fase Sólida (Solid Phase Microextraction, SPME) destacase principalmente pelo fato de o uso de solventes poder ser completamente eliminado. Esta técnica possibilita também à re-análise de uma determinada amostra. A fibra de adsorção pode ser utilizada muitas vezes sem perda de retenção e pode ser acoplada diretamente ao sistema cromatográfico. A técnica de SPME apresenta, porém, algumas limitações no que concerne a parâmetros de validação, como precisão e recuperação, que apresenta percentual relativamente baixo. A otimização do método é morosa e quanto à obtenção de materiais, há poucas fibras disponíveis comercialmente (Valsamaki et.al, 2006; Correia et. al, 2001).

A Extração com Membrana Assistida por Solvente (Membrane-Assited Solvent Extration, MASE) é uma técnica que possibilita a introdução direta de amostras não tratadas e análise de amostras complexas, requer menor quantidade de solvente, seu procedimento elimina interferentes e apresenta elevado grau de pré-concentração do analito, além da facilidade de automação. Como desvantagens, podem ser citadas a baixa eficiência, a sensibilidade a contaminantes sólidos que podem obstruir os poros da membrana, ocasionando um aumento no tempo de análise para o preparo de amostra e tempo prolongado de análise (Ling e Teng, 1997; Hyotylainen et. al, 2002).

A Extração Acelerada por Solventes (Pressurized Liquid Extraction, PLE) apresenta como vantagens principais a automação do processo de extração, o tempo reduzido de extração, a utilização de pequenas quantidades de solventes e um curto tempo de extração. No entanto, apresenta desvantagens como, por exemplo, a pouca seletividade na extração, a necessidade de etapa de limpeza do extrato, e a inviabilidade de utilização para compostos termolábeis (Holstege et.al, 1994; Papadakis et. al, 2006).

Com a Extração Assistida por Micro-ondas (Microwave Assisted Extraction, MAE) é possível realizar extração simultânea de diversas amostras, apresenta facilidade de operação, utiliza pequenas quantidades de solventes e curto tempo de extração. Porém, sua extração é pouco seletiva, necessita de etapa de limpeza do extrato e não pode ser utilizada para compostos termolábeis (Holstege et. al, 1994; Camel, 1998; Papadakis et. al, 2006). 
Estes são exemplos de métodos que apresentam, dentre outras características, elevada eficiência, entretanto, geralmente demandam investimento considerável em instrumentação (Prestes et. al, 2011).

Lesueur e colaboradores realizaram, em 2008, um trabalho de comparação entre quatro métodos de extração para análise de vinte e quatro pesticidas em amostras de solo. Os métodos de extração testados foram Extração por Solvente Ultrasônico (Ultrasonic Solvent Extraction, USE), Extração Acelerada por Solventes (Pressurized Liquid Extraction, PLE), método segundo norma européia DIN 12393 e QuEChERS (Quick, easy, cheap, effective, rugged and safe method). Os melhores resultados, porém, para os testes de recuperações dos padrões foram obtidos utilizando-se o método QuEChERS, com média de $72,7 \%$, seguido do método da norma européia DIN 12393- com média de 65,7; PLE com média de 63,5\% e USE com média de recuperação de $57 \%$. Os maiores LD foram alcançados com o método da norma européia DIN 12393, enquanto que os menores LD foram alcançados com os métodos QueChERS e PLE.

\subsubsection{QuEChERS}

O método de extração QuEChERs foi introduzido por Michelangelo Anastassiades em 2003, e foi desenvolvido inicialmente para extração multirresíduo de pesticidas aplicada em alimentos. Assim como outras técnicas, o QuEChERS surgiu a fim de atender às necessidades do analista, contudo esta técnica se destaca por executar uma maior demanda de amostras em menor tempo, com menor custo e gasto de solventes (Anastassiades et.al, 2003).

A elaboração do método teve como base uma revisão das condições comumente utilizadas em análise multirresíduo de pesticidas e foi proposto um método de preparo de amostra, baseado nas seguintes etapas: extração com acetonitrila, seguida da partição, promovida pela adição de sais (sulfato de magnésio, $\mathrm{MgSO}_{4}$, e cloreto de sódio, $\mathrm{NaCl}$ ). Juntamente com o QuEChERS, foi proposto um novo método de limpeza denominado Extração em Fase Sólida Dispersiva (Dispersive Solid Phase Extraction, D-SPE) (Prestes et. al, 2011). Prestes (2011) faz uma revisão do método, abrangendo as vantagens dos materiais e procedimentos estabelecidos, 
bem como algumas modificações realizadas no método que são descritos nos tópicos 2.7.1.1.1 a 2.7.1.2.

\subsection{Escolha do Solvente}

Os solventes mais comumente utilizados em análises multirresíduo de pesticidas são acetonitrila, acetona e acetato de etila. Eles apresentam altos valores de recuperação para uma ampla série de pesticidas. Cada um deles apresenta suas vantagens e desvantagens em termos de seletividade e em questões práticas.

A utilização da acetonitrila como solvente possibilita a extração de uma menor quantidade de co-extrativos lipofílicos provenientes da amostras, como por exemplo, ceras, gorduras e pigmentos. A acetonitrila proporciona a extração de uma ampla faixa de pesticidas com diferentes polaridades e, quando acidificada, permite recuperações satisfatórias de pesticidas que geralmente apresentam problemas de estabilidade. Uma outra vantagem é de que este solvente é mais adequado para GC-MS (Cromatógrafo a Gás - Espectrômetro de Massas) e LC-MS/MS (Cromatógrafo Líquido / Espectrometria de Massas Tandem) do que acetato de etila ou acetona (Anastassiades et. al, 2003; Prestes et. al, 2011).

\subsection{Escolha do tipo de agitação a ser empregada}

A maioria dos métodos multirresíduo de preparo de amostras utiliza "blenders", como o Ultraturrax, durante o processo de extração. O procedimento de agitação manual ou com auxílio de Vortex possui várias vantagens em relação à agitação mecânica, tais como, possibilidade de realizar a extração em campo; a extração ocorre em um único frasco fechado não expondo o analista; rapidez, uma vez que não há necessidade de lavagem do homogeneizador no intervalo entre as extrações. Portanto, no método QuEChERS a agitação pode ser feita manual ou utilizando Vortex (Anastassiades et. al, 2003; Prestes et. al, 2011).

\subsection{Escolha dos sais para extração e partição}

A adição de sais para promover o efeito salting out é utilizada em vários métodos multirresíduo. Dependendo da natureza do solvente utilizado na etapa de partição 
obtêm-se melhores percentuais de recuperação para analitos polares, uma vez que a adição de sais diminui a solubilidade destes compostos na fase aquosa, bem como a quantidade de água na fase orgânica e vice-versa.

Nos métodos multirresíduos que utilizam acetona, a partição é controlada através de uma combinação de $\mathrm{NaCl}$ e solventes apolares, porém tem como desvantagens a diluição do extrato e o consumo de um maior volume de solvente. Os métodos multirresíduo que utilizam acetonitrila, desenvolvidos até então, não empregam adição de nenhum tipo de solvente apolar no processo de partição. $\mathrm{Na}$ extração com acetonitrila, a adição de sais é muito conveniente uma vez que é rápida, tem baixo custo, tem grande vantagem de não diluir o extrato da amostra e proporciona a separação das fases orgânica e aquosa.

A utilização de sais secantes, como sulfato de sódio $\left(\mathrm{Na}_{2} \mathrm{SO}_{4}\right)$, tem a finalidade de melhorar a recuperação de pesticidas polares. A escolha do $\mathrm{MgSO}_{4}$ no desenvolvimento do método QuEChERS foi devido a maior capacidade de remover água quando comparado a outros sais. Além de reduzir o volume de fase aquosa, sua hidratação é uma reação exotérmica, tendo como resultado o aquecimento entre 40 e $45^{\circ} \mathrm{C}$ da amostra durante as etapas extração/partição, favorecendo a extração, especialmente dos compostos apolares (Anastassiades et. al, 2003; Prestes et. al, 2011).

\subsection{Escolha do sorvente para etapa de limpeza}

Tradicionalmente a etapa de limpeza emprega SPE, a qual utiliza cartuchos ou colunas que contêm entre 2,5 e $1 \mathrm{~g}$ de sorvente. Esta técnica envolve operação manual, uso de diferentes solventes para lavagem do sorvente, etapas de evaporação e secagem. Muitos fatores afetam a precisão quando se trabalha com SPE, entre eles o ajuste do sistema de vácuo e o fluxo dos solventes. Esta técnica quando automatizada requer manutenção frequente, além dos sistemas hoje disponíveis apresentarem um custo considerável.

O método de limpeza que emprega D-SPE permite que a limpeza e redução de água residual sejam efetuadas de forma rápida e simultânea. Esta etapa de remoção de água proporciona um extrato final de menor polaridade, facilitando assim a precipitação de co-extrativos polares. O sorvente PSA, "primary secondary 
amine" retém as interferências da matriz, sendo que depois da agitação manual e centrifugação o extrato está pronto para ser injetado em sistema cromatográfico.

A estrutura bidentada do PSA tem um elevado efeito quelante, devido a presença dos grupos amino primário e secundário. Como resultado, a retenção de ácidos graxos livres e de outros compostos polares presentes na matriz é muito forte. Uma limpeza eficiente garante uma maior vida útil para insersores e colunas cromatográficas, reduzindo assim a contaminação do sistema cromatográfico e minimizando o efeito matriz (Anastassiades et. al, 2003; Prestes et. al, 2011).

\subsubsection{Modificações do método QuEChERS}

Desde sua primeira versão, o método vem sofrendo adaptações e sendo empregado na extração de outros tipos de matrizes.

De acordo com Lehotay e Anastassiades, a adição de uma etapa de tamponamento foi a primeira modificação proposta para o método, com o objetivo de melhorar os percentuais de recuperação (70-120\%). Lehotay et. al, em 2005, desenvolveram o método "QuEChERS acetato", no qual o efeito tamponante ( $\mathrm{pH} \mathrm{4,8)}$ é promovido pela adição de acetato de sódio.

Anastassiades et. al propuseram o método "QuEChERS citrato", em 2007, que utiliza uma mistura de citrato de sódio diidratado e hidrogenocitrato sesquihidratado como responsáveis pelo efeito tamponante ( $\mathrm{pH} 5,0-5,5)$.

Em 2008 Lesueur et al. empregou o método de extração QuEChERS na análise de pesticidas em solo, baseando-se no método proposto inicialmente por Anastassiades, porém aplicou algumas modificações. O método de extração em solo objetivou a determinação de 24 pesticidas, dentre os quais podem ser citados os organoclorados lindano e dieldrin. Para isso, foram aplicados $20 \mathrm{~mL}$ de acetonitrila em $10 \mathrm{~g}$ de amostra de solo e procedeu-se agitação, em seguida adicionou-se $4 \mathrm{~g}$ de sulfato de magnésio, $1 \mathrm{~g}$ de cloreto de sódio, $1 \mathrm{~g}$ de citrato de sódio, $0,5 \mathrm{~g}$ de hidrogenocitrato de sódio sesquiidratado. Agitou-se e centrifugou-se, posteriormente efetuou-se a etapa de limpeza, adicionando-se ao sobrenadante, $150 \mathrm{mg}$ de bondesil PSA e 950mg de sulfato de magnésio, agitou-se e centrifugou-se. Retirou-se então o sobrenadante o qual estava pronto para análise. O método apresentou ótimos resultados nos testes de recuperação. 
A técnica de extração QuEChERS tem se destacado por ser de fácil e rápida execução além de ser relativamente barata, robusta e eficiente (Lesueur et. al, 2008).

\subsubsection{Cromatografia Gasosa}

A técnica de cromatografia foi utilizada pela primeira vez por Ramsey, em 1905 para separar misturas de gases e vapores. Porém, só em 1952, Martin e James introduziram a técnica de cromatografia a gás, até hoje considerada uma das técnicas mais úteis para análises de gases e compostos orgânicos voláteis ou derivados com igual característica (Cienfuegos e Vaitsman, 2000).

A Cromatografia Gasosa - GC (Gas Chromatography) é uma técnica utilizada para separação e análise de misturas de substâncias voláteis. A amostra é vaporizada e introduzida em um fluxo de um gás adequado denominado fase móvel (FM) ou gás de arraste. Este fluxo de gás juntamente com a amostra vaporizada passa por um tubo contendo a fase estacionária $(F E)$, coluna cromatográfica, onde ocorre a separação da mistura. A Fase Estacionária pode ser um sólido adsorvente (Cromatografia Gás-Sólido) ou, mais comumente, um filme de um líquido pouco volátil, suportado sobre um sólido inerte (Cromatografia Gás-Líquido com Coluna Empacotada ou Recheada) ou sobre a própria parede do tubo (Cromatografia Gasosa de Alta Resolução) (Ciola, 1985). A Figura 7 esquematiza um sistema cromatográfico simples, composto por um cilindro de gás de arraste, controladores de pressão e vazão, injetor, forno com colunas, detector e registrador.

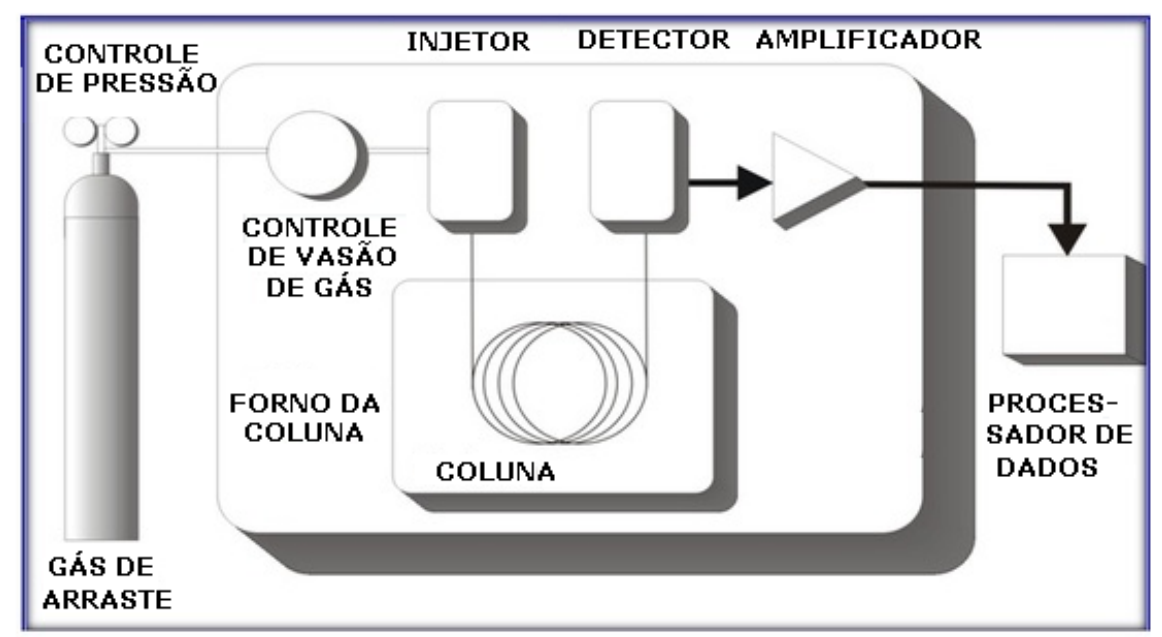

Figura 7. Esquema ilustrativo de um cromatógrafo a gás 
Ao passar pela FE, os compostos da amostra são separados de acordo com sua afinidade com a coluna cromatográfica, ou seja, de acordo com seu tempo de retenção (TR) e também sob influência da temperatura aplicada ao sistema (Cienfuegos e Vaitsman, 2000).

Após separação, são imediatamente expostas ao detector, que identificam e quantificam as amostras analisadas, gerando um cromatograma. O cromatograma é um registro gráfico dos sinais emitidos pelo detector. Pode-se, portanto, concluir que a teoria da cromatografia está baseada em duas características principais: a posição do pico e a velocidade de alargamento deste, durante a corrida (Cienfuegos e Vaitsman, 2000).

No desenvolvimento de um método cromatográfico, parâmetros como temperatura de ebulição do(s) composto(s) de interesse e do solvente, fluxo do gás de arraste e pressão devem ser cuidadosamente observados, pois a variação destes implica na eficiência do método em questão (Cienfuegos e Vaitsman, 2000).

\subsubsection{Estudo da Conformidade do Sistema}

Para garantir que todo o método analítico adotado forneça resultados com precisão e exatidão aceitáveis e confiáveis é necessária a realização de um estudo prévio do mesmo, como por exemplo, testes experimentais de conformidade do sistema cromatográfico que inclui a avaliação dos seguintes parâmetros: fator ou tempo de retenção $(k)$, fator de separação $(\alpha)$, resolução $(R S)$, número de pratos $(N)$ e fator de assimetria (As) (Lanças, 2004).

\subsubsection{Tempo de retenção}

O tempo de retenção é o tempo relativo em que o analito permanece na fase estacionária (F. E.). Ele está diretamente relacionado com o grau de afinidade entre o analito e a coluna cromatográfica. O fator de retenção é definido matematicamente pela Equação 1 (Ciola, 1985).

$$
\mathrm{t}^{\prime}=t_{1}-\mathrm{t}_{2}
$$


Em que $t_{1}$ é o tempo em que as moléculas do analito ficam na fase móvel e $t_{2}$ é o tempo gasto desde a injeção do analito no sistema cromatográfico até a saída do pico referente ao mesmo (Ciola, 1985).

\subsubsection{Cálculo do Fator de Retenção (K)}

O Fator de Retenção é determinado pelo tempo de retenção da substância (a) subtraído pelo tempo de retenção do composto não retido (b), dividido pelo tempo de retenção do composto não retido (b). Esses valores são obtidos considerando-se a Equação 2. (Cienfuegos e Vaitsman, 2000).

$$
\mathrm{R}_{f}=\frac{\mathrm{a}-\mathrm{b}}{\mathrm{b}}
$$

\subsection{Influência da estrutura molecular nos valores de K}

O grau de afinidade entre o composto e a FE baseia-se em conceitos químicos de forças intermoleculares e polaridade molecular. FE polares reterão mais concisamente compostos polares, por meio de interações do tipo dipolos permanentes (Figura 8 b) ou pontes de hidrogênio (Figura 9). No caso de fases estacionárias apolares, obviamente, ocorrerá maior afinidade por compostos apolares, regida por interações de dipolo induzido (Figura 8 a) (Ciola, 1985).

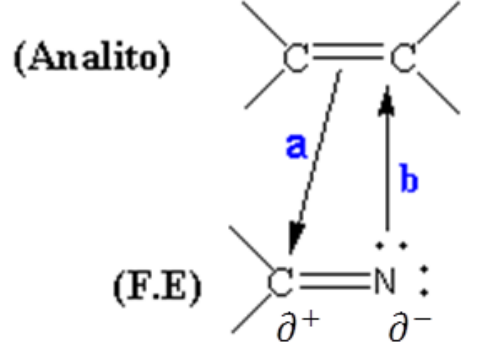

Figura 8. Interação entre analito e fase estacionária por (a) dipolo-induzido e (b) dipolopermanente. 


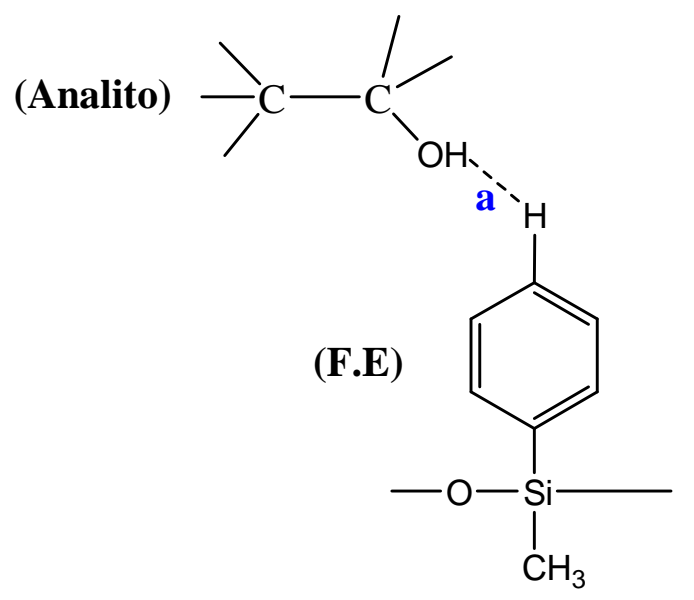

Figura 9. Interação entre analito e fase estacionária por (a) ponte de hidrogênio.

\subsection{Influência da temperatura nos valores de $K$}

O fator de retenção, como outras constantes físico-químicas, varia com a temperatura de acordo com a Equação 3.

$$
\mathrm{K}=\mathrm{k}_{0} \cdot \mathrm{e}^{-\Delta \mathrm{H} / \mathrm{RT}}
$$

Onde $\mathrm{k}_{0}$ é uma constante; $\Delta \mathrm{H}$, calor de dissolução (ou adsorção); $\mathrm{T}$ a temperatura; e R, a constante dos gases perfeitos.

Como a dissolução ou adsorção são fenômenos exotérmicos, $\mathrm{K}$ diminui exponencialmente com 0 aumento da temperatura, como expressa a Equação 4 (Ciola, 1985).

$$
\ln k=\ln \mathrm{k}_{0}-\frac{\Delta H}{R T}
$$

\subsection{Cálculo do Fator de Separação ( $\alpha$ )}

O Fator de Separação dimensiona a separação relativa entre dois componentes consecutivos em um cromatograma, como expressa matematicamente a Equação 5 (Ciola, 1985). 


$$
\alpha=k_{2} / K_{1}
$$

Onde $\alpha$ é o fator de separação, $K_{2}$ é o fator de retenção do pico 2 e $K_{1}$ é o fator de retenção do pico 1 .

\subsection{Resolução (Rs)}

No desenvolvimento de um método em cromatografia gasosa, a determinação da resolução necessária para a separação é fator crítico. A capacidade do sistema cromatográfico em separar dois componentes (par crítico), por exemplo, não depende apenas dos tempos de retenção absolutos, mas também da largura dos respectivos picos na linha de base que representa a eficiência de separação da coluna. A resolução R é determinada pela Equação 6 (Cienfuegos e Vaitsman, 2000).

$$
\mathrm{R}=\frac{\mathrm{t}_{\mathrm{r} 2}-\mathrm{t}_{\mathrm{r} 1}}{\mathrm{~W}_{2}+\mathrm{W}_{1}}
$$

Onde $t_{r 1}$ e $t_{r 2}$ é representam os tempos de retenção de dois analitos consecutivos, e $W_{1}$ e $W_{2}$ correspondem às larguras dos respectivos picos na linha de base.

\subsection{Número de Pratos Teóricos}

De acordo com a definição de coeficiente de partição (k), uma substância que entre na coluna juntamente com o gás de arraste se dissolverá na fase líquida até que se estabeleça um equilíbrio, de acordo com os valores da concentração nas fases estacionária e móvel. Durante a passagem da substância pela coluna, este equilíbrio é rompido pelo efeito de transporte e deve ser restabelecido consecutivamente. Do ponto de vista teórico, considerar este processo em vários estágios de equilíbrio é dividir a coluna em um número de seções iguais entre si e, em cada uma destas seções, o equilíbrio vapor-líquido deve ser restabelecido. A cada uma destas seções deu-se o nome de "Prato Teórico" (Cienfuegos e Vaitsman 2000). 
O poder de separação de uma coluna dependerá, dentre outros fatores, da troca entre a amostra e a fase líquida, isto é, quanto mais etapas de equilíbrio existam, maior será o poder de separação. Pode-se então dizer que coluna eficiente é aquela que possui um grande número de pratos teóricos por metro (Cienfuegos e Vaitsman, 2000). O valor do número de pratos teóricos é obtido a partir do cromatograma, pela Equação 7:

$$
\mathrm{N}=16(\operatorname{tr} / \mathrm{Wb})^{2}
$$

Onde tr é o tempo de retenção e Wb a largura do pico na linha de base.

\subsubsection{Detecção por captura eletrônica (ECD)}

A técnica de detecção por Captura de Elétrons (ECD) foi introduzida em 1960, e aliada à técnica de cromatografia gasosa, consolidou-se no campo de análise de compostos halogenados, devido a sua alta seletividade e especificidade (Maggs et. al, 1971). Este método de análise consiste em gerar elétrons livres pela exposição da amostra à pequena fonte de material radioativo $\left({ }^{3} \mathrm{H}\right.$ e $\left.{ }^{63} \mathrm{Ni}\right)$. Os elétrons produzidos neste processo são coletados no anodo, gerando corrente, que é amplificada por um eletrômetro, resultando a linha de base. Se a amostra possuir afinidade por elétrons, ao passar pelo detector, pode "capturar" alguns, causando diminuição na corrente produzida e gerando um sinal proporcional à sua concentração (Skoog et. al, 1998).

O ECD (Figura 10) é seletivo, possuindo grande sensibilidade para moléculas eletronegativas como halogenetos orgânicos, aldeídos conjugados, nitrilas, nitratos e organometálicos. É praticamente insensível a hidrocarbonetos, álcoois e cetonas (Cienfuegos e Vaitsman, 2000).

O detector pode funcionar por duas formas: por meio de corrente contínua ou por corrente pulsada. A principal diferença entre elas é que sob corrente contínua, os elétrons adquirem maior energia cinética (determinada pela força do campo elétrico) do que as moléculas do gás de arraste, enquanto que sob corrente pulsada, o período de pulso fornecido é grande, se comparado a largura, favorecendo um equilíbrio térmico entre os elétrons e as moléculas de gás. Consequentemente, as respostas 
anômalas obtidas, até então, pela corrente de pulso contínua, são eliminadas pelo pulso de corrente (Maggs et. al, 1971).

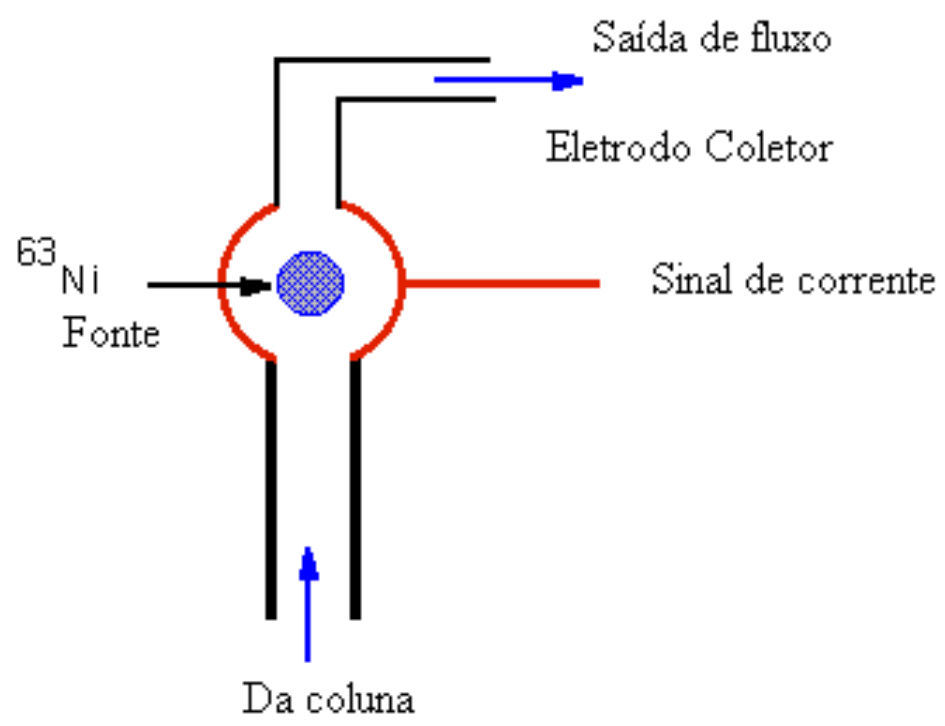

Figura 10. Esquema de Detector por Captura Eletrônica (ECD)

Uma importante aplicação do ECD consiste na determinação de pesticidas organoclorados, devido à sua alta sensibilidade e especificidade. Contudo sua linearidade é geralmente compreendida dentro de um intervalo de duas ordens de magnitude (Skoog et. al, 2000).

\subsubsection{Mecanismo de detecção}

A detecção por captura de elétrons é baseada na eletronegatividade das substâncias eluídas, ou seja, a habilidade das mesmas em formarem íons negativos para capturar elétrons. Íons negativos têm vários graus de estabilidade, que são expressas através de sua eletroafinidade relacionada com os fótons ionizantes. A eletroafinidade de um átomo ou molécula depende de sua configuração eletrônica, ou seja, quanto mais ocupado de elétrons o orbital de um íon negativo estiver, mais estável este íon estará. Geralmente, átomos com orbitais ocupados não formam íons negativos, enquanto átomos com uma única vacância em seu orbital mais externo, Ihes conferem forte eletroafinidade. A Tabela 5 mostra a eletroafinidade de alguns átomos e moléculas. 
Tabela 5. Eletroafinidade de alguns átomos e moléculas (Ševčík, 1976).

\begin{tabular}{cccc}
\hline Íon & Eletroafinidade $(\mathrm{eV})$ & Íon & Eletroafinidade $(\mathrm{eV})$ \\
\hline$H^{-}$ & 0,80 & $\mathrm{H}_{2}^{-}$ & 0,90 \\
$H e^{-}$ & 0,00 & $\mathrm{O}_{2}^{-}$ & 0,44 \\
$\mathrm{C}^{-}$ & 1,25 & $\mathrm{OH}^{-}$ & 1,78 \\
$\mathrm{~N}^{-}$ & 0,50 & $\mathrm{NO}^{-}$ & 0,91 \\
$\mathrm{O}^{-}$ & 1,46 & $\mathrm{NO}_{2}^{-}$ & 3,90 \\
$P^{-}$ & 1,33 & $C H^{-}$ & 1,60 \\
$S^{-}$ & 2,15 & $C N^{-}$ & 3,10 \\
$\mathrm{Cl}^{-}$ & 3,70 & $S F_{2}^{-}$ & 3,39 \\
$I^{-}$ & 3,23 & $S H^{-}$ & 2,50 \\
\hline
\end{tabular}

O mecanismo de captura de elétrons depende fortemente da energia de colisão do elétron, de acordo com o processo de termalização. O processo de termalização consiste na perda de energia gradual do gás de arraste, provocada pela emissão de partículas primárias (fótons, elétrons), emitidas por uma fonte adequada $\left({ }^{63} \mathrm{Ni}\right.$ ou ${ }^{3} \mathrm{H}$ ) para colidir com o mesmo. Este processo depende do tipo de partícula emitida pela fonte e também do tipo de gás de arraste (Ševčík, 1976).

Em cromatografia, o gás de arraste geralmente utilizado é o nitrogênio, gás diatômico, considerado mais eficiente do que os gases monoatômicos no que se refere ao processo de termalização. A colisão entre o gás e a partícula emitida pela fonte pode provocar uma ionização (Equação 8) ou a formação de um estado excitado, entretanto a probabilidade de formação de um estado excitado é insignificante, comparada a de ionização de uma molécula diatômica (Equação 9) .

$$
\begin{aligned}
& \beta+\mathrm{N}_{2} \rightarrow \beta^{\prime}+\mathrm{N}_{2}^{+}+\mathrm{e} \\
& \beta+\mathrm{N}_{2} \rightarrow \beta^{\prime}+\mathrm{N}_{2}^{*}
\end{aligned}
$$

Num dado instante, elétrons com várias energias estão presentes no detector, ocupando grande volume, alguns dos quais são capazes de ionizar átomos ou moléculas diretamente, e algumas dessas ionizações são realizadas por captura de elétrons. A captura eletrônica provoca redução da velocidade de transporte de carga, diminuindo a corrente de ionização no campo elétrico. Alguns mecanismos de captura de elétrons podem ser observados nas Equações 10 a 13. 


$$
\begin{gathered}
e+A \rightarrow A^{-}+h v \\
e+A+B \rightarrow A^{-}+B^{\prime} \\
e+\mathrm{NO}_{2}(O R G) \rightarrow \mathrm{NO}_{2}\left(O R G^{-}\right)^{*} \stackrel{\gamma}{\rightarrow} \mathrm{NO}_{2}\left(O R G^{-}\right)+\gamma \\
\left.e+\mathrm{Cl}(\mathrm{ORG}) \rightarrow \mathrm{Cl}(\mathrm{ORG})^{-}\right)^{*} \rightarrow \mathrm{Cl}^{-}+\mathrm{ORG}
\end{gathered}
$$

As reações envolvem a captura de elétrons de um átomo, e a probabilidade de isso ocorrer é baixa, se comparada com as reações 10 a 13, que envolvem moléculas (Ševčík, 1976).

\subsubsection{Sensibilidade e Seletividade do ECD}

A sensibilidade e a seletividade do ECD estão diretamente relacionadas capacidade de produção de sinal, isto é, a eletroafinidade das substâncias em análise no detector. Esta técnica é utilizada para análise de traços.

A sensibilidade do detector depende do campo elétrico produzido entre os eletrodos. Entretanto, a pequena distância entre eles, pode provocar muitas mudanças de intensidade do campo elétrico, podendo produzir ionizações diretas (Ševčík, 1976).

\subsubsection{Espectrometria de massas}

F. W. Aston, através da criação do espectrógrafo de massas (Figura 11), descobriu a causa das diferenças de massa de certo número de isótopos não radiativos. Introduzindo o gás neônio em seu instrumento, ele observou quatro linhas correspondentes a razões massa/carga de 10, 11, 20 e 22. O primeiro par correspondendo a íons duplamente carregados e o segundo par, a íons monoionizados. Também A. J. Dempster, trabalhando nos EUA, desenvolveu seu espectrômetro de massas e foi capaz de medir precisamente abundâncias isotópicas de vários elementos. O primeiro experimento de análise de compostos orgânicos foi realizado em 1940 por Hoover e Washburn que analisaram uma mistura de hidrocarbonetos (Beynon e Morgan, 1978). 


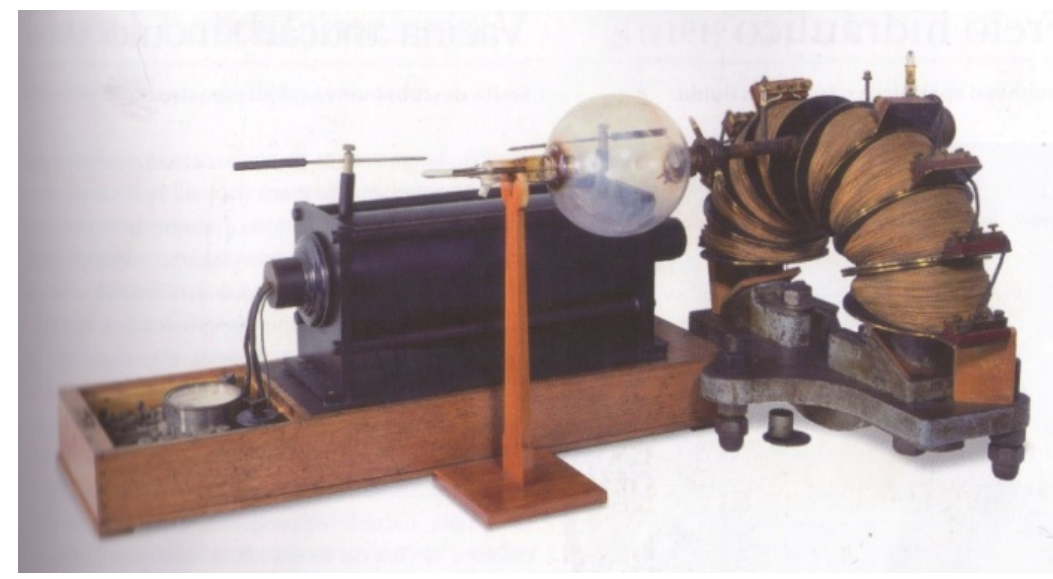

Figura 11. $\mathrm{O} 1^{\circ}$ Espectrômetro de massas (Challoner, 2010).

A partir dessas experiências pioneiras iniciou-se a ciência da espectrometria de massas, emergindo com instrumentos setoriais e posteriormente com 0 desenvolvimento de instrumentos quadrupolares, de tempo de vôo, de ressonância ciclotrônica, entre outros (Bustillos et. al, 2003; Asamoto, 1991; March, 1997).

Basicamente, todos os espectrômetros de massa possuem uma fonte e acelerador de íons, analisador de massas e detector de íons (Figura 12). Neles, uma amostra de pressão de vapor moderada é introduzida num sistema de injeção operado sob vácuo $\left(10^{-4}\right.$ a $10^{-7}$ torr) e temperatura superior a $300 \stackrel{\circ}{\circ}$. Após vaporização, a amostra com moléculas, $M$, do analito é levada à fonte de ionização onde sofre impacto por feixe de elétrons de alta energia, produzindo o íon positivo $\mathrm{M}^{+}$, chamado íon molecular.

O íon molecular é produzido em diferentes estados de energia. A energia interna é dissipada por reações de fragmentação e os fragmentos de menores massas são ionizados e convertidos a íons. $\mathrm{O}$ íon $\mathrm{M}^{+}$permite determinar diretamente o peso molecular do composto ou número inteiro mais próximo deste e os demais íons com razões massa-carga $(\mathrm{m} / \mathrm{z})$, fornecem informações importantes para a elucidação da estrutura. 


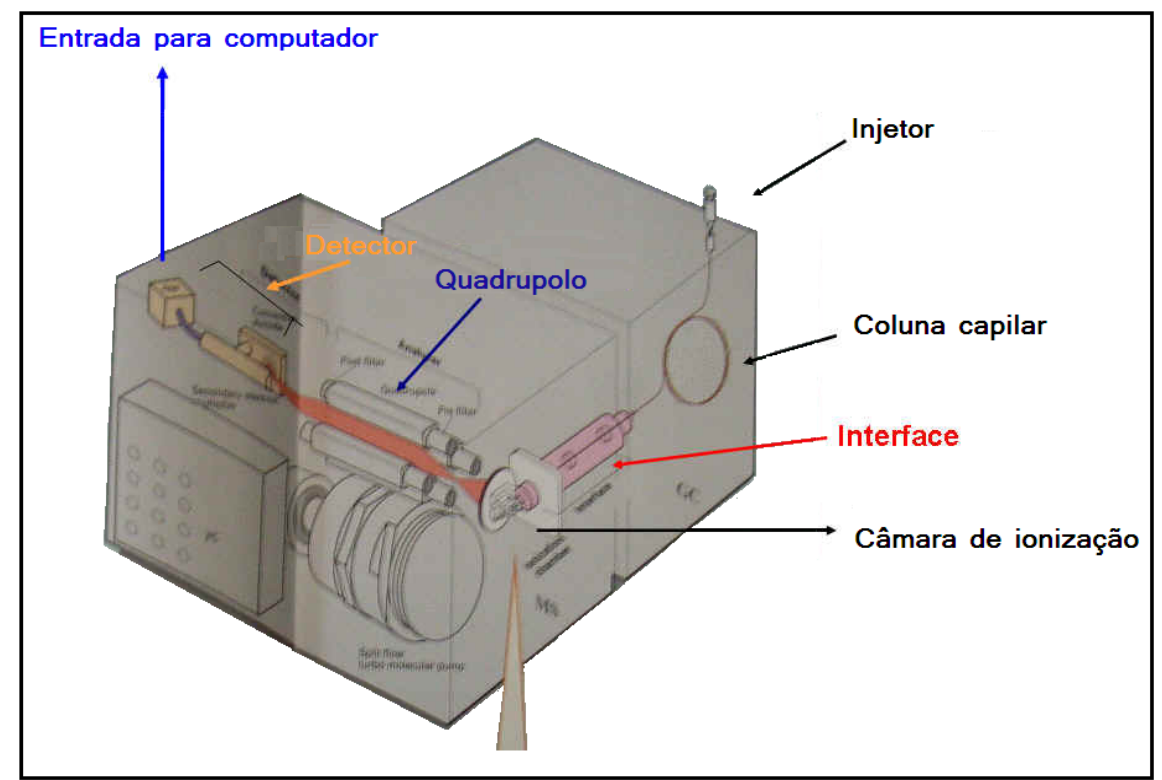

Figura 12. Cromatógrafo a Gás acoplado a Espectrômetro de Massas

Um aspecto a se destacar no que se refere aos espectrômetros de massas é a forma pela qual as moléculas do analito são ionizadas, uma vez que estas devem ser ionizadas por campos eletromagnéticos, sejam eles estáticos ou dinâmicos. Os vários métodos de ionização existentes foram desenvolvidos com o intuito de ampliar a gama de compostos que poderiam ser levados a fase gasosa e ionizados, independente de sua forma física, peso molecular ou característica de volatidade e etc (Dempster, 1921; Nier, 1947; Munson e Field, 1966; Barber et. al, 1981; Dole et. al, 1968; Yamashyta e Fenn, 1984; Horning et. al, 1973; Horning et. al, 1974; Torgeson et. al, 1974).

Entre os principais métodos existentes, destacam-se a ionização por impacto de elétrons que constitui um importante método de ionização empregado na análise de moléculas orgânicas. A Figura 13 representa esquematicamente uma fonte de íons por impacto de elétrons acoplada a um analisador de massas quadrupolar bidimensional. 


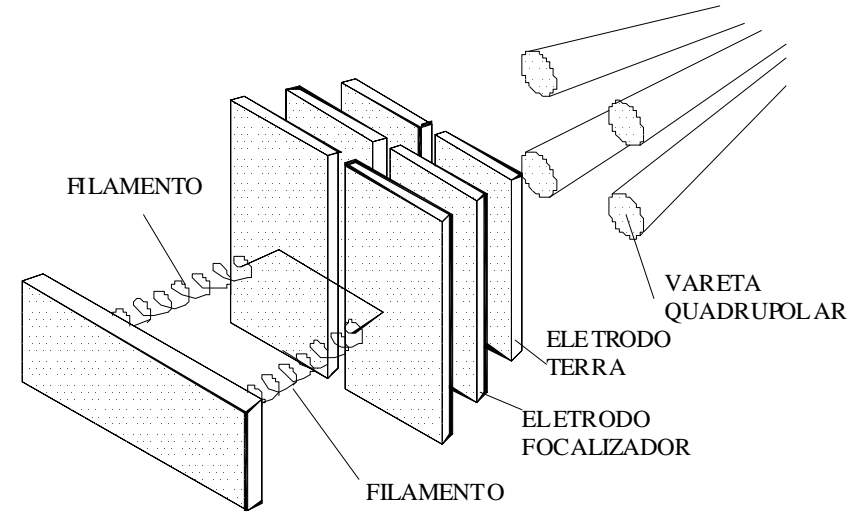

Figura 13. Representação esquemática de fonte de íons por impacto de elétrons acoplada a um analisador de massas quadrupolar bidimensional.

As fontes de ionização por impacto de elétrons possuem um filamento, geralmente de tungstênio ou rênio, o qual aquecido sob vácuo de $10^{-5}$ a $10^{-6} \mathrm{mbar}$ emite elétrons que são acelerados à câmara de ionização por uma diferença de potencial de $70 \mathrm{eV}$, embora diferentes energias de ionização possam ser utilizadas (Figura 13) (Hilderbrand, 2000; O'Connor, 1999 e 1998; Takayama, 1995). O feixe de elétrons produzido é então colimado passando por uma fenda da câmara de ionização e colide com as moléculas vaporizadas da amostra (Ashcroft, 1997). Quando as moléculas neutras do gás interagem com esse feixe, um elétron é removido da molécula com a deposição concominante de mais de $100 \mathrm{kcal}$ de energia interna dentro do novo cátion radicalar produzido. Quando o excesso de energia interna é redistribuido através do íon molecular, suficiente excitação será depositada nos vários graus de liberdade vibracionais, resultando em clivagem de uma ligação (Nier, 1947). No processo de ionização por impacto de elétrons formam-se tanto íons negativos como positivos e ambos possuem configurações análogas pois são dotados de elétrons desemparelhados. Entretanto o rendimento na formação dos íons positivos é da ordem de 104 vezes maior que para íons negativos, e por esse motivo, os estudos em geral, são concentrados em íons positivos no modo de impacto de elétrons (Gottlieb, 1968).

Acoplada ao Cromatógrafo a gás, líquido ou plasma, o Espectrômetro de Massas funciona como detector de alta seletividade e sensibilidade (Bustillos et. al, 2003). 


\subsubsection{Fragmentação na fonte de íons por impacto de elétrons}

A química orgânica convencional trata de reações iniciadas por reagentes químicos, calor ou energia radiante. A espectrometria de massas por sua vez, trata dos efeitos do bombardeio de moléculas orgânicas com feixes de elétrons ionizados a uma pressão de vapor de aproximadamente $10-5 \mathrm{mmHg}$, tratando-se portanto, de processos unimoleculares. Neste processo, somente uma pequena parte da energia necessária para a fragmentação é transferida como resultado do impacto (Silverstain et. al, 1963).

\subsubsection{A formação do espectro de massas}

Um espectro de massas pode fornecer vários tipos de informações quanto à natureza de um composto químico. Isso advém do fato de que um gráfico de espectro de massas no qual a abcissa indica a razão massa/carga e a ordenada indica a abundância relativa, fornece informações isotópicas de elementos, informações estruturais advindas do estudo de fragmentos da molécula e, em alguns casos, a massa molecular, caso o íon molecular esteja presente. No entanto, algumas destas informações não são utilizadas pelos analistas que, em muitos casos, procuram apenas pelo íon molecular. Porém, dependendo da estabilidade da molécula sob bombardeamento de elétrons energéticos, não é possível observá-lo (Smith e Busch, 1999). Cabe ressaltar que a simples verificação dos dados relativos à concordância dos espectros-padrão existentes nos bancos de dados de livrarias espectrométricas e o espectro da molécula alvo, pode induzir a erro, pois o espectro de massas da molécula alvo pode não estar presente no banco de dados ou podem ocorrer identificações errôneas em função da presença de moléculas interferentes. Dados preliminares tais como, a procedência da amostra, método de amostragem, extração, entre outros, são muitas vezes fundamentais na identificação do composto de interesse.

As linhas espectrais num espectro de massas correspondem a reações de fragmentação das moléculas submetidas ao bombardeamento eletrônico. A Figura 14 ilustra algumas reações de fragmentação que frequentemente ocorrem na fonte de impacto de elétrons. 


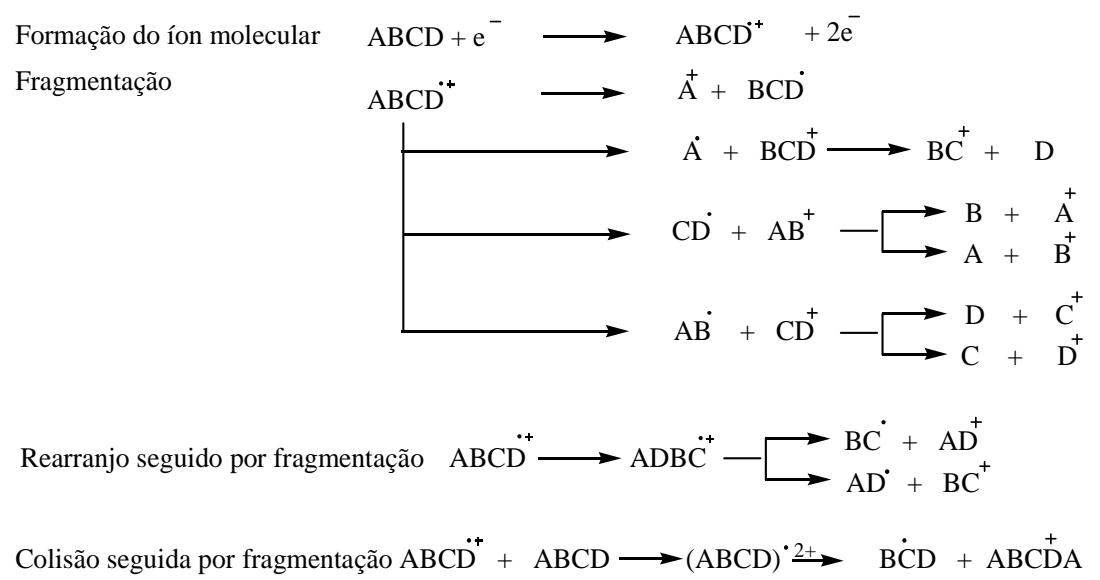

Figura 14. Algumas reações de fragmentação na fonte de impacto de elétrons (Skoog et. al, 1998)

\subsubsection{Funções de Varredura}

Função de varredura é uma representação visual da sequência de segmentos de programa no "software" que controla a operação do sistema quadrupolar, mostrando a variação temporal de todos os potenciais aplicados aos eletrodos do filtro quadrupolar.

O tipo de varredura a ser aplicado pode ser selecionado pelo operador, de acordo com o objetivo da análise, podendo ser escolhidos os modos: varredura (SCAN) e Monitoramento de Íons Selecionados (Select lon Monitoring, SIM) e ainda, é possível valer-se de um artifício do software designado Monitoramento de Corrente de ĺon (Monitoring lon Current, MIC).

\subsection{Função de Varredura SCAN}

A função de varredura SCAN consiste na determinação de uma faixa de massas a ser analisada, pré-determinada pelo operador, para qual o detector aplicará potenciais de corrente direta (Direct Current, DC) e radio frequência (Radio Frequence, RF) adequados (Bustillos et. al, 2003). Este tipo de varredura é recomendado para uma primeira análise, pois através dela é possível fazer um "scaneamento" de todas as substâncias presentes na amostra. Essa função é também indispensável como etapa inicial na elaboração de um método cromatográfico, quando se utiliza a técnica de GC/MS, ou qualquer outra técnica de detecção aliada à cromatografia. Dessa forma é possível realizar-se a injeção de 
padrão em concentração adequada, identificando seu tempo de retenção, como mais um fator de confirmação para o desenvolvimento subsequente do método e quantificação dos analitos de interesse (Bustillos et. al, 2003).

\subsection{Modo de Varredura SIM}

O modo de varredura SIM se baseia na escolha, pelo operador, dos íons a serem monitorados pelo detector de massas. Dessa forma o detector aplicará determinadas Dc e RF para o monitoramento dos íons de interesse, aumentando significativamente sua sensibilidade. Os íons escolhidos geralmente são os que apresentam maior intensidade no composto que se deseja analisar. É possível adquirir essas informações através da biblioteca NIST (National Institute of Standards and Technology) ou de uma primeira análise no modo SCAN dos padrões dos analitos em questão.

Esse modo de varredura é muito utilizado para quantificação e análise de traços, por proporcionar à análise menores limites de detecção e quantificação (Bustillos et. al, 2003).

\subsection{Modo de Varredura MIC}

O modo de varredura MIC consiste em um artifício disponível no software, através do qual é possível selecionar os íons de interesse a serem analisados em um cromatograma obtido pelo modo de varredura SCAN. O MIC funciona, portanto, como uma "lente de aumento", ou seja, dentre todos os íons monitorados pelo modo SCAN, este artifício exibirá os íons selecionados pelo operador (Bustillos et. al, 2003). 


\subsubsection{Validação de Método}

A validação de uma metodologia parte da necessidade de se garantir a confiabilidade dos dados gerados, através de sua comparabilidade, rastreabilidade e confiabilidade, e está sendo cada vez mais reconhecida e exigida. Dados analíticos não confiáveis podem conduzir a decisões desastrosas e a prejuízos financeiros irreparáveis. Para garantir que um novo método analítico gere informações confiáveis e interpretáveis sobre a amostra, ele deve passar por uma avaliação denominada validação. A validação de um método é um processo contínuo que começa no planejamento da estratégia analítica e continua ao longo de todo o seu desenvolvimento (CODEX, WHO, 1992).

A validação deve garantir, por estudos experimentais, que o método atenda às exigências das aplicações analíticas, assegurando a confiabilidade dos resultados (ANVISA, 2003).

\subsubsection{Legislação}

A fim de mostrar competência técnica, os laboratórios que executam as análises devem submeter-se a uma acreditação por um órgão vigente de âmbito nacional ou internacional.

Existem razões legais, técnicas e comerciais que justificam a implantação da validação de métodos analíticos de separação, apesar de não haver uma norma estabelecida de âmbito nacional ou internacional.

No Brasil, há duas agências para verificar a competência de laboratórios de ensaio, a ANVISA (Agência Nacional de Vigilância Sanitária) e o INMETRO (Instituto Nacional de Metrologia, Normalização e Qualidade Industrial). Estes órgãos disponibilizam guias para o procedimento de validação de métodos analíticos, respectivamente, a Resolução ANVISA RE ํㅡ 899, de 29/05/2003 (ANVISA, 2003), e o documento INMETRO DOQ-CGCRE-008 (2010). Suas similaridades e diferenças podem ser melhor visualizadas na Tabela 6.

É importante esclarecer que resoluções são documentos com poder de lei, que devem ser obedecidas e guias são documentos que sugerem uma linha a ser seguida e são, portanto, abertos para interpretação. Os guias são recomendações e são 
intencionalmente vagos para deixar aos analistas a flexibilidade de adaptá-los de acordo com o método a ser usado (Ribani et. al, 2004). Os parâmetros para validação de métodos têm sido definidos em diferentes grupos de trabalho de organizações nacionais ou internacionais. Infelizmente algumas definições são diferentes entre as diversas organizações. Uma tentativa para harmonizar estas diferenças foi feita para aplicações farmacêuticas, através da $\mathrm{ICH}$ "International Conference on Harmonization" (ICH, 1995a; ICH, 1995b), na qual representantes das indústrias e agências reguladoras dos EUA, Europa e Japão definiram parâmetros, requerimentos e, em alguns casos, também metodologias para validação dos métodos analíticos.

A IUPAC "International Union of Purê and Applied Chemystry" também redigiu um documento técnico que define um guia para validação de métodos analíticos que tem sido utilizado pela ISO (Thompson, 2002). A norma internacional ISO/IEC 17025, que é uma norma específica para laboratórios de ensaio e de calibração, apresenta a "validação de métodos" como um dos requisitos técnicos importantes na qualidade assegurada dos laboratórios de ensaio, bem como a documentação do trabalho de validação (ISO/IEC, 1999). O US-FDA "United States Food Administration" também tem proposto guias sobre validação de métodos (CDER, 1993; CDER, 1987).

Assim, órgãos como ICH, IUPAC, ISO, ANVISA, INMETRO e outros exigem o item "validação de métodos analíticos" como um requisito fundamental na acreditação para a qualidade assegurada e demonstração de competência técnica (CDER, 1987; ICH, 1995; Thompson, 2002; Ribani et.al, 2004).

O que se pode observar é que não há um procedimento normatizado que estabeleça como executar a validação de métodos instrumentais de separação. Como estes organismos são responsáveis por acompanhar e credenciar a competência de laboratórios de ensaios, é importante ressaltar que as diferentes terminologias e até algumas características de desempenho do método têm, em sua maior parte, o mesmo significado, porém descrito de uma maneira distinta, para aplicações diferentes. 


\subsubsection{Processo de Validação}

É essencial que os estudos de validação sejam representativos e conduzidos de modo que a variação da faixa de concentração e os tipos de amostras sejam adequados. Um método para um composto majoritário requer um critério de aceitação e uma abordagem diferente de um método desenvolvido para análise de traços. A frequência com que o método será utilizado (muitas vezes em um dia, uma vez em um dia para um estudo rápido, uma vez em um mês, etc.) também influencia o tipo de estudo de validação necessário. Os parâmetros analíticos devem ser baseados na intenção do uso do método. Por exemplo, se um método será usado para análise qualitativa em nível de traços, não há necessidade de testar e validar a linearidade do método sobre toda a faixa linear dinâmica do equipamento. O objetivo do método pode incluir também os diferentes tipos de equipamentos e os lugares em que o método será utilizado, ou seja, se o método é desenvolvido para ser utilizado em instrumento e laboratório específicos, não há necessidade de usar instrumentos de outras marcas ou incluir outros laboratórios nos experimentos de validação. Desta forma, os experimentos podem ser limitados para o que realmente é necessário (Ribani et. al, 2004).

Tabela 6. Parâmetros de validação do INMETRO e ANVISA (Ribani et. al, 2004)

\begin{tabular}{ll}
\hline \multicolumn{1}{c}{ INMETRO } & \multicolumn{1}{c}{ ANVISA } \\
\hline Especificidade/Seletividade & Especificidade/Seletividade \\
Faixa de trabalho e Faixa linear de trabalho & Intervalos da curva de calibração \\
Linearidade & Linearidade \\
Curva Analítica & Curva de Calibração \\
Limite de Detecção (LD) & Limite de Detecção (LD) \\
Limite de Quantificação (LQ) & Limite de Quantificação (LQ) \\
Sensibilidade (inclinação da curva) & - \\
Exatidão e tendência (bias) & Exatidão \\
Precisão & Precisão \\
Repetitividade & Repetitividade (precisão intra-corrida) \\
Precisão Intermediária & Precisão intermediária (precisão inter- \\
Reprodutibilidade & corrida) \\
Robustez & Reprodutibilidade (precisão inter-laboratorial) \\
Incerteza de medição & Robustez \\
\hline
\end{tabular}




\subsubsection{Parâmetros Analíticos para Validação de Métodos}

Os parâmetros analíticos normalmente encontrados para validação de métodos de separação são: seletividade; linearidade e faixa de aplicação; precisão; exatidão; limite de detecção; limite de quantificação e robustez. Estes termos são conhecidos como parâmetros de desempenho analítico (Swartz e Kruel, 1998), características de desempenho (INMETRO, 2010; Thompson et. al, 2002) e, algumas vezes, como figuras analíticas de mérito (Swartz e Kruel, 1998; Ribani et. al, 2004).

Neste trabalho, serão utilizados alguns dos parâmetros analíticos propostos: Precisão, Exatidão, Recuperação, Limite de Detecção (LD), Limite de Quantificação (LQ), Linearidade, Linearidade e Robustez.

\subsection{Especificidade e Seletividade}

O termo especificidade, muitas vezes é utilizado como sinônimo de seletividade, este define a capacidade do método em detectar o analito de interesse na presença de outros componentes da matriz (Brito et.al, 2003). Estes termos são frequentemente confundidos, entretanto é possível entender as definições de ambos, considerando que um método instrumental de separação que produz resposta para uma única substância de interesse, normalmente um dado elemento, pode ser chamado específico e um método que produz resposta para vários compostos químicos, com uma característica em comum, pode ser chamado seletivo (Ribani et. al, 2004).

Na prática, diferentes testes de especificidade e seletividade tentam abordar o mesmo problema: se o que é medido é o que realmente pensa-se ser medido. Entender os diferentes mecanismos que causam interferências pode ajudar na estruturação dos testes e achar soluções para os problemas encontrados (INMETRO, 2010).

Em análises qualitativas é necessário demonstrar a capacidade de seleção do método entre compostos com estruturas semelhantes que possam estar presentes na amostra. Isto deve ser confirmado pela obtenção de resultados positivos (preferivelmente em relação ao material de referência conhecido) em amostras contendo analito, comparativamente com resultados negativos obtidos em amostras 
que não contenham 0 analito de interesse, mas compostos estruturalmente semelhantes (INMETRO, 2010).

Em análises quantitativas e análises de impurezas, a especificidade pode ser determinada pela comparação dos resultados obtidos de amostras contaminadas com quantidades conhecidas do analito de interesse, compostos estruturalmente semelhantes e amostras não contaminadas, a fim de demonstrar que o resultado do teste não é afetado por esses materiais. Quando a impureza ou o padrão do produto de degradação não estiverem disponíveis, pode-se comparar os resultados do teste das amostras contendo impurezas ou produtos de degradação com resultados de um segundo procedimento bem caracterizado, como por exemplo, um outro método já validado (ANVISA, 2003).

Em métodos cromatográficos, segundo a IUPAC, o termo seletividade é mais apropriado para ser utilizado, pois existem poucos métodos específicos, ou seja, que respondem a um único analito de interesse. Em métodos cromatográficos devem-se tomar algumas precauções necessárias para garantir a pureza dos picos. A utilização de testes de pureza de pico é interessante para demonstrar que o pico é atribuído a um só componente (Ribani et.al, 2004).

\subsection{Especificidade}

Testes de especificidade necessitam de uma pesquisa cuidadosa do conhecimento disponível na área de aplicação, para que se encontrem todos os componentes que precisam ser testados. Assim sendo, o analito, a matriz com ou sem analito, matérias-primas do processo, impurezas dos materiais iniciais ou do processo, subprodutos e produtos de degradação ou metabólitos e reagentes em branco devem ser analisados. Às vezes se faz necessário expor todos os componentes e a matriz a condições extremas (calor, ácido, álcali, oxidação, radiação, UV/Visível, luz fluorescente) para determinar possíveis produtos de degradação (ANVISA, 2003; INMETRO, 2004).

Muito esforço foi dedicado para resolver os problemas de especificidade frequentemente encontrados com as técnicas mais comuns de espectrofotometria de UV/Visível ou de cromatografia líquida. Comparações de resultados, variando as condições de medição e análise de pureza de sinal, podem ser usadas para verificar 
que nenhum outro componente conhecido ou desconhecido esteja sendo determinado junto com o analito. Algumas vezes deve-se usar técnicas adicionais, como cromatografia de camada fina (CCF) ou espectroscopia de massas (EM), após a separação e a coleta do analito. Em particular, isso é necessário em métodos usados para avaliar estabilidade. Para este propósito, as amostras utilizadas nos ensaios de condições extremas são estudadas cuidadosamente para provar que nenhum produto de degradação conhecido ou desconhecido possa perturbar o sinal do analito (Ribani et.al, 2004; INMETRO, 2010).

Como exemplo, para técnicas cromatográficas, além das comparações visuais de cromatogramas, diferentes parâmetros devem ser calculados nos cromatogramas para descrever a especificidade do método. Os parâmetros mais importantes são: resolução, retenção relativa (fator de separação), fator de capacidade (fator de retenção), fator de simetria e número de pratos teóricos (INMETRO, 2010).

\subsection{Seletividade}

A matriz da amostra pode conter componentes que interferem no desempenho da medição pelo detector selecionado, sem causar um sinal visível no teste de especificidade. Os interferentes podem aumentar ou reduzir o sinal, e a magnitude do efeito também pode depender da concentração (INMETRO, 2010).

Vários testes e suas estatísticas correspondentes podem ser utilizados para o estudo da seletividade dependendo da disponibilidade do analito, da matriz da amostra sem analito ou um grupo satisfatório de amostras de referência disponíveis, podem ser aplicados os testes $F$ (Snedecor) de homogeneidade de variâncias e o teste $\mathrm{t}$ (Student) de comparação de médias, ou então realizada a análise dos desvios em relação aos valores de referência. Normalmente, parte-se da hipótese em que a matriz não afeta o sinal do analito em níveis de concentrações elevados ou acima da faixa. Preparam-se dois grupos de amostras de teste, um com a matriz e o outro sem, ambos os grupos com a concentração do analito idêntica em cada nível de concentração de interesse. O número de amostras paralelas em cada nível de concentração deve ser maior ou igual a 7 (sete) para permitir o uso adequado dos modelos estatísticos e proporcionar uma comparação válida. Primeiro, faz-se o teste 
F para verificar se as variâncias das amostras podem ser consideradas iguais, calculando-se o valor de $\mathrm{F}$ como representado pela Equação 14.

$$
F=\frac{s_{1}}{s_{2}}
$$

Onde: $s_{1}$ e $s_{2}$ são as variâncias de cada amostra, com a maior variância no numerador. Ao mesmo tempo, obtém-se o valor de $F$, com (n-1) graus de liberdade no numerador e (n-1) graus de liberdade no denominador; usualmente, adota-se um nível de confiança de $95 \%$. Tem-se dois casos:

(I) Se o teste $F$ não é significante, isto é, se $F$ calculado for menor que o $F$ tabelado, a matriz não tem um efeito importante sobre a precisão do método na faixa de concentração em estudo. Neste caso, os desvios-padrão dos grupos de testes podem ser agrupados e a significância das diferenças das médias dos dois conjuntos de amostras podem ser testados com a distribuição $t$ de Student. Neste caso, calculam-se:

$\bar{x}_{1}$ e $\bar{x}_{2}=$ médias das respostas dos analitos em amostras "com matriz" e "sem matriz" na mesma faixa de concentração;

$s_{1}$ e $s_{2}=$ desvios-padrão das respostas dos analitos dos dois grupos de amostras, bem como o valor de $t_{\text {calculado, }}$, como pode ser observado na Equação 15.

$$
t_{\text {calculado }}=\frac{\left|\overline{\mathrm{x}_{1}}-\overline{\mathrm{x}_{2}}\right|}{\sqrt{\mathrm{s}^{2} \frac{1}{\mathrm{n}_{1}}}+\frac{1}{\mathrm{n}_{2}}}
$$

Onde $S=\frac{(n-1) s_{1}+(n-1) s_{2}}{(n+n-2)}$ e $n_{1}$ e $n_{2}$ são os tamanhos das amostras.

O valor $t$ é obtido a partir da tabela da distribuição de Student para $(n+n-2)$ graus de liberdade e a confiança desejada.

(II) Se o teste $F$ é significante, a matriz tem um efeito importante sobre a precisão do método na faixa de concentração em estudo, as variâncias podem ser consideradas desiguais e o $t$ é calculado conforme a Equação 16. 


$$
t_{\text {calculado }}=\frac{\left|\overline{x_{1}}-\overline{x_{2}}\right|}{\sqrt{\frac{s_{1}^{2}}{n_{1}}+\frac{s_{s}^{2}}{n_{2}}}}
$$

Neste caso, para a obtenção do $t_{\text {tabelado, o número de graus de liberdade }(v) \text { é }}$ calculado conforme a Equação 17.

$$
v=\frac{\left(s_{1}^{2} / n_{1}+s_{2}^{2} / n_{2}\right)}{\frac{\left(s_{1}^{2} / n_{1}\right)}{n_{1}+1}+\frac{\left(s_{2}^{2} / n_{2}\right)}{n_{2}+1}}-2
$$

No caso de somente uma faixa relativamente estreita de concentrações interessarem, ou se o erro analítico devido a uma possível dependência com concentração for desprezível, o teste $t$ com dados pareados pode ser utilizado para verificar efeitos de matriz, como mostra a Equação18.

$$
t_{\text {calculado }}=\frac{\overline{x_{d} \sqrt{n}}}{s_{d}}
$$

onde:

$$
\bar{x}=\sum \frac{(d-d)}{n} \quad \text { e } \quad s=\frac{\sum[(d-d)-\bar{x}]}{n-1}
$$

Nas equações, $\bar{x}=$ média das diferenças entre as respostas dos pares de analitos; $d, d=$ respostas do analito para o par de amostras "com matriz" e "sem matriz"; $\mathrm{s}=$ desvio padrão das diferenças e $\mathrm{n}=$ números de pares. $\mathrm{O}$ valor de $\mathrm{t}$ tabelado é obtido da distribuição $t$ de Student com (n-1) graus de liberdade e a confiança desejada.

Se o valor de $t$ calculado for menor que o $t$ tabelado, pode-se concluir que a matriz não afeta o ensaio. Se o valor de $t$ for maior que o esperado, pode-se concluir que a matriz tem um efeito estatisticamente significante sobre o resultado do ensaio.

Se a matriz sem o analito não estiver disponível, a seletividade pode ser testada comparando-se as inclinações das curvas de adição padrão. Isto é feito preparando-se dois grupos de amostras que contenham a mesma adição de analito 
para cada nível de concentração. Um grupo inclui a matriz da amostra (contendo um nível básico do analito) e o outro grupo não inclui a matriz da amostra. Os resultados destas amostras podem ser representados em um mesmo gráfico em função da concentração de analito adicionado. Se as inclinações destas duas curvas de regressão linear forem as mesmas, o único efeito de matriz presente é a interferência natural causada pelo nível básico do analito.

\subsection{Precisão}

A precisão é geralmente expressa como desvio padrão ou desvio padrão relativo. A repetitividade e a reprodutibilidade são geralmente dependentes da concentração do analito e, deste modo, devem ser determinadas para um diferente número de concentrações e, em casos relevantes, a relação entre a precisão e a concentração do analito deve ser estabelecida. O desvio padrão relativo pode ser mais útil neste caso, pois foi normalizado com base na concentração e deste modo ele é praticamente constante ao longo da faixa de interesse, contanto que esta não seja muito grande (ICH, 1995a; INMETRO, 2010, Ribani et. al, 2004).

A precisão é avaliada pelo desvio padrão absoluto $(\sigma)$, que utiliza um número significativo de medições, normalmente maior que 20. Na prática, em validação de métodos, o número de determinações é geralmente pequeno e o que se calcula é a estimativa do desvio padrão absoluto (s), como mostra a Equação 19.

$$
s=\sqrt{\frac{\sum\left(x_{i}-\bar{x}\right)^{2}}{n-1}}
$$

x é a média aritmética de um pequeno número de medições (média das determinações), sendo uma estimativa de $\mu$, a média verdadeira (média da população); $x_{i}$ é o valor individual de uma medição e $n$ é o número de medições. A precisão também pode ser expressa pelo intervalo de confiança da média, que é uma faixa de valores no qual existe uma determinada probabilidade de se encontrar certo valor de uma variável, calculada como mostra a Equação 20 (Ribani et. al, 2004). 
Intervalo de confiança da média $=\bar{x} \pm t_{n-1} \frac{s}{\sqrt{n}}$

Em que: $t_{n-1}=$ valor crítico da distribuição de Student com $n-1$ graus de liberdade. O valor $\mathrm{t}$ é tabelado e apresenta valores para diferentes níveis de confiança. Outra expressão da precisão é através da estimativa do desvio padrão relativo (RSD), também conhecido como coeficiente de variação (CV) expresso na Equação 21.

$$
R S D(\%) \text { ou } C V(\%)=\frac{S}{V} \cdot 100
$$

Normalmente, métodos que quantificam compostos em macro quantidades requerem um $\mathrm{RSD}$ de 1 a $2 \%$. Em métodos de análise de traços ou impurezas, são aceitos RSD de até 20\%, dependendo da complexidade da amostra (Huber, 1998; Ribani et.al, 2004). Uma maneira simples de melhorar a precisão é aumentar o número de replicatas. A precisão em validação de métodos é considerada em três níveis diferentes: repetitividade, precisão intermediária e reprodutibilidade.

\subsection{Exatidão}

Exatidão do método é definida como a concordância entre o resultado de um ensaio e o valor de referência aceito como convencionalmente verdadeiro. A exatidão, quando aplicada a uma série de resultados de ensaios, implica numa combinação de componentes de erros aleatórios e sistemáticos (tendência) (Ribani et. al, 2004).

Representa o grau de concordância entre os resultados individuais encontrados em um determinado ensaio e um valor de referência aceito como verdadeiro (INMETRO, 2010; ICH, 1995b). É importante observar que um valor exato ou verdadeiro é o valor obtido por uma medição perfeita e este valor é indeterminado por (ISO, 1993).

A exatidão é sempre considerada dentro de certos limites, a um dado nível de confiança (ou seja, aparece sempre associada a valores de precisão). Estes limites podem ser estreitos em níveis de concentração elevados e mais amplos em níveis de traços. 
O número de ensaios varia segundo a legislação ou diretriz adotada e também com as características da pesquisa. A ICH (1995) estabelece que um mínimo de nove determinações envolvendo um mínimo de três diferentes níveis de concentração deve ser obedecido. Por exemplo, ensaios em triplicata para três níveis de concentração. Esta recomendação é também adotada pela ANVISA (2003; Ribani et. al, 2004).

Os processos mais utilizados para avaliar a exatidão de um método são: materiais de referência; comparação de métodos; ensaios de recuperação; adição padrão.

\subsection{Recuperação}

A recuperação do analito pode ser estimada pela análise de amostras adicionadas com quantidades conhecidas do mesmo (Spike). As amostras podem ser adicionadas com 0 analito em pelo menos três diferentes concentrações, por exemplo, próximo ao limite de detecção, próximo à concentração máxima permissível e em uma concentração próxima à média da faixa de uso do método.

A limitação deste procedimento é a de que a substância adicionada não está, necessariamente, na mesma forma que a que se encontra presente na amostra. Isso pode implicar, por exemplo, na presença de substâncias adicionadas em uma forma que proporcione melhor detecção, ocasionando avaliações excessivamente otimistas da recuperação. Pelo fato de outros componentes da matriz poder interferir na separação, detecção ou na quantificação da substância, efeitos dos componentes da matriz devem ser investigados (Ribani et. al, 2004).

A recuperação (ou fator de recuperação), $R$, é definida como a proporção da quantidade da substância de interesse, presente ou adicionada na porção analítica do material teste, que é extraída e passível de ser quantificada (INMETRO, 2010).

A informação de recuperação pode ser estimada de a partir de um material de referência certificado - CRM (certified reference material) em que a quantidade de substância é previamente conhecida, quando disponível, ou de um composto substituto. O substituto é definido como um composto ou elemento puro adicionado ao material teste, no qual o comportamento químico e físico é representativo da substância de interesse na forma nativa (Ribani et. al, 2004). Diz-se que o 
composto é um substituto porque este é transferido para a amostra e pode não estar efetivamente no mesmo equilíbrio que se encontra a substância na forma nativa, então determina-se a recuperação do substituto, fazendo uma "correção de recuperação" para a substância de interesse (Thompson, 1999; Ribani et. al, 2004). Os compostos substitutos, adicionados nas amostras, podem ser de vários tipos:

- padrão da substância adicionado à matriz isenta da substância ou à amostra (fortificação, incorporação, dopagem, enriquecimento); o US-FDA reconhece duas categorias de padrões de referência: compendiais e não compendiais. Os padrões de referência compendiais são obtidos de fontes como a USP e não necessitam de caracterização posterior. Os padrões de referência não compendiais são substâncias com elevado teor de pureza, que podem ser obtidas através de um esforço razoável e devem ser cuidadosamente caracterizados para garantir sua identidade, potência e pureza. É recomendável que fatores de correção de pureza sejam incluídos em qualquer cálculo existente no método.

- uma versão da substância modificada isotopicamente e composto quimicamente diferente da substância de interesse, mas representativo de seu comportamento. Algumas vezes este composto é denominado padrão interno (Cuadros-Rodríguez et. al, 2001; Leite, 2002; Ribani et. al, 2004).

É importante considerar como a eficiência do método varia em função da concentração da substância. Na maioria dos casos, a dispersão dos resultados aumenta com a diminuição da concentração e a recuperação pode diferir substancialmente a altas e baixas concentrações. Por esse motivo, a recuperação deve ser avaliada na faixa de concentração esperada para o composto de interesse. Para análises em nível de resíduos, o GARP (1999) recomenda que se trabalhe nos níveis de adição de 1, 2 e 10 vezes o valor de limite de quantificação. Para componentes em maiores concentrações, os níveis de adição podem ser 50 , 75, 100, 125 e 150\% do nível esperado para a substância (Snyder et. al, 1997; Ribani et. al, 2004).

As medições de recuperação são as mais comuns devido à dificuldade em se obterem Materiais de Referência Certificados (Cerfied Reference Materials, CRM) (que, para certas aplicações, nem existem) e são expressas em termos de 
porcentagem da quantidade medida da substância em relação à quantidade adicionada na matriz (branco ou placebo), em um determinado número de ensaios (Burns et. al, 2002).

Os intervalos aceitáveis de recuperação para análise de resíduos geralmente estão entre 70 e 120\%, com precisão de até $\pm 20 \%$ (Augusto et. al, 2010). Porém, dependendo da complexidade analítica e da amostra, este valor pode ser de 50 a $120 \%$, com precisão de até $\pm 15 \%$ (GARP, 1999).

\subsection{Limite de Detecção (LD)}

O limite de detecção (LD) representa a menor concentração da substância em exame que pode ser detectada, mas não necessariamente quantificada, utilizando um determinado procedimento experimental (Ribani et. al, 2004; ICH, 1995b).

O limite de detecção do método (LDM) é definido como a concentração mínima de uma substância medida e declarada com 95 a 99\% de confiança de que a concentração do analito é maior que zero. O LDM é determinado através de análise completa de uma dada matriz contendo o analito. O limite de detecção do equipamento (LDE) é definido como a concentração do analito que produz um sinal de três a cinco vezes a razão sinal/ruído do equipamento e o LD pode ser calculado de três maneiras diferentes: método visual, método relação sinal-ruído e método baseado em parâmetros da curva analítica (INMETRO, 2010; Ribani et. al, 2004).

\section{- Método Visual}

É utilizado para determinar o limite de detecção utilizando a matriz com adição de concentrações conhecidas da substância de interesse, de tal modo que se possa distinguir entre ruído e sinal analítico pela visualização da menor concentração visível (detectável).

Este procedimento também pode ser feito através do instrumento utilizando parâmetros de detecção no método de integração (Ribani et. al, 2004). 


\section{- Método da relação sinal-ruído}

Este método pode ser aplicado somente em procedimentos analíticos que mostram o ruído da linha de base. Para determinar a relação sinal-ruído, é feita a comparação entre a medição dos sinais de amostras em baixas concentrações conhecidas do composto de interesse na matriz e um branco (matriz isenta do composto de interesse) destas amostras (GARP, 1999; Ribani et. al, 2004). Assim, é estabelecida uma concentração mínima na qual a substância pode ser facilmente detectada. A relação sinal-ruído pode ser de 3:1 ou 2:1, proporções geralmente aceitas como estimativas do limite de detecção.

\section{- Método baseado em parâmetros da curva analítica}

O limite de detecção (LD) pode ser expresso como demonstra a Equação 22.

$$
\mathrm{LD}=3,3 \cdot \frac{\mathrm{s}}{\mathrm{s}}
$$

Onde s é a estimativa do desvio padrão da resposta, que pode ser a estimativa do desvio padrão do branco, da equação da linha de regressão ou do coeficiente linear da equação e $S$ é a inclinação ou coeficiente angular da curva analítica (Ribani et. al, 2004).

\subsection{Limite de Quantificação (LQ)}

O limite de Quantificação é a menor concentração do analito que pode ser determinada com um nível aceitável de precisão e veracidade (trueness). Pode ser considerada como sendo a concentração do analito correspondente ao valor da média do branco mais 5, 6 ou 10 desvios-padrão. Algumas vezes é também denominado "Limite de Determinação". Na prática, corresponde normalmente ao padrão de calibração de menor concentração (excluindo o branco). Este limite, após ter sido determinado, deve ser testado para averiguar se as exatidão e precisão conseguidas são satisfatórias (INMETRO, 2010).

Os critérios de LD podem ser usados para o LQ, utilizando a relação 10:1, ou seja, o LQ pode ser calculado utilizando o método visual, a relação sinal-ruído ou relação entre a estimativa do desvio padrão da resposta (s) e a inclinação da curva analítica (S), em níveis próximos do LQ, a partir da Equação 23. 


$$
\mathrm{LQ}=10 \cdot \frac{\mathrm{s}}{\mathrm{s}}
$$

O método mais utilizado é o da relação sinal/ruído para técnicas analíticas em geral, porém em técnicas analíticas de separação, como as cromatográficas e eletroforéticas, a medição do ruído não é trivial e às vezes subjetiva, devido a curva ser construída com as áreas e não somente com o sinal do detector. Além disso, tanto o $L D$ quanto o LQ podem ser afetados pelas condições cromatográficas.

A fim de sanar este problema de cálculo de LD e LQ, é utilizado o método baseado nos parâmetros da curva analítica, que é estatisticamente mais confiável. A curva analítica deve conter a concentração correspondente ao LQ (Ribani, et.al, 2004).

\subsection{Linearidade e Faixa de Trabalho}

Linearidade é a capacidade de o método analítico produzir resultados que sejam diretamente proporcionais à concentração do analito em amostras, em uma dada faixa de concentração. A quantificação requer que se conheça a dependência entre a resposta medida e a concentração do analito. A linearidade é obtida por padronização interna ou externa e formulada como expressão matemática usada para o cálculo da concentração do analito a ser determinado na amostra real. A equação da reta (24) relaciona as duas variáveis (Ribani et. al, 2004).

$$
y=a x+b
$$

Onde y é a resposta medida (absorbância, altura ou área do pico, etc); "x" é a concentração; "a" é inclinação da curva analítica que corresponde a sensibilidade, e "b" é a interseção com o eixo y, quando "x" é igual a 0 (zero).

A linearidade de um método pode ser observada pelo gráfico dos resultados dos ensaios em função da concentração do analito ou então calculados a partir da equação da regressão linear, determinado pelo método dos mínimos quadrados.

O coeficiente de correlação linear $(r)$ é frequentemente usado para indicar o quanto pode ser considerada adequada à reta como modelo matemático. Um valor maior que 0,90 é, usualmente requerido. O método pode ser considerado como livre 
de tendências (unbiased) se o corredor de confiança da reta de regressão linear contiver a origem (INMETRO, 2010; Ribani et. al, 2004).

A correlação entre o sinal medido (área ou altura do pico) e a massa ou concentração da espécie a ser quantificada muito raramente é conhecida inicialmente. Na maior parte dos casos, a relação matemática entre o sinal e a concentração ou massa da espécie de interesse deve ser determinada empiricamente, a partir de sinais medidos para massas ou concentrações conhecidas dessa espécie (Augusto et. al, 2010). Essa relação matemática, muitas vezes, pode ser expressa como uma equação de reta chamada de curva analítica. Um exemplo de curva analítica pode ser visto na Figura 15. Embora somente dois pontos definam uma reta, na prática as linhas devem ser definidas por no mínimo cinco pontos que não incluam, o ponto zero na curva, devido aos possíveis erros associados (Ribani et. al, 2004).

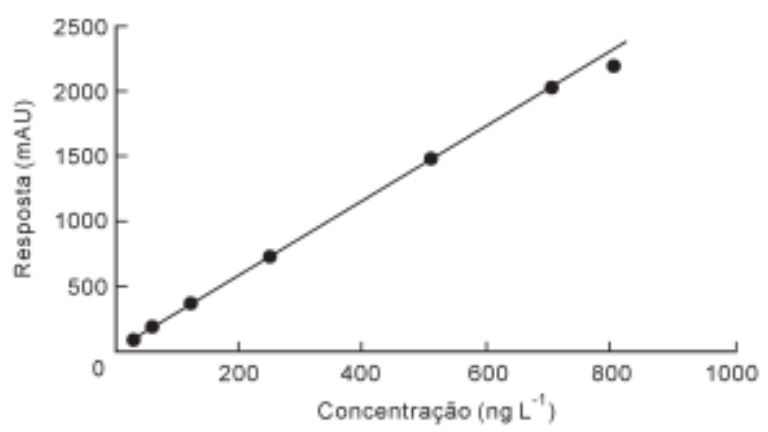

Figura 15. Curva Analítica Clássica

Em qualquer técnica instrumental, a relação linear simples, descrita pela Equação 24, só é válida em um determinado intervalo de massa ou concentração da espécie medida. Este intervalo de massas ou concentrações, no qual se pode construir uma curva analítica linear, é a faixa linear dinâmica. Ainda que as causas para a perda de linearidade sejam características de cada técnica, este é um fenômeno que pode ocorrer com qualquer conjunto de dados. Assim, o cálculo dos coeficientes de regressão de uma curva analítica deve ser acompanhado de uma cuidadosa inspeção, para verificar se todos os pontos a serem usados estão dentro da faixa linear dinâmica correspondente (Barros Neto et. al, 2002; Ribani et. al, 2004).

Como os desvios da linearidade são muitas vezes difíceis de serem detectados visualmente, pode-se verificar a sua adequação por meio do cálculo dos resíduos 
entre os valores medidos e os valores calculados a partir da equação de regressão. Calcula-se o valor de t segundo a Equação 25.

$$
t_{\text {calculado }}=\frac{\text { resíduo }}{\operatorname{Sr} / \sqrt{n}}
$$

Alguns procedimentos analíticos não demonstram linearidade mesmo após qualquer transformação. Nesses casos, a resposta analítica pode ser descrita por uma função adequada da concentração do analito na amostra. A faixa linear de trabalho de um método de ensaio é o intervalo entre os níveis inferior e superior de concentração do analito no qual foi demonstrado ser possível a determinação com a precisão, exatidão e linearidade exigida, sob as condições especificadas para o ensaio (INMETRO, 2010; Ribani et. al, 2004).

\subsection{Robustez}

Entende-se por método, tanto o método programado no equipamento de análise quanto o procedimento analítico adotado como um tempo, compreendendo desde a extração até a análise. A robustez de um método mede a sensibilidade que este apresenta frente a pequenas variações. Um método é considerado robusto quando não é afetado por pequenas variações em seus parâmetros. A robustez de um método cromatográfico é avaliada, por exemplo, pela variação de parâmetros como a concentração do solvente orgânico, pH e força iônica da fase móvel em HPLC, programação da temperatura, natureza do gás de arraste em GC, bem como o tempo de extração, agitação e etc. As mudanças introduzidas refletem as alterações que podem ocorrer quando um método é transferido para outros laboratórios, analistas e equipamentos (Ribani et.al, 2004).

Para o teste de robustez, o INMETRO (2010) recomenda o teste de Youden, que permite, além de analisar a robustez do método, também ordenar a influência de cada uma das variações nos resultados finais. São realizados oito ensaios com uma combinação fatorial dos efeitos e verifica-se qual é o efeito ou combinação de efeitos que apresentam variações (Ribani et. al, 2004).

A IUPAC utiliza o mesmo conceito de robustez para a palavra "ruggedness". A USP também utiliza o termo "ruggedness", mas com uma definição diferente, que 
lembra reprodutibilidade dos resultados dos testes obtidos pelas análises de algumas amostras sob uma variedade de condições normais de teste, tais como diferentes analistas, diferentes laboratórios, diferentes instrumentos, diferentes lotes de reagentes, diferentes dias e etc.

Em trabalhos nos quais há mudanças de fornecedores, marcas ou equipamentos ao longo do desenvolvimento e validação das metodologias, sem alteração significativa nos resultados, pode-se dizer que o método possui uma robustez intrínseca, pois manteve sua resposta em meio a mudanças de ambiente de análise (Ribani et.al,2004).

De acordo com o DOQ-CGCRE-008, o parâmetro robustez é analisado por meio de 8 ensaios, separados para determinar os efeitos da variação das 7 diferentes etapas, no procedimento analítico. As oito medições podem ser realizadas numa ordem aleatória. O teste de Youden pode ser realizado adotando-se os sete parâmetros e suas variações, denominando os fatores nominais por letras maiúsculas de $A$ a $G$ e a respectiva variação pela letra minúscula correspondente. Prepara-se então uma tabela idêntica a Tabela 7:

Tabela 7. Matriz de fatores para a determinação da robustez do método.

\begin{tabular}{ccccccccc}
\hline Valor do fator & \multicolumn{7}{c}{ Combinação ensaiada } \\
\hline & 1 & 2 & 3 & 4 & 5 & 6 & 7 & 8 \\
\hline A ou a & A & A & A & A & a & A & a & a \\
\hline B ou b & B & B & B & b & B & B & b & b \\
\hline C ou c & C & C & C & c & C & C & C & c \\
\hline D ou d & D & D & D & d & d & D & D & D \\
\hline E ou e & E & E & E & e & e & E & e & E \\
\hline F ou f & F & F & F & F & F & F & f & F \\
\hline G ou g & G & G & G & G & g & G & G & g \\
\hline Resultado & S & T & U & v & w & X & y & z \\
\hline
\end{tabular}

Para a combinação 1 ensaiada, o resultado será s, e assim sucessivamente até que todas as 8 combinações tenham sido ensaiadas. Para determinar a variação de um fator, deve-se encontrar os 4 valores correspondentes as letras maiúsculas e as 4 minúsculas e comparar as médias dos dois grupos. Por exemplo, ao calcular as alterações de C para c, usar os resultados como mostram as Equações 26 e 27. 


$$
\begin{gathered}
\frac{s+u+w+y}{4} \\
\frac{t+v+x+z}{4}
\end{gathered}
$$

No caso acima, o efeito do fator C/c é então calculado como mostra a Equação 28.

$$
\text { Efeito } \mathrm{C} / \mathrm{c}=\frac{s+u+w+y}{4}-\frac{t+v+x+z}{4}
$$

Calculam-se todos os 7 pares para obter 7 diferenças, que podem ser ordenados para revelar aqueles com efeito significativo no resultado.

Após análise crítica dos resultados obtidos, faz-se um controle mais rigoroso dos fatores de maior influência. Se não houver, portanto, diferença significativa, calcula-se a média e o desvio padrão dos oito resultados de s a z. O desvio padrão é uma estimativa realista da precisão do método (Ribani et. al, 2004).

\subsection{Incerteza de Medição}

Os estudos de validação produzem dados de desempenho global do método e fatores de influência individuais que podem ser aplicadas à estimativa da incerteza associada aos resultados dos métodos em rotina (INMETRO, 2010).

Segundo o guia EURACHEM (2002), o termo incerteza de medição é "um parâmetro associado ao resultado de uma medição, que caracteriza a dispersão de valores que poderiam ser razoavelmente atribuídos ao mensurando". Determinar a incerteza de um método é, portanto, estimar quantitativamente os limites dentro dos quais os desvios do valor de um mensurando são previstos de se situar, podendo ser expresso como um desvio padrão ou um múltiplo do mesmo. De acordo com o Vocabulário Internacional de Metrologia (VIM, 2009), o termo incerteza de medição é um "parâmetro não negativo que caracteriza a dispersão dos valores atribuídos a um mensurando, com base nas informações utilizadas".

Para a avaliação da estimativa de incerteza de um método é necessário identificar as fontes de incerteza que atuam sobre as grandezas de entrada. Para 
efetuar o cálculo das incertezas, deve-se atribuir um valor mensurável a cada uma dessas grandezas de entrada para que seja possível quantificar a contribuição de cada uma. Após o cálculo individual da contribuição de cada incerteza, essas são combinadas, obtendo-se um valor global que tem influência no resultado. É necessário considerar todas as etapas do processo para a identificação das fontes de incerteza. Como exemplo, podem ser avaliadas as etapas de amostragem, armazenamento, preparação das amostras, calibração de instrumentos, pureza dos reagentes, efeitos da matriz, experiência do analista, entre outros (Souza, 2011; Guia EURACHEM, 2002).

Neste trabalho, a incerteza da medição foi calculada a partir das incertezas associadas à curva analítica, à massa da amostra de solo, à recuperação do processo e ao volume final da solução. Para o cálculo destas incertezas, foram consideradas diferentes grandezas de entrada.

De um modo geral, para a avaliação da incerteza associada às principais grandezas de entrada (massa, volume e pureza), foram considerados, em todos os cálculos em que as envolveram, as incertezas parciais associadas aos seguintes parâmetros:

- Massa: gráfico de controle ou repetitividade, peso padrão da balança, informação do certificado de calibração e resolução da balança;

- Pureza do padrão: informação fornecida pelo fabricante (porcentagem de pureza);

- Volume: informação do fabricante, gráfico de controle ou repetitividade; coeficiente de dilatação e variação de temperatura.

As incertezas combinadas foram calculadas por meio das fontes de incertezas individuais das grandezas de entrada para cada uma das fontes identificadas. $O$ coeficiente de sensibilidade, ci, fatores de conversão de unidades de medida foram calculados a fim de combinar as diferentes unidades de medida, convertendo a incerteza padrão de cada variável, $\mathrm{u}(\mathrm{xi})$, para a mesma unidade de medida de $\mathrm{Y}$. O produto entre a incerteza padrão, $u(x i)$, e seu respectivo coeficiente de sensibilidade, ci, dá origem a contribuição de incerteza, ui(y), que corresponde a uma medida de dispersão equivalente a um desvio padrão, com a mesma unidade de medida do mensurando. Os coeficientes de sensibilidade são calculados através das derivadas parciais de $\mathrm{Y}$ em relação a cada variável X (Souza, 2011). 


\subsection{Incerteza associada à curva analítica}

Para o cálculo das incertezas associadas à curva analítica consideraram-se as incertezas vinculadas à preparação da solução padrão, às diluições das soluções de trabalho e às áreas obtidas como resposta do equipamento.

$\underline{\text { Incerteza associada à solução padrão }}$

As soluções padrão foram preparadas a partir dos padrões analíticos sólidos e as incertezas envolvidas no cálculo da incerteza da solução padrão foram as da massa, da pureza do padrão e da micropipeta.

A incerteza da balança, do peso padrão e de repetitividade foram vinculadas à

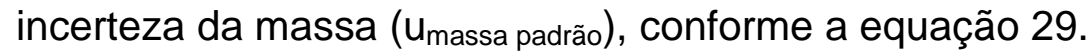

$$
u_{\text {massa padrão }}=\sqrt{\left(u_{\text {repe }}\right)^{2}+\left(u_{\text {peso padrão }}\right)^{2}+\left(u_{\text {calibr. balança }}\right)^{2}}
$$

Para estimar a incerteza da pureza do padrão analítico, considerou-se a pureza declarada pelo fabricante dividida pela raiz de 3 (distribuição retangular).

Para o volume do balão ( $\left.\mathrm{u}_{\text {vol. padrão }}\right)$ considerou-se as incertezas associadas à informação do fabricante, repetições, variação de temperatura e coeficiente de dilatação do vidro, de acordo com a equação 30 .

$$
u_{\text {vol. balão }}=\sqrt{\left(u_{\text {repe }}\right)^{2}+\left(u_{\text {fabricante }}\right)^{2}+\left(u_{\Delta t}\right)^{2}+\left(u_{\text {coef. dilatação }}\right)^{2}}
$$

A incerteza combinada da preparação da solução padrão ( $u_{c}$ (sol. padrão) foi calculada conforme a equação 31 .

$$
u_{c(\text { sol. padrão }}=\sqrt{\left(u_{\text {massa padrão }}\right)^{2}+\left(u_{\text {pureza padrão }}\right)^{2}+\left(u_{\text {vol.balão }}\right)^{2}}
$$


Incerteza associada à preparação das soluções de trabalho

As fontes de incertezas consideradas para o cálculo das incertezas associadas à preparação das soluções de trabalho são o volume dos volumes dos balões e os volumes pipetados. Para ambas as fontes de incerteza é preciso considerar as informações dos fabricantes, repetições, variações de temperatura e coeficiente de dilatação. Os cálculos foram realizados conforme a equação 30 .

As incertezas de cada uma das diluições são consideradas no cálculo da incerteza combinada da preparação das soluções de trabalho, conforme a equação 32.

$$
u_{(\text {sol.trab. })}=C_{\text {sol.trab. }} \sqrt{\left(\frac{u\left(V_{\text {sol.estoque }}\right)}{V_{\text {sol.estoque }}}\right)^{2}+\left(\frac{u\left(V_{f}\right)}{V_{f}}\right)^{2}+\left(\frac{u\left(C_{\text {sol.estoque }}\right)}{C_{\text {sol.estoque }}}\right)^{2}}
$$

Onde:

$\mathrm{C}_{\text {sol. trab. }}=$ concentração da solução mista de trabalho;

$\mathrm{uV}_{\text {sol.estoque }}=$ incerteza do volume pipetado da solução estoque individual para preparação da solução mista;

$\mathrm{V}_{\text {sol. estoque }}=$ volume pipetado da solução estoque individual para preparação da solução mista;

$u \mathrm{~V}_{f}=$ incerteza do volume final da solução mista de trabalho;

$V_{f}=$ volume final da solução mista de trabalho;

$\mathrm{uC}_{\text {sol. estoque }}=$ incerteza da solução estoque de cada composto.

As concentrações das soluções de trabalho foram calculadas segundo a equação 33.

$$
C_{\text {sol.trab. }}=C_{\text {sol.estoque }} \cdot \frac{V_{\text {estoque }}}{V_{f}}
$$

Incerteza associada à resposta do equipamento (área) 
Para o cálculo da incerteza vinculada à área obtida como resposta do equipamento de GC/ECD foram consideradas as incertezas da repetitividade e do equipamento, neste caso, considerou-se a resolução do equipamento.

A incerteza para a repetitividade $\left(\boldsymbol{u}_{\text {repe }}\right)$ das injeções no GC-ECD foi obtida seguindo-se a equação 34 .

$$
u_{\text {repe }}=\frac{s}{\sqrt{n}}
$$

Onde:

$\mathrm{S}=$ desvio padrão das medições;

$\mathrm{n}=$ número de injeções realizadas;

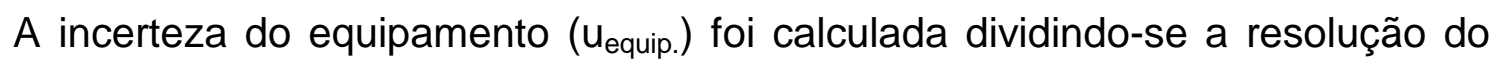
GC-ECD a meia altura base do pico cromatográfico por raiz de 3 (distribuição retangular).

A incerteza combinada da resposta do equipamento foi obtida pela equação 35 .

$$
u_{c(\text { área })}=\sqrt{\left(u_{\text {repe }}\right)^{2}+\left(u_{\text {equip. }}\right)^{2}}
$$

\subsection{Incerteza associada à recuperação}

A incerteza combinada relacionada à recuperação $\left(\mathrm{u}_{\mathrm{C}(\mathrm{rec})}\right)$ dos analitos foi calculada pela equação 36 .

$$
u_{C(\text { rec })}=R \sqrt{\left(\frac{u\left(C_{\text {real }}\right)}{C_{\text {real }}}\right)^{2}+\left(\frac{u\left(C_{\text {obtida }}\right)}{C_{\text {obtida }}}\right)^{2}}
$$

Onde $\mathrm{R}$ é o valor da recuperação, $\mathrm{u}\left(\mathrm{C}_{\text {real }}\right)$ é a incerteza da solução padrão adicionada, $\mathrm{C}_{\text {real }}$ corresponde a concentração real adicionada, $\mathrm{u}\left(\mathrm{C}_{\mathrm{obtida}}\right)$ é a concentração obtida e $\mathrm{C}_{\text {obtida }}$ é concentração obtida. 
A incerteza da solução padrão adicionada, $\mathrm{u}\left(\mathrm{C}_{\text {real }}\right)$, é calculada seguindo a equação 32 e a incerteza da concentração obtida, $u\left(C_{o b t i d a}\right)$, é calculada de acordo com a equação 37.

$$
u_{\text {Cobtida }}=\frac{s_{r e c}}{\sqrt{n}}
$$

Onde $S_{\text {rec }}$ corresponde ao desvio padrão dos ensaios de recuperação e n é o número de ensaios de recuperação.

\subsection{Incerteza associada ao volume final}

As incertezas envolvidas no volume final das amostras são as vinculadas ao vial de $1 \mathrm{~mL}$, ou seja, às referentes às informações do fabricante, variações de temperatura e ao coeficiente de dilatação térmica, conforme a equação 38.

$$
u_{C(V F)}=\sqrt{\left(u_{\text {fabricante }}\right)^{2}+\left(u_{\text {repe }}\right)^{2}+\left(u_{\Delta t}\right)^{2}+\left(u_{\text {coef.dilataçao }}\right)^{2}}
$$

\subsection{Incerteza combinada e expandida}

A incerteza combinada de todas as fontes de incertezas envolvidas na concentração dos organoclorados (org.) nas amostras das matrizes de Caieiras e Franco da Rocha, em que foram consideradas as incertezas da curva analítica ( $u_{\text {curva }}$ ), da recuperação ( $\left.u_{\text {rec }}\right)$ e do volume final ( $\left.u_{v F}\right)$ é expressa na equação 39.

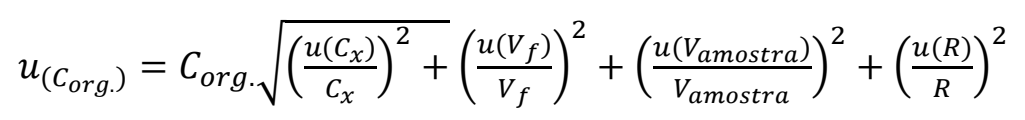

Para o cálculo da incerteza expandida multiplicou-se a incerteza combinada pelo fator de abrangência $k$, de acordo com a equação 40 . Neste estudo considerouse $k=1,96$, ou seja, com um nível de confiança de $95 \%$.

$$
u_{E(\text { organoclorado })}=u_{C(\text { organoclorado })} \cdot k
$$




\section{OBJETIVO}

Este trabalho tem como objetivo geral, desenvolver uma maneira de analisar os POPs, mais especificamente: BHC $\alpha-, \beta-, \gamma^{-}$, e $\delta$; clordano cis / trans $\left(\mathrm{C}_{10} \mathrm{H}_{6} \mathrm{Cl}_{8}\right)$; heptacloro $\left(\mathrm{C}_{10} \mathrm{H}_{5} \mathrm{Cl}_{7}\right)$ e heptacloro epóxido cis/ trans $\left(\mathrm{C}_{7} \mathrm{Cl}_{5} \mathrm{OH}\right)$, identificá-los e quantificá-los nas amostras coletadas, a fim de contribuir com o avanço das pesquisas para eliminação destes compostos que têm se mostrado ao decorrer dos anos, além de estáveis, muito prejudiciais aos seres vivos e ao meio ambiente. Para que este objetivo seja alcançado, foram traçados os seguintes objetivos específicos:

- Contribuir com o levantamento de áreas contaminadas no Brasil para observância ao Tratado de Estocolmo.

- Aplicar o método de extração QuEChERS em solo, contribuindo para a inovação das metodologias de extração multirresíduo de pesticidas no Brasil;

- Desenvolver metodologia analítica para de 9 compostos orgânicos considerados poluentes orgânicos persistentes, $\mathrm{BHC} \alpha-, \beta-, \gamma_{-}$, e $\delta$; clordano cis / trans $\left(\mathrm{C}_{10} \mathrm{H}_{6} \mathrm{Cl}_{8}\right)$; heptacloro $\left(\mathrm{C}_{10} \mathrm{H}_{5} \mathrm{Cl}_{7}\right)$ e heptacloro epóxido cis/ trans $\left(\mathrm{C}_{6} \mathrm{Cl}_{5} \mathrm{OH}\right)$, por Cromatografia Gasosa acoplada a espectrometria de massas (GC-MS) e quantificação por cromatografia gasosa acoplada a detector por Captura de elétrons (GC-ECD).

- Validar a qualidade dos dados gerados no processo analítico.

- Aplicar a metodologia para analisar amostras de solo de região industrial nos município de Caieiras e Franco da Rocha - SP, identificando e quantificando as substâncias presentes. 


\section{MATERIAIS E MÉTODOS}

\subsection{Equipamentos}

Para o desenvolvimento deste trabalho foram utilizados os seguintes equipamentos:

- Cromatógrafo a gás, Shimadzu - 17Ai, acoplado ao detector de espectrometria de massas, Shimadzu - QP 5000; microprocessador de dados equipado com o programa GCMS Solution, Shimadzu (Figura 16);

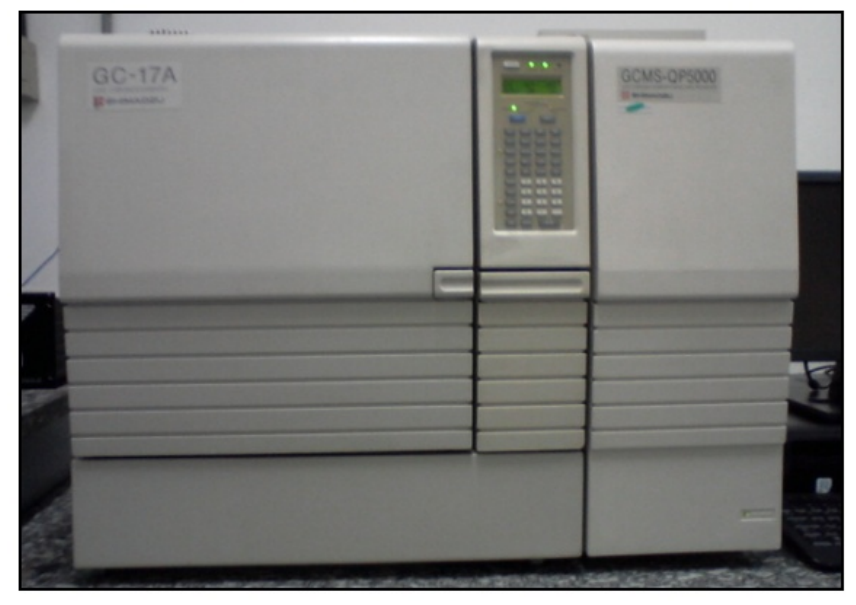

Figura 16. Cromatógrafo a gás (esquerda) acoplado a um espectrômetro de massas (direita)

- Coluna cromatográfica DB5 (5\% Siloxana), $30 \mathrm{~m} \times 0,25 \mathrm{~mm} \times 0,25 \mu \mathrm{m}$.

- Cromatógrafo a gás, Shimadzu - 2010, acoplado ao detector de captura eletrônica, Shimadzu; microprocessador de dados equipado com programa GC Solution (Figura 17); 


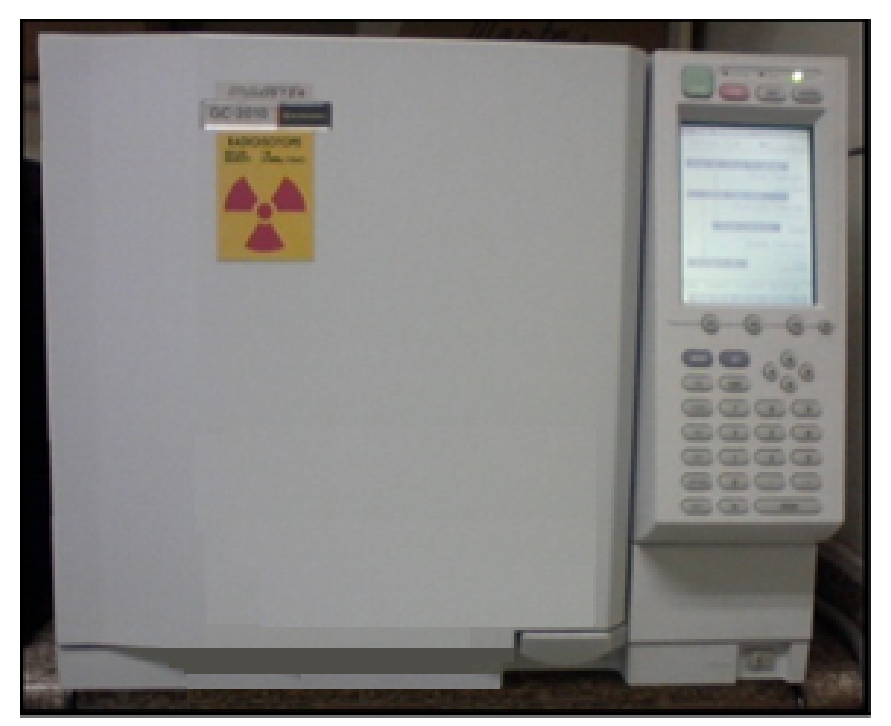

Figura 17. Cromatógrafo a gás (esquerda) acoplado a um detector por captura eletrônica (direita)

- Estufa FANEM, vortex mixer VIXAR, balança analítica Shimadzu.

- Coletor de amostras projetado pela equipe técnica do CQMA.

\subsection{Materiais e reagentes}

- Acetonitrila (ACN), iso-octano $\left(\mathrm{C}_{8} \mathrm{H}_{18}\right)$.

- Padrões de referência com certificado dos compostos: $\alpha-B H C, \beta-B H C, y-B H C, \delta-$ $\mathrm{BHC}$, clordano-cis, clordano- trans, heptacloro, heptacloro hepóxido-cis e heptaclorotrans.

- Sulfato de magnésio $\left(\mathrm{MgSO}_{4}\right)$, cloreto de sódio $(\mathrm{NaCl})$, citrato de sódio $\left(\mathrm{C}_{6} \mathrm{H}_{5} \mathrm{Na}_{3} \mathrm{O}_{7}\right)$, hidrogenocitrato de sódio sesquihidratado $\left(\mathrm{C}_{6} \mathrm{H}_{6} \mathrm{Na}_{2} \mathrm{O}_{7} \cdot 1,5 \mathrm{H}_{2} \mathrm{O}\right)$, absorvente bondesil PSA.

- Tubos de centrífuga (falcon), com volumes de 20 e $50 \mathrm{~mL}$.

Todos solventes utilizados são de grau analítico, cromatográfico ou compatível, fornecidos pela empresa Tedia Brasil. Para a confecção das curvas analíticas e desenvolvimento da metodologia foram utilizados padrões analíticos, com certificado de pureza de procedência Sigma Aldrich. As soluções padrões estoque foram preparadas em meio iso-octano, mantidas sob refrigeração e ausência de luz. 


\subsection{Amostragem}

Para o desenvolvimento do trabalho foram coletadas amostras de solo nos municípios de Caieiras e Franco da Rocha - SP, utilizando-se o extrator de solo elaborado pela equipe técnica do CQMA (Figura 18).

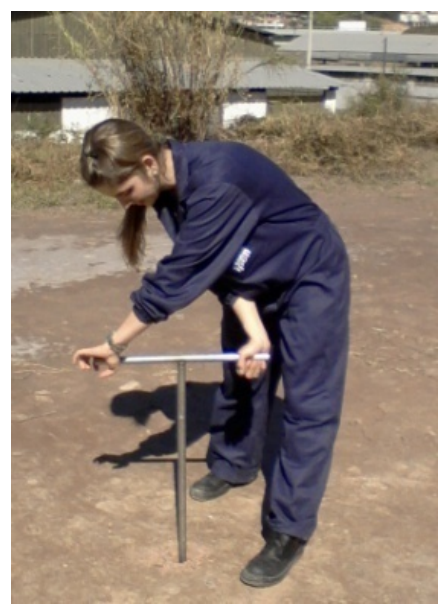

Figura 18. Coleta de amostras realizada em Caieiras - SP utilizando coletor de amostras de solo elaborado pela equipe técnica do CQMA.

Para manipulação e armazenamento das amostras, foram utilizadas embalagens inertes. Adotou-se o plano de amostragem com malha circular (CETESB,1999b) conforme Figura 19.

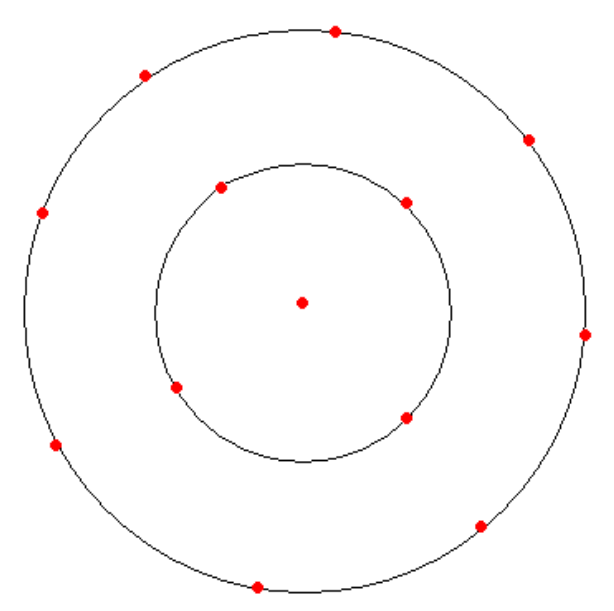

Figura 19. Plano de amostragem de solo circular

Foram realizadas 2 coletas, a primeira em abril/2011, ocasião na qual foi realizado um reconhecimento de área de coleta e coleta de três pontos em torno dos 
aterros industriais, afim de analisar o solo para adotar uma amostra "testemunho". Cada ponto de coleta foi monitorado por GPS e extraíram-se as coordenadas que podem ser observadas na Tabela 8.

Tabela 8. Coordenadas dos pontos de amostragem da primeira coleta realizada em torno do aterro.

\begin{tabular}{|c|c|}
\hline Caieirais - SP & Franco da Rocha - SP \\
\hline Ponto 01 - S: $23^{\circ} 40^{\prime} 441^{\prime \prime} / \mathrm{W}: 46^{\circ} 49^{\prime} 07^{\prime \prime}$ & Ponto 01 - S: $23^{\circ} 18^{\prime} 747^{\prime \prime} / \mathrm{W}: 46^{\circ} 48^{\prime} 972^{\prime \prime}$ \\
\hline Ponto 02 - S: $23^{\circ} 20^{\prime} 476^{\prime \prime}$ / W: $46^{\circ} 49^{\prime} 031^{\prime \prime}$ & Ponto 02 - S: $23^{\circ} 18^{\prime} 776^{\prime \prime}$ / W: $46^{\circ} 48^{\prime} 945^{\prime \prime}$ \\
\hline Ponto 03 - S: $23^{\circ} 20^{\prime} 419^{\prime \prime}$ / W: $46^{\circ} 49^{\prime} 009^{\prime \prime}$ & Ponto 03 - S: $23^{\circ} 18^{\prime} 761^{\prime \prime}$ / W: $46^{\circ} 49^{\prime} 001^{\prime \prime}$ \\
\hline
\end{tabular}

A segunda coleta, em agosto/2011, abrangeu todo o aterro e imediações, em ambos os municípios (Figuras 20 e 21), originadas da ferramenta Earth do site Google Maps. As coordenadas referentes aos pontos coletados podem ser visualizadas na Tabela 9.

Tabela 9. Coordenadas dos pontos de amostragem da segunda coleta realizada nos aterros e imediações.

\begin{tabular}{|c|c|}
\hline Caieirais - SP & Franco da Rocha - SP \\
\hline Ponto 01 - S: 23ํ2' 438” / W:46 49' 13”' & Ponto 01 - S: 23ํ 18' 764" / W: 46ㅇ 48' 968"' \\
\hline Ponto 02 - S: 23 20' 434" / W:46우 49' 132'” & Ponto 02 - S: 23ำ 18' 759”/ W: 46 48' 960" \\
\hline Ponto 03 - S: 23ํ20' 418” / W:46ำ 49' 25” & Ponto 03 - S: 23ำ 18' 759”/ W: 46우 48' 965” \\
\hline 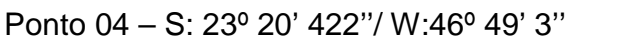 & 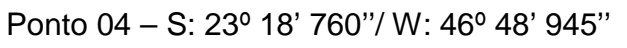 \\
\hline Ponto 05 - S: 23을' 403” / W:46 49' 988'” & Ponto 05 - S: 23ำ 18' 702”/ W: 46 48' 929" \\
\hline Ponto 06 - S: 23을' 437” / W:46 49' 991"' & Ponto 06 - S: 23ำ 18' 762”/ W: 46ำ 48' 929" \\
\hline 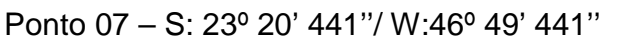 & 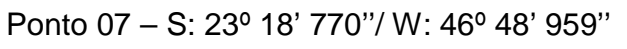 \\
\hline Ponto 08 - S: 23으 20' 442”/ W:46 49' 977”' & Ponto 08 - S: 23ำ 18' 749”/ W: 46 48’945” \\
\hline Ponto 09 - S: 23을' 465”/ W:46 49' 0,28'” & Ponto 09 - S: 23ำ 18' 750”/ W: 46ำ 48' 983”' \\
\hline Ponto 10 - S: 23 20' 470”/ W:46우 49' 470" & 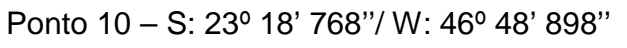 \\
\hline Ponto 11 - S: 23으 20' 491”/ W:46 49' 0,87”' & Ponto 11 - S: 23ำ 18' 770”/ W: 46ำ48' 928”' \\
\hline 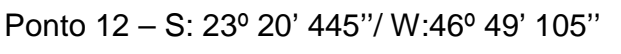 & Ponto 12 - S: 23ำ 18' 789”/ W: 46우 48' 981"' \\
\hline 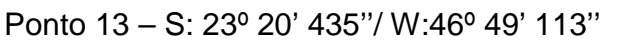 & 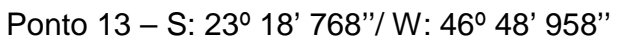 \\
\hline 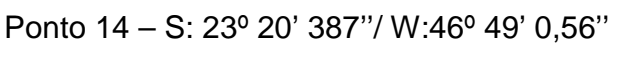 & Ponto 14 - S: 23ำ 18' 762"/ W: 46 48' 002" \\
\hline 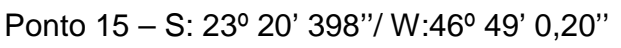 & 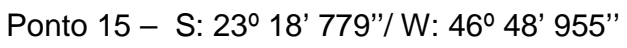 \\
\hline
\end{tabular}




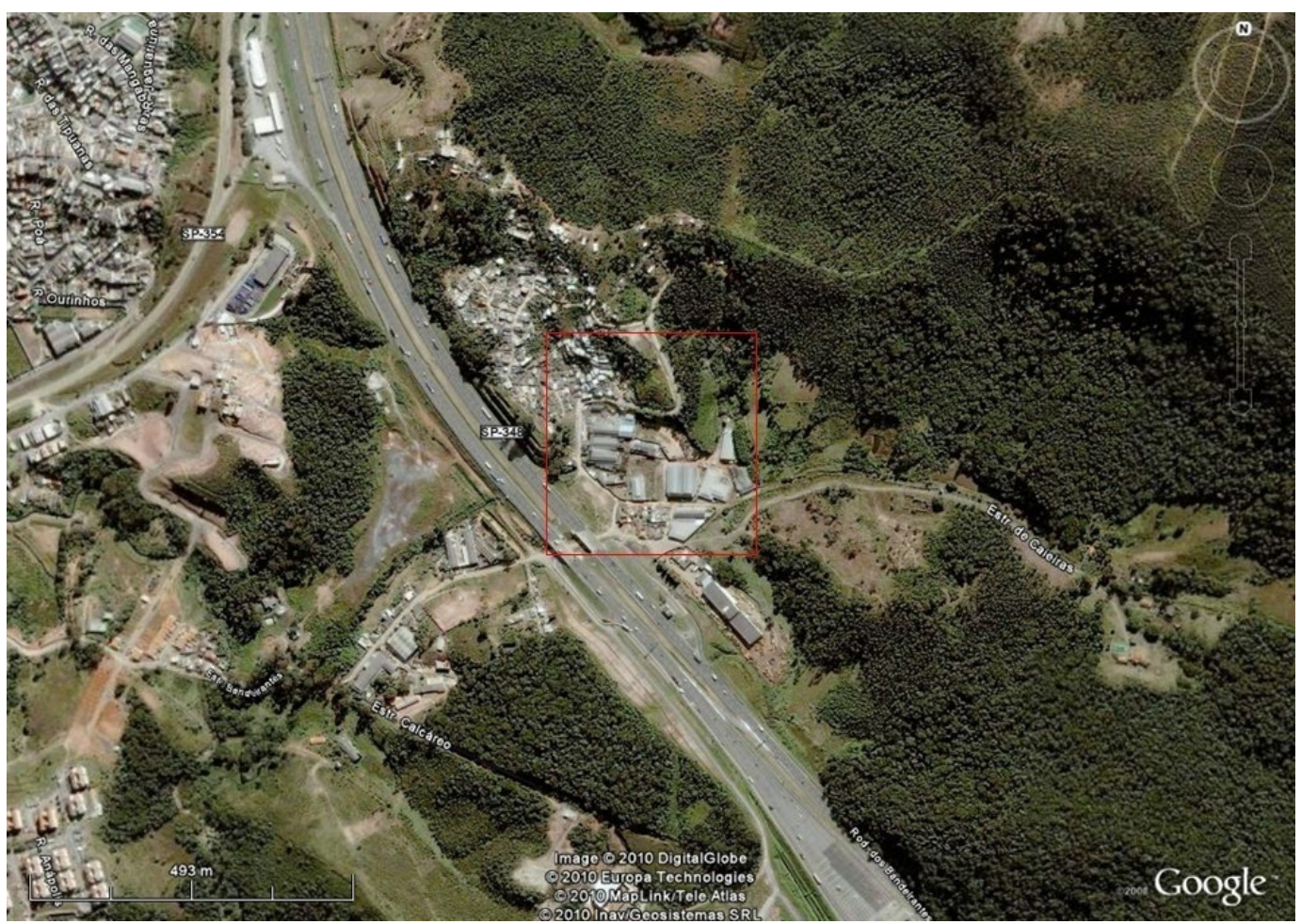

Figura 20. Região de coleta - município de Caieiras

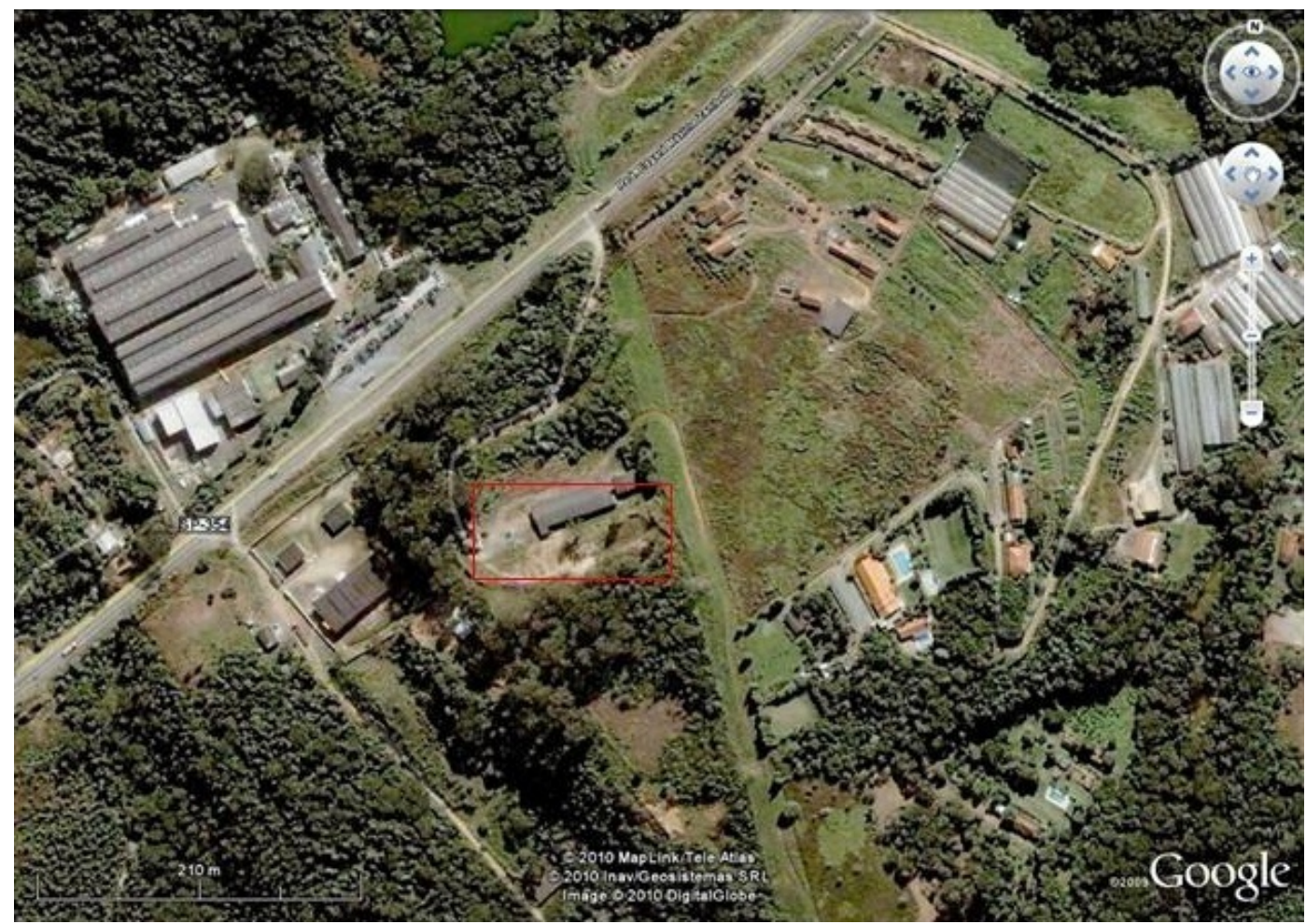

Figura 21. Região de coleta - município de Franco da Rocha 


\subsection{Caracterização do solo}

\subsubsection{Determinação de matéria orgânica}

Para determinar o teor de matéria orgânica das amostras em estudo, realizouse no laboratório, teste em duplicata para os solos de Caieiras e Franco da Rocha, seguindo o seguinte procedimento (ABNT, 1996):

a) Após a estabilização da balança analítica, aproximadamente 30 minutos, pesou-se quatro cápsulas de porcelana e anotou-se a massa pesada;

b) Em seguida, pesou-se $5 \mathrm{~g}$ da amostra de solo de Caieiras em duas das cápsulas de porcelana, devidamente identificadas e, de igual forma as amostras de Franco da Rocha foram pesadas.

c) Após a estabilização da estufa, aproximadamente 15 minutos, as amostras foram submetidas à temperatura de $110^{\circ} \mathrm{C}$ por 2 horas.

d) Passado este tempo, as cápsulas foram retiradas e depositadas em dessecador para esfriamento, por aproximadamente 15 minutos.

e) As cápsulas foram pesadas e anotaram-se as massas.

f) Após estabilização da mufla, aproximadamente 30 minutos, as cápsulas foram submetidas à temperatura de $375^{\circ} \mathrm{C}$ por 4 horas.

g) Passada esta etapa, programou-se a mufla para resfriamento até $150^{\circ} \mathrm{C}$, o que levou aproximadamente 3 horas para ocorrer.

h) As cápsulas foram retiradas e depositadas em dessecador a fim de resfriá-las por aproximadamente 15 minutos.

i) As cápsulas foram pesadas e anotaram-se as massas.

j) Calculou-se a porcentagem de matéria orgânica, de acordo com a Equação 29.

$$
\% M O=\frac{m(g) \text { solo seco em estufa }-m(g) \text { solo queimado em mufla }}{m(g) \text { solo seco em estufa }} \times 100
$$




\subsubsection{Determinação de granulometria}

Para determinar a granulometria das amostras em estudo, realizou-se no laboratório, teste em duplicata para os solos de Caieiras e Franco da Rocha, seguindo o seguinte procedimento (Paula e Duarte, 1997):

\section{- Preparação do dispersante}

a) Pesou-se $4 \mathrm{~g}$ de hidróxido de sódio, $\mathrm{NaOH}$, que foi dissolvido em $30 \mathrm{~mL}$ de água deionizada num béquer de $150 \mathrm{~mL}$.

b) Pesou-se $10 \mathrm{~g}$ de hexametafosfato de sódio (HMP) e agitou-se com um bastão até total dissolução.

c) Adicionou-se mais água deionizada completando volume de 1 litro e agitouse mecanicamente por 30 minutos.

\section{- Procedimento de determinação}

a) Após a estabilização da balança analítica, aproximadamente 30 minutos, pesou-se $50 \mathrm{~g}$ da amostra de solo de Caieiras em dois erlenmeyer de $500 \mathrm{~mL}$, devidamente identificadas e, de igual forma as amostras de Franco da Rocha foram pesadas.

b) Adicionou-se $250 \mathrm{~mL}$ de dispersante.

c) Agitou-se por 16 horas em agitador horizontal (shaker) em 170 RPM.

d) Transferiu-se a solução para a proveta de $1 \mathrm{~L}$ e completou-se com água de torneira.

e) Uma solução branco foi preparada em uma proveta de $1 \mathrm{~L}$, adicionando-se $250 \mathrm{~mL}$ da solução dispersante e completando-se com água de torneira.

f) A temperatura e a densidade da solução foi medida com densímetro de Boyoucos.

g) Agitou-se a solução da amostra usando êmbolo, com movimentos lentos de cima para baixo, até a solução se tornar homogênea.

h) Imediatamente após a agitação, iniciou-se contagem do tempo com cronômetro e fez-se leitura com densímetro de Boyoucos a 40 segundos.

i) Calculou-se o teor de argila, silte e areia das amostras de solo, conforme as Equações 42, 43 e 44. 


$$
\begin{gathered}
\% \text { Argila }=\frac{\text { leitura }(2 \mathrm{~h})-\text { leitura }(\text { branco })}{50} \\
\% \text { Silte }=\frac{(\text { leitura } 40 \text { s-leitura branco })-(\text { leitura }(2 h)-\text { leitura branco })}{50} \\
\% \text { Areia }=100-(\%) \text { Argila }-(\%) \text { Silte }
\end{gathered}
$$

\subsubsection{Determinação do pH}

Para determinar o $\mathrm{pH}$ das amostras em estudo, realizou-se no laboratório, teste em triplicata para os solos de Caieiras e Franco da Rocha, seguindo o seguinte procedimento (Paula e Duarte, 1997):

a) Após a estabilização da balança analítica, aproximadamente 30 minutos, pesou-se 74,56 g de cloreto de potássio, $\mathrm{KCl}$, e dissolveu-se o sal em $1 \mathrm{~L}$ de água destilada.

b) Pesou-se então, $10 \mathrm{~g}$ da amostra de solo de Caieiras em 3 tubos falcon de 50 $\mathrm{mL}$, devidamente identificados e, de igual forma as amostras de Franco da Rocha foram pesadas.

c) Adicionou-se $25 \mathrm{~mL}$ de solução de $\mathrm{KCl}(1,0 \mathrm{~mol} / \mathrm{L})$ em cada um dos 6 falcons.

d) Efetuou-se agitação em shaker, a 170 rpm por 15 minutos, conservando o tubo falcon na posição horizontal.

e) Centrifugou-se as amostras por 10 minutos, a 2500 rpm.

f) Realizou-se leitura em pHmetro previamente calibrado.

\subsection{Extração}

No laboratório, essas amostras foram inicialmente submetidas a uma secagem em estufa, a $40{ }^{\circ} \mathrm{C}$, por 24h. Posteriormente, as amostras foram peneiradas, homogeneizadas e quarteadas, separando-se uma fração representativa para pesagem. A extração foi realizada pelo método QuEChERS, definida pelo seguinte procedimento (Lesueur et. al, 2008): 

a) Pesagem $10 \mathrm{~g}$ de amostra de solo num falcon de $50 \mathrm{~mL}$, no qual são adicionados $20 \mathrm{~mL}$ de acetonitrila;
b) Agitação em vortex por 1 minuto;
c) Adição de $4 \mathrm{~g}$ de $\mathrm{MgSO}_{4}, 1 \mathrm{~g}$ de $\mathrm{NaCl}, 1 \mathrm{~g}$ de citrato de sódio e $0,5 \mathrm{~g}$ de hidrogenocitrato de sódio sesquihidratado;
d) Agitação da mistura em vortex por 1 minuto;
e) Centrifugação por 5 minutos, a 3000 RPM, em temperatura ambiente;
f) Transferência de uma alíquota de $10 \mathrm{~mL}$ do sobrenadante para um falcon de 20mL;
g) Adição de 0,95g de $\mathrm{MgSO}_{4}$ e $0,15 \mathrm{~g}$ de bondesil PSA;
h) Centrifugação por 5 minutos, a 3000 RPM, em temperatura ambiente;
i) Análise qualitativa, por GC-MS e quantitativa, por GC-ECD;

As etapas descritas nos itens "a" a "h", podem ser observados na Figura 22: 

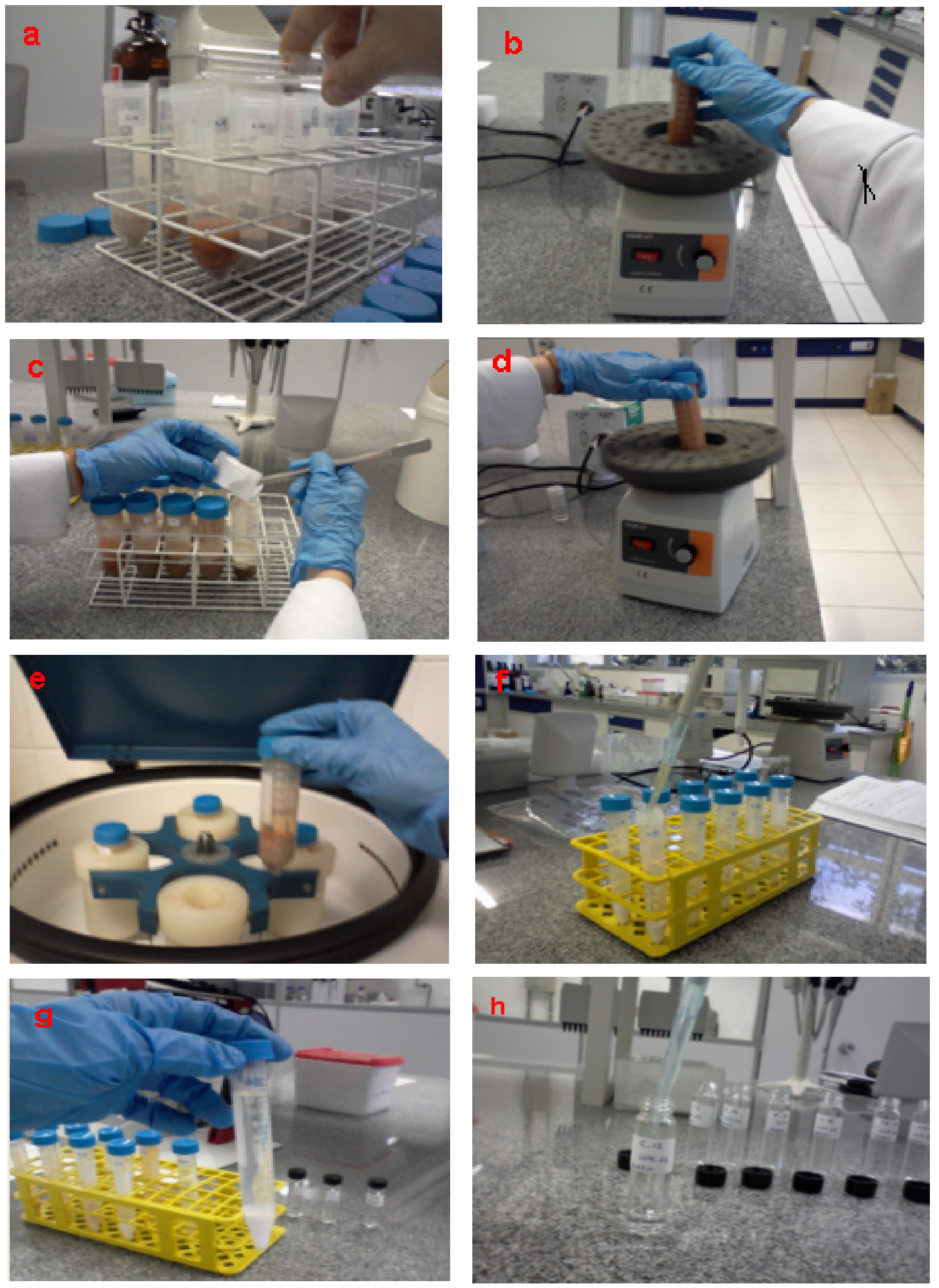

Figura 22. Esquema de extração por QuEChERS. 


\subsection{Escolha de equipamentos para análise}

O método de detecção foi desenvolvido no GC/MS, por ser uma técnica multielementar, de alta confiabilidade e seletividade. Os padrões dos contaminantes em estudo foram injetados isoladamente e em solução mista.

As amostras referentes à primeira coleta foram analisadas por esta técnica, na qual foi possível detectar a presença de BHC, confirmada pela comparação dos tempos de retenção dos picos encontrados nos cromatogramas de padrões e das amostras, e ainda pelo modo de varredura SIM, em que os íons presentes no espectro de padrão de fragmentação dos compostos de interesse são monitorados pelo detector do espectrômetro de massas, confirmando a presença dos mesmos nas amostras.

Para quantificação das amostras, a metodologia foi validada em GC/ECD, por ser uma técnica de alta sensibilidade para compostos halogenados, permitindo um aumento significativo nos limites de detecção e quantificação, além da possibilidade de análise de traços.

\subsection{Análises qualitativas por GC-MS}

\subsubsection{Desenvolvimento de método}

Inicialmente foram testados alguns métodos cromatográficos encontrados em literatura, entretanto, devido a não reprodução destes métodos no equipamento utilizado, e visando uma otimização no tempo de análise, foram testadas diversas modificações, como por exemplo, analises com e sem o emprego de isoterma de temperatura, foram testados métodos com o emprego de rampas de temperaturas. Alterou-se o fluxo do gás de arraste e a voltagem do detector. Para isso, injetou-se padrão e misturas de padrões, até que fosse obtido um resultado aceitável. O método cromatográfico depende de algumas variáveis que podem ser modificadas de acordo com o que se deseja analisar, os parâmetros ajustados foram: temperatura do injetor, rampa de temperatura do forno da coluna, temperatura da interface, velocidade do gás de arraste pela coluna, voltagem do detector e seleção de fragmentos a serem monitorados. 
São demonstrados a seguir alguns experimentos realizados a fim de otimizar o método cromatográfico. Na Figura 23 observa-se um cromatograma obtido a partir de um método montado nas seguintes condições: o forno da coluna iniciou temperatura em $60^{\circ} \mathrm{C}$ por 1 minuto elevou-se a temperatura a $180^{\circ} \mathrm{C}$, a uma taxa de $23^{\circ} \mathrm{C} \cdot \mathrm{min}^{-1}$ mantendo-se estas condições por 6 minutos, elevou-se novamente a temperatura a $330^{\circ} \mathrm{C}$ a uma taxa de $35^{\circ} \mathrm{C} / \mathrm{min}$. O fluxo do gás de arraste usado foi de $1,7 \mathrm{~mL} \cdot \mathrm{min}^{-1}$.

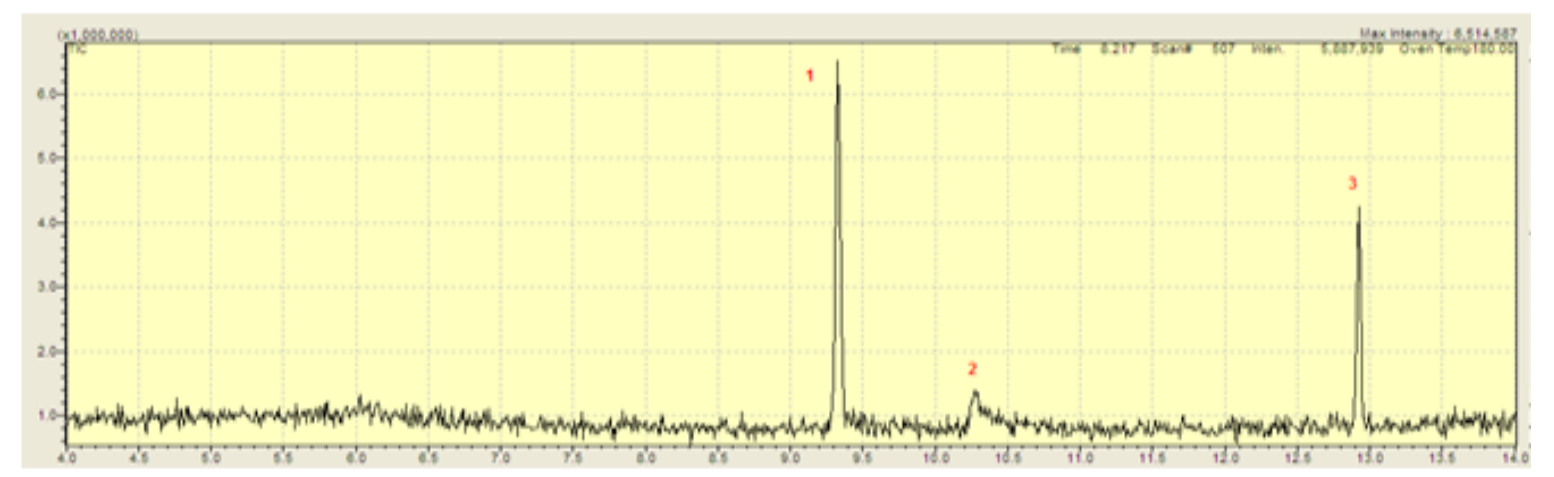

Figura 23. Cromatograma obtido pelo método SCAN, com injeção de mistura de padrões em concentração de $5 \mu \mathrm{g} \cdot \mathrm{mL}-1$, onde os picos cromatográficos correspondem aos padrões de (1) $\mathrm{Y}$-BHC, (2) pentaclorofenol e (3) heptacloro.

A Figura 24 representa um cromatograma obtido a partir de um método montado nas seguintes condições: o forno da coluna iniciou temperatura em $80^{\circ} \mathrm{C}$ por 1 minuto, elevou-se a temperatura a $210^{\circ} \mathrm{C}$, a uma taxa de $25^{\circ} \mathrm{C} / \mathrm{min}^{-1}$ mantendo-se estas condições por 6 minutos, elevou-se novamente a temperatura a $330^{\circ} \mathrm{C}$ a uma taxa de $35^{\circ} \mathrm{C} \cdot \mathrm{min}^{-1}$, com fluxo de gás de arraste igual a $1,5 \mathrm{~mL}$. $\mathrm{min}^{-1}$.

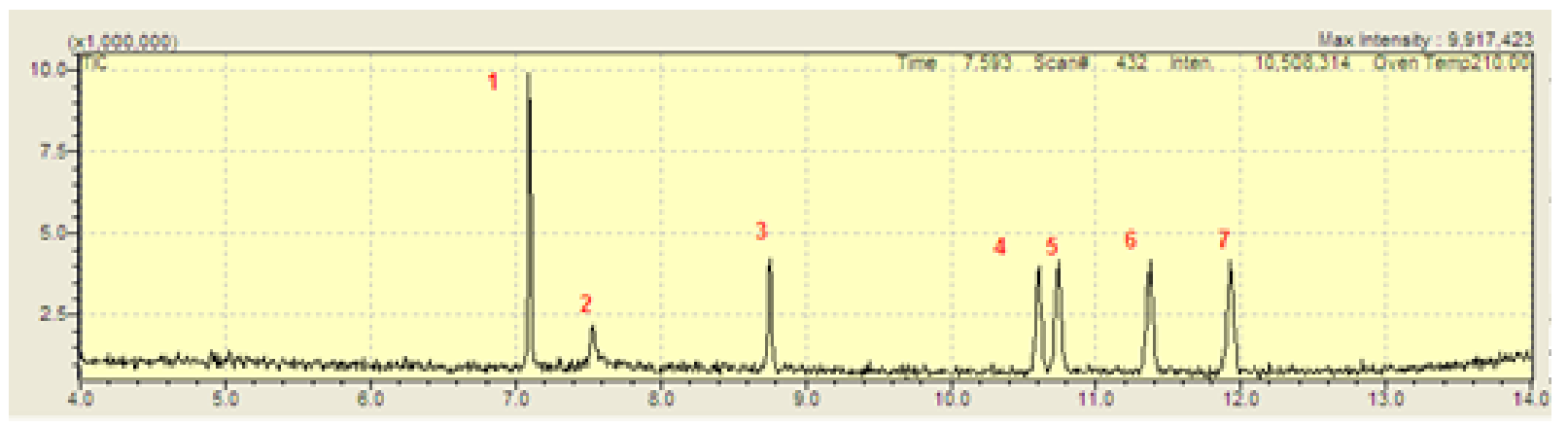

Figura 24. Cromatograma obtido pelo metodo SCAN, com injeção de mistura de padrões em concentração de $5 \mu \mathrm{g} \cdot \mathrm{mL}-1$, onde os picos cromatográficos correspondem aos padrões de (1) $\mathrm{Y}$-BHC, (2) pentaclorofenol, (3) heptacloro, (4) e (5) heptacloro epoxido cis/trans e (6) e (7) clordano trans e cis. 
A Figura 25 mostra um cromatograma obtido a partir de um método montado nas seguintes condições: o forno da coluna iniciou temperatura em $90{ }^{\circ} \mathrm{C}$ por 1 minuto, elevou-se a temperatura a $170{ }^{\circ} \mathrm{C}$, a uma taxa de $35{ }^{\circ} \mathrm{C} / \mathrm{min}$ mantendo-se estas condições por 5 minutos, elevou-se novamente a temperatura a $250^{\circ} \mathrm{C}$ a uma taxa de $40^{\circ} \mathrm{C} / \mathrm{min}$, com fluxo de gás de arraste igual a $1,6 \mathrm{~mL}$. $\mathrm{min}^{-1}$.

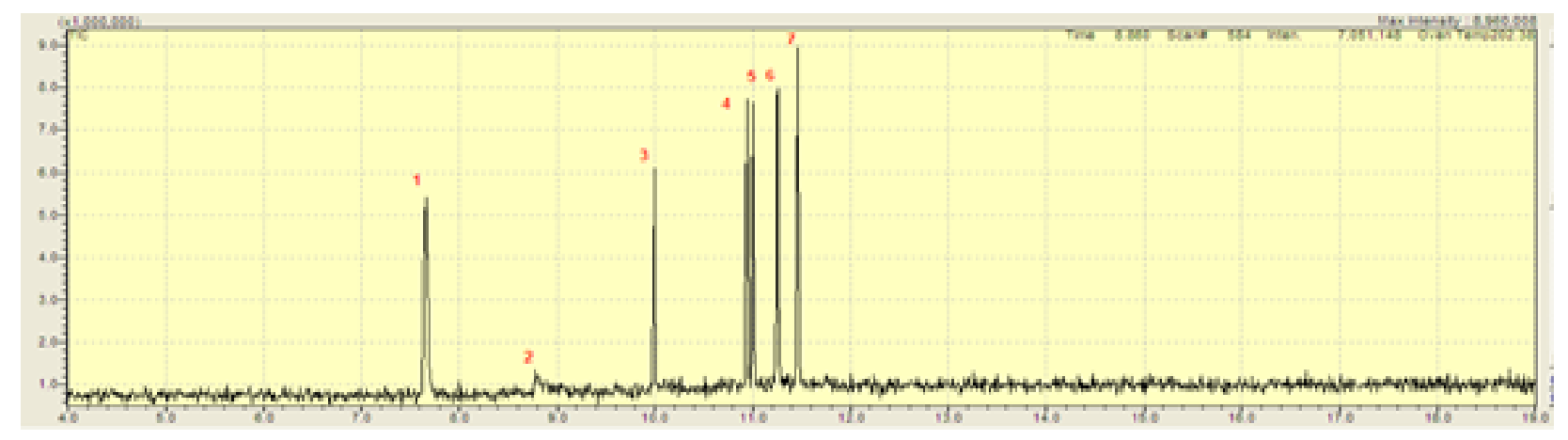

Figura 25. Cromatograma obtido pelo método SCAN, com injeção de mistura de padrões em concentração de $5 \mu \mathrm{g} \cdot \mathrm{mL}-1$, onde os picos cromatográficos correspondem aos padrões de (1) $\mathrm{Y}$-BHC, (2) pentaclorofenol, (3) heptacloro, (4) e (5) heptacloro epoxido cis/trans e (6) e (7) clordano trans e cis.

Com base na literatura e nos experimentos realizados para elaboração do método, foram fixadas as seguintes condições para o GC, com os quais foram obtidos melhores resultados:

- Temperatura do injetor: $250^{\circ} \mathrm{C}$;

- Temperatura da interface: $290^{\circ} \mathrm{C}$;

- Rampa de temperatura do forno, conforme Tabela 10.

- Fluxo na coluna: $1,1 \mathrm{~mL} \cdot \mathrm{min}^{-1}$;

- Fluxo total: $28 \mathrm{~mL} \cdot \mathrm{min}^{-1}$;

- Pressão total: $101 \mathrm{kPa}$;

- Velocidade Linear: $48.1 \mathrm{~cm} \cdot \mathrm{sec}^{-1}$.

- Tempo de análise: 16,2 min. 
Tabela 10. Programação de temperatura do forno do cromatográfico a gás (GC/MS).

\begin{tabular}{|ccc|}
\hline Taxa $\left({ }^{\circ} \mathrm{C} / \mathrm{min}\right)$ & $\begin{array}{c}\text { Tempetatura } \\
\left({ }^{\circ} \mathrm{C}\right)\end{array}$ & $\begin{array}{c}\text { Tempo de } \\
\text { espera }(\mathrm{min})\end{array}$ \\
\hline- & 80 & 1 \\
25 & 210 & 7 \\
35 & 290 & 1 \\
\hline
\end{tabular}

Os parâmetros definidos para o MS, com os quais foram obtidos melhores resultados são:

- Modo de aquisição dos dados: SIM - Select Íon Monitoring (Monitoramento de Íons Selecionados), conforme mostra a Tabela 11.

- Tempo de corte do solvente: 4 minutos;

- Voltagem do detector: $2,5 \mathrm{kV}$;

Tabela 11. Programação de monitoramento de íons para o detector do espectrômetro de massas (GC/MS).

\begin{tabular}{cccc}
\hline Composto químico & T inicial (min.) & T final (min.) & Íons Procurados \\
\hline Y-BHC & 4.00 & 5.45 & $109,181,183,217$ e 219 \\
Pentaclorofenol & 5.45 & 6.50 & $165,167,264,266,268$ \\
Heptacloro & 6.50 & 8.00 & $65,100,270.272$ e 274 \\
Heptacloro epóxido & 8.00 & 9.00 & $81,351,353,355$ e 357 \\
Clordano trans/cis & 9.00 & 15.00 & $237,371,373,375$ e 377 \\
\hline
\end{tabular}

Na Figura 26, pode-se observar o cromatograma obtido a partir da injeção de uma solução de mistura de padrões com concentração de $1 \mu \mathrm{g} \cdot \mathrm{mL}^{-1}$.

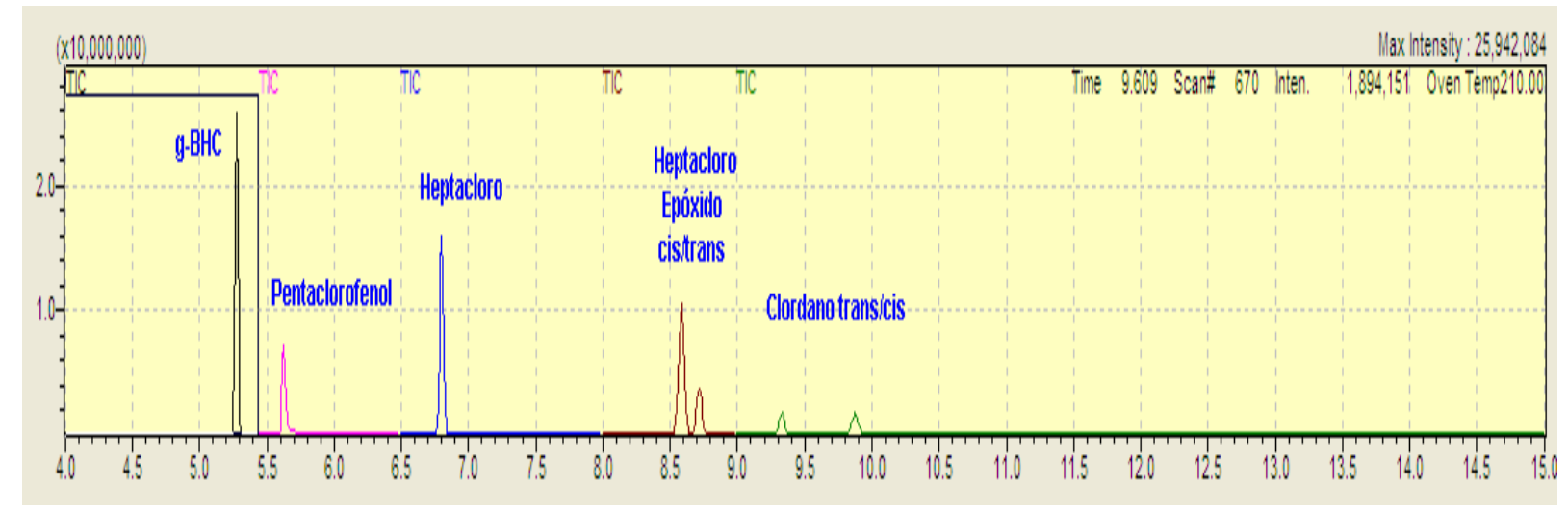

Figura 26. Cromatograma obtido pelo método SIM, pela injeção de $1 \mu \mathrm{L}$ de uma solução mistura de padrões em concentração de $1 \mu \mathrm{g} \cdot \mathrm{mL}^{-1}$ 


\subsubsection{Estudo da Fragmentação de Organoclorados na fonte de Íons por Impacto de Elétrons}

\section{- Sítio Inicial de lonização}

Os elétrons mais vulneráveis para a ejeção são aqueles em orbitais moleculares de energia mais alta. De fato, o potencial de ionização da molécula é definido como a energia necessária para remover completamente um desses elétrons da molécula (Smith e Busch, 1999). Esses orbitais também dão origem às ligações mais fracas nas moléculas. As energias relativas são similares àquelas para as transições eletrônicas que afetam o espectro ultravioleta. Os orbitais moleculares associados a ligações simples são designados como orbital sigma $(\sigma)$ e seus elétrons correspondentes são denominados elétrons $\sigma$. A dupla ligação em uma molécula orgânica contém dois tipos de orbitais moleculares: um orbital $\sigma$, correspondente a um par de elétrons ligados e um orbital molecular associado com o outro par. Em adição aos orbitais $\sigma$ e $\square \pi$, vários compostos orgânicos possuem elétrons não ligados. Estes elétrons não compartilhados são designados pela letra $n$. $O$ favorecimento para ionização geralmente está na ordem dos elétrons $\sigma$, e $\mathrm{n}^{23}$.

\section{- Clivagem indutiva (i)}

Em uma ligação simples, o par eletrônico compartilhado por átomos diferentes é mais fortemente atraído pelo átomo mais eletronegativo do par (Sykes, 1969). A indução de carga pode ocorrer tanto para moléculas com número ímpar de elétrons (NIE) como com número par de elétrons (NPE), sendo as reações virtualmente indistinguíveis pelo espectrômetro de massas pois levam à formação de fragmentos neutros e radicalares, respectivamente, ambos sem carga e portanto não sujeitos a ação do campo eletromagnético.

A clivagem da ligação sigma $\mathrm{C}-\mathrm{Cl}$ ocorre regida pelo efeito indutivo provocado pela nuvem eletrônica do átomo de cloro, como mostra a Figura 27. 
<smiles>Oc1c(Cl)c(Cl)c(Cl)c(Cl)c1Cl</smiles>

$\mathrm{m} / \mathrm{z} 264$<smiles>OC1=[C+]C(Cl)=C(Cl)C(Cl)=C1Cl</smiles>

$\mathrm{m} / \mathrm{z} 228$

Figura 27. Mecanismo de fragmentação do pentaclorofenol por clivagem indutiva.

\section{- Decomposição retro Diels-Alder}

A reação Diels-Alder consiste na reação entre um dieno conjugado e um composto contendo uma dupla ligação, denominado dienófilo. Nesta reação, duas novas ligações $\sigma$ são formadas as custas de duas ligações $\pi$ do dieno e do dienófilo (Solomons, 1968). No espectrômetro de massas observa-se a reação reversa (Ovcharengo et. al, 2003). Em geral os espectros por impacto de elétrons de inseticidas policiclodienoclorados possuem como principais fragmentos, íons correspondentes ao processo retro Diels-Alder, com perdas preliminares ou subseqüentes de $\mathrm{Cl}$ e $\mathrm{HCl}$ (Ostwald et. al, 1974). Este tipo de mecanismo pode ser observado na fragmentação da molécula de heptacloro que formam íons-fragmentos de m/z 100 e m/z 270 (Figura 28):
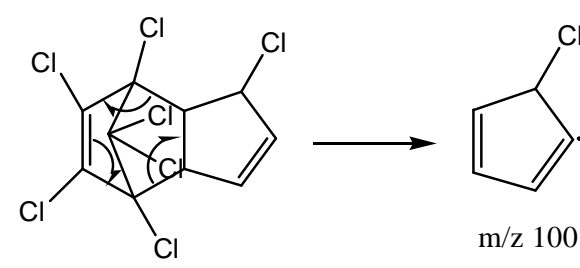

$\mathrm{m} / \mathrm{z} 100$
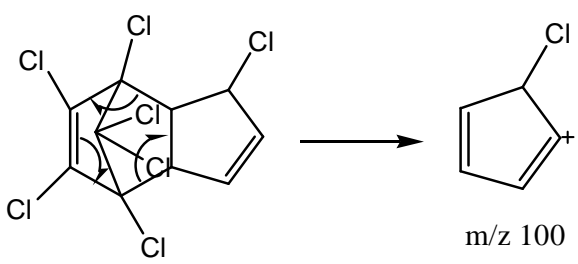

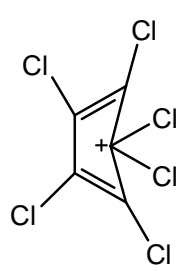

$\mathrm{m} / \mathrm{z} 270$

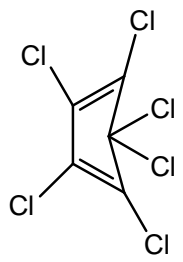

$\mathrm{m} / \mathrm{z} 270$

Figura 28. Mecanismos de fragmentação do íon-molécula heptacloro, por retro Diels-Alder. 
O mesmo ocorre para a molécula de clordano, com a formação dos fragmentos de $\mathrm{m} / \mathrm{z} 270$ e 135 (Figura 29).

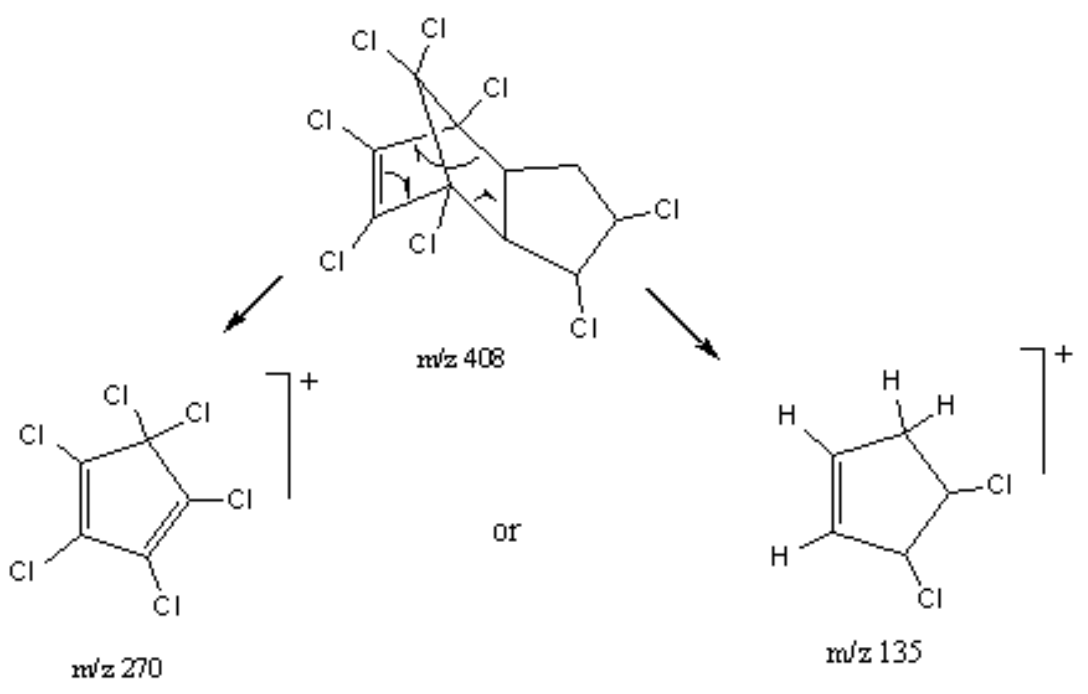

Figura 29. Mecanismos de fragmentação do íon-molécula clordano, por retro Diels-Alder.

\section{- Rearranjo}

O pentaclorofenol é uma molécula de grande estabilidade garantida por sua aromaticidade, portanto, os picos referentes a íons-fragmentos em seu espectro apresentam baixa intensidade. A Figura 30 mostra o mecanismo de fragmentação para os íons fragmentos de m/z 170 e 94.

Este mecanismo se inicia com uma clivagem $\alpha$, por conseqüência de uma forte tendência de pareamento eletrônico, ou seja, o elétron é doado para formar uma nova ligação com um átomo adjacente. A clivagem a inicia-se no sítio radicalar (Hussain et. al, 2001). Esse processo é acompanhado pela ruptura de outra ligação ao átomo $\alpha$ como ocorre na molécula de pentaclorofenol, em que o átomo de oxigênio forma uma segunda ligação com o átomo de carbono à custa da ruptura da ligação sigma carbono-carbono existente, definida como clivagem alfa (Figura 30.a). 
<smiles>Oc1c(Cl)c(Cl)c(Cl)c(Cl)c1Cl</smiles>

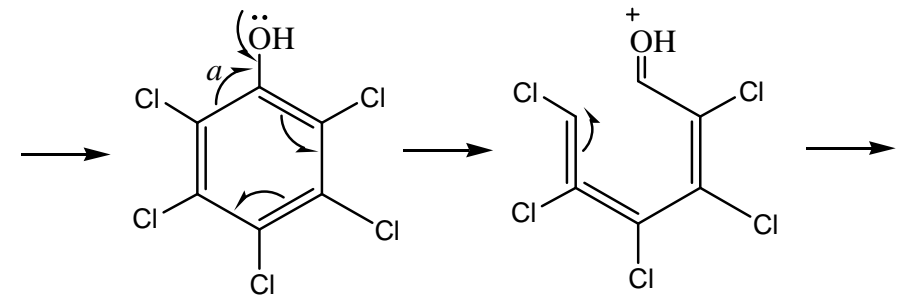

b<smiles>CC(CCl)=C(Cl)C(Cl)=C(Cl)C(C)C</smiles><smiles>CC(C)=C(Cl)C(Cl)C(Cl)=CCl</smiles><smiles>OCC(Cl)=C(Cl)CCl</smiles>

Figura 30. Mecanismos de fragmentação do íon-molécula pentaclorofenol, por rearranjo.

Ainda na Figura 30.a pode-se observar o rearranjo do sistema aromático, buscando a estabilização. Devido à tetravalência do carbono, a estrutura Figura 30.b não é eletronicamente possível, ocorrendo então, instantaneamente ao rearranjo das ligações $\pi$, uma migração eletrônica para o carbono periférico. A estrutura Figura 30.c ilustra um outro rearranjo de ligação e $\pi$ seguida da clivagem da ligação $\sigma$ que origina os fragmentos de m/z 94 e 170.

\subsection{Análises quantitativas por GC-ECD}

Inicialmente o método adotado para o GC-ECD foi semelhante ao adotado para o GC-MS, entretanto foram necessárias algumas alterações. Os parâmetros definidos para o GC, com os quais foram obtidos melhores resultados são:

- Temperatura do injetor: $250^{\circ} \mathrm{C}$;

- Temperatura da interface: $280^{\circ} \mathrm{C}$;

- Rampa de temperatura do forno, conforme mostra a Tabela 12. 
Tabela 12. Programação de temperatura do forno da coluna cromatográfica (GC/ECD).

\begin{tabular}{|ccc|}
\hline Rate $\left({ }^{\circ} \mathrm{C} / \mathrm{min}\right)$ & Temp. $\left({ }^{\circ} \mathrm{C}\right)$ & Hold time $(\mathrm{min})$ \\
\hline- & 80 & 1 \\
25 & 210 & 9 \\
35 & 290 & 1 \\
\hline
\end{tabular}

- Fluxo na coluna: $1,5 \mathrm{~mL} \cdot \mathrm{min}^{-1}$;

- Fluxo total: $19,5 \mathrm{~mL} \cdot \mathrm{min}^{-1}$;

- Pressão: 1,19 bar;

- Velocidade Linear: $36,5 \mathrm{~cm} \cdot \mathrm{sec}^{-1}$

- Tempo de análise: 18,2 min.

\subsection{Validação da metodologia}

A partir da melhor condição analítica pré-estabelecida foram iniciados os critérios de aceitabilidade embasados no procedimento orientativo de validação de métodos de ensaios do INMETRO, 2010. De acordo com esses documentos foram avaliados os seguintes parâmetros: Seletividade, Faixa Linear de Trabalho, Linearidade, Precisão, Exatidão, Limite de Detecção, Limite de Quantificação e Robustez. Em cada um desses parâmetros foi realizada uma série de experimentos em número estatisticamente significativo $(n=7)$ com e sem matriz, alguns experimentos em um mesmo dia e outros em dias diferentes. Com os dados obtidos foi avaliada a homogeneidade, pelo teste $\mathrm{F}$ e teste $\mathrm{T}$, calculando-se a variância de cada uma das replicatas. Foi avaliada estatisticamente a interferência ou não da matriz nos resultados e a linearidade dos resultados com e sem a matriz.

\subsubsection{Recuperação}

A recuperação foi determinada em três níveis de concentração: $0,75 \mu \mathrm{g} \cdot \mathrm{mL}^{-1}$, $1,0 \mu \mathrm{g} \cdot \mathrm{mL}^{-1}$ e $2,0 \mu \mathrm{g} \cdot \mathrm{mL}^{-1}$. Para o estudo, utilizou-se amostra de solo de Caieiras. 


\section{- Preparação das soluções de padrões}

Para as soluções de concentração 0,$75 ; 1,0$ e $2,0 \mu \mathrm{g} . \mathrm{mL}^{-1}$ foram aliquotados 200; 250 e $580 \mu \mathrm{L}$, respectivamente, de cada um dos 9 padrões em tubos de ensaio, a fim de se preparar três soluções mix de padrões, uma para cada nível de concentração em estudo.

Em seguida realizou-se uma pré-concentração, evaporando-se as misturas a um fluxo de ar constante e retomando-se em 200; 250 e $580 \mu \mathrm{L}$, respectivamente, de ACN.

Para cada nível de concentração, partiu-se da mesma solução preparada para realizar o "spike" nas amostras contaminadas antes e após o processo de extração.

\section{- Ensaios de Recuperação}

Para cada nível de concentração testado, foram utilizadas duas amostras de solo, sendo que uma foi contaminada antes da extração e a outra, após.

Nas amostras de solo contaminadas antes da extração, foram aliquotados 150; 200 e $400 \mu \mathrm{L}$, respectivamente, de solução mix de padrões. Foram deixadas em repouso por 24 horas, à temperatura ambiente. Realizou-se então a extração em ambos os conjuntos de amostras (contaminadas antes e após o processo de extração).

Nas amostras contaminadas após a extração, foram aliquotados volumes 30 ; 40 e $160 \mu \mathrm{L}$ de solução mix de padrões para as concentrações 0,$75 ; 1,0$ e $2,0 \mu \mathrm{g} \cdot \mathrm{mL}^{-1}$ e volume final de 4 ; 4 e $8 \mathrm{~mL}$.

Para mensurar a recuperação dos analitos, foram comparadas as áreas dos compostos obtidas das amostras contaminadas antes e após o processo de extração, e realizou-se o cálculo, segundo a Equação 45.

$$
\% \text { Recup }=\frac{A_{1}}{A_{2}} \times 100
$$

Onde: $A_{1}$ é a média das áreas obtidas da amostra contaminada antes da extração e $A_{2}$ é média das áreas obtidas da amostra contaminada após a extração. 


\subsubsection{Robustez}

Para determinação de robustez foi aplicado o teste em que a robustez é igual ao planejamento fatorial de 7 variáveis com 8 experimentos (planejamento fracionário saturado) de acordo com a metodologia proposta por Vander Heyden (2001), a qual segue o procedimento INMETRO, 2010. Os parâmetros escolhidos para os testes de robustez são apresentados na Tabela 13.

Tabela 13. Parâmetros selecionados para os testes de robustez.

\begin{tabular}{|c|c|c|}
\hline Fator & Nominal & Variação \\
\hline Volume de injeção & $1 \mathrm{uL}$ & $2 u L$ \\
\hline Fracionamento de vol. Injetado & Split 01:10 & Splitless \\
\hline Tempo de aquisição de sinal & $40 \mathrm{msec}$ & $80 \mathrm{msec}$ \\
\hline Fluxo coluna & $1,5 \mathrm{~mL} / \mathrm{min}$ & $1,3 \mathrm{~mL} / \mathrm{min}$ \\
\hline Volume de Acetonitrila & $20 \mathrm{~mL}$ & $15 \mathrm{~mL}$ \\
\hline Massa da amostra & $10 \mathrm{~g}$ & $5 \mathrm{~g}$ \\
\hline Temperatura do injetor & $250^{\circ} \mathrm{C}$ & $260^{\circ} \mathrm{C}$ \\
\hline
\end{tabular}




\section{RESULTADOS E DISCUSSÕES}

\subsection{Caracterização do solo}

\subsubsection{Determinação de Matéria Orgânica (M.O.)}

Foram analisadas amostras de solo de Caieiras e Franco da Rocha, em duplicata. Através dos testes, foi possível constatar que o solo de ambas regiões possuem baixo teor de matéria orgânica, como pode ser observado na Tabela 14 que expressa os dados e resultados obtidos.

Tabela 14. Dados e resultados obtidos para o teste de determinação de Matéria Orgânica.

\begin{tabular}{|c|c|c|c|c|c|c|}
\hline \multicolumn{6}{|c|}{ Massa(g) pesada } & \multirow{2}{*}{$\begin{array}{l}\text { \% M.O.O. } \\
\text { (média) }\end{array}$} \\
\hline \multicolumn{2}{|c|}{ Amostras } & ${ }^{\star} \mathrm{C} . P$. & Solo $+{ }^{*}$ C.P. & Solo S.E. & Solo *M. & \\
\hline \multirow{2}{*}{ Caieiras } & 1 & 55,738 & 60,734 & 60,687 & 60,647 & \multirow{2}{*}{0,8} \\
\hline & 2 & 50,309 & 55,308 & 55,264 & 55,222 & \\
\hline \multirow{2}{*}{$\begin{array}{l}\text { Franco da } \\
\text { Rocha }\end{array}$} & 1 & 55,904 & 60,892 & 60,881 & 60,793 & \multirow{2}{*}{1,76} \\
\hline & 2 & 56,186 & 61,179 & 61,168 & 61,080 & \\
\hline
\end{tabular}

${ }^{*}$ C.P.: Cápsula de Porcelana; *S.E.: Seco em Estufa; *M.: Mufla.

Um baixo teor de matéria orgânica no solo, pode significar que essas matrizes não tendem a reter os contaminantes, ou seja, há grande probabilidade de haver lixiviação dos mesmos.

\subsubsection{Determinação da Granulometria}

Foram analisadas amostras de solo de Caieiras e Franco da Rocha, em duplicata. Através dos testes, foi possível constatar que o solo Caieiras possui uma composição balanceada, ou seja, possui características granulométricas de solo argiloso, siltoso e arenoso, em proporções aproximadamente iguais. O solo de Franco da Rocha, entretanto, apresenta características granulométricas predominantemente de solo siltoso e arenoso, em proporções semelhantes, como podem ser observados na Tabela 15 que expressa os dados e resultados obtidos. 
Tabela 15. Dados e resultados obtidos para o teste de determinação de Granulometria.

\begin{tabular}{|c|c|c|c|c|c|c|}
\hline \multicolumn{4}{|c|}{ Densidade(g/L) medida } & \multirow{4}{*}{$\begin{array}{l}\text { \% Argila } \\
\text { (média) }\end{array}$} & \multirow{4}{*}{$\begin{array}{c}\text { \% Silte } \\
\text { (média) }\end{array}$} & \multirow{4}{*}{$\begin{array}{c}\text { \% Areia } \\
\text { (média) }\end{array}$} \\
\hline \multicolumn{4}{|c|}{$\begin{array}{c}\text { Leitura } \\
\end{array}$} & & & \\
\hline \multicolumn{2}{|c|}{ Amostras } & $40 \mathrm{~s}$ & $2 \mathrm{~h}$ & & & \\
\hline Branco & \# & 4 & 3 & & & \\
\hline \multirow{2}{*}{ Caieiras } & 1 & 37 & 22 & \multirow{2}{*}{37} & \multirow{2}{*}{31} & \multirow{2}{*}{32} \\
\hline & 2 & 39 & 23 & & & \\
\hline \multirow{2}{*}{$\begin{array}{l}\text { Franco da } \\
\text { Rocha }\end{array}$} & 1 & 33 & 8 & \multirow{2}{*}{8} & \multirow{2}{*}{50} & \multirow{2}{*}{42} \\
\hline & 2 & 33 & 8 & & & \\
\hline
\end{tabular}

\subsubsection{Determinação do pH}

Foram analisadas amostras de solo de Caieiras e Franco da Rocha, em triplicata. Através dos testes, foi possível constatar que o solo Caieiras possui pH 3,5, e o solo de Franco da Rocha, possui $\mathrm{pH}$ 2,9. Ambos possuem $\mathrm{pH}$ ácido que pode funcionar como facilitador da lixiviação.

\subsection{Resultados de validação}

\subsubsection{Seletividade}

A seletividade da metodologia foi avaliada realizando-se a análise cromatográfica da solução mix dos nove padrões analíticos no método previamente estabelecido. Inicialmente a solução foi preparada em solvente (ACN) e posteriormente nas matrizes de solo dos municípios de Caieiras e de Franco da Rocha. Na Figura 31 é apresentado como exemplo, o cromatograma da mistura padrão dos pesticidas estudados em solvente (a) e em matriz de Caieiras (b), referente à concentração de aproximadamente $0,1 \mu \mathrm{g} \cdot \mathrm{mL}^{-1}$, onde pode ser observada a excelente separação dos compostos estudados, além da separação desses compostos dos demais presentes como impurezas. 

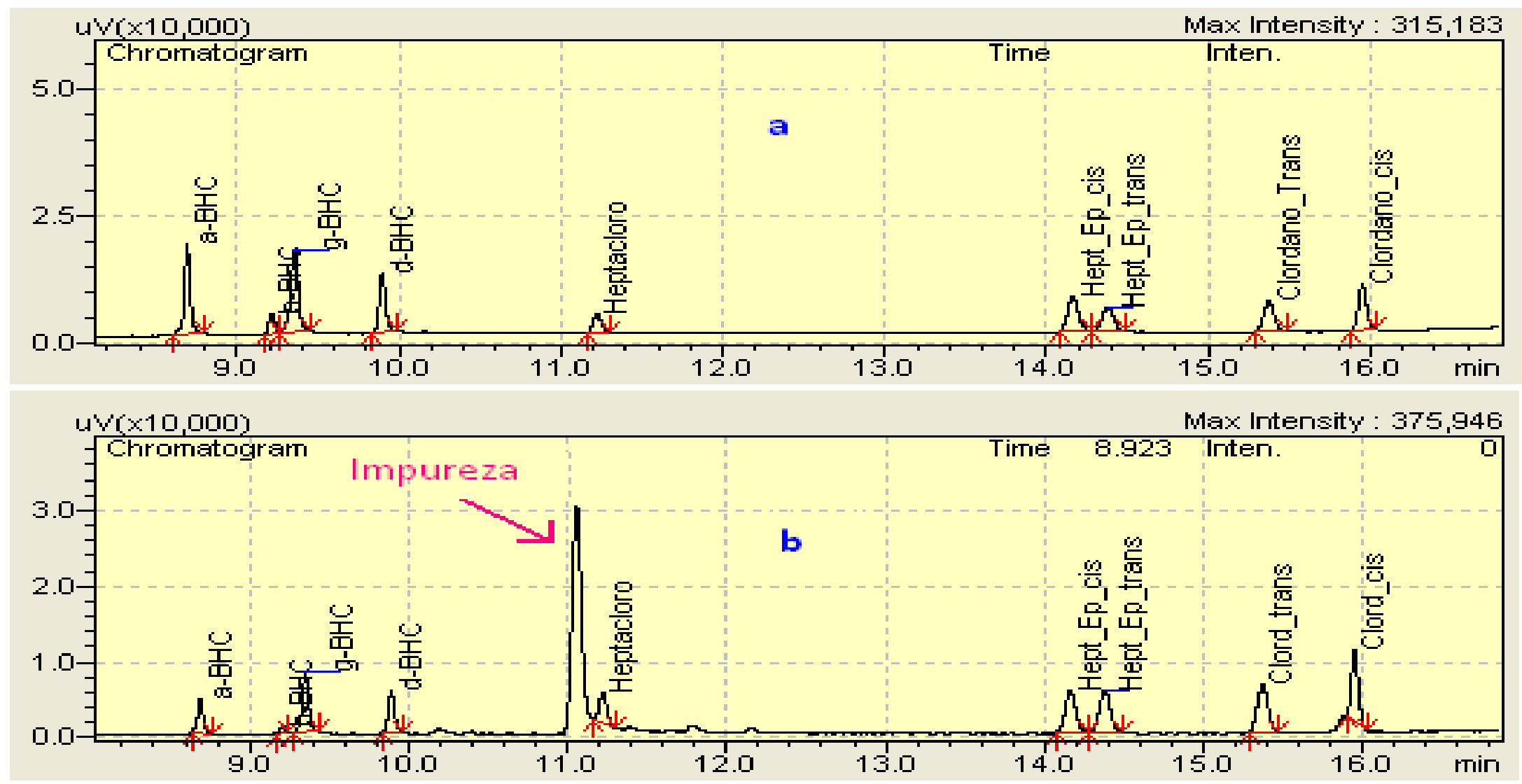

Figura 31. Cromatograma de padrão misto de pesticidas em: (a) solvente e (b) matriz, em concentração $0,1 \mu \mathrm{g} / \mathrm{mL}$, obtido em GC-ECD. 
Foi realizado, por meio de cálculos estatísticos específicos, o teste $\mathrm{F}$ (Snedecor) de homogeneidade das variâncias nas medidas de adição padrão em dois grupos de soluções, sendo um somente com o solvente e o outro com a matriz, para $n$ igual a 7 e $95 \%$ de confiança, apresentado na Tabela 16. Os resultados foram comparados com o valor crítico $\mathrm{F}_{(6,6,95 \%)}=4,28$ mostrando que para praticamente todos os compostos estudados o valor de $\mathrm{F}$ foi superior ao tabelado. Portanto estatisticamente, por este teste, a matriz não interfere na precisão das medidas para nenhum dos compostos. O efeito da matriz foi avaliado também pelo teste de significância das diferenças das médias, (teste $t$ - Student), dos conjuntos de amostras (matriz de Caieiras/solvente e matriz de Franco da Rocha/solvente). Os resultados do teste $\mathrm{t}$ (Student) igualmente foram comparados ao valor crítico $\mathrm{t}_{12,95 \%=}=$ 2,179, e para valores abaixo desse valor crítico, considera-se que as médias não apresentam diferenças significativas. Os ensaios indicaram existir diferenças entre as condições (adição no solvente e adição na matriz) para praticamente todas as concentrações avaliadas. Essa avaliação evidencia que resultados obtidos contra uma curva analítica preparada somente com o solvente será diferente se obtido contra uma curva preparada com uma matriz igual ou semelhante à amostra. $\mathrm{Na}$ metodologia desenvolvida, como a matriz não é certificada (padrão), as determinações foram realizadas a partir da adição de padrões a uma amostra adotada como branco, de acordo com o procedimento INMETRO, 2010. A Tabela 16 apresenta os resultados obtidos de seletividade pela aplicação dos testes $\mathrm{F}$ e t para os compostos estudados, pela adição padrão em solvente e nas matrizes dos solos de Caieiras e Franco da Rocha. Para o teste F, considerou-se $n$ igual a 7, com 6 graus de liberdade e $F$ tabelado igual a 4,28. Para o teste $t$, considerou-se também 0 $\mathrm{n}$ igual a 7 , com 6 graus de liberdade e t tabelado igual a 2,179. 
Tabela 16. Resultados da seletividade pela aplicação dos testes $\mathrm{F}$ e t para os compostos estudados, pela adição padrão somente no solvente e nas matrizes de solo de Caieiras e Franco da Rocha (teste $F$, considera o $n=7$, com 6 graus de liberdade; o teste t considera o $n$ $=14$, com 12 graus de liberdade e $95 \%$ de confiança). Tabela com os resultados dos valores calculados, considerando e $F_{\text {tabelado }}=4,28$ e $t_{\text {tabelado }}=2,179$.

\begin{tabular}{|c|c|c|c|c|c|c|c|c|c|}
\hline \multicolumn{10}{|c|}{$\alpha$-BHC - Concentração, $\mu \mathrm{g} \cdot \mathrm{mL}^{-1}$} \\
\hline & [ ] & 0,1 & 0,25 & 0,5 & 0,75 & 1 & 2,5 & 5 & 10 \\
\hline $\begin{array}{c}\text { SEM } \\
\text { Matriz }\end{array}$ & $s^{2}$ & $3,82 E+06$ & $1,65 E+07$ & $4,28 \mathrm{E}+07$ & $3,41 E+08$ & $1,64 \mathrm{E}+09$ & $3,19 E+09$ & $7,93 \mathrm{E}+10$ & $4,77 \mathrm{E}+10$ \\
\hline \multirow{3}{*}{ Caieiras } & $s^{2}$ & $3,56 \mathrm{E}+05$ & $2,89 \mathrm{E}+06$ & $3,82 E+06$ & $2,04 \mathrm{E}+07$ & $4,24 E+07$ & $2,37 \mathrm{E}+07$ & $2,10 E+08$ & $7,51 \mathrm{E}+08$ \\
\hline & $\mathrm{F}_{\text {calc/ }}$ & 0,09 & 0,18 & 0,09 & 0,06 & 0,03 & 0,01 & 0,00 & 0,02 \\
\hline & $t_{\text {calc }}$ & 40,16 & 47,22 & 58,89 & 26,76 & 17,28 & 28,27 & 10,93 & 23,08 \\
\hline \multirow{3}{*}{$\begin{array}{c}\text { Franco } \\
\text { da Rocha }\end{array}$} & $s^{2}$ & $9,31 \mathrm{E}+04$ & $3,34 \mathrm{E}+06$ & $3,07 E+07$ & $3,20 \mathrm{E}+07$ & $1,78 \mathrm{E}+07$ & $4,17 \mathrm{E}+08$ & $1,34 \mathrm{E}+09$ & $4,07 \mathrm{E}+09$ \\
\hline & $\mathrm{F}_{\text {calc }}$ & 0,02 & 0,20 & 0,72 & 0,09 & 0,01 & 0,13 & 0,02 & 0,09 \\
\hline & $t_{\text {calc }}$ & 37,01 & 41,63 & 34,92 & 19,43 & 13,51 & 20,07 & 9,24 & 15,38 \\
\hline \multicolumn{10}{|c|}{$\beta$-BHC - Concentração, $\mu \mathrm{g} \cdot \mathrm{mL}^{-1}$} \\
\hline $\begin{array}{c}\text { SEM } \\
\text { Matriz }\end{array}$ & $s^{2}$ & $1,42 E+06$ & $2,92 E+07$ & $1,33 E+07$ & $4,09 \mathrm{E}+07$ & $1,99 \mathrm{E}+08$ & $1,94 \mathrm{E}+08$ & $6,41 E+09$ & $5,15 \mathrm{E}+09$ \\
\hline \multirow{3}{*}{ Caieiras } & $s^{2}$ & $3,38 E+04$ & $9,19 \mathrm{E}+05$ & $1,05 E+06$ & $1,51 \mathrm{E}+06$ & $1,70 E+06$ & $7,06 \mathrm{E}+06$ & $2,36 \mathrm{E}+07$ & $6,34 \mathrm{E}+07$ \\
\hline & $\mathrm{F}_{\text {calc }}$ & 0,02 & 0,03 & 0,08 & 0,04 & 0,01 & 0,04 & 0,00 & 0,01 \\
\hline & $t_{\text {calc }}$ & 16,50 & 7,80 & 25,13 & 19,33 & 13,06 & 31,04 & 11,53 & 22,38 \\
\hline \multirow{3}{*}{$\begin{array}{c}\text { Franco } \\
\text { da } \\
\text { Rocha }\end{array}$} & $s^{2}$ & $2,94 E+05$ & $6,81 \mathrm{E}+05$ & $2,37 E+06$ & $2,60 E+06$ & $9,98 \mathrm{E}+05$ & $1,56 \mathrm{E}+07$ & $6,69 \mathrm{E}+07$ & $2,05 E+08$ \\
\hline & $F_{\text {calc }}$ & 0,21 & 0,02 & 0,18 & 0,06 & 0,01 & 0,08 & 0,01 & 0,04 \\
\hline & $t_{\text {calc }}$ & 11,12 & 6,69 & 18,44 & 15,30 & 11,03 & 24,19 & 10,12 & 19,78 \\
\hline \multicolumn{10}{|c|}{ Y-BHC - Concentração, ug.mL ${ }^{-1}$} \\
\hline $\begin{array}{c}\text { SEM } \\
\text { Matriz }\end{array}$ & $s^{2}$ & $1,89 \mathrm{E}+07$ & $7,94 \mathrm{E}+07$ & $8,76 \mathrm{E}+07$ & $2,48 E+08$ & $9,62 E+08$ & $1,78 E+09$ & $5,34 \mathrm{E}+10$ & $3,47 E+10$ \\
\hline \multirow{3}{*}{ Caieiras } & $s^{2}$ & $9,80 \mathrm{E}+05$ & $4,36 \mathrm{E}+07$ & $8,40 E+06$ & $5,17 E+07$ & 4,07E+07 & $6,91 \mathrm{E}+07$ & $2,89 E+08$ & $1,32 \mathrm{E}+09$ \\
\hline & $F_{\text {calc }}$ & 0,05 & 0,55 & 0,10 & 0,21 & 0,04 & 0,04 & 0,01 & 0,04 \\
\hline & $t_{\text {calc }}$ & 15,32 & 9,53 & 22,83 & 13,50 & 11,27 & 19,39 & 7,45 & 16,60 \\
\hline \multirow{3}{*}{$\begin{array}{l}\text { Franco } \\
\text { da } \\
\text { Rocha }\end{array}$} & $s^{2}$ & $1,61 \mathrm{E}+14$ & $6,39 \mathrm{E}+14$ & $3,14 \mathrm{E}+15$ & $1,93 E+16$ & 4,24E+17 & $1,46 \mathrm{E}+18$ & $1,41 \mathrm{E}+21$ & $5,57 \mathrm{E}+20$ \\
\hline & $F_{\text {calc }}$ & 0,10 & 0,10 & 0,95 & 0,33 & 0,02 & 0,47 & 0,05 & 0,20 \\
\hline & $t_{\text {calc }}$ & 12,70 & 8,60 & 5,81 & 3,94 & 4,30 & 5,30 & 4,58 & 5,12 \\
\hline
\end{tabular}


...Continuação Tabela 16.

\begin{tabular}{|c|c|c|c|c|c|c|c|c|c|}
\hline \multicolumn{10}{|c|}{ ס-BHC - Concentração, $\mu \mathrm{g} \cdot \mathrm{mL}^{-1}$} \\
\hline $\begin{array}{c}\text { SEM } \\
\text { Matriz }\end{array}$ & $s^{2}$ & $4,32 E+06$ & $2,31 E+07$ & $2,42 E+07$ & 1,81E+08 & $9,63 E+08$ & $2,90 \mathrm{E}+09$ & $5,96 \mathrm{E}+10$ & $3,88 \mathrm{E}+10$ \\
\hline \multirow{3}{*}{ Caieiras } & $s^{2}$ & $2,91 \mathrm{E}+05$ & $1,28 \mathrm{E}+07$ & $1,35 \mathrm{E}+07$ & $8,69 \mathrm{E}+07$ & $8,46 \mathrm{E}+07$ & $1,97 \mathrm{E}+07$ & $4,53 E+08$ & $1,18 E+09$ \\
\hline & $F_{\text {calc }}$ & 0,07 & 0,55 & 0,56 & 0,48 & 0,09 & 0,01 & 0,01 & 0,03 \\
\hline & $\mathrm{t}_{\text {calc }}$ & 19,52 & 17,45 & 29,76 & 12,99 & 9,73 & 15,07 & 6,97 & 16,08 \\
\hline \multirow{3}{*}{$\begin{array}{c}\text { Franco } \\
\text { da } \\
\text { Rocha }\end{array}$} & $s^{2}$ & $1,40 \mathrm{E}+06$ & $5,49 E+06$ & $9,79 \mathrm{E}+07$ & $3,19 E+07$ & $4,02 \mathrm{E}+07$ & $7,58 \mathrm{E}+08$ & $1,52 \mathrm{E}+09$ & $3,95 \mathrm{E}+09$ \\
\hline & $F_{\text {calc }}$ & 0,32 & 0,24 & 4,04 & 0,18 & 0,04 & 0,26 & 0,03 & 0,10 \\
\hline & tcalc & 14,15 & 17,73 & 7,56 & 7,82 & 6,16 & 7,69 & 5,57 & 12,90 \\
\hline \multicolumn{10}{|c|}{ Heptacloro - Concentração, $\mu \mathrm{g} \cdot \mathrm{mL}^{-1}$} \\
\hline $\begin{array}{c}\text { SEM } \\
\text { Matriz }\end{array}$ & $s^{2}$ & $3,73 E+05$ & $1,95 E+05$ & $6,45 E+06$ & $2,82 E+07$ & $1,40 \mathrm{E}+08$ & $5,22 E+08$ & $1,33 E+10$ & $9,21 E+09$ \\
\hline \multirow{3}{*}{ Caieiras } & $s^{2}$ & $3,55 \mathrm{E}+05$ & $5,03 E+06$ & $7,46 \mathrm{E}+06$ & $2,30 \mathrm{E}+07$ & 5,92E+07 & $2,22 E+07$ & $2,25 E+08$ & $4,36 E+08$ \\
\hline & $F_{\text {calc }}$ & 0,95 & 25,85 & 1,16 & 0,82 & 0,42 & 0,04 & 0,02 & 0,05 \\
\hline & $\mathrm{t}_{\text {calc }}$ & 6,00 & 6,77 & 7,36 & 6,70 & 2,27 & 0,87 & 1,43 & 6,53 \\
\hline \multirow{3}{*}{$\begin{array}{c}\text { Franco } \\
\text { da } \\
\text { Rocha }\end{array}$} & $s^{2}$ & $3,69 E+05$ & $2,91 E+06$ & $5,30 \mathrm{E}+07$ & $4,92 \mathrm{E}+07$ & $3,97 \mathrm{E}+07$ & $3,81 E+08$ & $9,54 \mathrm{E}+08$ & $1,89 E+09$ \\
\hline & $F_{\text {calc }}$ & 0,99 & 14,94 & 8,21 & 1,75 & 0,28 & 0,73 & 0,07 & 0,21 \\
\hline & $\mathrm{t}_{\text {calc }}$ & 24,43 & 20,95 & 15,09 & 16,65 & 12,60 & 11,50 & 1,87 & 0,07 \\
\hline \multicolumn{10}{|c|}{ Heptacloro Epóxido Cis- Concentração, $\mu \mathrm{g} \cdot \mathrm{mL}^{-1}$} \\
\hline \multirow{2}{*}{$\begin{array}{c}\text { SEM } \\
\text { Matriz }\end{array}$} & $s^{2}$ & 2,27E+06 & 9,37E+06 & $6,48 E+07$ & $8,10 \mathrm{E}+07$ & $1,14 \mathrm{E}+09$ & $1,88 \mathrm{E}+09$ & $5,09 E+10$ & $3,21 E+10$ \\
\hline & $s^{2}$ & 7,89E+05 & $1,04 E+07$ & 1,03E+07 & 7,23E+07 & 1,41E+08 & 5,21E+07 & $9,18 E+08$ & 2,49E+09 \\
\hline \multirow[t]{3}{*}{ Caieiras } & $F_{\text {calc }}$ & 0,35 & 1,12 & 0,16 & 0,89 & 0,12 & 0,03 & 0,02 & 0,08 \\
\hline & $t_{\text {calc }}$ & 7,43 & 5,38 & 8,83 & 4,94 & 4,09 & 8,44 & 4,45 & 11,71 \\
\hline & $s^{2}$ & $1,90 \mathrm{E}+06$ & $9,60 E+06$ & 4,99E+07 & 1,93E+08 & $1,00 E+08$ & $8,06 E+08$ & $3,56 \mathrm{E}+09$ & $9,62 E+09$ \\
\hline \multirow{2}{*}{$\begin{array}{c}\text { Franco } \\
\text { da Rocha }\end{array}$} & $F_{\text {calc }}$ & 0,84 & 1,03 & 0,77 & 2,39 & 0,09 & 0,43 & 0,07 & 0,30 \\
\hline & $\mathrm{t}_{\text {calc }}$ & 5,80 & 0,50 & 6,82 & 7,42 & 1,49 & 2,07 & 2,51 & 7,30 \\
\hline \multicolumn{10}{|c|}{ Heptacloro Epóxido Trans Concentração, $\mu \mathrm{g} \cdot \mathrm{mL}^{-1}$} \\
\hline \multirow[t]{2}{*}{$\begin{array}{c}\text { SEM } \\
\text { Matriz }\end{array}$} & $s^{2}$ & $1,14 \mathrm{E}+06$ & 4,71E+06 & $5,26 \mathrm{E}+07$ & 4,71E+07 & $8,10 \mathrm{E}+08$ & $1,30 \mathrm{E}+09$ & $3,75 E+10$ & $2,36 \mathrm{E}+10$ \\
\hline & $s^{2}$ & $6,63 \mathrm{E}+05$ & $1,52 \mathrm{E}+07$ & $9,52 E+06$ & $9,10 \mathrm{E}+07$ & $1,58 E+08$ & $6,44 \mathrm{E}+07$ & $1,15 E+09$ & 2,59E+09 \\
\hline \multirow[t]{3}{*}{ Caieiras } & $F_{\text {calc }}$ & 0,58 & 3,23 & 0,18 & 1,93 & 0,20 & 0,05 & 0,03 & 0,11 \\
\hline & $\mathrm{t}_{\text {calc }}$ & 8,05 & 8,93 & 7,02 & 10,03 & 2,51 & 3,34 & 0,64 & 5,30 \\
\hline & $s^{2}$ & $1,41 E+06$ & $1,68 \mathrm{E}+07$ & $6,27 \mathrm{E}+07$ & $1,95 E+08$ & 1,13E+08 & $1,36 \mathrm{E}+09$ & $4,89 E+09$ & $1,22 E+10$ \\
\hline \multirow{2}{*}{$\begin{array}{c}\text { Franco } \\
\text { da Rocha }\end{array}$} & $F_{\text {calc }}$ & 1,24 & 3,57 & 1,19 & 4,14 & 0,14 & 1,05 & 0,13 & 0,52 \\
\hline & $\mathrm{t}_{\text {calc }}$ & 24,21 & 15,31 & 21,81 & 21,76 & 10,48 & 13,88 & 2,11 & 0,22 \\
\hline
\end{tabular}


...Continuação Tabela 16.

\begin{tabular}{|c|c|c|c|c|c|c|c|c|c|}
\hline \multicolumn{10}{|c|}{ Clordano Trans Concentração, $\mu \mathrm{g} \cdot \mathrm{mL}^{-1}$} \\
\hline $\begin{array}{c}\text { SEM } \\
\text { Matriz }\end{array}$ & $s^{2}$ & $1,50 \mathrm{E}+06$ & $9,31 \mathrm{E}+06$ & $4,42 E+07$ & $7,21 \mathrm{E}+07$ & $1,14 \mathrm{E}+09$ & $2,28 \mathrm{E}+09$ & $7,13 E+10$ & $4,44 E+10$ \\
\hline \multirow{3}{*}{ Caieiras } & $s^{2}$ & $3,67 \mathrm{E}+05$ & $2,08 \mathrm{E}+07$ & $2,41 E+07$ & $1,54 \mathrm{E}+08$ & $2,27 E+08$ & $1,59 \mathrm{E}+08$ & $2,16 \mathrm{E}+09$ & $5,08 E+09$ \\
\hline & $F_{c}$ & 0,25 & 2,23 & 0,54 & 2,14 & 0,20 & 0,07 & 0,03 & 0,11 \\
\hline & $\mathrm{t}_{\text {calc }}$ & 7,07 & 6,49 & 5,91 & 6,90 & 1,42 & 0,56 & 1,51 & 7,64 \\
\hline \multirow{3}{*}{$\begin{array}{c}\text { Franco } \\
\text { da Rocha }\end{array}$} & $s^{2}$ & $9,22 \mathrm{E}+05$ & $1,18 \mathrm{E}+07$ & $4,38 \mathrm{E}+07$ & $2,17 \mathrm{E}+08$ & $1,65 \mathrm{E}+08$ & $1,28 \mathrm{E}+09$ & $6,16 \mathrm{E}+09$ & $1,72 \mathrm{E}+10$ \\
\hline & $F_{c}$ & 0,62 & 1,26 & 0,99 & 3,02 & 0,14 & 0,56 & 0,09 & 0,39 \\
\hline & $t_{\text {calc }}$ & 13,84 & 4,37 & 14,25 & 11,83 & 4,00 & 4,82 & 1,46 & 5,85 \\
\hline \multicolumn{10}{|c|}{ Clordano cis Concentração, $\mu \mathrm{g} \cdot \mathrm{mL}^{-1}$} \\
\hline $\begin{array}{c}\text { SEM } \\
\text { Matriz }\end{array}$ & $s^{2}$ & $1,54 \mathrm{E}+06$ & $5,88 \mathrm{E}+06$ & $3,93 \mathrm{E}+07$ & $1,10 \mathrm{E}+08$ & $1,24 \mathrm{E}+09$ & $1,96 \mathrm{E}+09$ & $6,11 \mathrm{E}+10$ & $2,98 E+10$ \\
\hline \multirow{3}{*}{ Caieiras } & $s^{2}$ & $3,04 \mathrm{E}+05$ & $2,16 \mathrm{E}+07$ & $2,62 \mathrm{E}+07$ & $2,27 \mathrm{E}+08$ & $3,69 \mathrm{E}+08$ & $2,28 \mathrm{E}+08$ & $2,82 E+09$ & $8,45 \mathrm{E}+09$ \\
\hline & $F_{\text {calc }}$ & 0,20 & 3,67 & 0,67 & 2,07 & 0,30 & 0,12 & 0,05 & 0,28 \\
\hline & $\mathrm{t}_{\text {calc }}$ & 0,44 & 10,42 & 11,22 & 9,29 & 2,22 & 3,12 & 0,35 & 6,56 \\
\hline \multirow{3}{*}{$\begin{array}{l}\text { Franco } \\
\text { da Rocha }\end{array}$} & $s^{2}$ & $1,45 \mathrm{E}+06$ & $4,51 E+07$ & $8,06 E+07$ & $4,92 \mathrm{E}+08$ & $1,96 \mathrm{E}+08$ & $1,29 \mathrm{E}+09$ & $9,19 \mathrm{E}+09$ & $2,51 E+10$ \\
\hline & $F_{\text {calc }}$ & 0,94 & 7,67 & 2,05 & 4,49 & 0,16 & 0,66 & 0,15 & 0,84 \\
\hline & $\mathrm{t}_{\mathrm{calc}}$ & 15,51 & 8,38 & 21,28 & 14,16 & 7,52 & 11,52 & 1,00 & 1,84 \\
\hline
\end{tabular}

Para que a matriz não apresente efeito sobre a precisão do método em ambos os testes estatísticos os valores calculados devem ser menores que os valores tabelados. Como se observa na Tabela 16 , os valores de $\mathrm{F}$ calculados foram inferiores ao valor crítico ( $F=4,28$ com 6 graus de liberdade e 95\% de confiança) para praticamente todos os compostos nas oito concentrações consideradas, demonstrando por este teste não haver interferência das matrizes nos ensaios. É necessário, porém, considerar ambos os testes, $\mathrm{F}$ e t para concluir efetivamente a interferência das matrizes nos ensaios.

No teste $t$, os valores calculados foram superiores ao valor crítico $(t=2,179$ com 12 graus de liberdade e $95 \%$ de confiança) em ambas as matrizes, evidenciando, portanto, que as matrizes interferem no ensaio.

As Figuras 32 e 33 representam graficamente a seletividade, em que se observa comportamento diversificado dos compostos nas diferentes matrizes. Os compostos $\alpha$-BHC, $\beta$-BHC, $\gamma-B H C, \delta$-BHC e heptacloro epóxido cis apresentaram maior inclinação da reta para a matriz de Caieiras, seguida da reta para a matriz de 
Franco da Rocha e menor inclinação para o ensaio sem matriz. Os compostos heptacloro, heptacloro epóxido trans e clordano cis, apresentaram, entretanto, inclinação da reta na matriz de Franco da Rocha muito semelhante à inclinação da reta para o ensaio sem matriz. E por fim, o clordano trans apresentou comportamento diferente de todos os outros compostos, com inclinação da reta semelhante em ambas as matrizes.
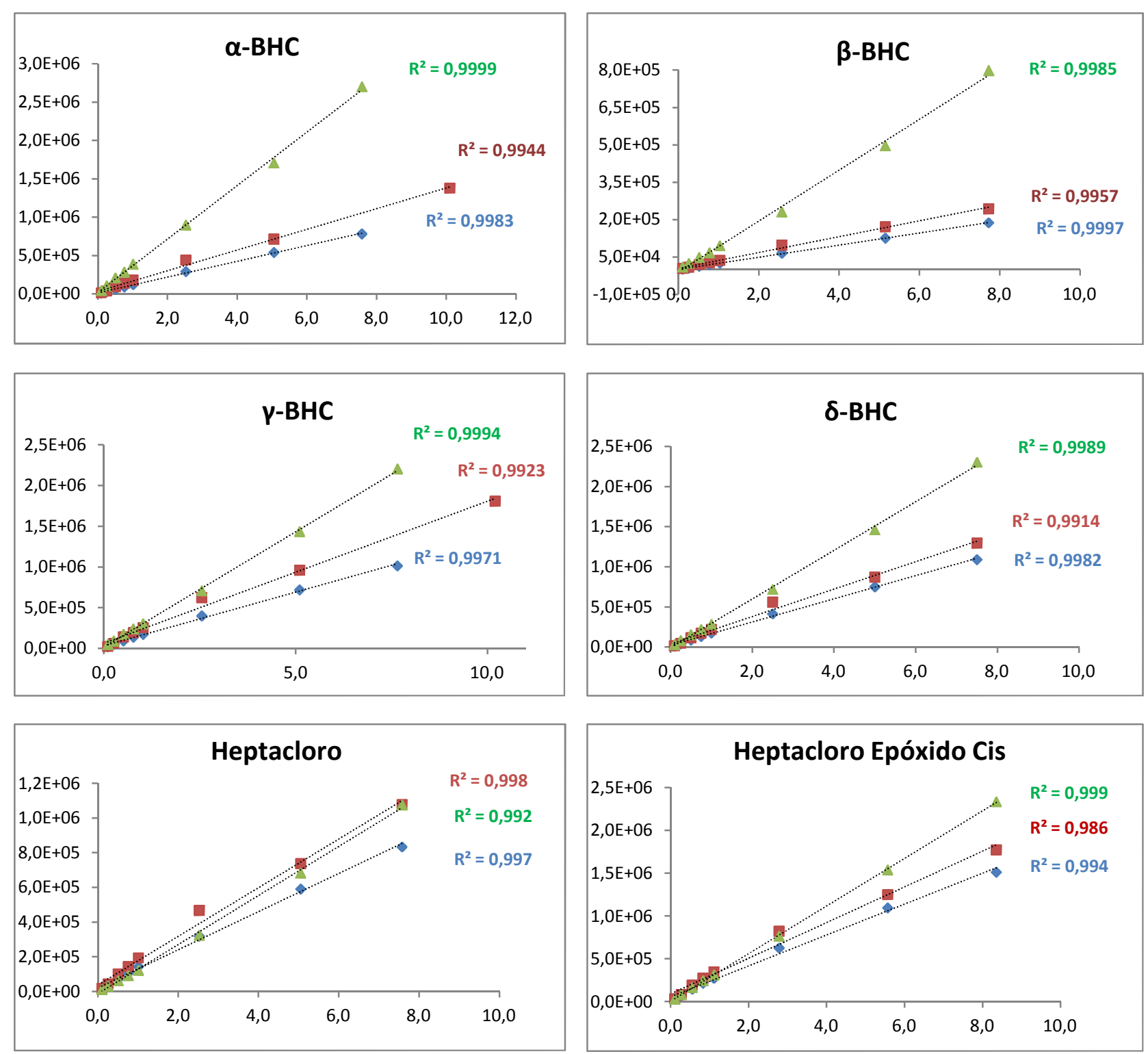

Legenda: Caieiras

F. da Rocha $\Delta$ Solvente

Figura 32. Gráficos de seletividade representados pelas retas obtidas nos ensaios com solvente $(\mathrm{ACN})$, solo de Caieiras e de Franco da Rocha para os compostos $\alpha-\mathrm{BHC}$ e $\beta-\mathrm{BHC}, \mathrm{\gamma}-\mathrm{BHC}$, $\delta-$ $\mathrm{BHC}$, heptacloro, heptacloro epóxido cis. 

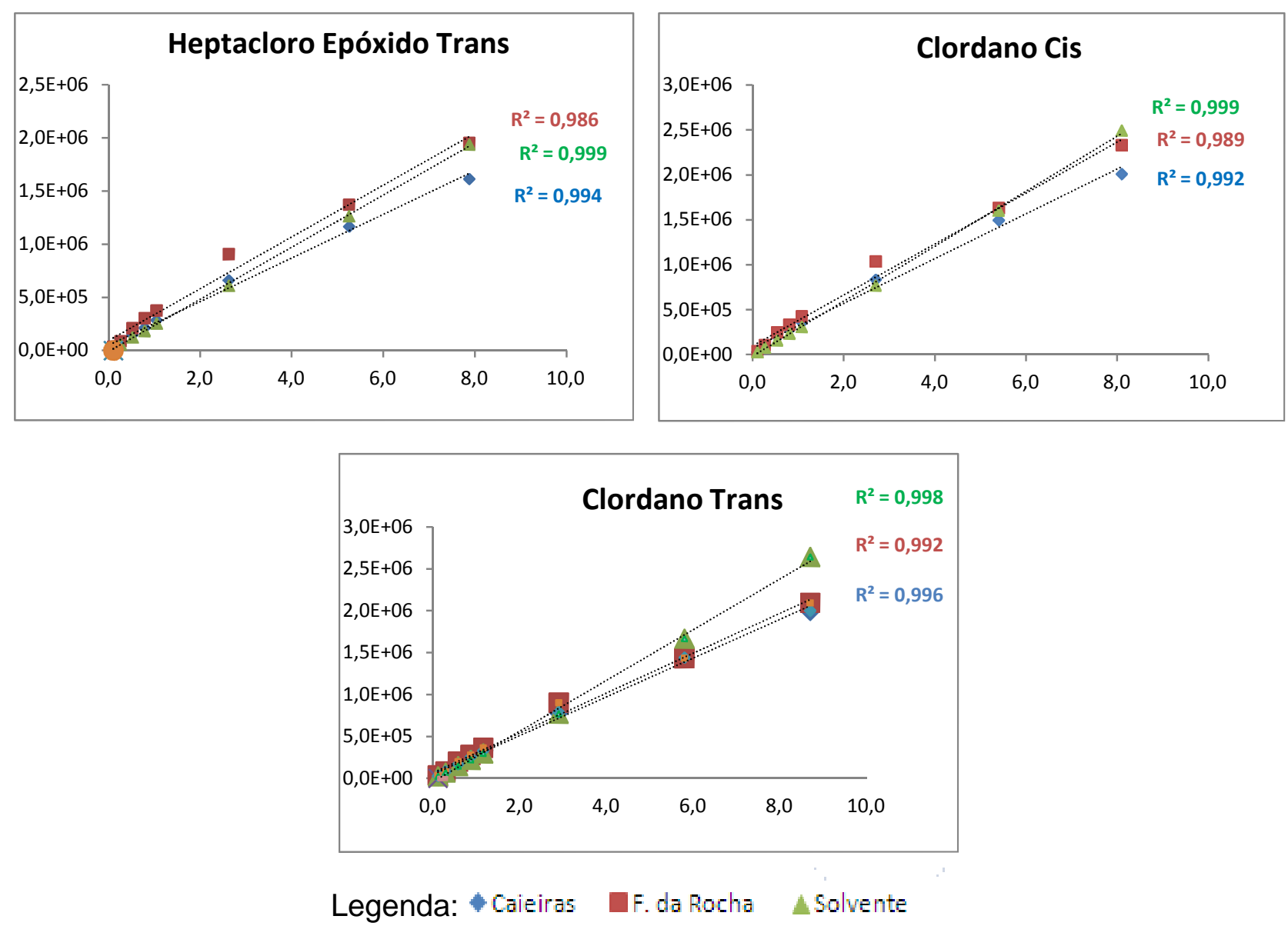

Figura 33. Gráficos de seletividade representados pelas retas obtidas nos ensaios com solvente (ACN), solo de Caieiras e de Franco da Rocha para os compostos heptacloro epóxido trans e clordano cis / trans.

\subsubsection{Linearidade}

A linearidade do método foi observada pelas curvas analíticas, considerandose o coeficiente de correlação linear (r), que segundo o INMETRO (2010) deve ser superior a 0,90, que resulta em um coeficiente de determinação $\left(r^{2}\right)$ igual a 0,81. 0 coeficiente de correlação linear foi obtido pela regressão linear de cada composto nos três ensaios, avaliando-se ainda a análise de resíduos pelo teste t de Student e o gráfico de resíduos.

Para cada uma das retas obtidas pelas curvas analíticas, pode ser observada a perfeita linearidade e os coeficientes de correlação linear maiores que 0,90 conforme sugerido pelo INMETRO (2010). Nas tabelas 17 a 19 são apresentados os intervalos lineares para cada um dos compostos estudados, a equação das retas e os coeficientes de determinação $\left(r^{2}\right)$ obtidos nos ensaios com e sem matriz. As curvas 
analíticas dos compostos estudados nos ensaios com solvente (ACN), matrizes de Caieiras e de Franco da Rocha são representadas nas Figuras 34 a 36.

Tabela 17. Faixa de trabalho para cada composto, equação da reta e coeficiente de determinação (r2) obtidos pela adição padrão na matriz de Caieiras.

\begin{tabular}{c|c|c|c}
\hline \multicolumn{5}{c}{ Adição em Matriz Caieiras } \\
\hline Composto & Intervalo Linear $\left(\boldsymbol{\mu g} \cdot \mathbf{m L}^{-1}\right)$ & Equação da Reta & $\mathbf{r}^{2}$ \\
\hline$\alpha-B H C$ & $0,101-1,010$ & $y=1,21 \mathrm{E}+05 x-1.651$ & 0,999 \\
$\beta-B H C$ & $0,103-1,030$ & $y=25827 x-277,1$ & 0,999 \\
Y-BHC & $0,102-1,020$ & $y=16445 x+9228$ & 0,997 \\
$\delta-B H C$ & $0,100-1,000$ & $y=18069 x-2448$ & 0,999 \\
Heptacloro & $0,101-1,010$ & $y=12245 x-197,7$ & 0,999 \\
Hept. Epóxido Cis & $0,111-1,114$ & $y=25022 x+2840$ & 0,997 \\
Hept. Epóxido Trans & $0,105-1,050$ & $y=271470 x+1393$ & 0,998 \\
Clordano Cis & $0,108-1,080$ & $y=33889 x+4037$ & 0,992 \\
Clordano Trans & $0,116-1,160$ & $y=290550 x-1090$ & 0,999 \\
\hline
\end{tabular}
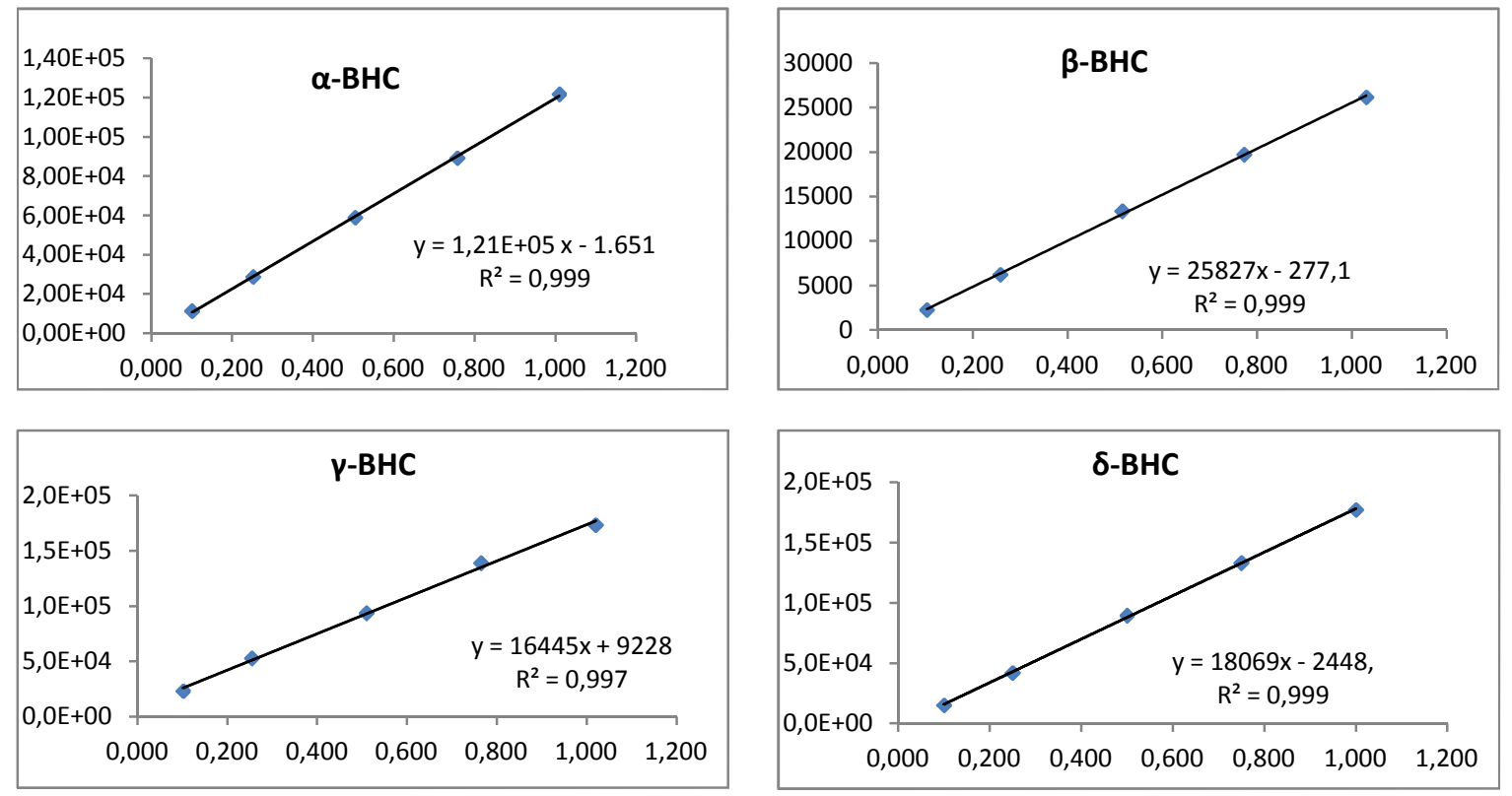

Figura 34. Representação gráfica da linearidade para os compostos $\alpha-B H C, \beta-B H C, \gamma-$ $\mathrm{BHC}$ e $\delta$-BHC estudados em matriz de Caieiras. 

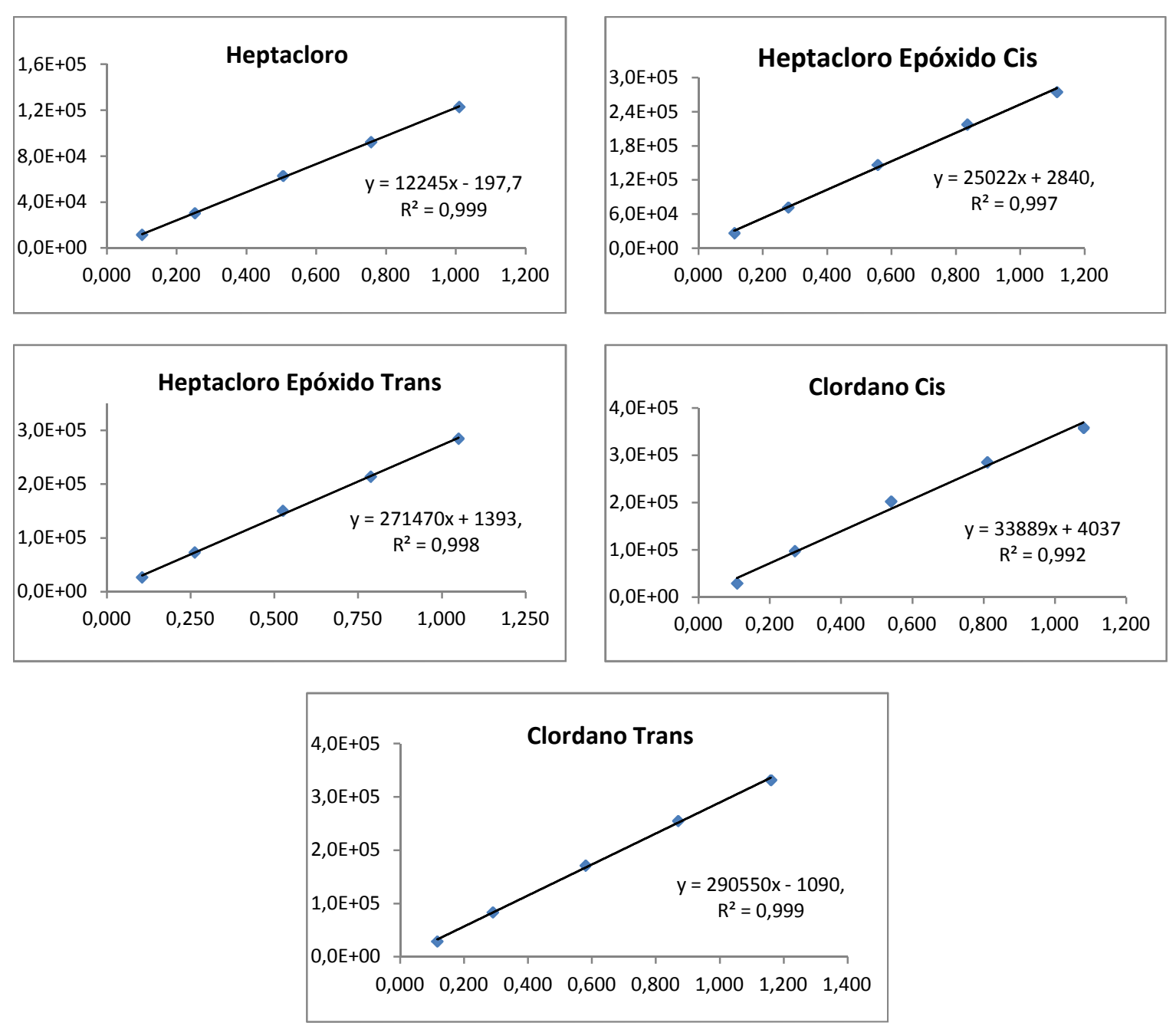

Figura 35. Representação gráfica da linearidade para todos os compostos estudados em matriz de Caieiras.

Tabela 18. Faixa de trabalho para cada composto, equação da reta e coeficiente de determinação (r2) obtidos pela adição padrão na matriz de Franco da Rocha.

\begin{tabular}{cccc}
\hline \multicolumn{5}{c}{ Adição em Matriz Franco da Rocha } \\
\hline Composto & Intervalo Linear $\left(\boldsymbol{\mu g} \cdot \mathbf{m L}^{-1}\right)$ & Equação da Reta & $\mathbf{r}^{2}$ \\
\hline$\alpha-B H C$ & $0,101-1,010$ & $y=185647 x-4813,9$ & 0,996 \\
$\beta-B H C$ & $0,103-1,030$ & $y=35554 x+874,03$ & 0,997 \\
Y-BHC & $0,102-1,020$ & $y=252763 x+3265,8$ & 0,995 \\
$\delta$-BHC & $0,100-1,000$ & $y=230201 x-4067$ & 0,995 \\
Heptacloro & $0,101-1,010$ & $y=193815 x-839,56$ & 0,998 \\
Hept. Epóxido Cis & $0,111-1,114$ & $y=319563 x+3990,6$ & 0,994 \\
Hept. Epóxido Trans & $0,105-1,050$ & $y=369190 x+1021$ & 0,991 \\
Clordano Cis & $0,108-1,080$ & $y=402186 x+5373,2$ & 0,990 \\
Clordano Trans & $0,116-1,160$ & $y=322090 x-2608$ & 0,995 \\
\hline
\end{tabular}



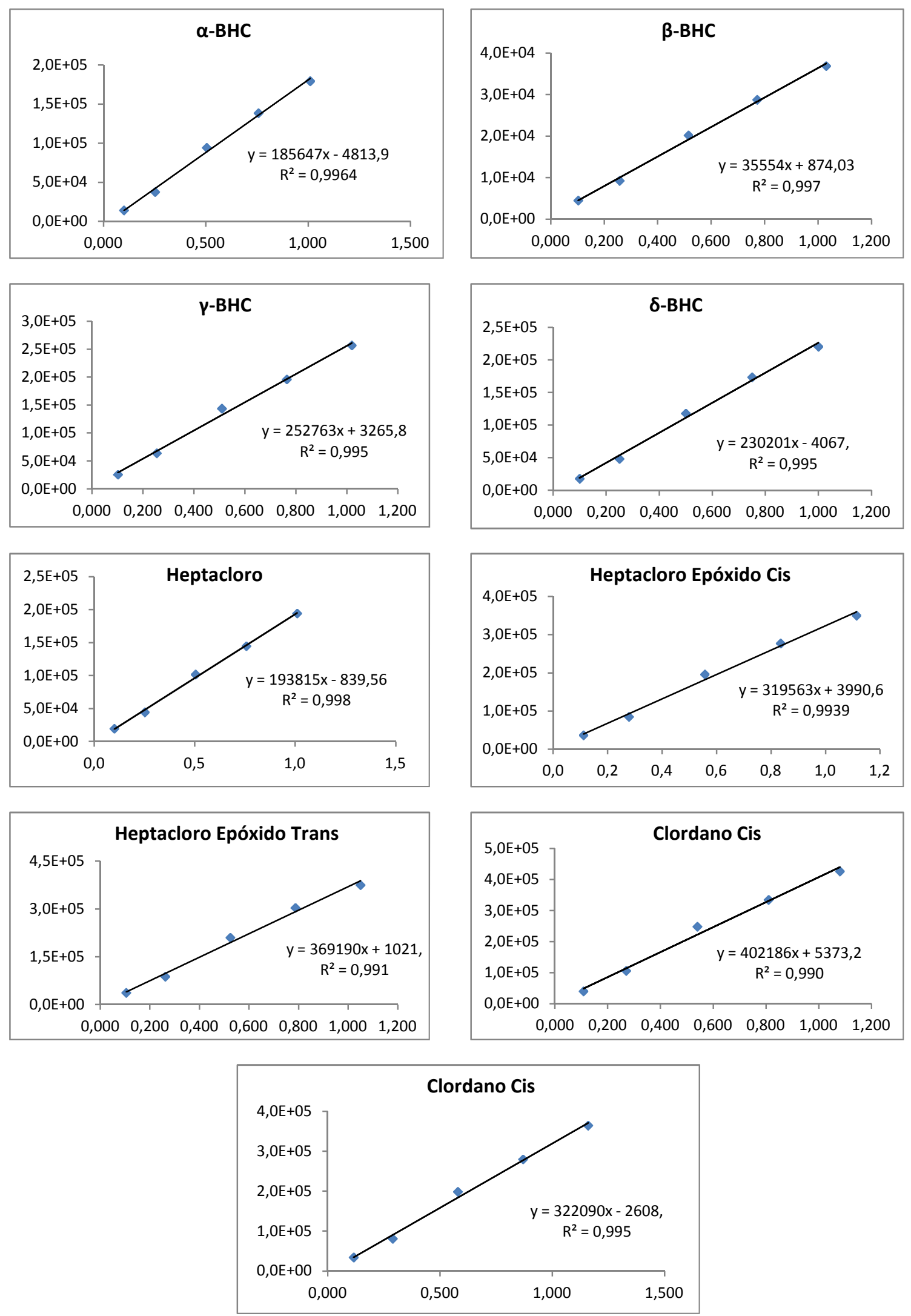

Figura 36. Representação gráfica da linearidade para todos os compostos, em matriz de Franco da Rocha. 
Tabela 19. Faixa de trabalho para cada composto, equação da reta e coeficiente de determinação (r2) obtidos pela adição padrão em solvente (ACN).

\begin{tabular}{|c|c|c|c|}
\hline \multicolumn{4}{|c|}{ Adição em solvente (ACN) } \\
\hline Composto & Intervalo Linear $\left(\mu \mathrm{g} \cdot \mathrm{mL}^{-1}\right)$ & Equação da Reta & $r^{2}$ \\
\hline$\alpha-B H C$ & $0,101-1,010$ & $y=3,72 E+05 x+9,86 E+03$ & 0,998 \\
\hline$\beta-\mathrm{BHC}$ & $0,103-1,030$ & $y=91966 x-656,33$ & 0,999 \\
\hline $\mathrm{y}-\mathrm{BHC}$ & $0,102-1,020$ & $y=35554 x+874,03$ & 0,997 \\
\hline$\delta-\mathrm{BHC}$ & $0,100-1,000$ & $y=278039 x+10590$ & 0,997 \\
\hline Heptacloro & $0,101-1,010$ & $y=129344 x-1946$ & 0,999 \\
\hline Hept. Epóxido Cis & $0,111-1,114$ & $y=312320 x-6795,2$ & 0,998 \\
\hline Hept. Epóxido Trans & $0,105-1,050$ & $y=232739 x-2407$ & 0,998 \\
\hline Clordano Cis & $0,108-1,080$ & $y=286709 x+1111,2$ & 0,999 \\
\hline Clordano Trans & $0,116-1,160$ & $y=260109 x-2265$ & 0,997 \\
\hline
\end{tabular}
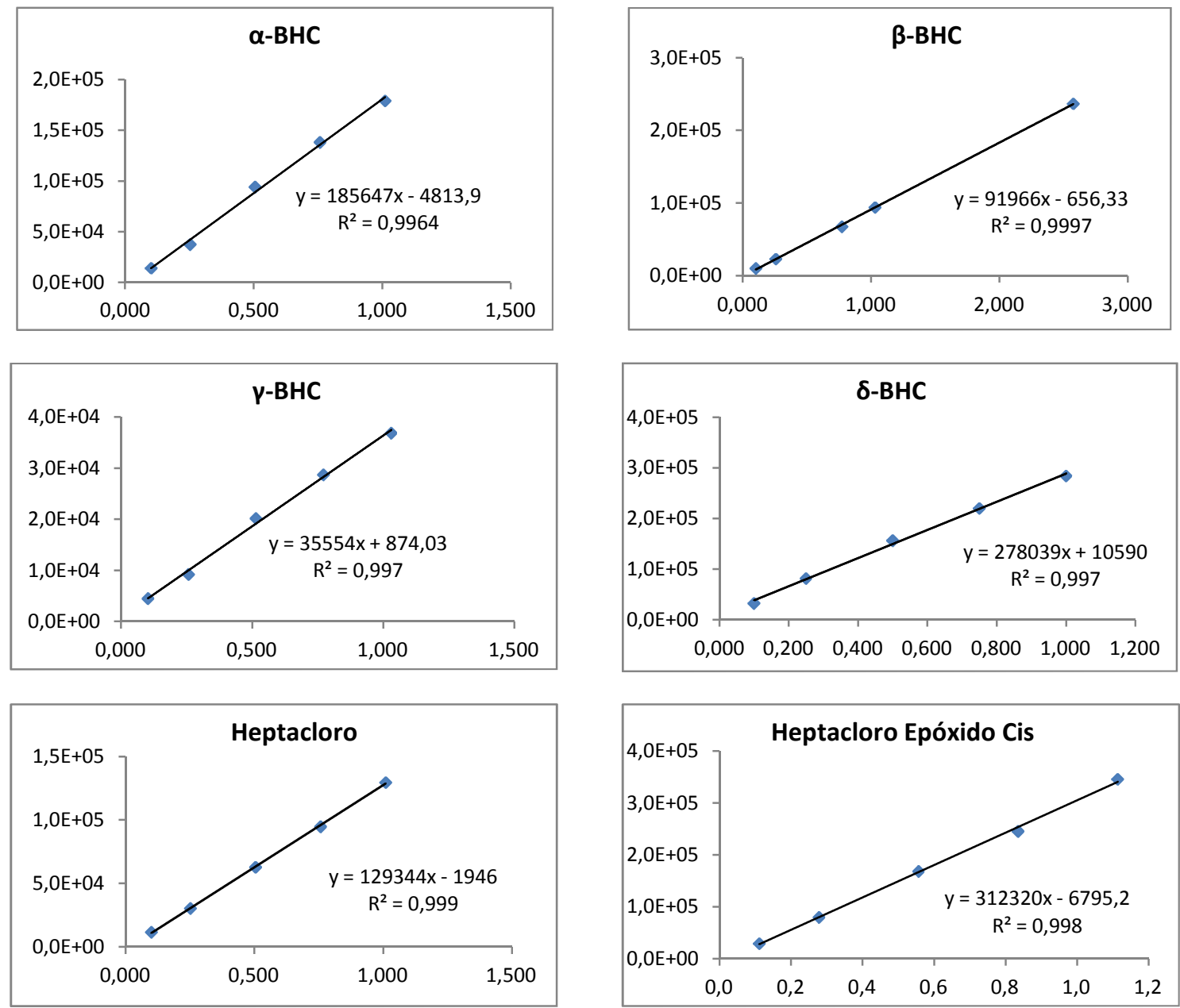

Figura 37. Representação gráfica da linearidade para os compostos $\alpha-B H C, \beta-B H C, \gamma-$ $\mathrm{BHC}, \delta-\mathrm{BHC}$, heptacloro e Heptacloro epóxido cis em matriz de Franco da Rocha. 

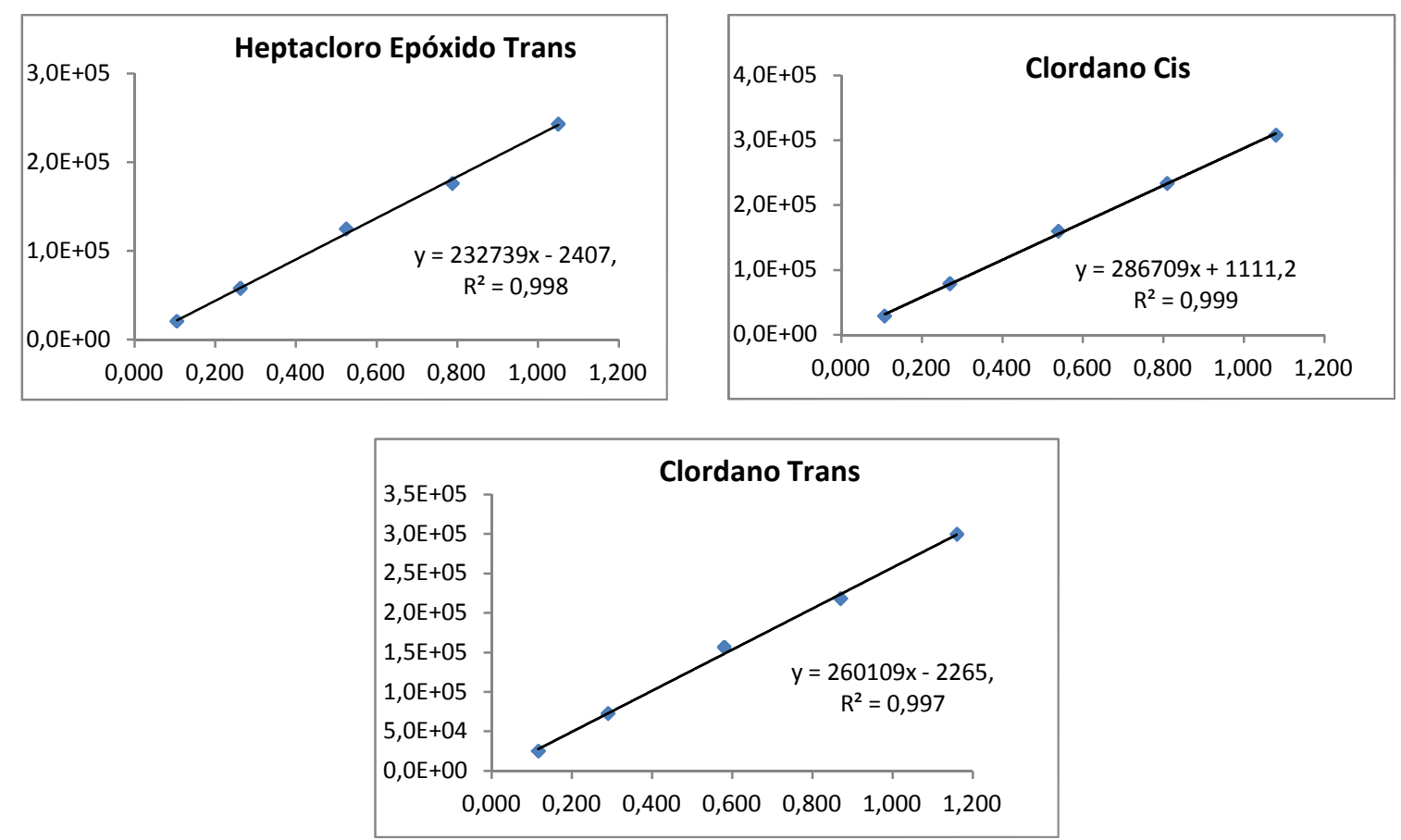

Figura 38. Representação gráfica da linearidade para os compostos Heptacloro Epóxido Trans e Clordano Cis / Trans estudados em solvente (ACN).

As retas obtidas nas faixas de concentração avaliadas demonstraram-se lineares, com coeficientes de determinação acima de 0,99 em ambas as matrizes, como pode ser observado nas Tabelas 17 e 19 e nas Figuras 37 a 39.

A análise de resíduo (diferença entre o valor medido e o valor calculado) foi realizada pelo teste t de Student, no qual os valores de $t$ calculado acima do valor crítico $\mathrm{t}_{(8,95 \%)}=2,365$ indicam que o ponto não pode ser considerado como pertencente à reta de regressão. Os resultados obtidos para t calculado nos ensaios com e sem matriz são apresentados nas Tabelas 20 a 24.

Tabela 20. Valores de $t_{\text {calculado }}$ obtidos pelo teste $t$ Student para a verificação do desvio da linearidade de cada ponto da curva para os nove compostos estudados na matriz de Caieiras, onde o valor de $t_{\text {tabelado }}=2,365$, considerando 7 graus de liberdade $(n-1)$ e $95 \%$ de confiança.

\begin{tabular}{rccccccccc}
\hline \multirow{2}{*}{$-\mathrm{BHC}$} & $\boldsymbol{\mu g} \cdot \mathrm{mL}^{-1}$ & $\mathbf{0 , 1 0 1}$ & $\mathbf{0 , 2 5 3}$ & $\mathbf{0 , 5 0 5}$ & $\mathbf{0 , 7 5 8}$ & $\mathbf{1 , 0 1 0}$ & $\mathbf{2 , 5 2 5}$ & 5,050 & $\mathbf{7 , 5 7 5}$ \\
\cline { 2 - 9 } & $\mathbf{t}_{\text {calc }}$ & $\mathbf{2 , 5 8 5}$ & $\mathbf{2 , 3 7 4}$ & $\mathbf{0 , 5 1 8}$ & $\mathbf{1 , 0 7 5}$ & $\mathbf{0 , 1 7 1}$ & $\mathbf{5 , 2 2 2}$ & $\mathbf{2 , 1 9 3}$ & $\mathbf{3 , 1 8 5}$ \\
\hline \multirow{2}{*}{$\boldsymbol{\beta}-$-BHC } & $\boldsymbol{\mu g} \cdot \mathbf{m L}^{-1}$ & 0,103 & 0,258 & 0,515 & 0,773 & 1,030 & 2,575 & 5,150 & 7,725 \\
\cline { 2 - 9 } & $\mathbf{t}_{\text {calc }}$ & $\mathbf{2 , 9 6 0}$ & $\mathbf{2 , 8 0 5}$ & $\mathbf{0 , 5 5 8}$ & $\mathbf{3 , 2 2 4}$ & $\mathbf{0 , 3 8 5}$ & $\mathbf{5 , 0 6 6}$ & $\mathbf{1 , 3 8 3}$ & $\mathbf{0 , 9 7 0}$ \\
\hline
\end{tabular}

... Continuação Tabela 20. 


\begin{tabular}{|c|c|c|c|c|c|c|c|c|c|}
\hline \multirow[b]{2}{*}{$\mathrm{Y}-\mathrm{BHC}$} & $\mu \mathrm{g} \cdot \mathrm{mL}^{-1}$ & 0,102 & 0,255 & 0,510 & 0,765 & 1,020 & 2,550 & 5,100 & 7,650 \\
\hline & $t_{\text {calc }}$ & 3,383 & 2,043 & 0,375 & 1,583 & 0,460 & 4,460 & 2,597 & 3,299 \\
\hline \multirow{2}{*}{$\delta-\mathrm{BHC}$} & $\mu \mathrm{g} \cdot \mathrm{mL}^{-1}$ & 0,100 & 0,250 & 0,500 & 0,750 & 1,000 & 2,500 & 5,000 & 7,5 \\
\hline & $t_{\text {calc }}$ & 3,304 & 2,391 & 0,342 & 1,350 & 0,864 & 5,416 & 0,947 & 2,541 \\
\hline \multirow{2}{*}{ Heptacloro } & $\mu \mathrm{g} \cdot \mathrm{mL}^{-1}$ & 0,101 & 0,253 & 0,505 & 0,758 & 1,010 & 2,525 & 5,050 & 7,575 \\
\hline & $t_{\text {calc }}$ & 3,471 & 2,273 & 0,244 & 1,376 & 1,150 & 4,000 & 2,842 & 3,381 \\
\hline \multirow{2}{*}{$\begin{array}{l}\text { Hept. Epóx } \\
\text { Cis }\end{array}$} & $\mu \mathrm{g} \cdot \mathrm{mL}^{-1}$ & 0,111 & 0,278 & 0,557 & 0,835 & 1,114 & 2,784 & 5,568 & 8,352 \\
\hline & $t_{\text {calc }}$ & 3,185 & 1,979 & 0,465 & 0,811 & 0,829 & 4,824 & 2,478 & 3,312 \\
\hline \multirow{2}{*}{$\begin{array}{c}\text { Hept. Epóx } \\
\text { Trans }\end{array}$} & $\mu \mathrm{g} \cdot \mathrm{mL}^{-1}$ & 0,105 & 0,263 & 0,525 & 0,788 & 1,050 & 2,626 & 5,251 & 7,877 \\
\hline & $t_{\text {calc }}$ & 3,092 & 1,946 & 0,469 & 0,778 & 0,693 & 4,780 & 2,646 & 3,390 \\
\hline \multirow{2}{*}{$\begin{array}{l}\text { Clordano } \\
\text { Cis }\end{array}$} & $\mu \mathrm{g} \cdot \mathrm{mL}^{-1}$ & 0,108 & 0,270 & 0,540 & 0,810 & 1,080 & 2,700 & 5,400 & 8,100 \\
\hline & $t_{\text {calc }}$ & 3,015 & 1,682 & 0,080 & 0,846 & 0,133 & 3,797 & 3,804 & 3,802 \\
\hline \multirow{2}{*}{$\begin{array}{c}\text { Clordano } \\
\text { Trans }\end{array}$} & $\mu \mathrm{g} \cdot \mathrm{mL}^{-1}$ & 0,116 & 0,290 & 0,580 & 0,870 & 1,160 & 2,900 & 5,799 & 8,699 \\
\hline & $t_{\text {calc }}$ & 2,771 & 1,808 & 0,393 & 0,572 & 0,336 & 4,351 & 3,426 & 3,713 \\
\hline
\end{tabular}

Tabela 21. Valores de $t_{\text {calculado }}$ obtidos pelo teste t Student para a verificação do desvio da linearidade de cada ponto da curva para os nove compostos estudados na matriz de Franco da Rocha, onde o valor de $t_{\text {tabelado }}=2,365$, considerando 7 graus de liberdade $(n-1)$ e $95 \%$ de confiança.

\begin{tabular}{|c|c|c|c|c|c|c|c|c|c|}
\hline \multirow{2}{*}{$\alpha-B H C$} & $\mu \mathrm{g} \cdot \mathrm{mL}^{-1}$ & 0,101 & 0,2525 & 0,505 & 0,7575 & 1,01 & 2,525 & 5,05 & 10,1 \\
\hline & $t_{\text {calc }}$ & 2,887 & 2,780 & 0,149 & 0,723 & 0,551 & 6,065 & 0,004 & 1,518 \\
\hline \multirow{2}{*}{$\beta$-BHC } & $\mu \mathrm{g} \cdot \mathrm{mL}^{-1}$ & 0,103 & 0,2575 & 0,515 & 0,7725 & 1,03 & 2,575 & 5,15 & 7,725 \\
\hline & $t_{\text {calc }}$ & 1,883 & 2,350 & 0,304 & 0,441 & 0,369 & 6,527 & 1,747 & 0,923 \\
\hline \multirow{2}{*}{ Y-BHC } & $\mu \mathrm{g} \cdot \mathrm{mL}^{-1}$ & 0,102 & 0,255 & 0,510 & 0,765 & 1,020 & 2,550 & 5,100 & 10,200 \\
\hline & $t_{\text {calc }}$ & 3,148 & 2,692 & 0,014 & 0,430 & 0,694 & 5,896 & 0,566 & 1,761 \\
\hline \multirow{2}{*}{ ठ-BHC } & $\mu \mathrm{g} \cdot \mathrm{mL}^{-1}$ & 0,100 & 0,250 & 0,500 & 0,750 & 1,000 & 2,500 & 5,000 & 7,500 \\
\hline & $t_{\text {calc }}$ & 2,708 & 2,563 & 0,415 & 0,628 & 0,552 & 6,173 & 1,193 & 1,305 \\
\hline \multirow{2}{*}{ Heptacloro } & $\mu \mathrm{g} \cdot \mathrm{mL}^{-1}$ & 0,101 & 0,253 & 0,505 & 0,758 & 1,010 & 2,525 & 5,050 & 7,575 \\
\hline & $t_{\text {calc }}$ & 2,837 & 2,507 & 0,092 & 0,484 & 1,009 & 6,104 & 0,727 & 1,618 \\
\hline \multirow{2}{*}{$\begin{array}{l}\text { Hept. Epóx } \\
\text { Cis }\end{array}$} & $\mu \mathrm{g} \cdot \mathrm{mL}^{-1}$ & 0,111 & 0,278 & 0,557 & 0,835 & 1,114 & 2,784 & 5,568 & 8,352 \\
\hline & $t_{\text {calc }}$ & 3,088 & 2,602 & 0,021 & 0,966 & 0,891 & 5,730 & 0,359 & 2,236 \\
\hline
\end{tabular}


... Continuação Tabela 21.

\begin{tabular}{cccccccccc}
\hline $\begin{array}{c}\text { Hept. Epóx } \\
\text { Trans }\end{array}$ & $\boldsymbol{\mu g} \cdot \mathrm{mL}^{-1}$ & 0,105 & 0,263 & 0,525 & 0,788 & 1,050 & 2,626 & 5,251 & $\mathbf{7 , 8 7 7}$ \\
\cline { 2 - 9 } & $\mathbf{t}_{\text {calc }}$ & $\mathbf{3 , 0 3 2}$ & $\mathbf{2 , 5 7 6}$ & $\mathbf{0 , 0 1 3}$ & $\mathbf{0 , 9 2 9}$ & $\mathbf{0 , 7 7 6}$ & $\mathbf{5 , 8 2 9}$ & $\mathbf{0 , 2 2 5}$ & $\mathbf{2 , 1 6 4}$ \\
\hline $\begin{array}{c}\text { Clordano } \\
\text { Cis }\end{array}$ & $\boldsymbol{\mu g} \cdot \mathrm{mL}^{-1}$ & 0,108 & 0,270 & 0,540 & 0,810 & 1,080 & 2,700 & 5,400 & 8,100 \\
\cline { 2 - 9 } & $\mathbf{t}_{\text {calc }}$ & $\mathbf{3 , 1 3 8}$ & $\mathbf{2 , 5 8 5}$ & $\mathbf{0 , 2 4 0}$ & $\mathbf{1 , 1 2 3}$ & $\mathbf{0 , 4 9 2}$ & $\mathbf{5 , 7 4 7}$ & $\mathbf{0 , 3 0 9}$ & $\mathbf{2 , 1 8 8}$ \\
\hline $\begin{array}{c}\text { Clordano } \\
\text { Trans }\end{array}$ & $\mathbf{\mu g} \cdot \mathrm{mL}^{-1}$ & 0,116 & 0,290 & 0,580 & 0,870 & 1,160 & 2,900 & 5,799 & 8,699 \\
\cline { 2 - 9 } & $\mathbf{t}_{\text {calc }}$ & $\mathbf{2 , 8 2 4}$ & $\mathbf{2 , 6 6 3}$ & $\mathbf{0 , 0 8 8}$ & $\mathbf{0 , 9 3 5}$ & $\mathbf{0 , 5 7 6}$ & $\mathbf{5 , 9 9 7}$ & $\mathbf{0 , 1 7 8}$ & $\mathbf{1 , 9 3 0}$ \\
\hline
\end{tabular}

Tabela 22. Valores de $t_{\text {calculado }}$ obtidos pelo teste $t$ Student para a verificação do desvio da linearidade de cada ponto da curva para os nove compostos estudados na em solvente $(A C N)$, onde $o$ valor de $t_{\text {tabelado }}=2,365$, considerando 7 graus de liberdade $(n-1)$ e $95 \%$ de confiança.

\begin{tabular}{|c|c|c|c|c|c|c|c|c|c|}
\hline \multirow{2}{*}{$\alpha-B H C$} & $\mu \mathrm{g} \cdot \mathrm{mL}^{-1}$ & 0,101 & 0,253 & 0,505 & 0,758 & 1,010 & 2,525 & 5,050 & 10,100 \\
\hline & $t_{\text {calc }}$ & 2,232 & 1,66 & 0,706 & 0,604 & 0,135 & 2,709 & 5,81 & 3,451 \\
\hline \multirow{2}{*}{$\beta-B H C$} & $\mu \mathrm{g} \cdot \mathrm{mL}^{-1}$ & 0,103 & 0,258 & 0,515 & 0,773 & 1,030 & 2,575 & 5,150 & 7,725 \\
\hline & $t_{\text {calc }}$ & 1,622 & 1,087 & 1,231 & 0,040 & 0,332 & 3,191 & 5,992 & 4,870 \\
\hline \multirow{2}{*}{$\mathrm{V}-\mathrm{BHC}$} & $\mu \mathrm{g} \cdot \mathrm{mL}^{-1}$ & 0,102 & 0,255 & 0,510 & 0,765 & 1,020 & 2,550 & 5,100 & 10,200 \\
\hline & $t_{\text {calc }}$ & 1,984 & 1,658 & 0,512 & 0,707 & 0,111 & 2,406 & 6,032 & 3,466 \\
\hline \multirow{2}{*}{ ठ-BHC } & $\mu \mathrm{g} \cdot \mathrm{mL}^{-1}$ & 0,100 & 0,250 & 0,500 & 0,750 & 1,000 & 2,500 & 5,000 & 7,500 \\
\hline & $t_{\text {calc }}$ & 0,797 & 1,192 & 1,357 & 0,082 & 0,112 & 1,415 & 6,718 & 4,816 \\
\hline \multirow{2}{*}{ Heptacloro } & $\mu \mathrm{g} \cdot \mathrm{mL}^{-1}$ & 0,101 & 0,253 & 0,505 & 0,758 & 1,010 & 2,525 & 5,050 & 7,575 \\
\hline & $t_{\text {calc }}$ & 1,728 & 1,356 & 1,074 & 0,034 & 0,457 & 2,206 & 6,364 & 4,902 \\
\hline \multirow{2}{*}{$\begin{array}{l}\text { Hept. Epóx } \\
\text { Cis }\end{array}$} & $\mu \mathrm{g} \cdot \mathrm{mL}^{-1}$ & 0,111 & 0,278 & 0,557 & 0,835 & 1,114 & 2,784 & 5,568 & 8,352 \\
\hline & $t_{\text {calc }}$ & 0,593 & 0,101 & 1,917 & 0,367 & 1,099 & 0,532 & 6,693 & 4,333 \\
\hline \multirow{2}{*}{$\begin{array}{l}\text { Hept. Epóx } \\
\text { Trans }\end{array}$} & $\mu \mathrm{g} \cdot \mathrm{mL}^{-1}$ & 0,105 & 0,263 & 0,525 & 0,788 & 1,050 & 2,626 & 5,251 & 7,877 \\
\hline & $t_{\text {calc }}$ & 0,998 & 0,966 & 1,691 & 0,259 & 0,235 & 1,929 & 6,543 & 4,841 \\
\hline \multirow{2}{*}{$\begin{array}{c}\text { Clordano } \\
\text { Cis }\end{array}$} & $\mu \mathrm{g} \cdot \mathrm{mL}^{-1}$ & 0,108 & 0,270 & 0,540 & 0,810 & 1,080 & 2,700 & 5,400 & 8,100 \\
\hline & $t_{\text {calc }}$ & 1,183 & 1,156 & 1,705 & 0,184 & 0,109 & 2,230 & 6,390 & 4,869 \\
\hline
\end{tabular}




\begin{tabular}{cccccccccc}
\hline \multirow{2}{*}{$\begin{array}{c}\text { Clordano } \\
\text { Trans }\end{array}$} & $\boldsymbol{\mu g} \cdot \mathrm{mL}^{-1}$ & 0,116 & 0,290 & 0,580 & 0,870 & 1,160 & 2,900 & 5,799 & 8,699 \\
\cline { 2 - 8 } & $\mathbf{t}_{\text {calc }}$ & $\mathbf{1 , 8 8 2}$ & $\mathbf{1 , 4 8 8}$ & $\mathbf{1 , 3 2 4}$ & $\mathbf{0 , 1 7 2}$ & $\mathbf{0 , 4 0 1}$ & $\mathbf{3 , 1 2 9}$ & $\mathbf{5 , 8 2 5}$ & $\mathbf{4 , 8 3 4}$ \\
\hline
\end{tabular}

A partir dos resultados apresentados nas Tabelas 20 a 22 é possível constatar que vários pontos estão acima do valor crítico 2,365, concluindo-se então, que os mesmos não poderiam ser considerados como pertencentes à reta de regressão da curva analítica.

A matriz de Caieiras apresentou valores superiores ao $t_{\text {tabelado, tanto para os }}$ pontos mais baixos, quanto para os pontos mais altos da curva, enquanto a matriz de Franco da Rocha apresentou valores superiores ao $t_{\text {tabelado }}$ predominantemente para os pontos mais baixos da curva. O mesmo foi observado nos resultados obtidos para o ensaio sem matriz. Entretanto, avaliando-se cada resultado individualmente, observa-se que alguns estão muito próximos do valor tabelado, sendo possível considerar que estes dados podem ser utilizados para quantificação dos analitos. Além disso, ao confrontar estes resultados com os obtidos para os coeficientes de determinação $\left(r^{2}\right)$ de cada composto em estudo, conclui-se que é possível realizar-se a quantificação, uma vez que todos os compostos, nas duas matrizes, apresentaram $r^{2}>0,99$, valor este acima do recomendado pelo INMETRO (2010).

A linearidade foi também avaliada pelos gráficos de resíduos. Nas Figuras 40 a 45 são apresentados os gráficos de distribuição espacial dos resíduos absolutos em função das concentrações e a distribuição dos resíduos em função da probabilidade normalizada nos ensaios com as amostras de Caieiras, Franco da Rocha e somente em ACN, respectivamente. 
(a)
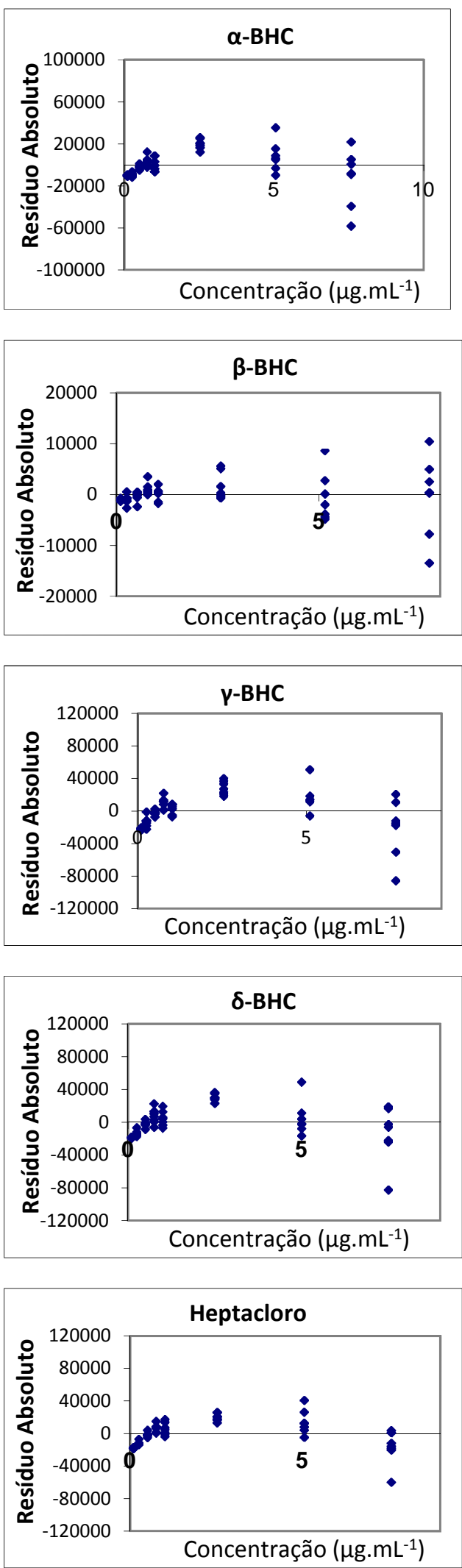

(b)
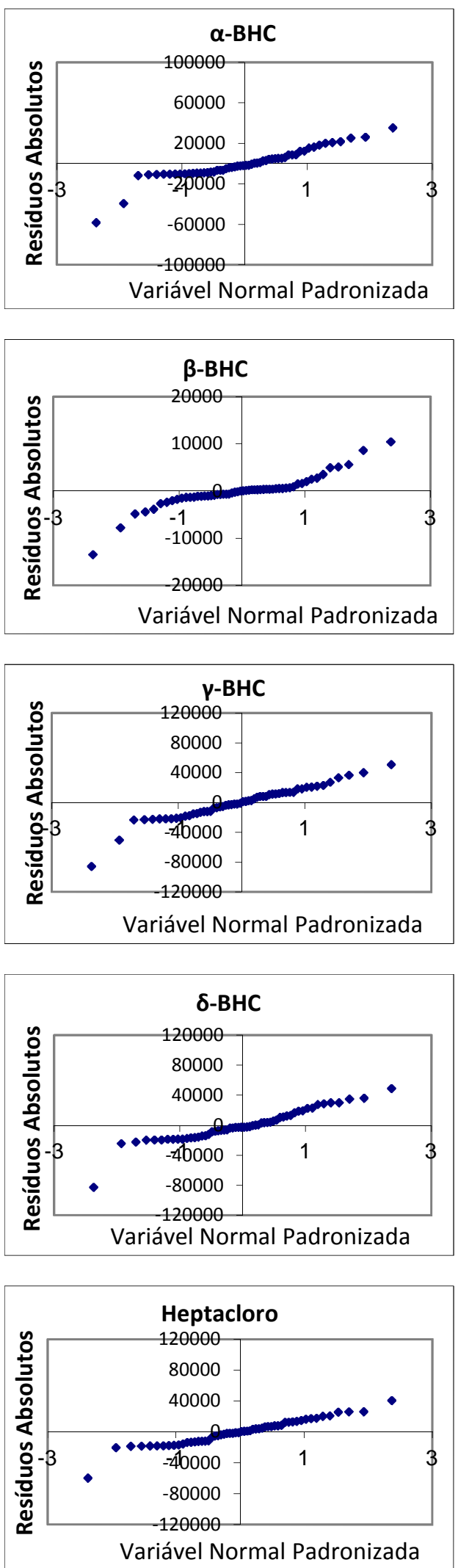

Figura 39. Gráficos dos resíduos absolutos (a) e normalizados (b) para os compostos $\mathrm{BHC} \alpha-, \beta-, \gamma^{-}, \delta-\mathrm{e}$ heptacloro no ensaio com matriz de Caieiras. 
(a)
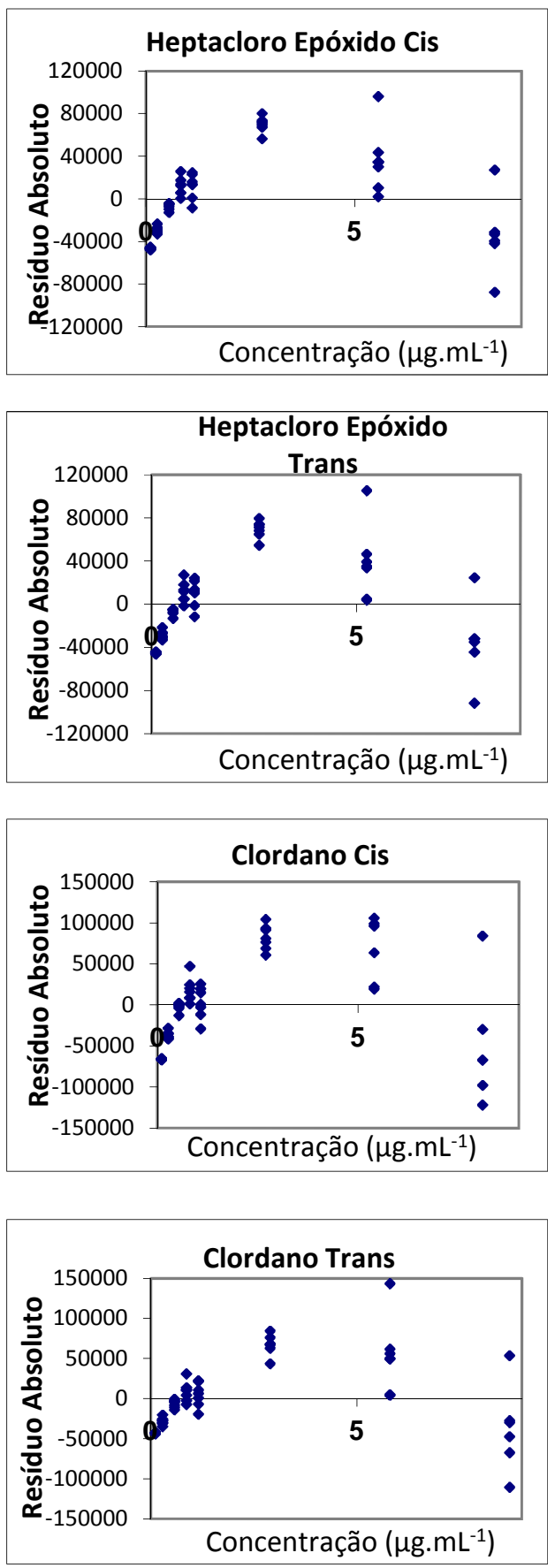

(b)
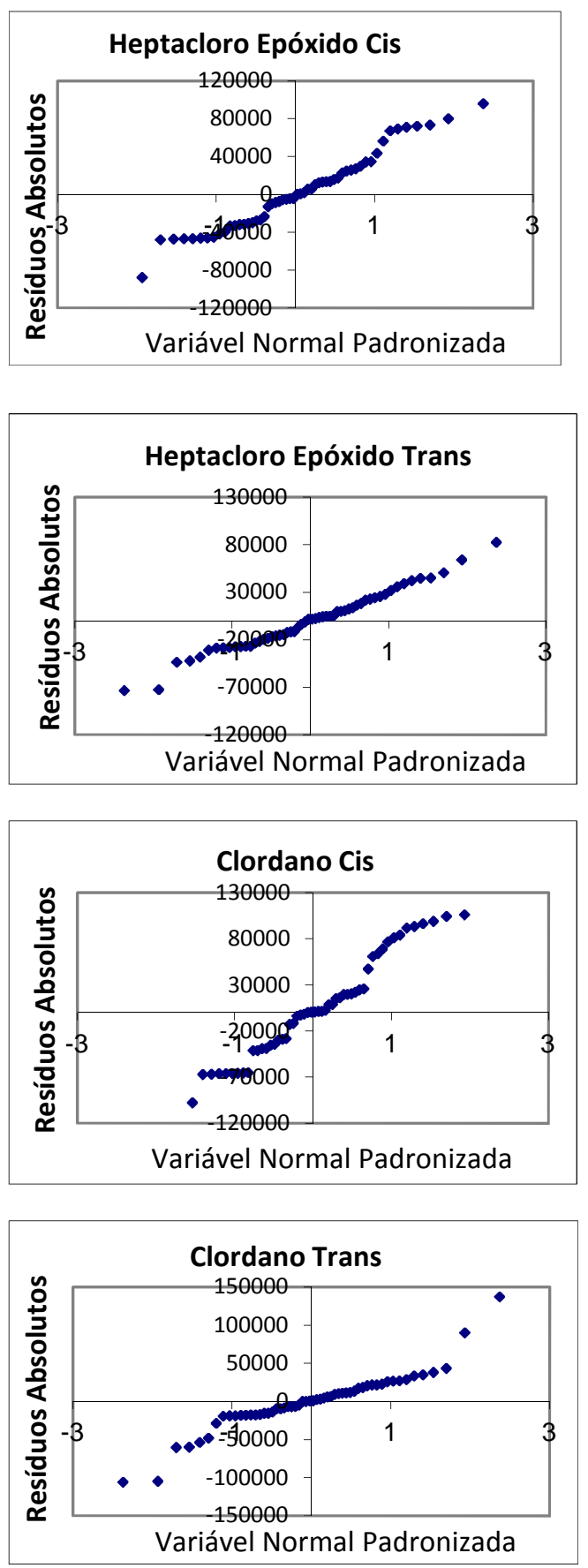

Figura 40. Gráficos dos resíduos absolutos (a) e normalizados (b) para o Heptacloro Epóxido Cis/Trans e Clordano Cis/Trans no ensaio com matriz de Caieiras. 
(a)
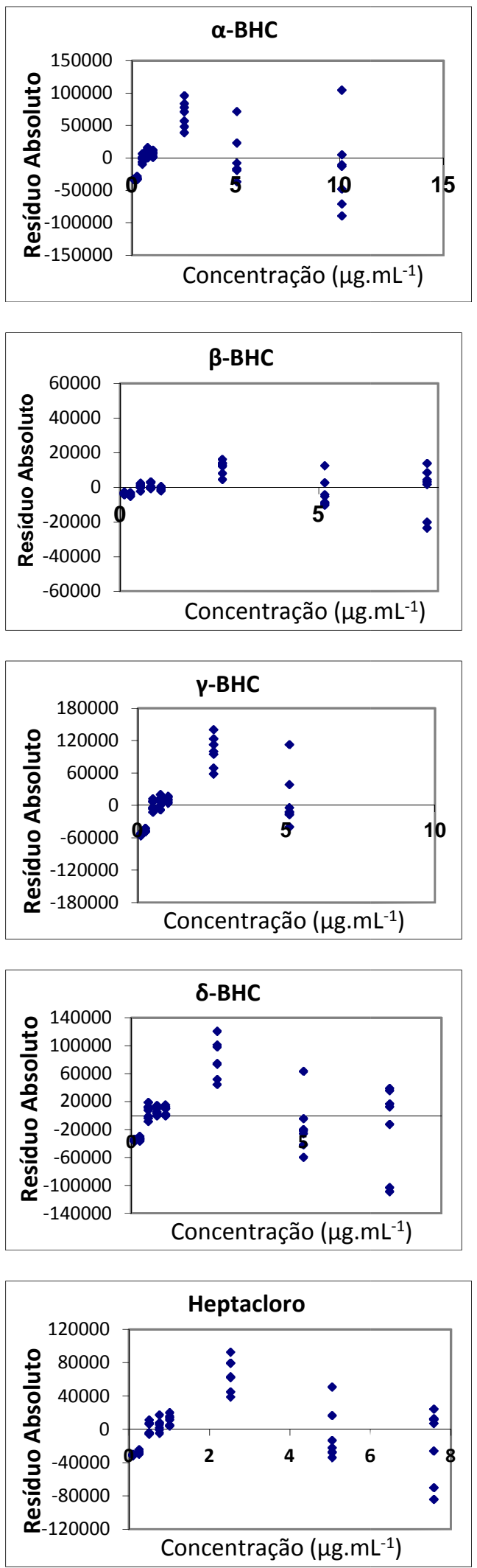

(b)
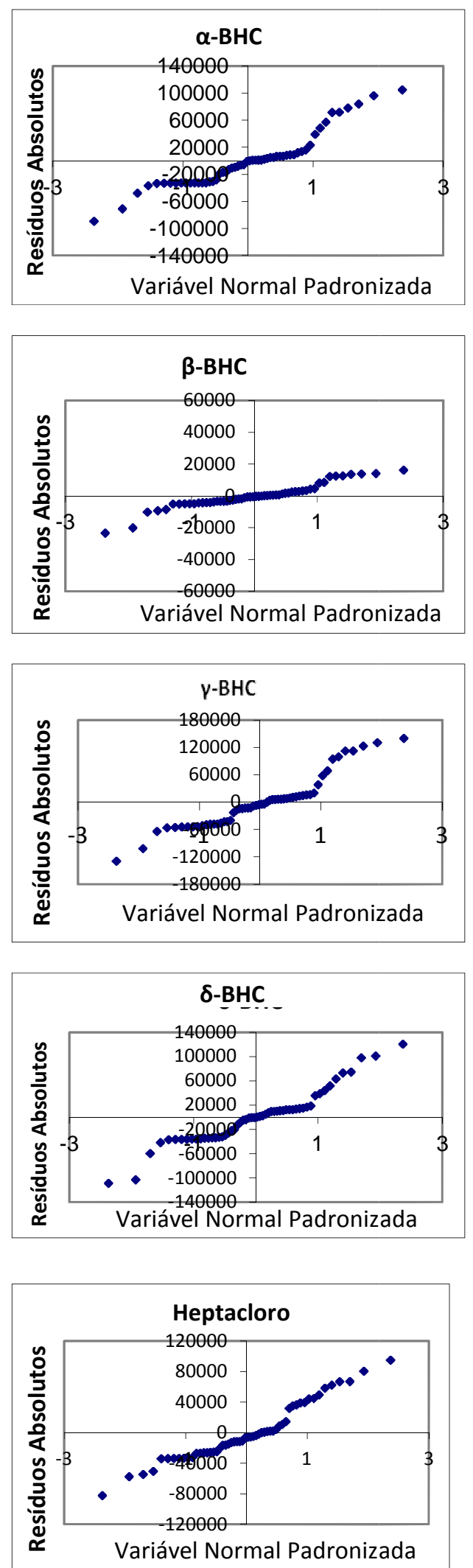

Figura 41. Gráficos dos resíduos absolutos (a) e normalizados (b) para os compostos BHC $\alpha$-, $\beta$ - e $\gamma$ - e $\delta$ - e Heptacloro ensaio com matriz de Franco da Rocha. 
(a)
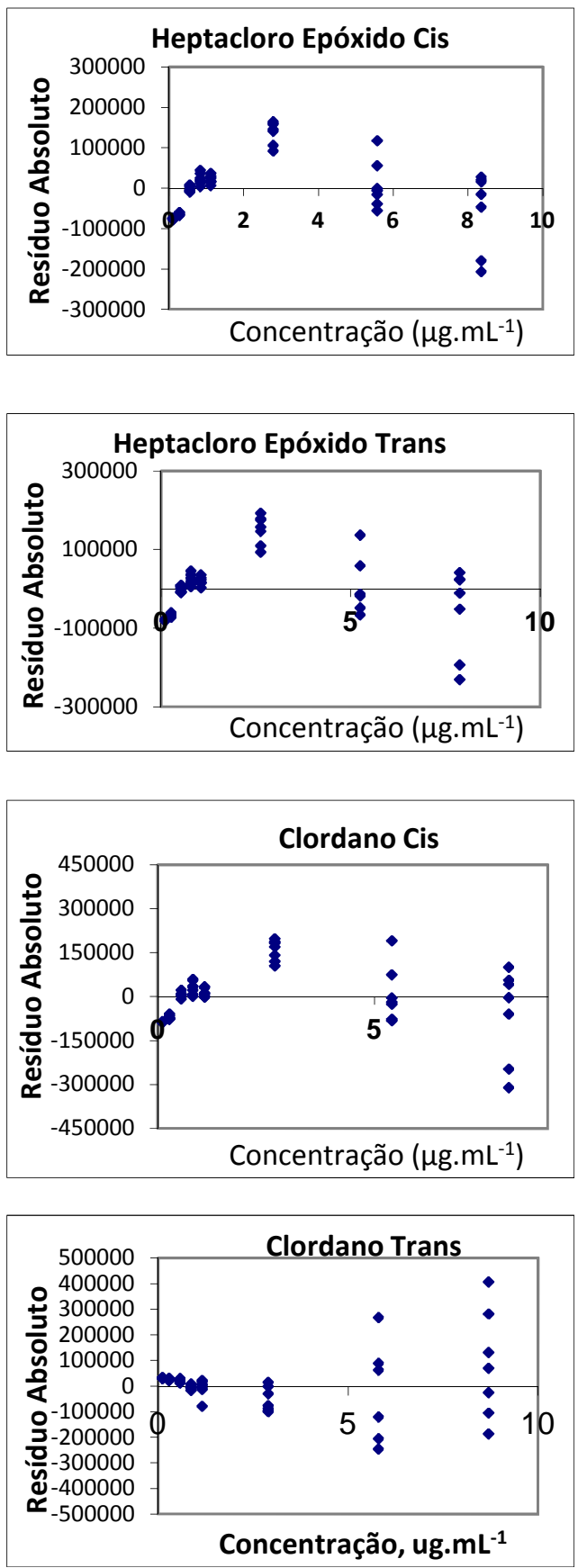

(b)
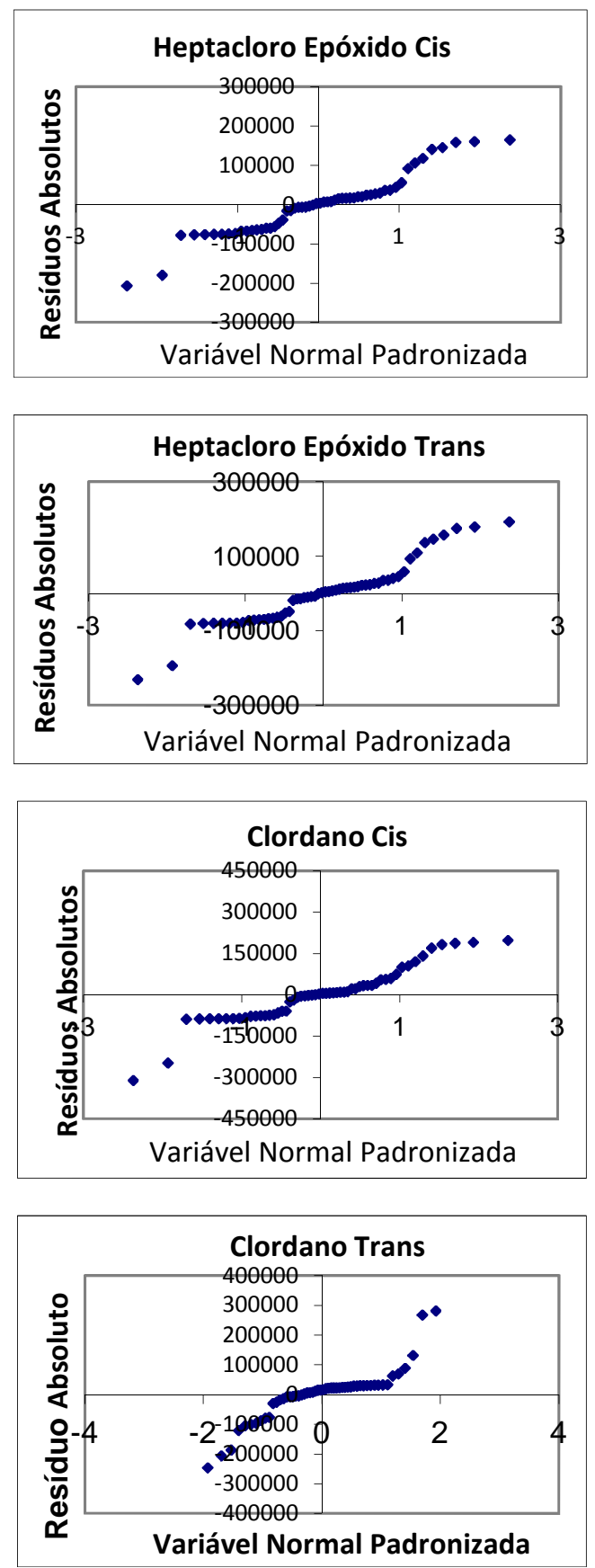

Figura 42. Gráficos dos resíduos absolutos (a) e normalizados (b) para o composto Heptacloro Epóxido Cis / Trans e Clordano Cis/ Trans no ensaio com matriz de Franco da Rocha. 
(a)
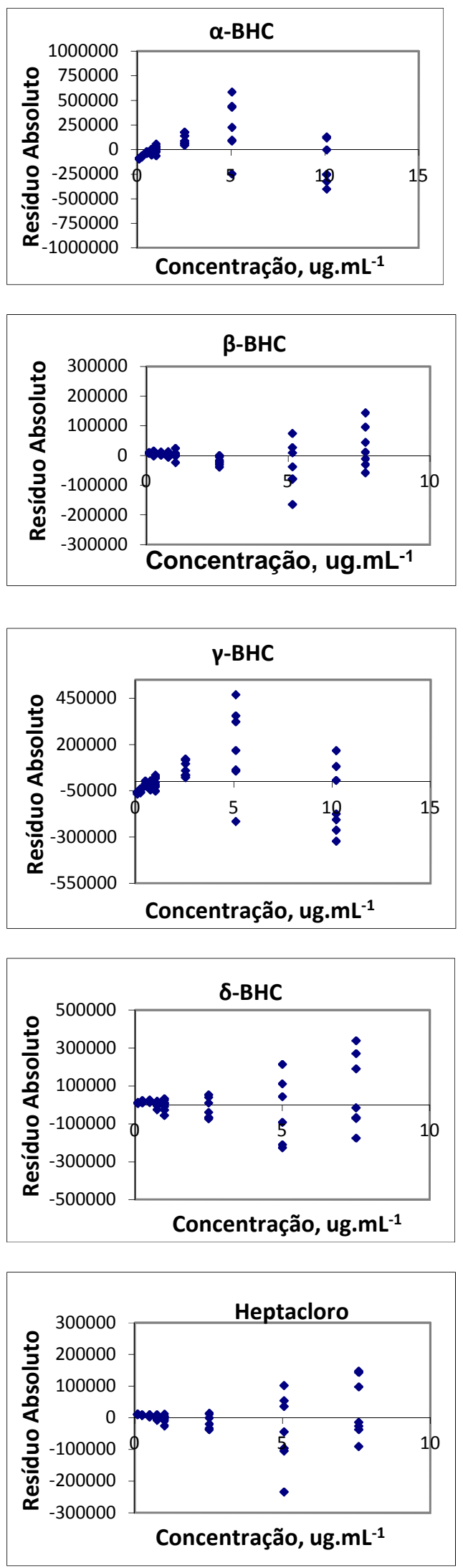

(b)
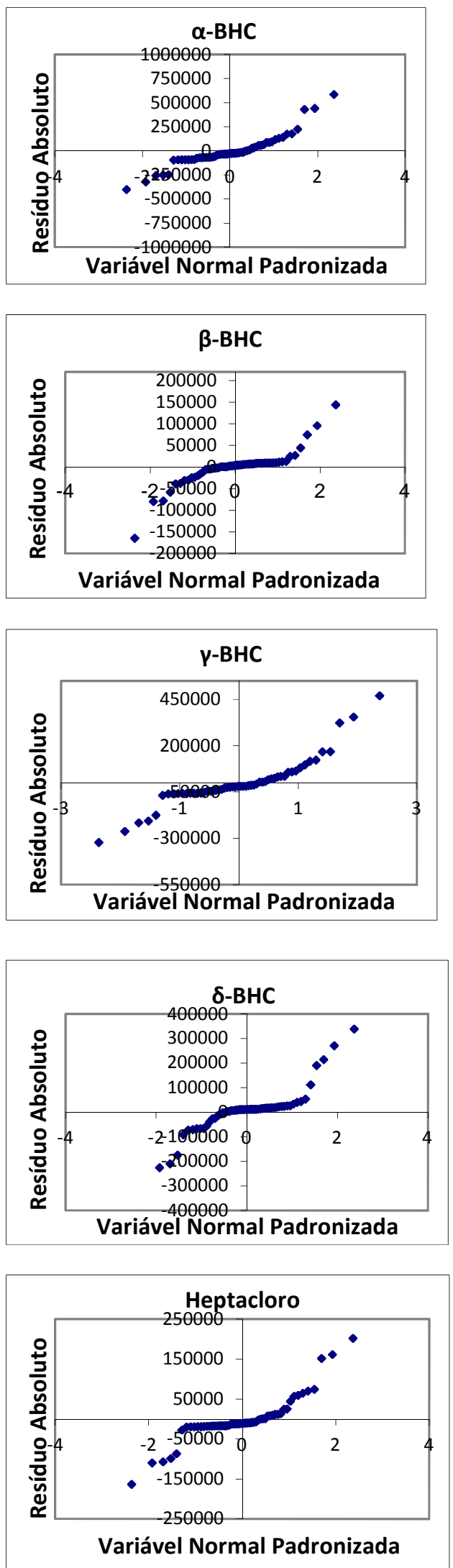

Figura 43. Gráficos dos resíduos absolutos (a) e normalizados (b) para os compostos BHC $\alpha-, \beta-, \gamma^{-}, \delta$ e Heptacloro no ensaio com solvente (ACN). 
(a)
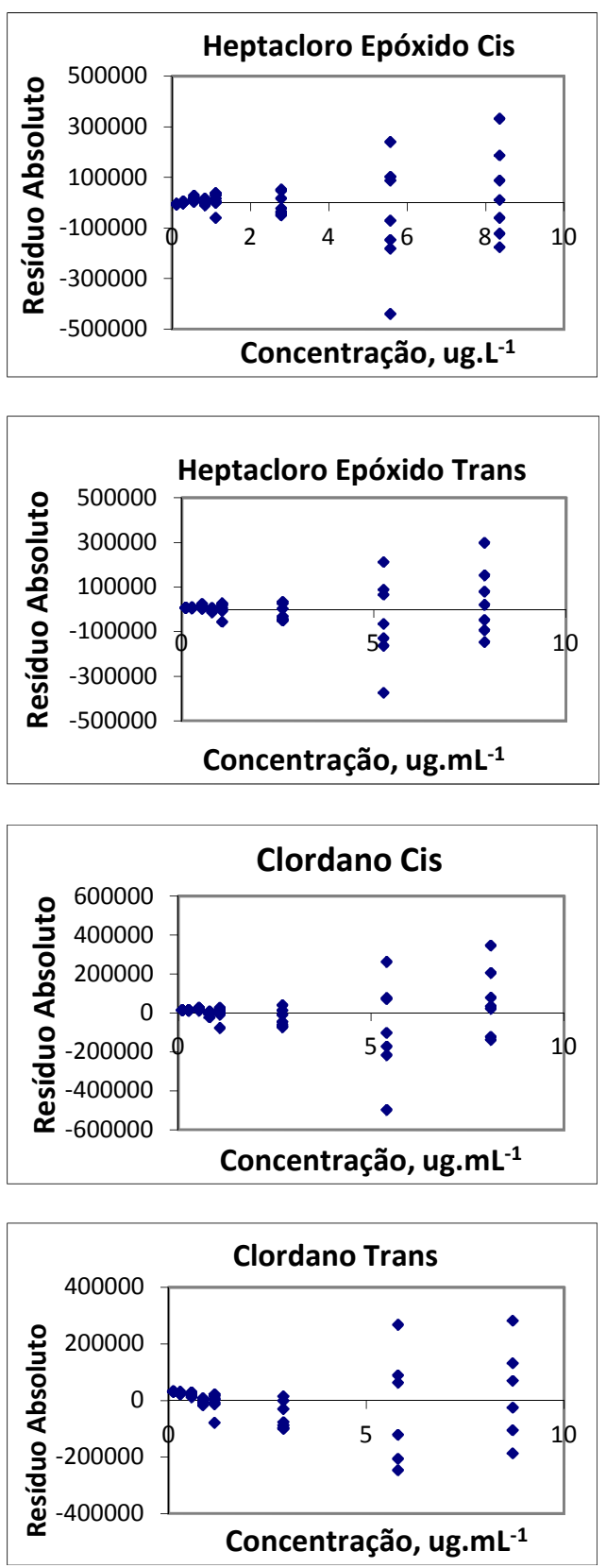

(b)
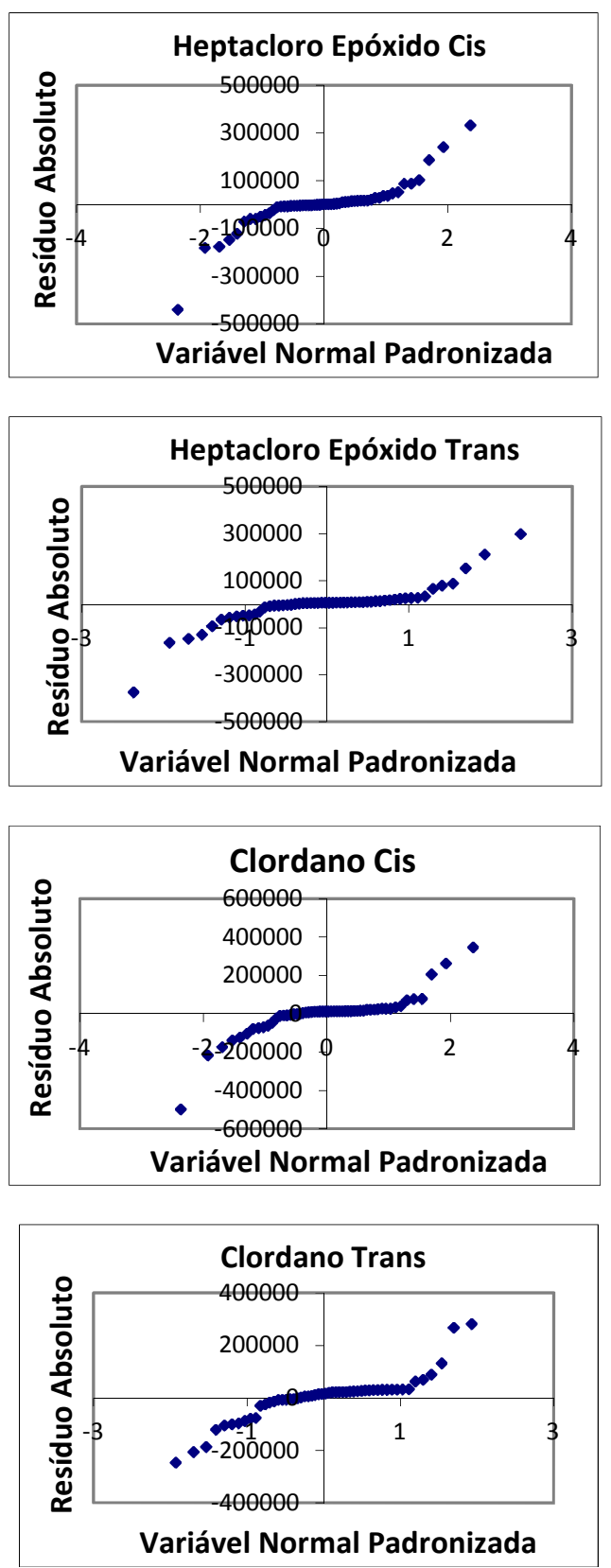

Figura 44. Gráficos dos resíduos absolutos (a) e normalizados (b) para o composto Heptacloro Epóxido Cis / Trans e Clordano Cis / Trans no ensaio com solvente $(\mathrm{ACN})$.

Ao observar os gráficos da distribuição dos resíduos absolutos versus a concentração (Figuras 40 a 45(a) percebe-se uma maior flutuação entre as replicatas, tanto positiva quanto negativa, nas concentrações mais altas. Entretanto, ao analisar os gráficos dos resíduos pela probabilidade normal (Figuras 40 a 45(b)) nota-se que a 
maioria dos pontos está distribuída no intervalo de probabilidade de -2 a +2 , ou seja, dentro de \pm 2 desvios padrão, com 95\% de confiança. Nota-se ainda, que a distribuição se aproxima de uma reta, sem grandes tendências que descaracterizem o comportamento linear.

Através da análise de variância (ANOVA), calcula-se a porcentagem de variação explicada e a porcentagem máxima explicável $\left(r^{2}\right)$. E por meio do teste $\mathrm{F}$ de regressão verifica-se se o modelo de regressão adotado é significativo, isto é, se o modelo é linear, representado pela equação da reta, se ajusta ao conjunto de dados obtidos com 95\% de confiança. Os resultados obtidos para os cálculos de porcentagens de variações explicadas e explicáveis e do teste $F$ de regressão podem ser observados na Tabela 23.

Tabela 23. Resumo dos resultados da análise de variância (ANOVA) para os nove compostos estudados nas matrizes de Caieiras e Franco da Rocha.

\begin{tabular}{|c|c|c|c|c|c|}
\hline \multicolumn{2}{|c|}{ Composto } & \multirow{2}{*}{$\begin{array}{c}\text { Regressão } \\
F_{\text {tab(1, 14,95\%) }}=3,81 \\
=4,6\end{array}$} & \multirow{2}{*}{$\begin{array}{c}\text { Ajuste } \\
\begin{array}{c}\text { F }_{\text {tab }}(6,8,95 \%) \\
=3,69\end{array} \\
3,58\end{array}$} & \multirow{2}{*}{$\begin{array}{c}\begin{array}{c}\% \text { de } \\
\text { Variação } \\
\text { Explicada }\end{array} \\
98,72\end{array}$} & \multirow{2}{*}{$\begin{array}{c}\text { \% Máxima } \\
\text { de Variação } \\
\text { Explicável }\end{array}$} \\
\hline & Caieiras & & & & \\
\hline$\alpha-B H C$ & Franco da Rocha & 3,81 & 3,69 & 99,42 & 99,88 \\
\hline \multirow{2}{*}{$\beta-\mathrm{BHC}$} & Caieiras & 4,6 & 3,58 & 98,41 & 98,94 \\
\hline & Franco da Rocha & 3,81 & 3,69 & 99,52 & 99,84 \\
\hline \multirow{2}{*}{ V-BHC } & Caieiras & 3,81 & 3,69 & 99,70 & 99,94 \\
\hline & Franco da Rocha & 3,81 & 3,69 & 99,25 & 99,87 \\
\hline \multirow{2}{*}{$\delta-B H C$} & Caieiras & 4,6 & 3,58 & 98,39 & 98,78 \\
\hline & Franco da Rocha & 3,81 & 3,69 & 99,18 & 99,85 \\
\hline \multirow{2}{*}{ Heptacloro } & Caieiras & 4,6 & 3,58 & 98,37 & 98,74 \\
\hline & Franco da Rocha & 3,81 & 3,69 & 99,23 & 99,89 \\
\hline \multirow{2}{*}{$\begin{array}{l}\text { Heptacloro } \\
\text { Epóxido Cis }\end{array}$} & Caieiras & 4,6 & 3,58 & 99,00 & 99,15 \\
\hline & Franco da Rocha & 4,6 & 3,58 & 99,00 & 99,15 \\
\hline \multirow{2}{*}{$\begin{array}{l}\text { Heptacloro } \\
\text { Epóxido Trans }\end{array}$} & Caieiras & 3,81 & 3,69 & 99,47 & 99,95 \\
\hline & Franco da Rocha & 3,81 & 3,69 & 98,72 & 99,82 \\
\hline \multirow{2}{*}{ Clordano Cis } & Caieiras & 3,81 & 3,69 & 99,23 & 99,91 \\
\hline & Franco da Rocha & 4,6 & 3,58 & 98,96 & 99,25 \\
\hline \multirow[b]{2}{*}{ Clordano Trans } & Caieiras & 3,81 & 3,69 & 99,60 & 99,94 \\
\hline & Franco da Rocha & 3,81 & 3,69 & 99,13 & 99,76 \\
\hline
\end{tabular}


Com os resultados obtidos pelo teste de regressão, observa-se que a regressão aplicada é significativa para ambas as matrizes, uma vez que os valores de $F_{\text {calculado }}$ foram iguais ou superiores ao valor de $F_{\text {tabelado }}\left(F_{\text {tab }}=3,81\right)$.

Os resultados obtidos pelo teste de ajuste indicam que não houve falta de ajuste nos ensaios realizados em ambas as matrizes para todos os compostos

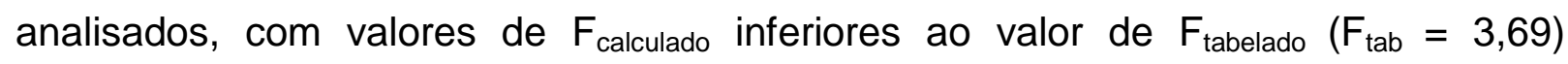
significando que a dispersão entre os pontos não é significativa, isto é, que os pontos estão dentro.

As porcentagens de variação explicadas estão próximas às porcentagens máximas explicáveis, com valores acima de $90 \%$ para todos os compostos em ambas as matrizes, significando que as variações foram explicadas satisfatoriamente pelos modelos lineares adotados e que os mesmos se ajustam ao conjunto de dados.

Nos gráficos das Figuras 46 e 47 são apresentadas as faixas de intervalos de confiança para cada composto, nas faixas de trabalho consideradas. Dentro desta faixa, os resultados são estatisticamente aceitáveis, sendo considerado estreito o intervalo de confiança em praticamente toda a faixa de trabalho para todos os compostos analisados.
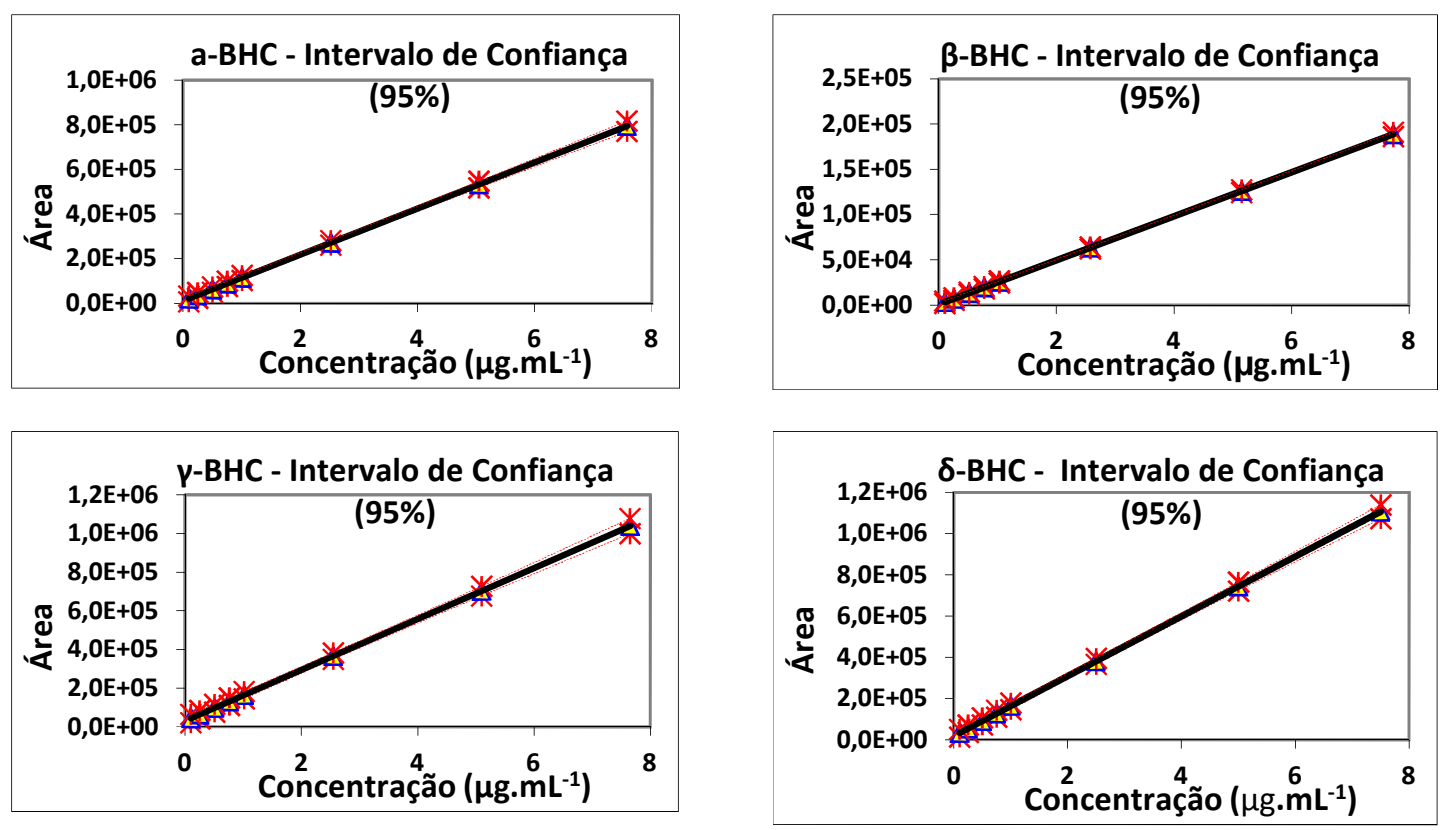

Figura 45. Gráficos da faixa de intervalo de confiança no ensaio sem matriz para os compostos $\mathrm{BHC} \alpha-, \beta-, \gamma-$ e $\delta$-, estudado na faixa de trabalho considerada. 


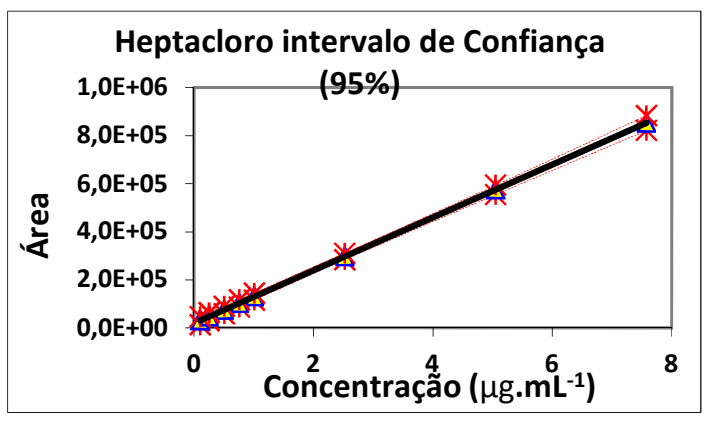

Hept.Ep.Trans. - Intervalo de Confiança (95\%)

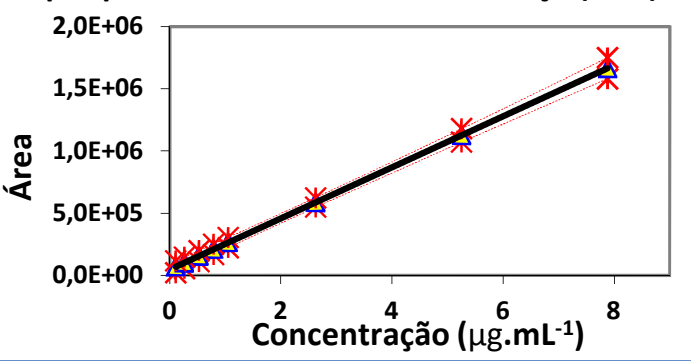

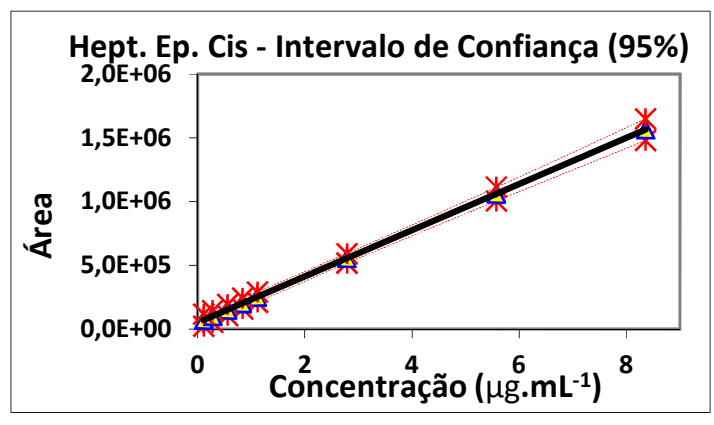

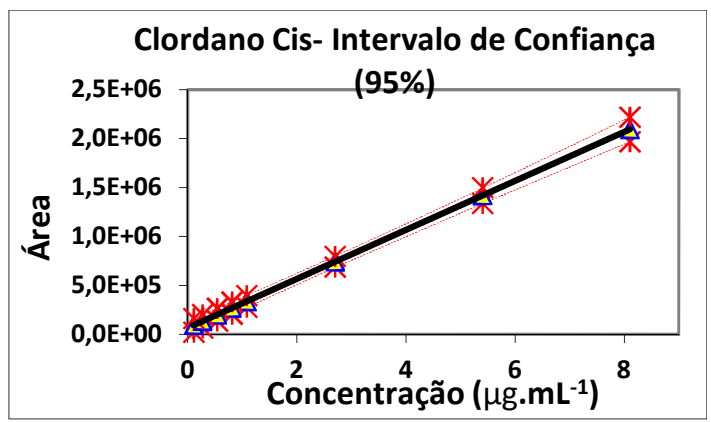

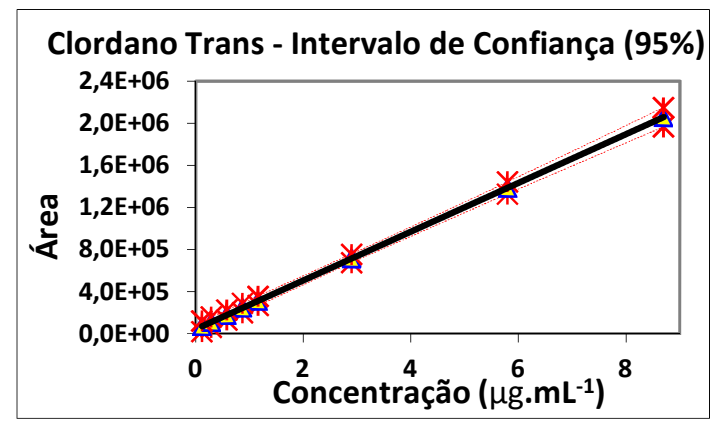

Figura 46. Gráficos da faixa de intervalo de confiança no ensaio sem matriz para o composto Clordano Trans estudado na faixa de trabalho considerada.

\subsubsection{Limites de Detecção (LD) e Quantificação (LQ)}

O limite de detecção (LD) do método foi obtido pelo desvio padrão das replicatas $(n=7)$ da menor concentração dos analitos (definida após sucessivas diluições da solução dos padrões dos nove compostos em estudo) adicionadas às matrizes e ao solvente (ACN).

Para o limite de quantificação (LQ) foi utilizado o branco das matrizes de solo de Caieiras e Franco da Rocha. Foram utilizadas as médias das replicatas $(n=7)$ da menor concentração do analito, tanto para quando a matriz não apresentou sinal analítico para um determinado composto, quanto no caso do branco de solvente (ensaio sem matriz). 
Na Tabela 24 são apresentados os limites de detecção (LD) e de quantificação (LQ) do método, considerando $10 \mathrm{~g}$ de amostra. Em função da sensibilidade do equipamento ser diferente para cada composto e variar também para cada matriz, os limites alcançados são diferentes.

Tabela 24. Limites de detecção e de quantificação para os compostos estudados.

\begin{tabular}{|c|c|c|c|c|c|c|}
\hline \multirow{3}{*}{ Composto } & \multicolumn{6}{|c|}{ Limites do Método $\left(\mu \mathrm{g} \cdot \mathrm{g}^{-1}\right)$} \\
\hline & \multicolumn{2}{|c|}{ Caieiras } & \multicolumn{2}{|c|}{ Franco da Rocha } & \multicolumn{2}{|c|}{ Solvente $(\mathrm{ACN})$} \\
\hline & LD & $\mathbf{L Q}$ & LD & LQ & LD & LQ \\
\hline$\alpha-B H C$ & 0,0012 & 0,0126 & 0,0004 & 0,0110 & 0,0013 & 0,0116 \\
\hline$\beta-\mathrm{BHC}$ & 0,0017 & 0,0120 & 0,0003 & 0,0121 & 0,0032 & 0,0131 \\
\hline $\mathrm{y}-\mathrm{BHC}$ & 0,0015 & 0,0116 & 0,0016 & 0,0114 & 0,0038 & 0,0117 \\
\hline$\delta-\mathrm{BHC}$ & 0,0008 & 0,0116 & 0,0013 & 0,0122 & 0,0019 & 0,0123 \\
\hline Heptacloro & 0,0010 & 0,0108 & 0,0008 & 0,0116 & 0,0012 & 0,0124 \\
\hline Hept. Ep. Cis & 0,0009 & 0,0115 & 0,0010 & 0,0125 & 0,0013 & 0,0126 \\
\hline Hept. Ep. trans & 0,0003 & 0,0110 & 0,0008 & 0,0120 & 0,0011 & 0,0131 \\
\hline Clordano Cis & 0,0004 & 0,0079 & 0,0007 & 0,0103 & 0,0011 & 0,0123 \\
\hline Clordano Trans & 0,0005 & 0,0109 & 0,0007 & 0,0128 & 0,0011 & 0,0143 \\
\hline
\end{tabular}

\subsubsection{Precisão}

A precisão, definida como a dispersão dos resultados entre ensaios independentes, repetidos de uma mesma amostra, amostras semelhantes ou padrões sob condições determinadas, foi avaliada em termos de desvio-padrão (DP) e desvio padrão relativo (DPR), conhecido como coeficiente de variação (CV).

Nos processos de validação de métodos analíticos de resíduos e impurezas a taxa aceitável de DPR é de até $20 \%$, dependendo da complexidade da amostra (Horwitz e Albert, 2006). Considerando-se os resultados de repetitividade e reprodutibilidade, todos os DPR foram inferiores a $20 \%$, como pode ser observado na Tabela 25 
Tabela 25. Coeficientes de variação (CV \%) para os compostos em três níveis de concentração nos ensaios com as matrizes de Caieiras (C) e Franco da Rocha (FR).

\begin{tabular}{|c|c|c|c|c|c|c|c|}
\hline Composto & Matriz & $\mu \mathrm{g} \cdot \mathrm{mL}^{-1}$ & CV (\%) & $\mu \mathrm{g} \cdot \mathrm{mL}^{-1}$ & CV (\%) & $\mu \mathrm{g} \cdot \mathrm{mL}^{-1}$ & CV (\%) \\
\hline \multirow{2}{*}{$\alpha-B H C$} & $\mathrm{C}$ & 0,253 & 4,15 & 0,505 & 2,20 & 1,010 & 2,66 \\
\hline & FR & 0,253 & 4,02 & 0,505 & 2,24 & 1,010 & 1,16 \\
\hline \multirow{2}{*}{$\beta-B H C$} & $\mathrm{C}$ & 0,258 & 5,64 & 0,515 & 4,19 & 1,030 & 0,68 \\
\hline & FR & 0,258 & 5,96 & 0,515 & 6,11 & 1,030 & 1,26 \\
\hline \multirow{2}{*}{ Y-BHC } & $\mathrm{C}$ & 0,255 & 1,35 & 0,510 & 2,53 & 1,020 & 0,32 \\
\hline & FR & 0,255 & 2,87 & 0,510 & 2,62 & 1,020 & 0,34 \\
\hline \multirow{2}{*}{ ठ-BHC } & $\mathrm{C}$ & 0,250 & 5,08 & 0,500 & 0,54 & 1,000 & 3,82 \\
\hline & FR & 0,250 & 3,59 & 0,500 & 3,15 & 1,000 & 1,11 \\
\hline \multirow{2}{*}{ Heptacloro } & $\mathrm{C}$ & 0,253 & 2,76 & 0,505 & 1,77 & 1,010 & 3,62 \\
\hline & FR & 0,253 & 0,16 & 0,505 & 0,43 & 1,010 & 1,61 \\
\hline \multirow{2}{*}{$\begin{array}{l}\text { Hept. Ep. } \\
\text { Cis }\end{array}$} & $\mathrm{C}$ & 0,278 & 1,91 & 0,557 & 1,36 & 1,114 & 1,70 \\
\hline & FR & 0,278 & 2,13 & 0,557 & 0,68 & 1,114 & 1,75 \\
\hline \multirow{2}{*}{$\begin{array}{c}\text { Hept. Ep. } \\
\text { Trans }\end{array}$} & C & 0,263 & 1,11 & 0,525 & 0,92 & 1,050 & 1,95 \\
\hline & FR & 0,263 & 6,36 & 0,525 & 0,47 & 1,050 & 1,72 \\
\hline \multirow{2}{*}{$\begin{array}{c}\text { Clordano } \\
\text { Cis }\end{array}$} & C & 0,270 & 2,11 & 0,540 & 0,56 & 1,080 & 1,48 \\
\hline & FR & 0,270 & 6,28 & 0,540 & 2,90 & 1,080 & 2,80 \\
\hline \multirow{2}{*}{$\begin{array}{c}\text { Clordano } \\
\text { Trans }\end{array}$} & C & 0,290 & 1,98 & 0,580 & 1,85 & 1,160 & 1,95 \\
\hline & FR & 0,290 & 4,04 & 0,580 & 0,34 & 1,160 & 2,18 \\
\hline
\end{tabular}

A repetitividade foi avaliada pelo limite de repetitividade $(r)$, considerando três níveis de concentrações e sete replicatas de cada ensaio e foram analisadas sob as mesmas condições (mesmo dia, equipamento e analista). As concentrações consideradas, as médias dos desvios-padrão entre as replicatas e os resultados obtidos para as duas matrizes são demonstrados nas Tabelas 26 e 27.

Tabela 26. Valores do limite de repetitividade ( $r$ ) para os compostos em três níveis de concentração no ensaio com matriz de Caieiras.

\begin{tabular}{ccccc}
\hline \multirow{2}{*}{$\boldsymbol{\alpha}-B H C$} & $\mu \mathrm{g} \cdot \mathrm{mL}^{-1}$ & 0,101 & 0,505 & 2,525 \\
\cline { 2 - 5 } & $\bar{S}$ replicatas & 0,0048 & 0,0157 & 0,0391 \\
\cline { 2 - 5 } & $\mathbf{r}$ & $\mathbf{0 , 0 1 3 4}$ & $\mathbf{0 , 0 4 3 9}$ & $\mathbf{0 , 1 0 9 4}$ \\
\hline \multirow{3}{*}{$\boldsymbol{\beta}-$ BHC $\mathrm{mL}^{-1}$} & 0,103 & 0,773 & 5,150 \\
\cline { 2 - 5 } & $\bar{S}$ replicatas & 0,0071 & 0,0472 & 0,1869 \\
\cline { 2 - 5 } & $\mathbf{r}$ & $\mathbf{0 , 0 1 9 8}$ & $\mathbf{0 , 1 3 2 3}$ & $\mathbf{0 , 5 2 3 4}$ \\
\hline
\end{tabular}


... Continuação Tabela 26.

\begin{tabular}{|c|c|c|c|c|}
\hline \multirow{3}{*}{ Y-BHC } & $\mu \mathrm{g} \cdot \mathrm{mL}^{-1}$ & 0,102 & 0,765 & 5,100 \\
\hline & $\bar{S}$ replicatas & 0,0071 & 0,0472 & 0,1869 \\
\hline & $\mathbf{r}$ & 0,0198 & 0,1323 & 0,5234 \\
\hline \multirow{3}{*}{ ठ-BHC } & $\mu \mathrm{g} \cdot \mathrm{mL}^{-1}$ & 0,100 & 0,750 & 5,000 \\
\hline & $\bar{S}$ replicatas & 0,0071 & 0,0472 & 0,1869 \\
\hline & $r$ & 0,0198 & 0,1323 & 0,5234 \\
\hline \multirow{3}{*}{ Heptacloro } & $\mu \mathrm{g} \cdot \mathrm{mL}^{-1}$ & 0,101 & 0,758 & 5,050 \\
\hline & $\bar{S}$ replicatas & 0,0071 & 0,0472 & 0,1869 \\
\hline & $r$ & 0,0198 & 0,1323 & 0,5234 \\
\hline \multirow{3}{*}{$\begin{array}{l}\text { Hept. Ep. } \\
\text { Cis }\end{array}$} & $\mu \mathrm{g} \cdot \mathrm{mL}^{-1}$ & 0,111 & 0,835 & 5,568 \\
\hline & $\bar{S}$ replicatas & 0,0071 & 0,0472 & 0,1869 \\
\hline & $\mathbf{r}$ & 0,0198 & 0,1323 & 0,5234 \\
\hline \multirow{3}{*}{$\begin{array}{l}\text { Hept. Ep. } \\
\text { Trans }\end{array}$} & $\mu \mathrm{g} \cdot \mathrm{mL}^{-1}$ & 0,105 & 0,788 & 5,251 \\
\hline & $\bar{S}$ replicatas & 0,0071 & 0,0472 & 0,1869 \\
\hline & $r$ & 0,0198 & 0,1323 & 0,5234 \\
\hline \multirow{3}{*}{$\begin{array}{c}\text { Clordano } \\
\text { Cis }\end{array}$} & $\mu \mathrm{g} \cdot \mathrm{mL}^{-1}$ & 0,108 & 0,270 & 0,540 \\
\hline & $\bar{S}$ replicatas & 0,0071 & 0,0472 & 0,1869 \\
\hline & $\mathbf{r}$ & 0,0198 & 0,1323 & 0,5234 \\
\hline \multirow{3}{*}{$\begin{array}{c}\text { Clordano } \\
\text { Trans }\end{array}$} & $\mu \mathrm{g} \cdot \mathrm{mL}^{-1}$ & 0,116 & 0,870 & 5,799 \\
\hline & $\bar{S}$ replicatas & 0,0071 & 0,0472 & 0,1869 \\
\hline & $r$ & 0,0198 & 0,1323 & 0,5234 \\
\hline
\end{tabular}

Tabela 27. Valores do limite de repetitividade $(r)$ para os compostos em três níveis de concentração no ensaio com matriz de Franco da Rocha.

\begin{tabular}{ccccc}
\hline \multirow{2}{*}{-BHC } & $\mu \mathrm{gg} \cdot \mathrm{mL}^{-1}$ & 0,101 & 0,505 & 2,525 \\
\cline { 2 - 5 } & $\bar{S}$ replicatas & 0,0048 & 0,0157 & 0,0391 \\
\cline { 2 - 5 } & $\mathbf{r}$ & $\mathbf{0 , 0 1 3 4}$ & $\mathbf{0 , 0 4 3 9}$ & $\mathbf{0 , 1 0 9 4}$ \\
\hline \multirow{3}{*}{$\boldsymbol{\mu}-$ Bg. $\mathrm{mL}^{-1}$} & 0,103 & 0,773 & 5,150 \\
\cline { 2 - 5 } & $\bar{S}$ replicatas & 0,0071 & 0,0472 & 0,1869 \\
\cline { 2 - 5 } & $\mathbf{r}$ & $\mathbf{0 , 0 1 9 8}$ & $\mathbf{0 , 1 3 2 3}$ & $\mathbf{0 , 5 2 3 4}$ \\
\hline \multirow{3}{*}{ V-BHC } & $\overline{\mu g} \cdot \mathrm{mL}^{-1}$ & 0,102 & 0,765 & 5,100 \\
\cline { 2 - 5 } & $\bar{S}$ replicatas & 0,0071 & 0,0472 & 0,1869 \\
\cline { 2 - 5 } & $\mathbf{r}$ & $\mathbf{0 , 0 1 9 8}$ & $\mathbf{0 , 1 3 2 3}$ & $\mathbf{0 , 5 2 3 4}$ \\
\hline
\end{tabular}


... Continuação Tabela 27.

\begin{tabular}{|c|c|c|c|c|}
\hline \multirow{3}{*}{ ठ-BHC } & $\mu \mathrm{g} \cdot \mathrm{mL}^{-1}$ & 0,100 & 0,750 & 5,000 \\
\hline & $\bar{S}$ replicatas & 0,0071 & 0,0472 & 0,1869 \\
\hline & $r$ & 0,0198 & 0,1323 & 0,5234 \\
\hline \multirow{3}{*}{ Heptacloro } & $\mu \mathrm{g} \cdot \mathrm{mL}^{-1}$ & 0,101 & 0,758 & 5,050 \\
\hline & $\bar{S}$ replicatas & 0,0031 & 0,0362 & 0,1593 \\
\hline & $\mathbf{r}$ & 0,0088 & 0,1014 & 0,4461 \\
\hline \multirow{3}{*}{$\begin{array}{l}\text { Hept. Ep. } \\
\text { Cis }\end{array}$} & $\mu \mathrm{g} \cdot \mathrm{mL}^{-1}$ & 0,111 & 0,557 & 1,114 \\
\hline & $\bar{S}$ replicatas & 0,0043 & 0,0221 & 0,0313 \\
\hline & $r$ & 0,0121 & 0,0619 & 0,0878 \\
\hline \multirow{3}{*}{$\begin{array}{c}\text { Hept. Ep. } \\
\text { Trans }\end{array}$} & $\mu \mathrm{g} \cdot \mathrm{mL}^{-1}$ & 0,105 & 0,788 & 5,251 \\
\hline & $\bar{S}$ replicatas & 0,0032 & 0,0378 & 0,1895 \\
\hline & $r$ & 0,0090 & 0,1059 & 0,5306 \\
\hline \multirow{3}{*}{$\begin{array}{c}\text { Clordano } \\
\text { Cis }\end{array}$} & $\mu \mathrm{g} \cdot \mathrm{mL}^{-1}$ & 0,108 & 0,270 & 0,540 \\
\hline & $\bar{S}$ replicatas & 0,0071 & 0,0472 & 0,1869 \\
\hline & $r$ & 0,0198 & 0,1323 & 0,5234 \\
\hline \multirow{3}{*}{$\begin{array}{c}\text { Clordano } \\
\text { Trans }\end{array}$} & $\mu \mathrm{g} \cdot \mathrm{mL}^{-1}$ & 0,116 & 0,870 & 5,799 \\
\hline & $\bar{S}$ replicatas & 0,0071 & 0,0472 & 0,1869 \\
\hline & $r$ & 0,0198 & 0,1323 & 0,5234 \\
\hline
\end{tabular}

Para a precisão, ainda se considerou a reprodutibilidade do método por meio do cálculo do limite de reprodutibilidade $(R)$. As análises foram realizadas em sete replicatas com a solução mix dos padrões em estudo, em três níveis de concentrações, porém, em dias diferentes. As Tabelas 28 e 29 mostram os resultados obtidos, assim como os três níveis de concentrações considerados e as médias dos desvios padrão entre as replicatas.

Tabela 28. Resultados do limite de reprodutibilidade (R) para os compostos em três níveis de concentrações no ensaio com matriz de Caieiras.

\begin{tabular}{ccccc}
\hline \multirow{2}{*}{$\boldsymbol{\alpha}$-BHC } & $\mu \mathrm{gg} \cdot \mathrm{mL}^{-1}$ & 0,101 & 0,505 & 2,525 \\
\cline { 2 - 5 } & $\bar{S}$ replicatas & 0,0018 & 0,0096 & 0,0218 \\
\cline { 2 - 5 } & $\mathbf{r}$ & $\mathbf{0 , 0 0 5 1}$ & $\mathbf{0 , 0 2 6 9}$ & $\mathbf{0 , 0 6 0 9}$ \\
\hline \multirow{3}{*}{$\beta$-BHC } & $\mu \mathrm{g} \cdot \mathrm{mL}^{-1}$ & 0,103 & 0,773 & 5,150 \\
\cline { 2 - 5 } & $\bar{S}$ replicatas & 0,0020 & 0,0188 & 0,0879 \\
\cline { 2 - 5 } & $\mathbf{R}$ & $\mathbf{0 , 0 0 5 6}$ & $\mathbf{0 , 0 5 2 6}$ & $\mathbf{0 , 2 4 6 0}$ \\
\hline
\end{tabular}


... Continuação Tabela 28.

\begin{tabular}{|c|c|c|c|c|}
\hline \multirow{3}{*}{ V-BHC } & $\mu \mathrm{g} \cdot \mathrm{mL}^{-1}$ & 0,102 & 0,765 & 5,100 \\
\hline & $\bar{S}$ replicatas & 0,0052 & 0,0273 & 0,0295 \\
\hline & $\mathbf{R}$ & 0,0144 & 0,0763 & 0,0826 \\
\hline \multirow{3}{*}{ ठ-BHC } & $\mu \mathrm{g} \cdot \mathrm{mL}^{-1}$ & 0,100 & 0,750 & 5,000 \\
\hline & $\bar{S}$ replicatas & 0,0010 & 0,0215 & 0,0321 \\
\hline & $\mathbf{R}$ & 0,0028 & 0,0603 & 0,0899 \\
\hline \multirow{3}{*}{ Heptacloro } & $\mu \mathrm{g} \cdot \mathrm{mL}^{-1}$ & 0,101 & 0,758 & 5,050 \\
\hline & $\bar{S}$ replicatas & 0,0017 & 0,0188 & 0,0310 \\
\hline & $\mathbf{R}$ & 0,0047 & 0,0526 & 0,0867 \\
\hline \multirow{3}{*}{$\begin{array}{l}\text { Hept. Ep. } \\
\text { Cis }\end{array}$} & $\mu g \cdot \mathrm{mL}^{-1}$ & 0,111 & 0,835 & 5,568 \\
\hline & $\bar{S}$ replicatas & 0,0019 & 0,0107 & 0,0299 \\
\hline & $\mathbf{R}$ & 0,0054 & 0,0299 & 0,0836 \\
\hline \multirow{3}{*}{$\begin{array}{l}\text { Hept. Ep. } \\
\text { Trans }\end{array}$} & $\mu \mathrm{g} \cdot \mathrm{mL}^{-1}$ & 0,105 & 0,788 & 5,251 \\
\hline & $\bar{S}$ replicatas & 0,0019 & 0,0112 & 0,0307 \\
\hline & $\mathbf{R}$ & 0,0052 & 0,0313 & 0,0861 \\
\hline \multirow{3}{*}{$\begin{array}{c}\text { Clordano } \\
\text { Cis }\end{array}$} & $\mu \mathrm{g} \cdot \mathrm{mL}^{-1}$ & 0,108 & 0,270 & 0,540 \\
\hline & $\bar{S}$ replicatas & 0,0038 & 0,0039 & 0,0051 \\
\hline & $\mathbf{R}$ & 0,0105 & 0,0110 & 0,0143 \\
\hline \multirow{3}{*}{$\begin{array}{c}\text { Clordano } \\
\text { Trans }\end{array}$} & $\mu \mathrm{g} \cdot \mathrm{mL}^{-1}$ & 0,116 & 0,870 & 5,799 \\
\hline & $\bar{S}$ replicatas & 0,0009 & 0,0132 & 0,0388 \\
\hline & $\mathbf{R}$ & 0,0027 & 0,0369 & 0,1085 \\
\hline
\end{tabular}

Tabela 29. Resultados do limite de reprodutibilidade $(R)$ para os compostos em três níveis de concentrações no ensaio com matriz de Franco da Rocha.

\begin{tabular}{|c|c|c|c|c|}
\hline & $\mu \mathrm{g} \cdot \mathrm{mL}^{-1}$ & 0,101 & 0,505 & 2,525 \\
\hline \multirow[t]{2}{*}{$\alpha-B H C$} & $\bar{S}$ replicatas & 0,0012 & 0,0117 & 0,0709 \\
\hline & $r$ & 0,0033 & 0,0329 & 0,1985 \\
\hline \multirow{3}{*}{$\beta-B H C$} & $\mu \mathrm{g} \cdot \mathrm{mL}^{-1}$ & 0,103 & 0,773 & 5,150 \\
\hline & $\bar{S}$ replicatas & 0,0065 & 0,0239 & 0,1016 \\
\hline & $\mathbf{R}$ & 0,0182 & 0,0669 & 0,2845 \\
\hline \multirow{3}{*}{ V-BHC } & $\mu \mathrm{g} \cdot \mathrm{mL}^{-1}$ & 0,102 & 0,765 & 5,100 \\
\hline & $\bar{S}$ replicatas & 0,0013 & 0,0237 & 0,0763 \\
\hline & $\mathbf{R}$ & 0,0037 & 0,0664 & 0,2136 \\
\hline
\end{tabular}


... Continuação Tabela 29.

\begin{tabular}{|c|c|c|c|c|}
\hline \multirow{3}{*}{ ठ-BHC } & $\mu \mathrm{g} \cdot \mathrm{mL}^{-1}$ & 0,100 & 0,750 & 5,000 \\
\hline & $\bar{S}$ replicatas & 0,0033 & 0,0052 & 0,0594 \\
\hline & $\mathbf{R}$ & 0,0093 & 0,0146 & 0,1664 \\
\hline \multirow{3}{*}{ Heptacloro } & $\mu \mathrm{g} \cdot \mathrm{mL}^{-1}$ & 0,101 & 0,758 & 5,050 \\
\hline & $\bar{S}$ replicatas & 0,0018 & 0,0136 & 0,0673 \\
\hline & $\mathbf{R}$ & 0,0050 & 0,0382 & 0,1885 \\
\hline \multirow{3}{*}{$\begin{array}{l}\text { Hept. Ep. } \\
\text { Cis }\end{array}$} & $\mu \mathrm{g} \cdot \mathrm{mL}^{-1}$ & 0,111 & 0,557 & 1,114 \\
\hline & $\bar{S}$ replicatas & 0,0025 & 0,0085 & 0,4065 \\
\hline & $\mathbf{R}$ & 0,0071 & 0,0238 & 1,1382 \\
\hline \multirow{3}{*}{$\begin{array}{c}\text { Hept. Ep. } \\
\text { Trans }\end{array}$} & $\mu \mathrm{g} \cdot \mathrm{mL}^{-1}$ & 0,105 & 0,788 & 5,251 \\
\hline & $\bar{S}$ replicatas & 0,0024 & 0,0136 & 0,0862 \\
\hline & $\mathbf{R}$ & 0,0067 & 0,0382 & 0,2415 \\
\hline \multirow{3}{*}{$\begin{array}{c}\text { Clordano } \\
\text { Cis }\end{array}$} & $\mu \mathrm{g} \cdot \mathrm{mL}^{-1}$ & 0,108 & 0,270 & 0,540 \\
\hline & $\bar{S}$ replicatas & 0,0035 & 0,0088 & 0,0115 \\
\hline & $\mathbf{R}$ & 0,0099 & 0,0246 & 0,0323 \\
\hline \multirow{3}{*}{$\begin{array}{c}\text { Clordano } \\
\text { Trans }\end{array}$} & $\mu \mathrm{g} \cdot \mathrm{mL}^{-1}$ & 0,116 & 0,870 & 5,799 \\
\hline & $\bar{S}$ replicatas & 0,0013 & 0,0174 & 0,0938 \\
\hline & $\mathbf{R}$ & 0,0037 & 0,0487 & 0,2627 \\
\hline
\end{tabular}

Para que o método apresente repetitividade e reprodutibilidade, os valores de $r$ e $\mathrm{R}$ devem ser superiores à diferença entre as replicatas (Souza, 2011). Observandose as Tabelas 25 a 29 , percebe-se que os resultados foram bem inferiores às concentrações consideradas e os limites para repetibilidade $(r)$ e reprodutibilidade $(R)$ encontram-se acima das médias do desvio padrão das replicatas. Para os três níveis de concentração avaliados, as diferenças absolutas entre os resultados das replicatas dos ensaios obtidos sob condições de repetibilidade e reprodutibilidade foram inferiores aos valores de $r$ e $R$, demonstrando a precisão do método (Souza, 2011).

\subsubsection{Exatidão}

A exatidão do método analítico pode ser avaliada por várias ferramentas, entre elas, o teste $z$ (Score), cujos resultados podem ser observados na Tabela 30 e os ensaios de recuperação, utilizando materiais de referência certificados. $O$ teste $z$ 
Score foi aplicado considerando-se as sete replicatas dos ensaios realizados com e sem matriz. Para que a metodologia seja considerada exata, os valores de $|z|$ devem ser inferiores a 2. Se o $|z|$ estiver entre 2 e 3 , o resultado é considerado questionável, e para $|z|>3$, o resultado é considerado insatisfatório.

$\mathrm{Na}$ Tabela 30, podem ser observados os resultados para o índice $\mathrm{z}$, com valores inferiores a 2 para todos os compostos, demonstrando que os resultados são satisfatórios e o método tem exatidão na faixa de concentração considerada nos ensaios realizados em ambas as matrizes.

Tabela 30. Resultados do z Score para os compostos estudados nos ensaios em matriz de Caieiras e Franco da Rocha.

\begin{tabular}{|c|c|c|c|c|}
\hline Composto & $\begin{array}{l}\text { Concentração } \\
\left(\mu \mathrm{g} \cdot \mathrm{g}^{-1}\right)\end{array}$ & $\begin{array}{c}\text { z Score } \\
\text { (Caieiras) }\end{array}$ & $\begin{array}{l}\text { Concentração } \\
\left(\mu \mathrm{g} \cdot \mathrm{g}^{-1}\right)\end{array}$ & $\begin{array}{c}\text { z Score } \\
\text { (F. da Rocha) }\end{array}$ \\
\hline$\alpha-B H C$ & 0,010 & 0,0148 & 0,102 & 0,672 \\
\hline$\beta-B H C$ & 0,096 & 1,409 & 0,518 & 0,067 \\
\hline Y-BHC & 0,233 & 0,699 & 0,533 & 1,431 \\
\hline$\delta$-BHC & 0,101 & 0,188 & 0,530 & 1,876 \\
\hline Heptacloro & 0,099 & 0,991 & 0,104 & 1,588 \\
\hline Hept. Epóxido Cis & 0,574 & 1,818 & 0,868 & 0,696 \\
\hline Hept. Epóxido Trans & 0,111 & 1,447 & 0,098 & 1,587 \\
\hline Clordano Cis & 0,281 & 1,487 & 0,574 & 1,486 \\
\hline Clordano Trans & 0,289 & 0,069 & 0,599 & 0,878 \\
\hline
\end{tabular}

\subsubsection{Recuperação}

A eficácia do método proposto foi avaliada através dos ensaios de recuperação, para isso foram utilizadas amostras testemunho do município de Caieiras, por apresentar um histórico de menores índices de contaminação, segundo informações coletadas com equipe da Vigilância Sanitária.

O teste de recuperação foi realizado segundo o item 4.9.1. As análises das amostras testemunho detectaram a presença do composto $\alpha-\mathrm{BHC}$, cuja concentração foi descontada de cada ensaio de recuperação segundo a Equação 30 do item 4.9.1, a fim de não superestimar a eficiência do método.

Como pode ser observado na Tabela 31, as médias de porcentagens de recuperação concentraram-se na faixa de 70 a $120 \%$, para a maioria dos compostos, 
exceto para o a-BHC, que apresentou $57,8 \%$ de recuperação. Todas as médias de porcentagens de recuperação estão dentro da faixa recomendada pela literatura, 70 a a120\% para análise de resíduos, ou de 50 a 120\% para amostras complexas (Ribani et al., 2004).

As porcentagens de recuperação acima de $100 \%$ podem ser explicadas pela influência da matriz sobre o ensaio, especialmente tratando-se de matrizes complexas como as ambientais. A variação dos resultados observada entre os compostos é explicada pela forma distinta com que se comportam na matriz em estudo. O $\alpha$-BHC é o composto que apresentou maior influência da matriz. 
Tabela 31. Teste de recuperação dos compostos estudados (médias de 3 resultados).

\begin{tabular}{|c|c|c|c|c|c|c|c|c|c|c|}
\hline \multicolumn{11}{|c|}{ Concentração Adicionada $(\mu \mathrm{g} / \mathrm{mL})$} \\
\hline & \multicolumn{3}{|c|}{0,75} & \multicolumn{3}{|c|}{1,00} & \multicolumn{3}{|c|}{2,00} & \multirow[b]{2}{*}{$\begin{array}{r}\text { Recup } \\
\text { Total } \\
\end{array}$} \\
\hline Composto & $\begin{array}{c}\text { Área } \\
\left({ }^{*} \mathrm{Ad} \text {. Pd. }\right)\end{array}$ & $\begin{array}{c}\text { Área } \\
\text { (Recup.) }\end{array}$ & $\begin{array}{c}\text { Recup. } \\
(\%)\end{array}$ & $\begin{array}{c}\text { Área } \\
\left({ }^{*} \mathrm{Ad} . \mathrm{Pd} .\right)\end{array}$ & $\begin{array}{c}\text { Área } \\
\text { (Recup.) }\end{array}$ & $\begin{array}{c}\text { Recup. } \\
\text { (\%) }\end{array}$ & $\begin{array}{c}\text { Área } \\
\left({ }^{*} \mathrm{Ad} \text {. Pd.) }\right.\end{array}$ & $\begin{array}{c}\text { Área } \\
\text { (Recup.) }\end{array}$ & $\begin{array}{c}\text { Recup. } \\
(\%)\end{array}$ & \\
\hline$\alpha-B H C$ & 89241 & 239388 & 37,3 & 368869 & 400603 & 92,1 & 195378 & 442849 & 44,1 & 57,8 \\
\hline$\beta-B H C$ & 19728 & 81768 & 24,1 & 41879 & 41429 & 101,1 & 65107 & 76814 & 84,8 & 70,0 \\
\hline$\gamma$-BHC & 139046 & 242863 & 57,3 & 319296 & 360501 & 88,6 & 843068 & 398576 & 211,5 & 119,1 \\
\hline$\delta-\mathrm{BHC}$ & 133380 & 162010 & 82,3 & 201793 & 260552 & 77,4 & 368161 & 561928 & 65,5 & 75,1 \\
\hline Heptacloro & 106702 & 80835 & 132,0 & 263534 & 262345 & 100,5 & 390684 & 593158 & 65,9 & 99,4 \\
\hline Heptacloro Ep. Cis & 217998 & 242254 & 90,0 & 351418 & 340478 & 103,2 & 880940 & 1056894 & 83,4 & 92,2 \\
\hline Heptacloro Ep. Trans & 213789 & 208102 & 102,7 & 265052 & 277469 & 95,5 & 570104 & 574938 & 99,2 & 99,1 \\
\hline Clordano Trans & 254936 & 231293 & 110,2 & 479078 & 468069 & 102,4 & 650746 & 774952 & 84,0 & 98,8 \\
\hline Clordano Cis & 285332 & 233121 & 122,4 & 620881 & 591373 & 105,0 & 1523569 & 1807067 & 84,3 & 103,9 \\
\hline
\end{tabular}

*Ad. Pd.: Adição Padrão 


\subsubsection{Robustez}

A fim de verificar a sensibilidade do método analítico por efeito de pequenas variações, conforme os parâmetros selecionados na Tabela 13 (item 4.9.2), foram realizados cálculos de robustez pelo planejamento fatorial de 7 variáveis com 8 experimentos (planejamento fracionário saturado), como pode ser observado na Tabela 6 (item 2.6.5.3.10) utilizando-se como ferramenta a planilha "Validação de Ensaios Químicos" (Furusawa, 2007).

Os resultados obtidos podem ser melhor entendidos por meio das representações gráficas, onde é possível avaliar se o método é robusto para as alterações nos parâmetros escolhidos dos compostos apresentada nas Figuras $47 \mathrm{e}$ 48, que possibilitam entender se esses efeitos são ou não significativos, avaliar se o método é ou não robusto para as condições escolhidas, bem como ordenar a influência de cada uma das variações nos resultados finais.

Nas Figuras 47 e 48 são apresentados os gráficos dos efeitos para os nove compostos estudados na matriz de Caieiras, onde é possível avaliar se o parâmetro selecionado influencia de forma positiva ou negativa o ensaio. Os gráficos de probabilidade normal e de rankit (meia-normal) são apresentados nas Figura 49 a 51, referentes também aos ensaios com a matriz de Caieiras. Cada um dos sete pontos representados nos gráficos referenciam um parâmetro escolhido para variação, e para que a metodologia seja considerada robusta, os mesmos devem se encontrar abaixo da margem de erro mais crítica (ME, margin of error), se o resultado estiver entre a ME e a SME (simultaneous margin of error) indica que se deve ter cuidado com o parâmetro em questão na realização do método.

Observando os gráficos de influência (Figuras 47 e 48), é possível constatar que os resultados obtidos foram bem diversificados para os compostos estudados. Alguns parâmetros, como a temperatura do injetor, a massa da amostra, o volume de acetonitrila usado na extração, o fluxo da coluna e o volume de injeção, não apresentaram influências relevantes, tanto positiva quanto negativamente, exceto para os compostos Clordano Cis / Trans, que apresentaram grandes influências positivas para a temperatura do injetor e para o volume de injeção. E para o composto $\delta$-BHC, que apresentou grande influência positiva para fracionamento de volume. Entretanto, estes parâmetros ficaram abaixo da ME nos gráficos de rankit 
(Figuras 50 e 51), significando que as influências evidenciadas não foram relevantes. $\mathrm{O}$ aumento de volume injetado de 1 para $2 \mu \mathrm{L}$, assim como 0 fracionamento de volume de injeção apresentaram forte influência negativa para a maioria dos compostos.
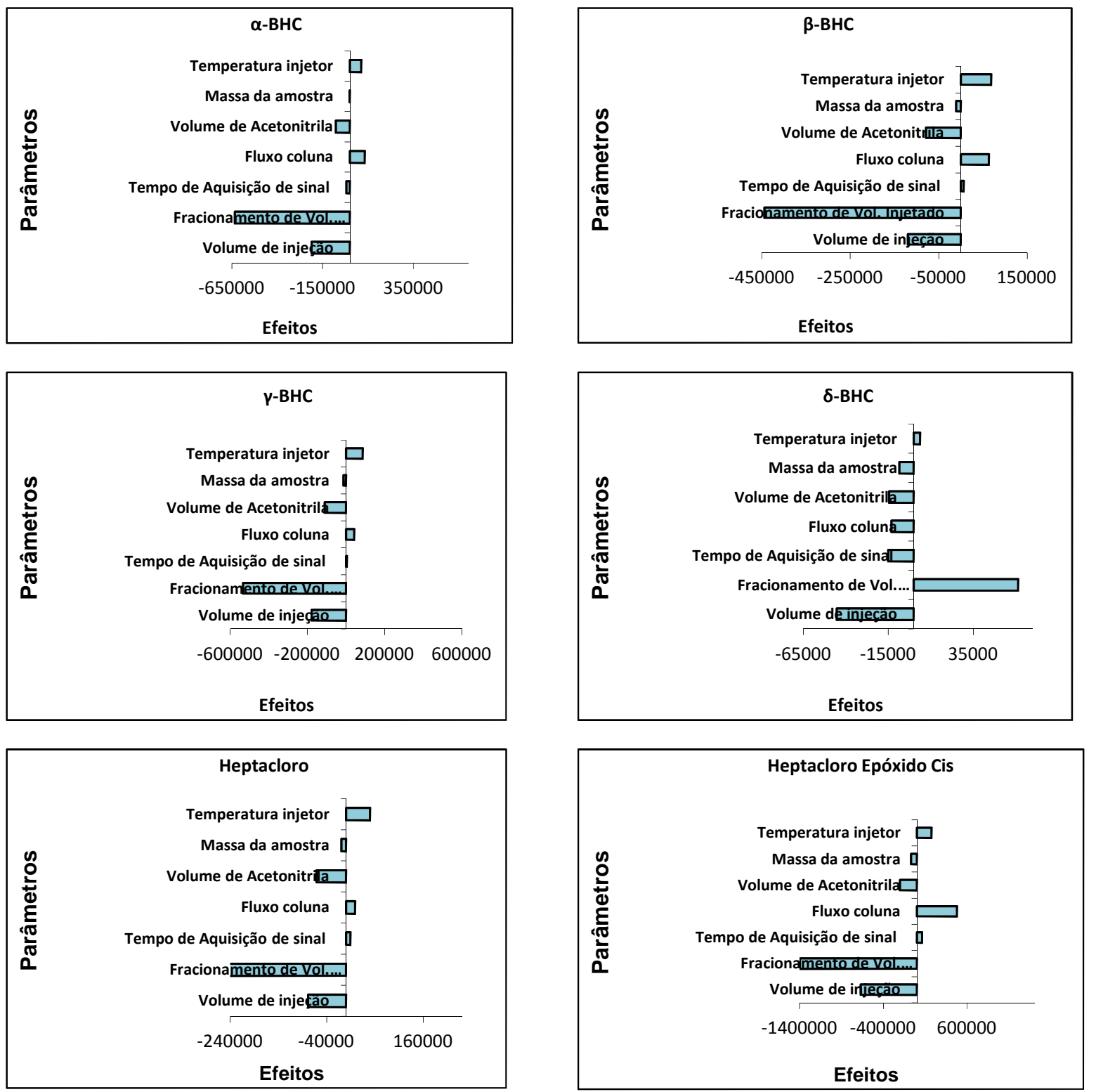

Figura 47. Gráficos para os compostos $\alpha-B H C, \beta-B H C, y-B H C, \delta-B H C$, Heptacloro, Heptacloro Epóxido Cis representando teste de verificação de significância dos efeitos. 

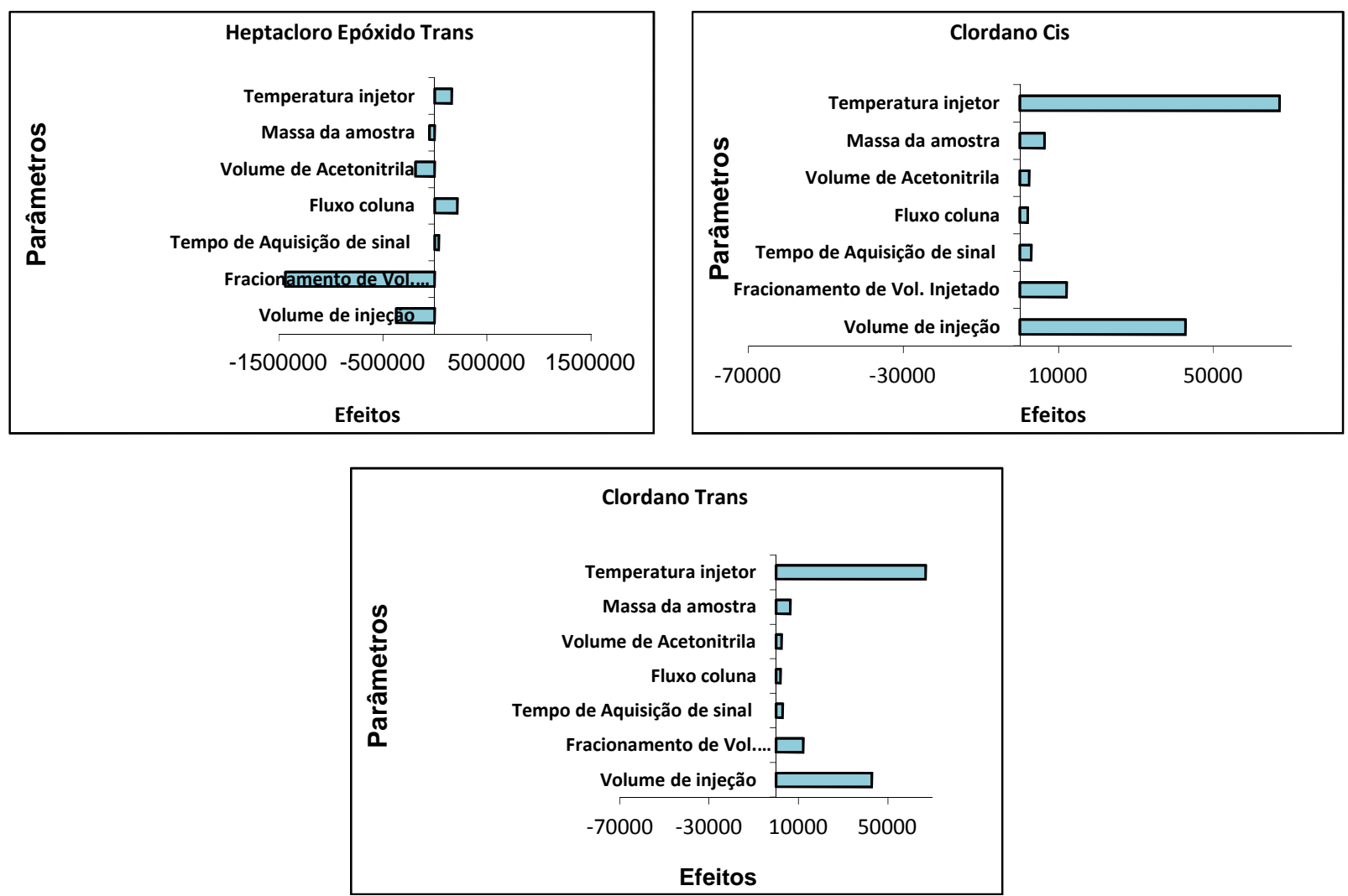

Figura 48. Gráficos para os compostos Heptacloro Epóxido Trans e Clordano Cis/ Trans, representando teste de verificação de significância dos efeitos.

Avaliando-se as Figuras 50 a 52 é possível concluir que não é necessário realizar alterações na metodologia, tanto para extração quanto para análise das amostras, uma vez que todos os fatores ficaram abaixo da margem de erro mais crítico (ME). Os gráficos de probabilidade normal apresentaram valores entre $-2 \mathrm{a}+2$, ou seja, bem distribuídos, significando que provavelmente não haja outliers.
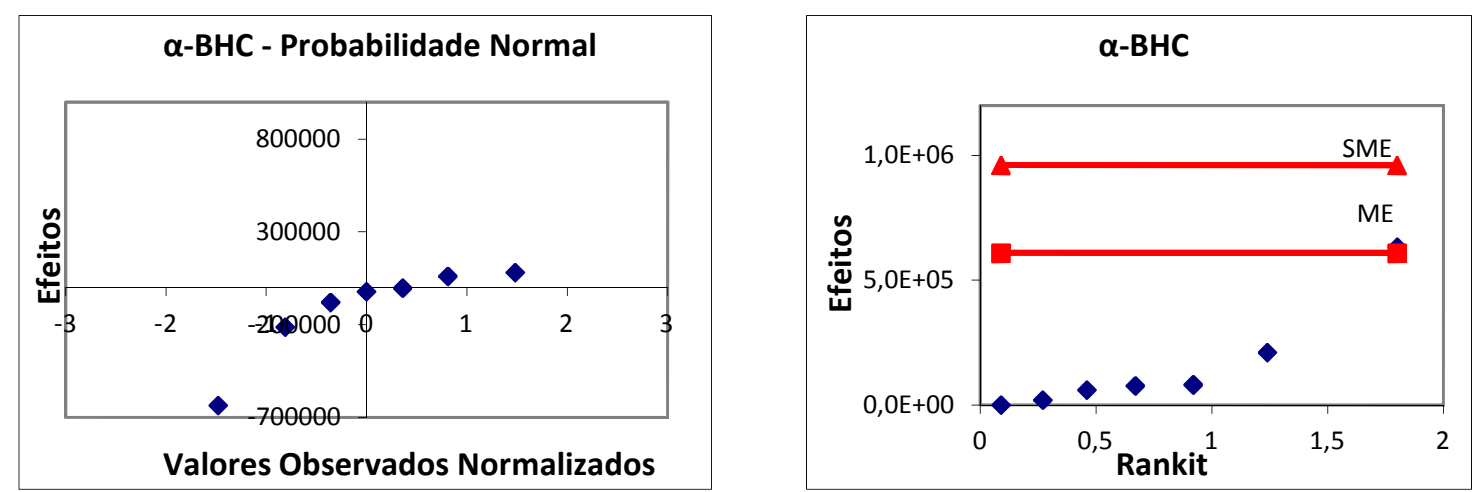

Figura 49. Gráficos para os compostos $\alpha$-BHC representando teste de verificação de significância dos efeitos. 

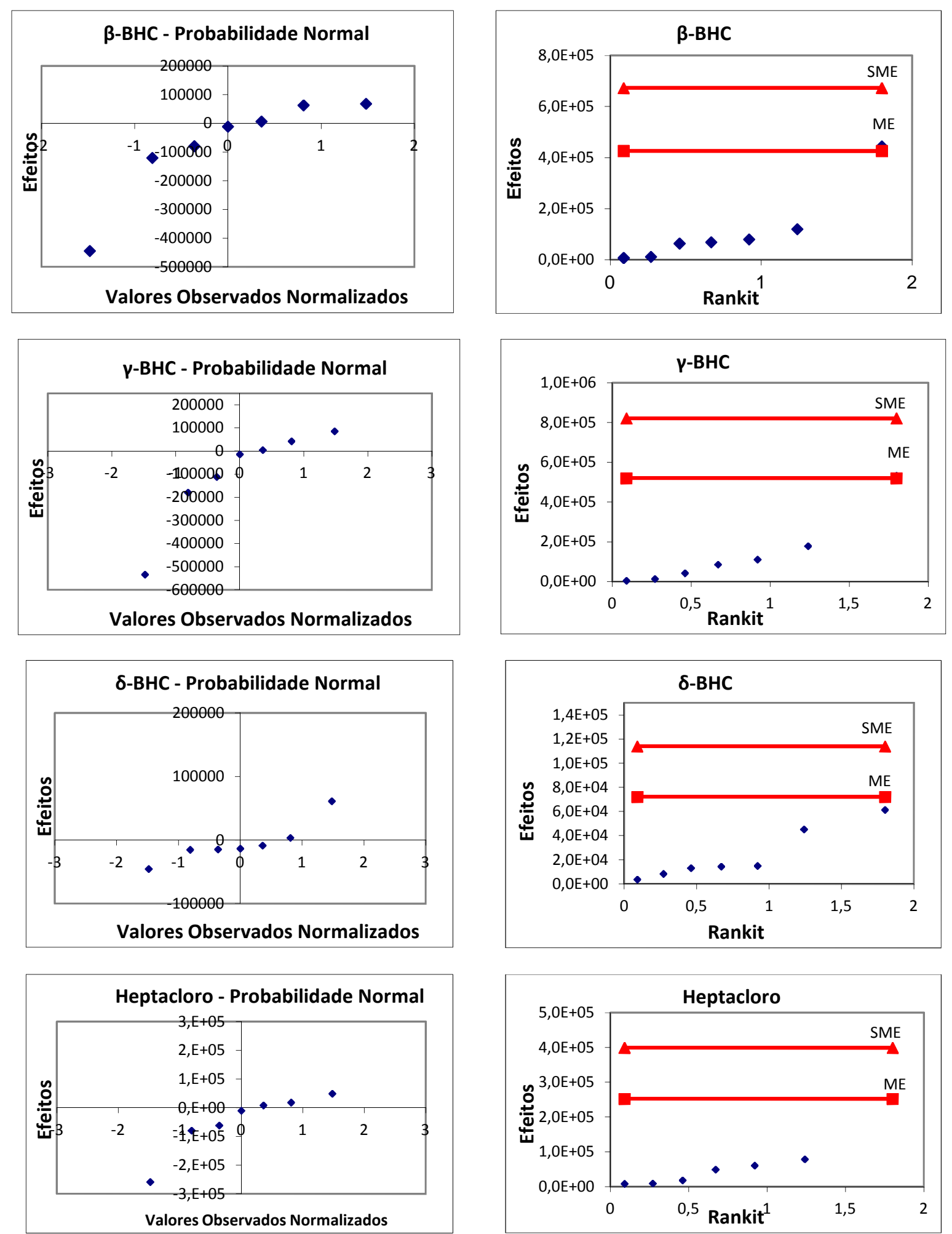

Figura 50. Gráficos para os compostos $\beta-B H C, y-B H C, \delta-B H C$, Heptacloro, representando teste de verificação de significância dos efeitos. 

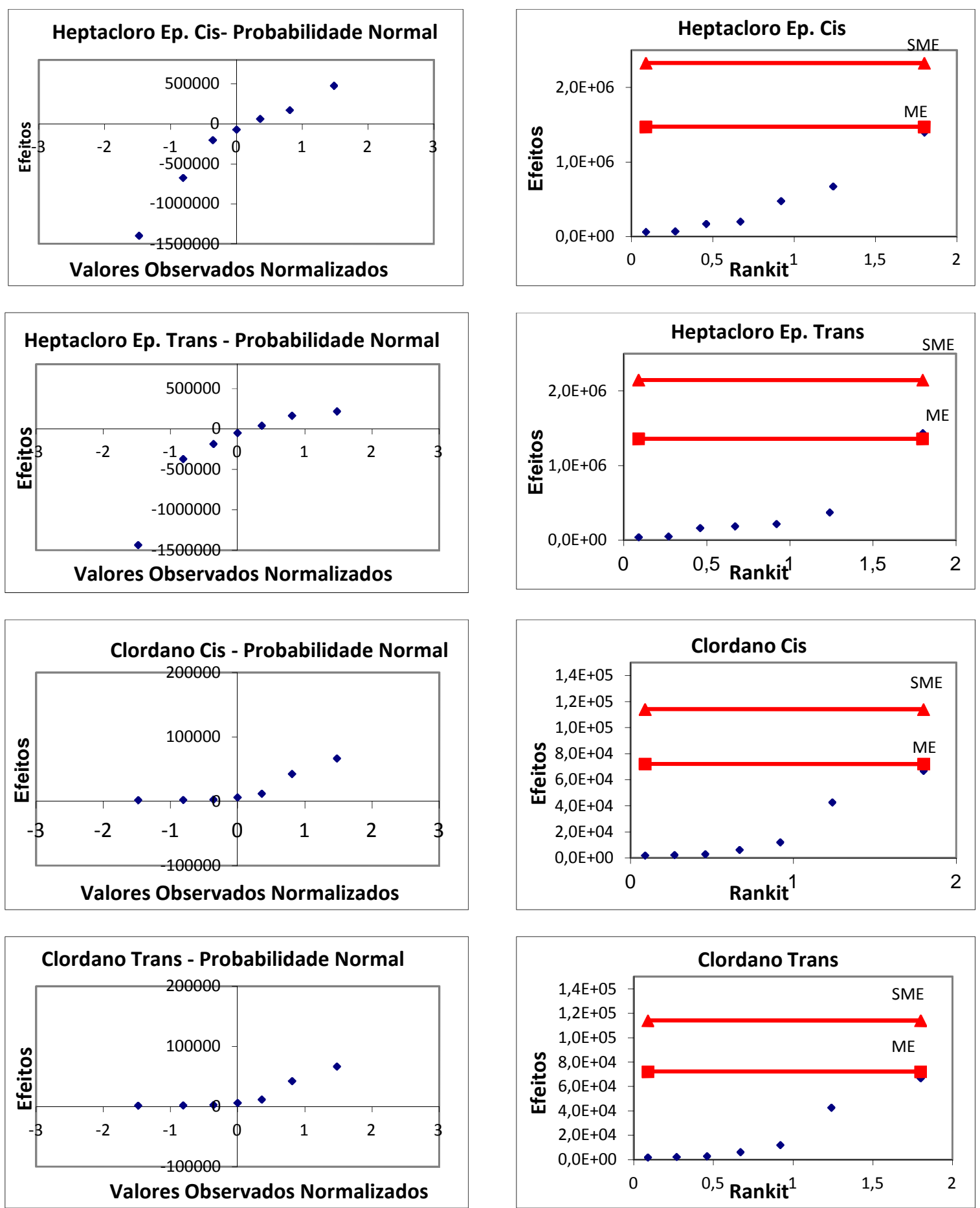

Figura 51. Gráficos para os compostos Heptacloro Epóxido Cis / Trans e Clordano Cis / Trans, representando teste de verificação de significância dos efeitos. 


\subsubsection{Cálculo de incertezas}

$\mathrm{Na}$ Tabela 32 são apresentados os resultados dos cálculos de incerteza expandida para os compostos estudados nas matrizes de Caieiras e Franco da Rocha, considerando-se um ponto intermediário da curva.

Tabela 32. Resultados para as Incertezas expandidas referente a um ponto intermediário das curvas analíticas nas matrizes de Caieiras (C) e Franco da Rocha (FR), considerando $k=1,96$ e $95 \%$ de confiança.

\begin{tabular}{|c|c|c|c|c|c|}
\hline Composto & Matriz & [ ] $\left(\mu \mathrm{g} \cdot \mathrm{g}^{-1}\right)$ & & Incerteza Expandida & $\%$ \\
\hline \multirow{2}{*}{$\alpha-B H C$} & C & 0,363 & \pm & $0,014 \mathrm{mg} \cdot \mathrm{g}^{-1}$ & 3,90 \\
\hline & FR & 0,388 & \pm & $0,019 \mathrm{mg} \cdot \mathrm{g}^{-1}$ & 4,82 \\
\hline \multirow{2}{*}{$\beta-B H C$} & C & 0,415 & \pm & $0,016 \mathrm{mg} \cdot \mathrm{g}^{-1}$ & 3,77 \\
\hline & FR & 0,483 & \pm & $0,020 \mathrm{mg} \cdot \mathrm{g}^{-1}$ & 4,23 \\
\hline \multirow{2}{*}{ v-BHC } & C & 0,409 & \pm & $0,012 \mathrm{mg} \cdot \mathrm{g}^{-1}$ & 2,99 \\
\hline & FR & 0,420 & \pm & $0,024 \mathrm{mg} \cdot \mathrm{g}^{-1}$ & 5,72 \\
\hline \multirow{2}{*}{ ठ-BHC } & C & 0,306 & \pm & $0,015 \mathrm{mg} \cdot \mathrm{g}^{-1}$ & 4,81 \\
\hline & FR & 0,342 & \pm & $0,022 \mathrm{mg} \cdot \mathrm{g}^{-1}$ & 6,35 \\
\hline \multirow{2}{*}{ Heptacloro } & C & 0,401 & \pm & $0,019 \mathrm{mg} \cdot \mathrm{g}^{-1}$ & 4,69 \\
\hline & FR & 0,435 & \pm & $0,038 \mathrm{mg} \cdot \mathrm{g}^{-1}$ & 8,78 \\
\hline \multirow{2}{*}{$\begin{array}{l}\text { Hept. Ep. } \\
\text { Cis }\end{array}$} & C & 0,479 & \pm & $0,015 \mathrm{mg} \cdot \mathrm{g}^{-1}$ & 3,22 \\
\hline & FR & 0,513 & \pm & $0,023 \mathrm{mg} \cdot \mathrm{g}^{-1}$ & 4,42 \\
\hline \multirow{2}{*}{$\begin{array}{c}\text { Hept. Ep. } \\
\text { Trans }\end{array}$} & C & 0,453 & \pm & $0,015 \mathrm{mg} \cdot \mathrm{g}^{-1}$ & 3,42 \\
\hline & FR & 0,479 & \pm & $0,022 \mathrm{mg} \cdot \mathrm{g}^{-1}$ & 4,68 \\
\hline \multirow{2}{*}{$\begin{array}{c}\text { Clordano } \\
\text { Cis }\end{array}$} & C & 0,496 & \pm & $0,015 \mathrm{mg} \cdot \mathrm{g}^{-1}$ & 3,12 \\
\hline & FR & 0,313 & \pm & $0,020 \mathrm{mg} \cdot \mathrm{g}^{-1}$ & 6,40 \\
\hline \multirow{2}{*}{$\begin{array}{c}\text { Clordano } \\
\text { Trans }\end{array}$} & C & 0,485 & \pm & $0,017 \mathrm{mg} \cdot \mathrm{g}^{-1}$ & 3,56 \\
\hline & FR & 0,438 & \pm & $0,016 \mathrm{mg} \cdot \mathrm{g}^{-1}$ & 3,74 \\
\hline
\end{tabular}

Como exposto nas Tabelas 33 e 34 ainda nos gráficos das Figuras 53 a 56, nas matrizes de Caieiras e Franco da Rocha, as incertezas associadas à curva analítica foram as maiores fontes de contribuição para a incerteza combinada de todos os compostos. Estes resultados são coerentes, uma vez que em ambas estão relacionados às concentrações e à resposta do equipamento. 
Tabela 33. Contribuição da incerteza de cada grandeza de entrada no cálculo do mensurando no ensaio com a matriz de Caieiras, considerando o ponto médio do intervalo de concentração das curvas analíticas dos compostos estudados.

\begin{tabular}{|c|c|c|c|c|c|c|}
\hline \multirow{2}{*}{ Composto } & \multirow{2}{*}{$\begin{array}{c}\text { Valor real } \\
\text { calculado } \\
\left(\mu \mathrm{g} \cdot \mathrm{g}^{-1}\right)\end{array}$} & \multicolumn{5}{|c|}{$\begin{array}{c}\text { Contribuições Individuais de cada Incerteza - } \\
\text { Matriz Caieiras }\end{array}$} \\
\hline & & $U_{\text {curva }}$ & $\mathrm{U}_{\mathrm{m}(\mathrm{g}) \text { solo }}$ & $U_{\text {vol.final }}$ & $\mathrm{U}_{\mathrm{rec}}$ & $U_{\text {combinada }}$ \\
\hline$\alpha-B H C$ & 0,3629 & 0,0175 & 0,0017 & 0,0060 & 0,0059 & 0,0071 \\
\hline$\beta-\mathrm{BHC}$ & 0,4150 & 0,0167 & 0,0017 & 0,0060 & 0,0061 & 0,0078 \\
\hline $\mathrm{Y}-\mathrm{BHC}$ & 0,4094 & 0,0124 & 0,0017 & 0,0060 & 0,0055 & 0,0061 \\
\hline ठ-BHC & 0,3061 & 0,0227 & 0,0017 & 0,0060 & 0,0051 & 0,0074 \\
\hline Heptacloro & 0,4015 & 0,0216 & 0,0017 & 0,0060 & 0,0067 & 0,0094 \\
\hline Heptacloro Ep. Cis & 0,4786 & 0,0136 & 0,0017 & 0,0060 & 0,0059 & 0,0077 \\
\hline Heptacloro Ep. Trans & 0,4534 & 0,0147 & 0,0017 & 0,0060 & 0,0061 & 0,0077 \\
\hline Clordano Cis & 0,4964 & 0,0129 & 0,0017 & 0,0060 & 0,0061 & 0,0077 \\
\hline Clordano Trans & 0,4850 & 0,0157 & 0,0017 & 0,0060 & 0,0056 & 0,0086 \\
\hline
\end{tabular}
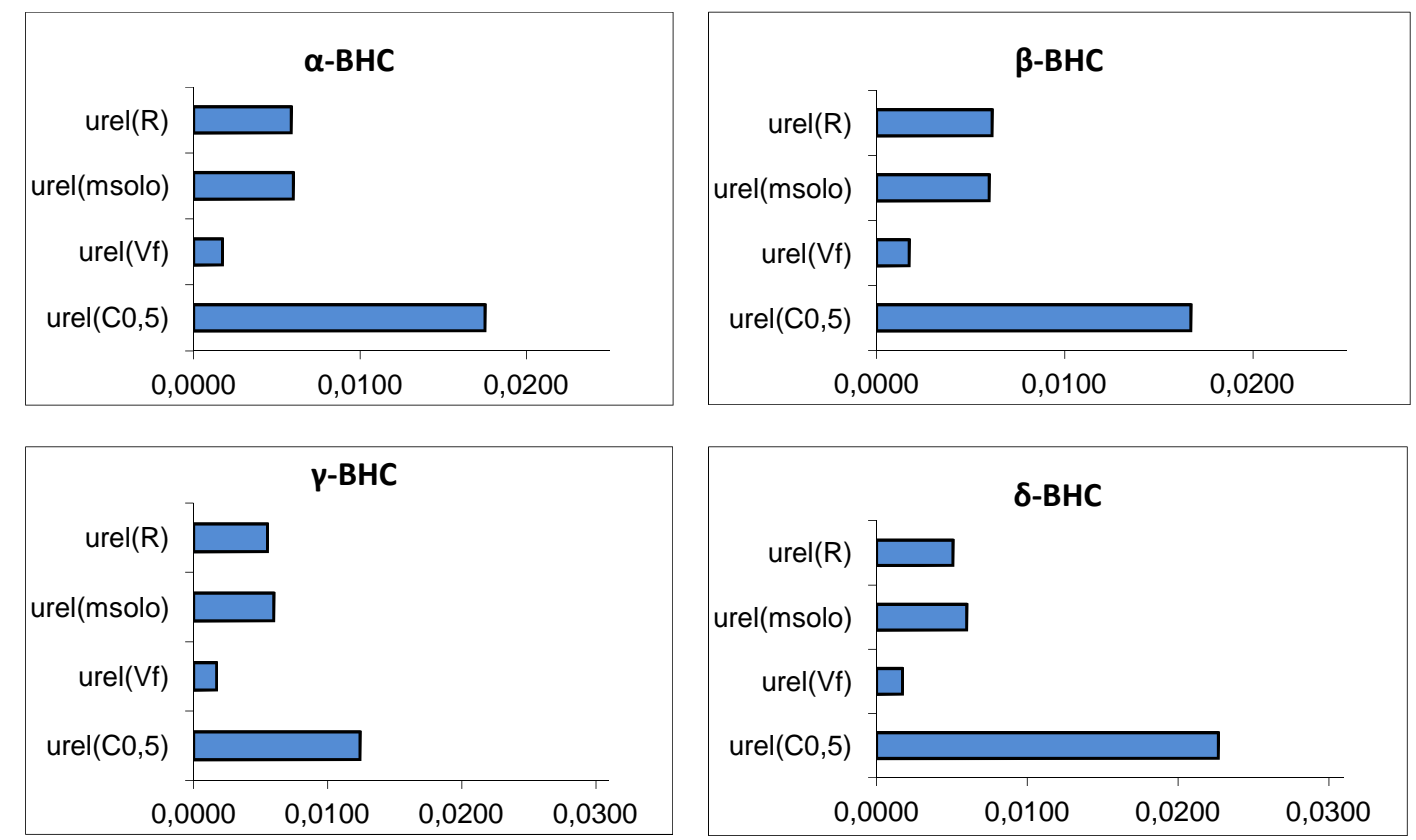

Figura 52. Representações gráficas das incertezas individuais envolvidas na análise dos compostos $\mathrm{BHC} \alpha-, \beta-, \gamma-\mathrm{e} \delta$ - na matriz de Caieiras. 

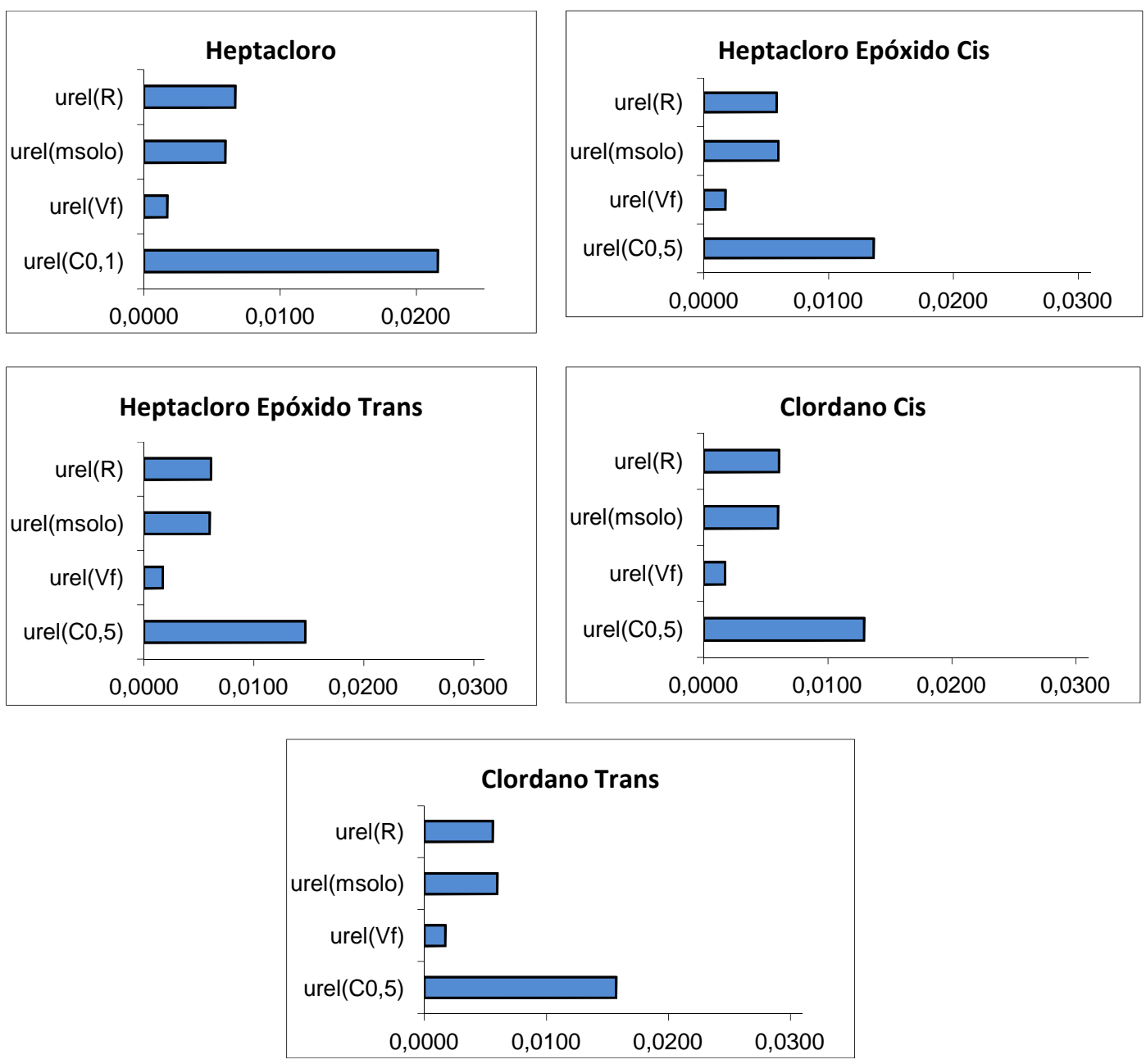

Figura 53. Representações gráficas das incertezas individuais envolvidas na análise dos compostos heptacloro, heptacloro epóxido cis/trans e clordano cis/trans na matriz de Caieiras. 
Tabela 34. Contribuição da incerteza de cada grandeza de entrada no cálculo do mensurando no ensaio com a matriz de Franco da Rocha, considerando o ponto médio do intervalo de concentração das curvas analíticas dos compostos estudados.

\begin{tabular}{|c|c|c|c|c|c|c|}
\hline \multirow{2}{*}{ Composto } & \multirow{2}{*}{$\begin{array}{l}\text { Valor real } \\
\text { calculado } \\
\left(\mu \mathrm{g} \cdot \mathrm{mL}^{-1}\right)\end{array}$} & \multicolumn{5}{|c|}{$\begin{array}{c}\text { Contribuições Individuais de cada Incerteza - } \\
\text { Matriz Franco da Rocha }\end{array}$} \\
\hline & & $U_{\text {curva }}$ & $U_{m(g) \text { solo }}$ & $U_{\text {vol.final }}$ & $\mathrm{U}_{\mathrm{rec}}$ & $\mathbf{U}_{\text {combinada }}$ \\
\hline$\alpha-B H C$ & 0,3878 & 0,0225 & 0,0017 & 0,0060 & 0,0062 & 0,0094 \\
\hline$\beta-B H C$ & 0,4828 & 0,0192 & 0,0017 & 0,0060 & 0,0061 & 0,0102 \\
\hline $\mathrm{Y}-\mathrm{BHC}$ & 0,4195 & 0,0274 & 0,0017 & 0,0060 & 0,0055 & 0,0120 \\
\hline ठ-BHC & 0,3420 & 0,0307 & 0,0017 & 0,0060 & 0,0051 & 0,0109 \\
\hline Heptacloro & 0,4350 & 0,0414 & 0,0017 & 0,0060 & 0,0132 & 0,0191 \\
\hline Heptacloro Ep. Cis & 0,5126 & 0,0204 & 0,0017 & 0,0060 & 0,0059 & 0,0113 \\
\hline Heptacloro Ep. Trans & 0,4792 & 0,0217 & 0,0017 & 0,0060 & 0,0061 & 0,0112 \\
\hline Clordano Cis & 0,3125 & 0,0308 & 0,0017 & 0,0060 & 0,0061 & 0,0100 \\
\hline Clordano Trans & 0,4375 & 0,0167 & 0,0017 & 0,0060 & 0,0056 & 0,0082 \\
\hline
\end{tabular}
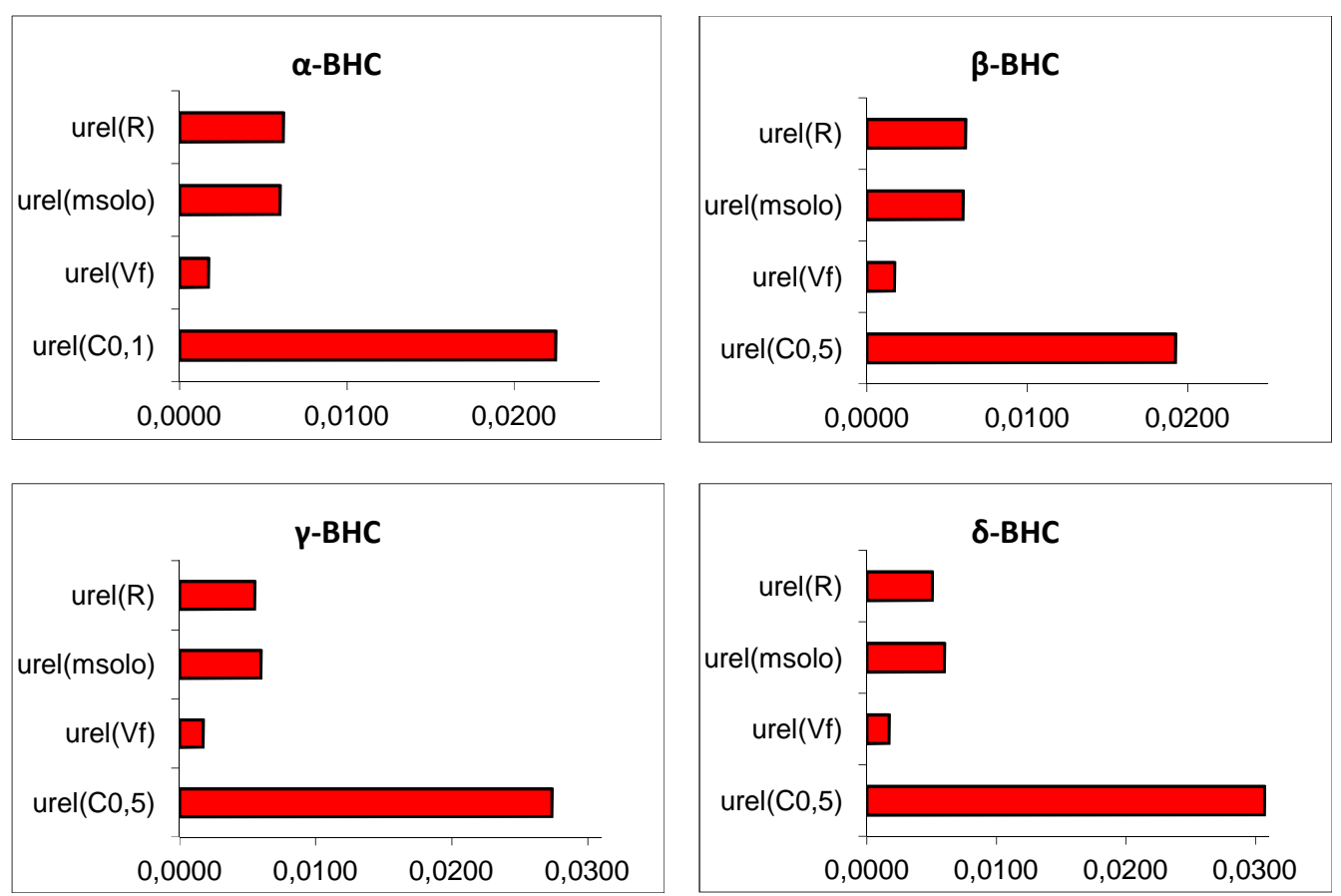

Figura 54. Representações gráficas das incertezas individuais envolvidas na análise dos compostos BHC $\alpha-, \beta-, \gamma-$ e $\delta$ - na matriz de Franco da Rocha. 

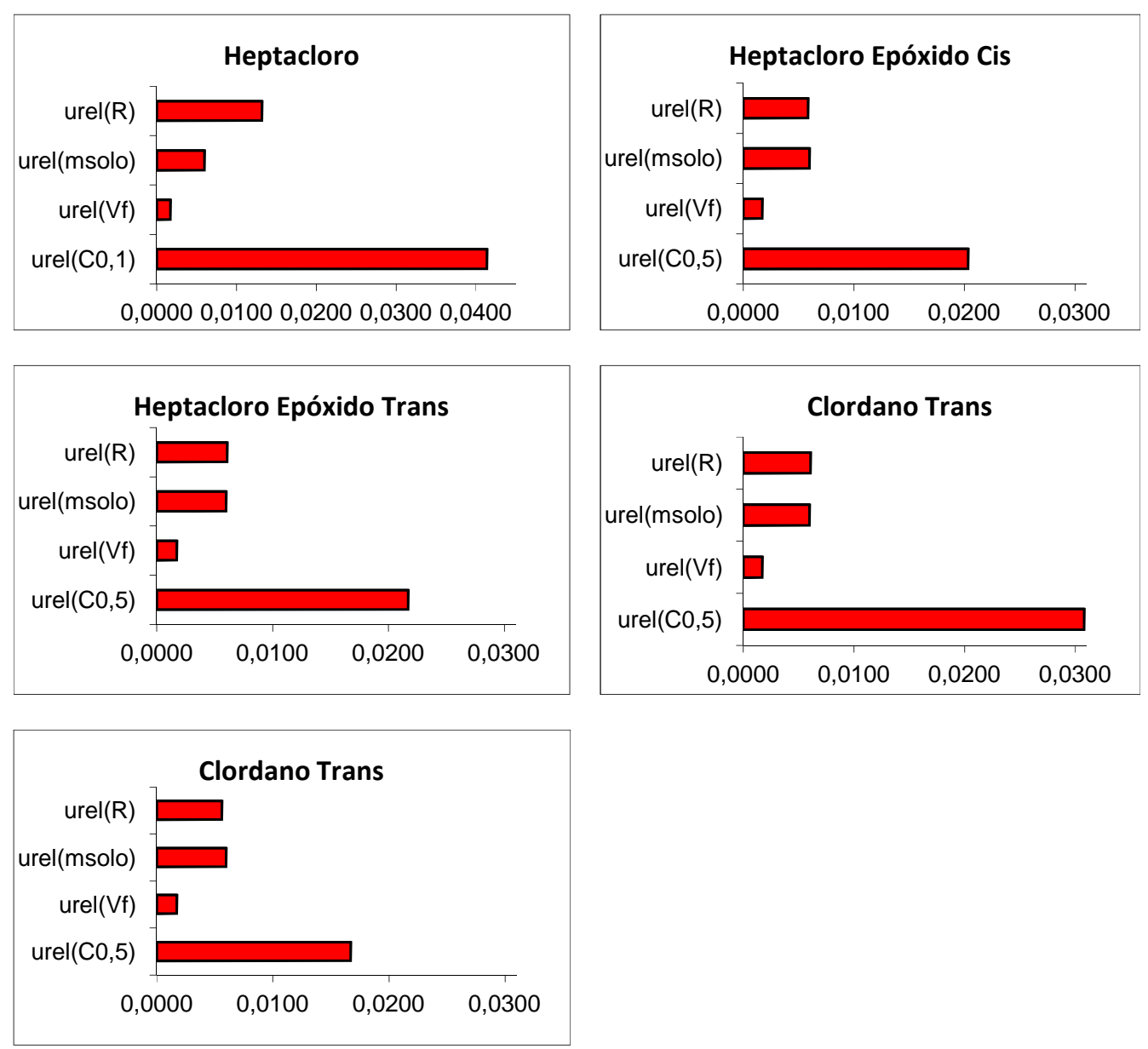

Figura 55. Representações gráficas das incertezas individuais envolvidas na análise dos compostos Heptacloro, Heptacloro Epóxido Cis/ Trans e Clordano Cis / Trans na matriz de Franco da Rocha.

Obs.: Por representar uma contribuição insignificante $(<0,04 \%)$, se comparada às demais, o valor da incerteza relacionada à dilatação do vidro, pode ser desprezado no cálculo. 


\subsection{Resultados das amostras}

As amostras foram coletadas em duas campanhas, sendo a primeira realizada para fazer um reconhecimento de área e alguns testes preliminares a fim de se escolher a amostra testemunho para os ensaios de validação, não sendo, portanto, seus resultados incluídos nos expostos nas Tabelas 35 e 36 .

Os resultados para a 2a Campanha são apresentados nos gráficos das Figuras 57 e 59 e nas Tabelas 35 e 36 . Na Tabela 35 são apresentados os resultados obtidos para as amostras coletadas do município de Caieiras. $\mathrm{Na}$ Figura 55, o aterro industrial pode ser identificado como a região em que foram coletadas as amostras dos pontos 1 a 7 . Nestes pontos foram observadas maiores concentrações de contaminantes. As amostras analisadas compreenderam a faixa de 3 a $66 \mu \mathrm{g} \cdot \mathrm{g}^{-1}$ para o $\alpha$-BHC, o limite máximo permissível para solo industrial, de acordo com a EPA, é de $0,27 \mu \mathrm{g} \cdot \mathrm{g}^{-1}$, para este composto. As amostras dos pontos 8 a 15 foram coletadas em região circunvizinha ao aterro, parte da qual é habitada por uma população carente. Nessas amostras foi detectado a-BHC na faixa de 0,2 a $\quad 47 \mu \mathrm{g} \cdot \mathrm{g}^{-1}$, sendo o limite máximo permissível deste composto para solo, de 0,0077 $\mu \mathrm{g} \cdot \mathrm{g}^{-1}$.

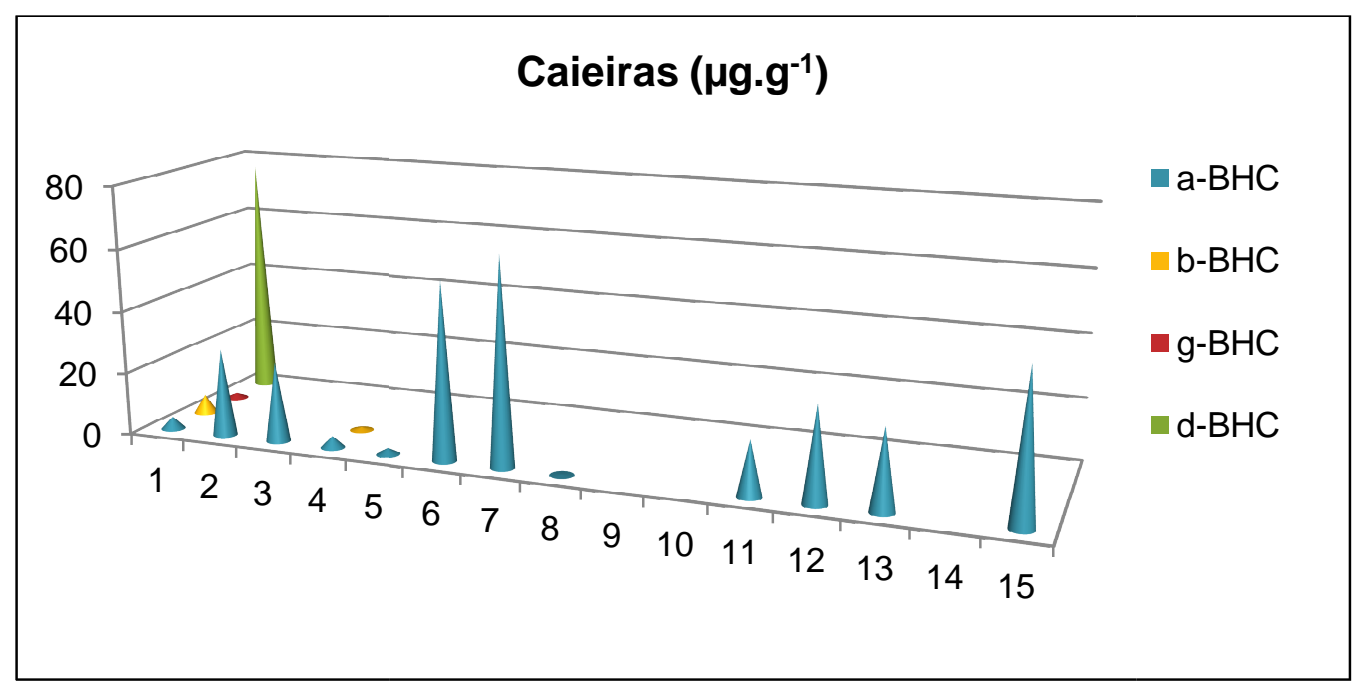

Figura 56. Gráfico que representa os níveis de concentração dos contaminantes encontrados nas amostras referentes aos 15 pontos coletados no município de Caieiras -SP. 
As amostras analisadas apresentaram contaminação superior aos limites máximos permissíveis, segundo a EPA. Os pontos 9, 10 e 14 foram exceções, sendo o último referente a uma região mais elevada que a do aterro e bem próxima às moradias, nesse ponto não foi detectada a presença de contaminantes.

Tabela 35. Resultados das análises das amostras coletadas em $2^{\underline{a}}$ Campanha no município de Caieiras.

\begin{tabular}{|c|c|c|c|c|c|c|c|c|}
\hline \multicolumn{9}{|c|}{ Caieiras } \\
\hline Amostra & $\mathrm{a}-\mathrm{BHC}$ & Unid. & b-BHC & Unid. & $\mathrm{g}-\mathrm{BHC}$ & Unid. & $\mathrm{d}-\mathrm{BHC}$ & Unid. \\
\hline 1 & $3,91 \pm 0,18$ & $g . g^{-1}$ & $6,23 \pm 0,33$ & $\mathrm{mg} \cdot \mathrm{g}^{-1}$ & $1,61 \pm 0,07$ & $\mathrm{mg} \cdot \mathrm{g}^{-1}$ & $76,76 \pm 5,92$ & $\mu g \cdot g^{-1}$ \\
\hline 2 & $28,07 \pm 9,56$ & $\mu \mathrm{g} \cdot \mathrm{g}^{-1}$ & $<0,0120^{a}$ & - & $<0,0116^{a}$ & - & $<0,0116^{a}$ & - \\
\hline 3 & $25,57 \pm 3,28$ & $\mu \mathrm{g} \cdot \mathrm{g}^{-1}$ & $<0,0120^{a}$ & - & $<0,0116^{a}$ & - & $<0,0116^{a}$ & - \\
\hline 4 & $3,69 \pm 0,17$ & $\mathrm{mg} \cdot \mathrm{g}^{-1}$ & $0,97 \pm 0,05$ & $\mathrm{mg} \cdot \mathrm{g}^{-1}$ & $<0,0116^{a}$ & - & $<0,0116^{a}$ & - \\
\hline 5 & $2,04 \pm 0,08$ & $\mathrm{mg} \cdot \mathrm{g}^{-1}$ & $<0,120^{\mathrm{a}}$ & - & $<0,0116^{a}$ & - & $<0,0116^{a}$ & - \\
\hline 6 & $56,73 \pm 4,26$ & $\mu \mathrm{g} \cdot \mathrm{g}^{-1}$ & $<0,120^{a}$ & - & $<0,0116^{a}$ & - & $<0,0116^{a}$ & - \\
\hline 7 & $66,01 \pm 4,01$ & $\mu \mathrm{g} \cdot \mathrm{g}^{-1}$ & $<0,120^{a}$ & - & $<0,0116^{a}$ & - & $<0,0116^{a}$ & - \\
\hline 8 & $0,29 \pm 0,01$ & $\mathrm{mg} \cdot \mathrm{g}^{-1}$ & $<0,120^{a}$ & - & $<0,0116^{a}$ & - & $<0,0116^{a}$ & - \\
\hline 9 & $<0,0126^{a}$ & - & $<0,120^{a}$ & - & $<0,0116^{a}$ & - & $<0,0116^{a}$ & - \\
\hline 10 & $<0,0126^{a}$ & - & $<0,120^{\mathrm{a}}$ & - & $<0,0116^{a}$ & - & $<0,0116^{a}$ & - \\
\hline 11 & $17,50 \pm 1,25$ & $\mu g \cdot g^{-1}$ & $<0,120^{a}$ & - & $<0,0116^{a}$ & - & $<0,0116^{a}$ & - \\
\hline 12 & $30,00 \pm 1,84$ & $\mu g \cdot g^{-1}$ & $<0,120^{a}$ & - & $<0,0116^{a}$ & - & $<0,0116^{a}$ & - \\
\hline 13 & $25,55 \pm 1,15$ & $\mu g \cdot g^{-1}$ & $<0,120^{a}$ & - & $<0,0116^{a}$ & - & $<0,0116^{a}$ & - \\
\hline 14 & $<0,0126^{a}$ & - & $<0,120^{a}$ & - & $<0,0116^{a}$ & - & $<0,0116^{a}$ & - \\
\hline 15 & $47,30 \pm 4,73$ & $\mu \mathrm{g} \cdot \mathrm{g}^{-1}$ & $<0,120^{a}$ & - & $<0,0116^{a}$ & - & $<0,0116^{a}$ & - \\
\hline
\end{tabular}

alimite de quantificação

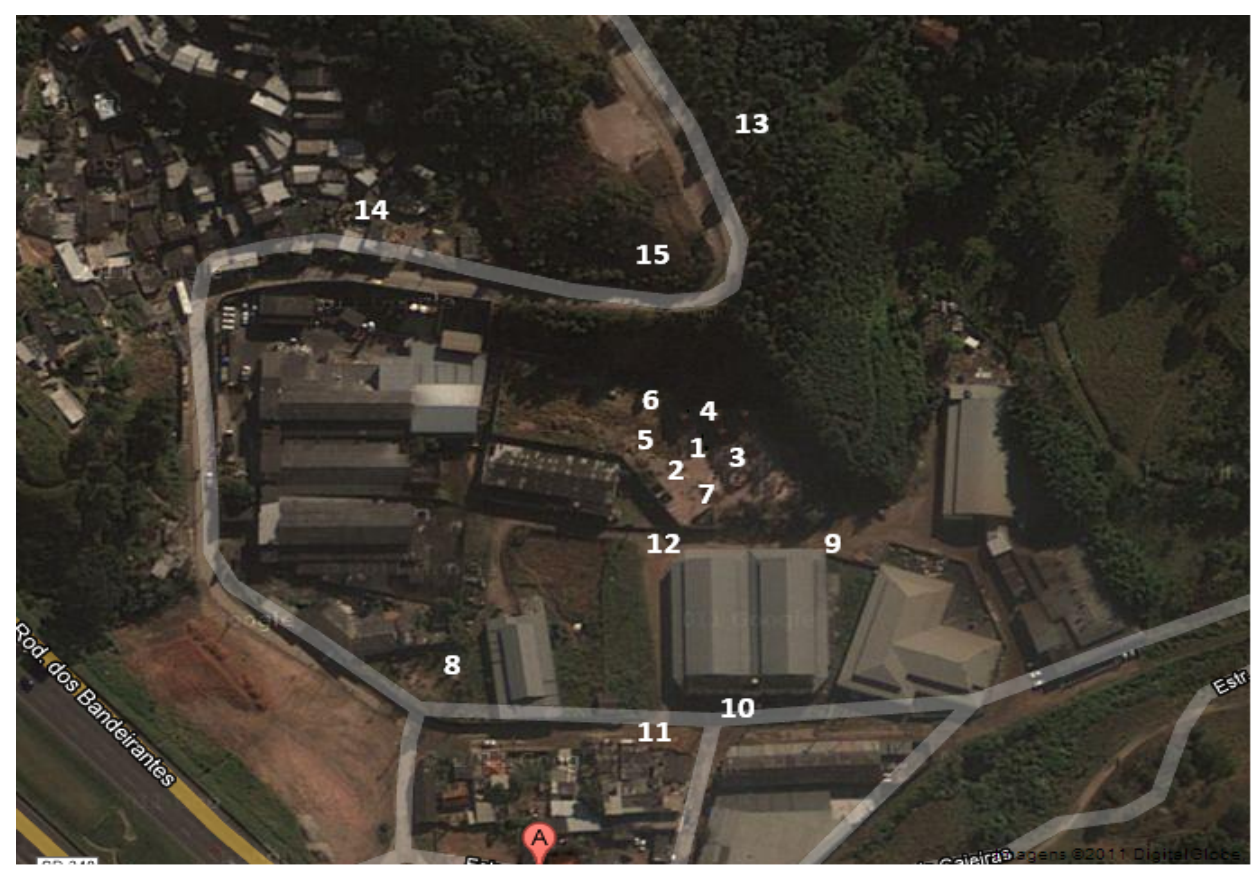

Figura 57. Esquema de amostragem da região de Caieiras. 
No gráfico da Figura 59 e na Tabela 36 são apresentados os resultados das análises realizadas para as amostras coletadas em região industrial no município de Franco da Rocha. Essa região, se comparada a de Caieiras, é bem isolada, não apresentando população circunvizinha. Analisando-se os resultados, é possível aferir que as concentrações dos isômeros de BHC encontradas foram altas, predominando sempre o $\alpha-B H C$. As concentrações obtidas para o $\alpha-B H C$ estiveram na faixa de 0,2 a $70 \mu \mathrm{g} \cdot \mathrm{g}^{-1}$, superiores aos limites máximos permissíveis para solo industrial, $0,27 \mu \mathrm{g} \cdot \mathrm{g}^{-1}$, de acordo com a EPA.

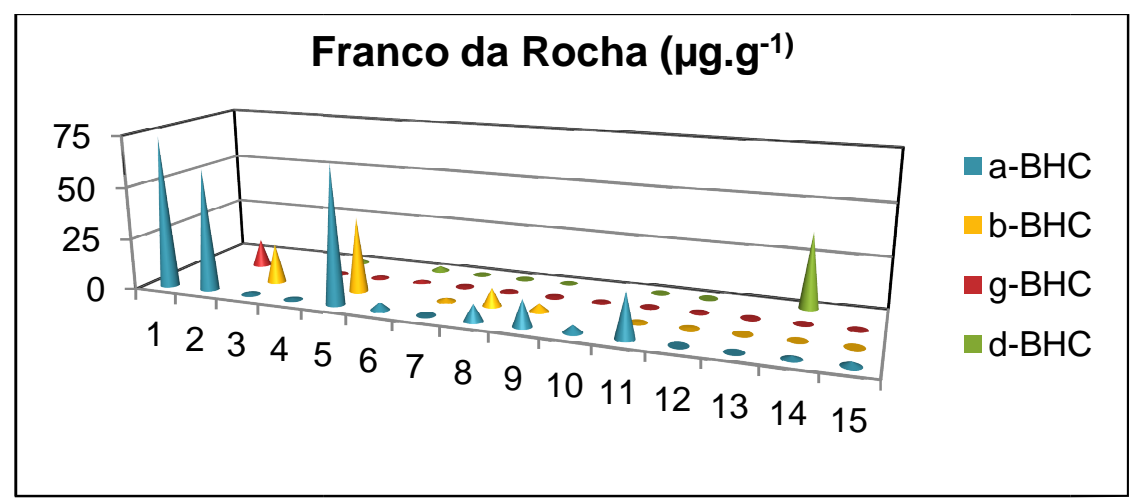

Figura 58. Gráfico que representa os níveis de concentração dos contaminantes encontrados nas amostras referentes aos 15 pontos coletados no município de Caieiras $-\mathrm{SP}$.

Tabela 36. Resultados das análises das amostras coletadas em $2^{\mathrm{a}}$ Campanha no município de Franco da Rocha.

\begin{tabular}{c|ccc|c|c|c|c|c|c}
\hline \multicolumn{8}{c}{ Franco da Rocha } \\
\hline & $\alpha-B H C$ & Unid. & $\beta-B H C$ & Unid. & $\gamma-B H C$ & Unid. & $\delta-B H C$ & Unid. \\
\hline 1 & $73,87 \pm 5,95$ & $\mu \mathrm{g} \cdot \mathrm{g}^{-1}$ & $<0,0121^{\mathrm{a}}$ & - & $<0,0114^{\mathrm{a}}$ & - & $<0,0122^{\mathrm{a}}$ & - \\
2 & $59,82 \pm 2,60$ & $\mu \mathrm{g} \cdot \mathrm{g}^{-1}$ & $<0,0121^{\text {a }}$ & - & $13,69 \pm 0,62$ & $\mu \mathrm{g} \cdot \mathrm{g}^{-1}$ & $<0,0122^{\mathrm{a}}$ & - \\
3 & $0,85 \pm 0,04$ & $\mathrm{mg} \cdot \mathrm{g}^{-1}$ & $19,13 \pm 1,27$ & $\mathrm{mg} \cdot \mathrm{g}^{-1}$ & $<0,0114^{\mathrm{a}}$ & - & $<0,0122^{\mathrm{a}}$ & - \\
4 & $0,72 \pm 0,09$ & $\mathrm{mg} \cdot \mathrm{g}^{-1}$ & $<0,0121^{\mathrm{a}}$ & - & $0,96 \pm 0,11$ & $\mathrm{mg} \cdot \mathrm{g}^{-1}$ & $2,03 \pm 0,35$ & $\mathrm{mg} \cdot \mathrm{g}^{-1}$ \\
5 & $66,72 \pm 3,98$ & $\mathrm{mg} \cdot \mathrm{g}^{-1}$ & $36,25 \pm 4,58$ & $\mathrm{mg} \cdot \mathrm{g}^{-1}$ & $1,00 \pm 0,11$ & $\mathrm{mg} \cdot \mathrm{g}^{-1}$ & $<0,0122^{\mathrm{a}}$ & $\mathrm{mg} \cdot \mathrm{g}^{-1}$ \\
6 & $3,86 \pm 0,13$ & $\mathrm{mg} \cdot \mathrm{g}^{-1}$ & $<0,0121^{\mathrm{a}}$ & - & $1,52 \pm 0,06$ & $\mathrm{mg} \cdot \mathrm{g}^{-1}$ & $2,15 \pm 0,15$ & $\mathrm{mg} \cdot \mathrm{g}^{-1}$ \\
7 & $0,17 \pm 0,01$ & $\mathrm{~g} \cdot \mathrm{g}^{-1}$ & $1,50 \pm 0,12$ & $\mathrm{~g} \cdot \mathrm{g}^{-1}$ & $0,38 \pm 0,03$ & $\mathrm{~g} \cdot \mathrm{g}^{-1}$ & $0,18 \pm 0,01$ & $\mathrm{~g} \cdot \mathrm{g}^{-1}$ \\
8 & $8,01 \pm 0,26$ & $\mathrm{mg} \cdot \mathrm{g}^{-1}$ & $8,60 \pm 0,30$ & $\mathrm{mg} \cdot \mathrm{g}^{-1}$ & $0,43 \pm 0,04$ & $\mathrm{mg} \cdot \mathrm{g}^{-1}$ & $0,21 \pm 0,01$ & $\mathrm{mg} \cdot \mathrm{g}^{-1}$ \\
9 & $13,01 \pm 0,62$ & $\mathrm{mg} \cdot \mathrm{g}^{-1}$ & $3,73 \pm 0,33$ & $\mathrm{mg} \cdot \mathrm{g}^{-1}$ & $0,36 \pm 0,02$ & $\mathrm{mg} \cdot \mathrm{g}^{-1}$ & $0,10 \pm 0,01$ & $\mathrm{mg} \cdot \mathrm{g}^{-1}$ \\
10 & $3,72 \pm 0,23$ & $\mathrm{mg} \cdot \mathrm{g}^{-1}$ & $<0,0121^{\text {a }}$ & - & $0,36 \pm 0,02$ & $\mathrm{mg} \cdot \mathrm{g}^{-1}$ & $<0,0122^{\mathrm{a}}$ & - \\
11 & $21,40 \pm 0,64$ & $\mathrm{mg} \cdot \mathrm{g}^{-1}$ & $0,31 \pm 0,01$ & $\mathrm{mg} \cdot \mathrm{g}^{-1}$ & $0,22 \pm 0,01$ & $\mathrm{mg} \cdot \mathrm{g}^{-1}$ & $0,07 \pm 0,01$ & $\mathrm{mg} \cdot \mathrm{g}^{-1}$ \\
12 & $31,31 \pm 0,90$ & $\mathrm{mg} \cdot \mathrm{g}^{-1}$ & $0,32 \pm 0,01$ & $\mathrm{mg} \cdot \mathrm{g}^{-1}$ & $0,43 \pm 0,01$ & $\mathrm{mg} \cdot \mathrm{g}^{-1}$ & $0,10 \pm 0,005$ & $\mathrm{mg} \cdot \mathrm{g}^{-1}$ \\
13 & $2,50 \pm 0,17$ & $\mathrm{mg} \cdot \mathrm{g}^{-1}$ & $0,80 \pm 0,15$ & $\mathrm{mg} \cdot \mathrm{g}^{-1}$ & $0,19 \pm 0,02$ & $\mathrm{mg} \cdot \mathrm{g}^{-1}$ & $<0,0122^{\mathrm{a}}$ & - \\
14 & $1,51 \pm 0,06$ & $\mathrm{~g} \cdot \mathrm{g}^{-1}$ & $0,11 \pm 0,01$ & $\mathrm{~g} \cdot \mathrm{g}^{-1}$ & $8,70 \pm 1,33$ & $\mathrm{~g} \cdot \mathrm{g}^{-1}$ & $36,67 \pm 5,47$ & $\mathrm{mg} \cdot \mathrm{g}^{-1}$ \\
15 & $1,86 \pm 0,08$ & $\mathrm{mg} \cdot \mathrm{g}^{-1}$ & $0,25 \pm 0,02$ & $\mathrm{mg} \cdot \mathrm{g}^{-1}$ & $0,14 \pm 0,03$ & $\mathrm{mg} \cdot \mathrm{g}^{-1}$ & $<0,0122^{\mathrm{a}}$ & - \\
\hline
\end{tabular}

${ }^{a}$ limite de quantificação 


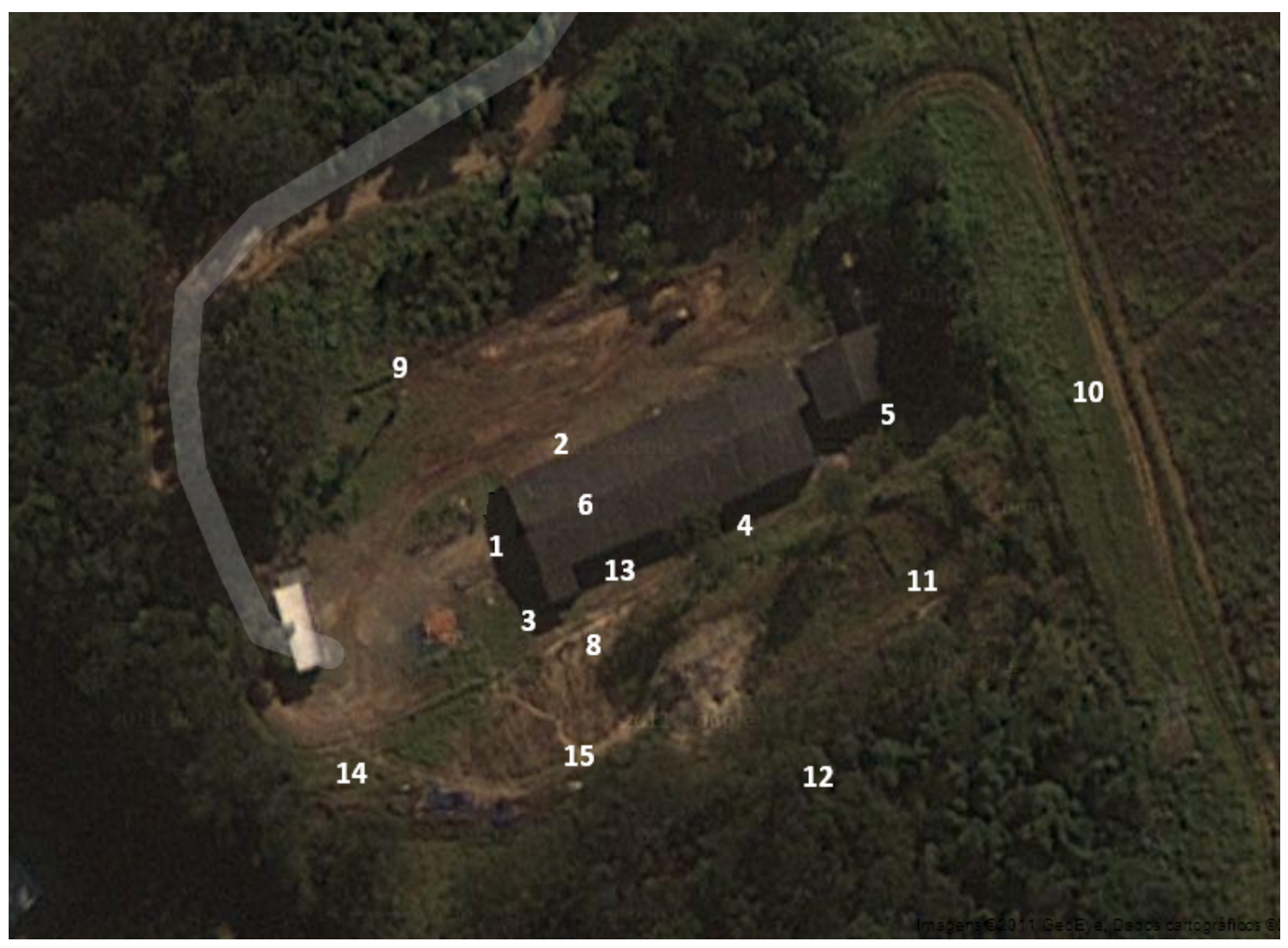

Figura 59. Esquema de amostragem em região industrial no município de Franco da Rocha. 


\section{CONCLUSÕES}

A metodologia desenvolvida se mostrou adequada mediante o processo de validação para a todos os compostos estudados, sendo ainda um método simples que permite a minimização da contaminação e da perda de compostos por excesso de manipulação. A validação do método, a partir dos parâmetros estudados permite que se assegure a qualidade dos resultados obtidos e que 0 desempenho tenha sido avaliado conforme indicado em documento de referência (INMETRO, 2010). Os testes de robustez demonstraram que o método é robusto diante de pequenas variações das condições inicialmente estabelecidas no método para todos os compostos. Todas as variações observadas encontram-se abaixo do ME, não sendo consideradas significativas.

O método de detecção é sensível e seletivo, visto que os compostos estudados apresentaram boa separação, o que fornece segurança na determinação destes para a metodologia desenvolvida.

A recuperação do método foi obtida na faixa de 50 a $120 \%$ para todos os compostos, o que é considerado aceitável para matrizes complexas, demonstrando que o método de extração QuEChERS é vantajoso por ser de fácil e rápida aplicação, tem baixo custo, e além disso, baixo consumo de reagentes, o que faz o seu uso ambientalmente justificável.

Os limites de detecção e quantificação do método compreenderam as faixas de 0,0002 e $0,01 \mu \mathrm{g} \cdot \mathrm{g}^{-1}$, respectivamente, atendendo as necessidades da análise em questão, uma vez que o histórico dos locais de coleta são de grande contaminação, não sendo necessário dispor limites mais baixos, já que não se trata de análise de traços.

Durante a validação foi possível observar que a metodologia, além de seletividade e exata, possui precisão, repetitividade e reprodutibilidade, apesar da dispersão dos resultados entre ensaios repetidos, o que pode ser atribuído à injeção manual.

A metodologia desenvolvida mostrou ser linear na faixa de trabalho proposta, fornecendo resultados de área diretamente proporcionais à concentração dos analitos dentro de uma variação aceitável. 
O processo de validação demonstrou que a metodologia desenvolvida pode ser aplicada à análise proposta nas condições dos parâmetros avaliados.

Através dos experimentos de caracterização dos solos, constatou-se que os solos de ambas as regiões apresentam baixo teor de matéria orgânica, o que pode significar a não retenção dos contaminantes no solo, podendo assim haver lixiviação dos mesmos.

As regiões estudadas apresentam perfil diferente quanto às circunvizinhanças dos aterros, pois o aterro de Caieiras é rodeado por uma população, enquanto o aterro de Franco da Rocha é uma área isolada.

As amostras coletadas nos municípios de Caieiras e Franco da Rocha apresentaram contaminação por BHC $\alpha$-, $\beta$-, $\gamma$ - e $\delta$-, sendo o $\alpha$-BHC o que apresentou maiores concentrações. A região de Caieiras apresentou maior contaminação nos pontos coletados dentro do aterro, na faixa de 2 a $66 \mu \mathrm{g} \cdot \mathrm{g}^{-1}$ para o $\alpha$-BHC. Os pontos coletados em torno do aterro obtiveram resultados na faixa de 0,26 a $47 \mu \mathrm{g} \cdot \mathrm{g}^{-1}$. A região de Franco da Rocha também apresentou contaminação, predominantemente, pelo isômero $\alpha-\mathrm{BHC}$, na faixa de 0,7 a 73 $\mu \mathrm{g} \cdot \mathrm{g}^{-1}$. Os limites máximos permissíveis para este composto, em solo residencial é de $0,077 \mu \mathrm{g} \cdot \mathrm{g}^{-1}$, e em solo industrial, é de $0,27 \mu \mathrm{g} \cdot \mathrm{g}^{-1}$ de acordo com a EPA. As faixas de concentração encontradas estão, portanto, acima dos limites máximos, de acordo com a legislação vigente. 


\section{CONSIDERAÇÕES E PERSPECTIVAS}

O presente trabalho, que teve como objetivo desenvolver um método para identificar e quantificar organoclorados em solo de regiões industriais da grande São Paulo, é de suma importância, pois além de realizar o diagnóstico ambiental de áreas que apresentam forte histórico de contaminação, no que se refere a alguns pesticidas, auxiliará o plano de gestão de ações de remediação de solo da região. Contribuirá para o entendimento dos órgãos responsáveis, como a Vigilância Sanitária (VGS), que tem apresentado grande interesse nestas análises.

Como sugestão para trabalhos posteriores, recomenda-se a continuação do monitoramento desses organoclorados, construindo uma malha de amostragem mais complexa, a fim de estudar os níveis de profundidade nos quais os compostos estão permeando.

Seria interessante também o estudo de outras matrizes, como a água da região e até mesmo matriz biológica, uma vez que essas análises são de interesse da saúde pública.

Outro fato relevante seria a utilização de padrão interno, como um padrão deuterado, a fim de otimizar o estudo da recuperação do método. 


\section{APÊNDICE}

Resultados das incertezas parciais envolvidas no cálculo de Incertezas para os compostos estudados nas matrizes de Caieiras e Franco da Rocha.

\section{CÁLCULO DE INCERTEZAS PARA O $\alpha-B H C$}

1. Incerteza da preparação da solução padrão estoque.

Grandezas de entrada: pureza do padrão u(P) e volume final da solução estoque $\mathrm{u}(\mathrm{V})$.

Componentes de incertezas:

$\mathrm{u}(\mathrm{P})=0,009815$

$\mathrm{u}(\mathrm{V})=0,0585434 \mathrm{~mL}$

Incerteza combinada:

$\mathrm{U}_{\mathrm{c}}(\mathrm{\alpha}-\mathrm{BHC}$ sol. padrão $)=0,0070 \mu \mathrm{g} \cdot \mathrm{mL}^{-1}$ (referente à solução estoque: $99,283 \mu \mathrm{g} \cdot \mathrm{mL}^{-1}$ )

\section{Incerteza da preparação da solução de trabalho}

Grandezas de entrada: incerteza da solução estoque, volume pipetado da solução estoque individual para preparação da solução mista de trabalho e volume final da solução mista de trabalho.

Componentes de incertezas:

$$
\begin{aligned}
& \mathrm{u}\left(\mathrm{C}_{\text {sol. trabalho }}\right)=0,000704079 \mu \mathrm{g} \cdot \mathrm{mL}^{-1} \\
& \mathrm{u}\left(\mathrm{V}_{\mathrm{i} \text { _ sol. trabalho }}\right)=0,000600002 \mathrm{~mL} \\
& \text { calibração }=0,000519615 \\
& \text { repe }=0,0003 \\
& \Delta \mathrm{t}=1,7320 \mathrm{E}-06 \\
& \mathrm{u}\left(\mathrm{V}_{\text {final }}\right)=0,001760767 \mathrm{~mL} \\
& \text { calibração }=0,001732051 \\
& \text { repe }=0,000316228 \\
& \Delta \mathrm{t}=1,73205 \mathrm{E}-05
\end{aligned}
$$

Incerteza combinada

$\mathrm{u}_{\mathrm{c}}\left(\alpha-\mathrm{BHC}_{\text {sol_trabalho }}\right)=0,020694163 \mu \mathrm{g} \cdot \mathrm{mL}^{-1}\left(\right.$ Sol. $\left.9,9283 \mu \mathrm{g} \cdot \mathrm{mL}^{-1}\right)$ 


\section{Incerteza da preparação das soluções de calibração para a curva analítica.}

Grandezas de entrada: incerteza da solução de trabalho, volume pipetado da solução de trabalho e volume dos balões usados para a diluição das soluções.

Incerteza de volume pipetado para cada solução da curva:

$\mathrm{u}(\mathrm{V} 1$ _sol. calibração $)=0,000173498 \mathrm{~mL}$

calibração $=0,000173205$

repe $=0,00001$

$\Delta \mathrm{t}=1,21244 \mathrm{E}-06$

$\mathrm{u}(\mathrm{V} 2$ _sol. calibração $)=0,000433744 \mathrm{~mL}$

calibração $=0,000433013$

repe $=0,000025$

$\Delta \mathrm{t}=3,03109 \mathrm{E}-06$

$\mathrm{u}(\mathrm{V} 3$ _sol. calibração $)=0,000293036 \mathrm{~mL}$

calibração $=0,000288675$

repe $=0,00005$

$\Delta \mathrm{t}=6,06218 \mathrm{E}-06$

$\mathrm{u}(\mathrm{V} 4$ _sol. calibração $)=0,000439554 \mathrm{~mL}$

calibração $=0,000433013$

repe $=0,000075$

$\Delta \mathrm{t}=9,09327 \mathrm{E}-06$

$\mathrm{u}(\mathrm{V} 5$ _sol. calibração $)=0,000586072 \mathrm{~mL}$

calibração $=0,00057735$

repe $=0,0001$

$\Delta \mathrm{t}=1,21244 \mathrm{E}-05$

Incerteza do vial de $1 \mathrm{~mL}$ :

$\mathrm{u}\left(\mathrm{V} \_1 \mathrm{~mL}\right)=0,00586072 \mathrm{~mL}$

calibração $=0,005773503$ 


$$
\begin{aligned}
& \text { repe }=0,001 \\
& \Delta t=0,000121244
\end{aligned}
$$

Incerteza combinada para cada uma das soluções da curva

$\mathrm{u}_{\mathrm{c}}\left(\right.$ a-BHC_C1 $\left.1_{\text {sol_curva }}\right)=0,0018299 \mu \mathrm{g} \cdot \mathrm{mL}^{-1}$ (solução 0,0993 $\mu \mathrm{g} \cdot \mathrm{mL}^{-1}$ )

$\mathrm{u}_{\mathrm{c}}\left(\alpha-B H C \_C 2\right.$ sol_curva $)=0,00457475 \mu \mathrm{g} \cdot \mathrm{mL}^{-1}$ (solução $0,2482 \mu \mathrm{g} \cdot \mathrm{mL}^{-1}$ )

$\mathrm{u}_{\mathrm{c}}\left(\alpha-B H C \_C 3_{\text {sol_curva }}\right)=0,004242552 \mu \mathrm{g} \cdot \mathrm{mL}^{-1}$ (solução 0,4964 $\mu \mathrm{g} \cdot \mathrm{mL}^{-1}$ )

$\mathrm{u}_{\mathrm{c}}\left(\alpha-B H C \_C 4_{\text {sol_curva }}\right)=0,006363828 \mu \mathrm{g} \cdot \mathrm{mL}^{-1}$ (solução $0,7446 \mu \mathrm{g} \cdot \mathrm{mL}^{-1}$ )

$\mathrm{u}_{\mathrm{c}}\left(\alpha-B H C \_C 5_{\text {sol_curva }}\right)=0,008485103 \mu \mathrm{g} \cdot \mathrm{mL}^{-1}$ (solução 0,9928 $\mu \mathrm{g} \cdot \mathrm{mL}^{-1}$ )

Os cálculos até aqui apresentados podem ser aplicados às duas matrizes (Caieiras e Franco da Rocha), uma vez que as grandezas de entrada não envolvem as respostas das amostras. A seguir são descritas individualmente as incertezas calculadas para as curvas analíticas e a recuperação de cada matriz.

\section{MATRIZ CAIEIRAS}

\section{Incerteza da curva analítica}

Grandezas de entrada: área da amostra, área do branco, soluções da curva (C1 a C5), áreas referentes às soluções da curva.

Incerteza combinada da curva analítica

$\mathrm{u}_{\mathrm{c}}\left(\alpha-\mathrm{BHC}_{\text {curva analítica }}\right)=0,0086 \mu \mathrm{g} \cdot \mathrm{mL}^{-1}$

\section{Incerteza da recuperação}

Grandezas de entrada: concentração da solução padrão e resultado da concentração encontrada.

Incerteza combinada da recuperação

$\mathrm{u}_{\mathrm{c}}(\alpha-\mathrm{BHC}$ recuperação $)=0,0064 \mu \mathrm{g} \cdot \mathrm{mL}^{-1}$

$\mathrm{u}\left(\mathrm{C}_{\text {real }}\right)=0,002503804 \mu \mathrm{g} \cdot \mathrm{mL}^{-1}$

$\mathrm{u}\left(\mathrm{C}_{\text {encontrado }}\right)=0,005303505 \mu \mathrm{g} \cdot \mathrm{mL}^{-1}$ 


\section{MATRIZ FRANCO DA ROCHA}

\section{Incerteza da curva analítica}

Grandezas de entrada: área das amostras, área do branco, soluções da curva (C1 a C5), áreas referentes às soluções da curva.

Incerteza combinada da curva analítica

$\mathrm{u}_{\mathrm{C}}\left(\alpha-\mathrm{BHC}_{\text {curva analitica }}\right)=0,0118 \mu \mathrm{g} \cdot \mathrm{mL}^{-1}$

\section{Incerteza da recuperação}

Grandezas de entrada: concentração da solução padrão e resultado da concentração encontrada.

$$
\begin{aligned}
& \text { Incerteza combinada da recuperação } \\
& u_{c}\left(\alpha-B H C_{\text {recuperação })=0,0067 \mu \mathrm{g} \cdot \mathrm{mL}^{-1}}\right. \\
& \mathrm{u}\left(\mathrm{C}_{\text {real }}\right)=0,002503804 \mu \mathrm{g} \cdot \mathrm{mL}^{-1} \\
& \mathrm{u}\left(C_{\text {encontrado }}\right)=0,005671872 \mu \mathrm{g} \cdot \mathrm{mL}^{-1}
\end{aligned}
$$

\section{CÁLCULO DE INCERTEZAS PARA O $\beta$-BHC}

\section{Incerteza da preparação da solução padrão estoque.}

Grandezas de entrada: pureza do padrão $u(P)$ e volume final da solução estoque $\mathrm{u}(\mathrm{V})$.

Componentes de incertezas

$u(P)=0,009237604$

$\mathrm{u}(\mathrm{V})=0,058543431 \mathrm{~mL}$

Incerteza combinada

$\mathrm{u}_{\mathrm{c}}\left(\beta-\mathrm{BHC}_{\text {sol. padrão }}\right)=0,00070 \mu \mathrm{g} \cdot \mathrm{mL}^{-1}\left(\right.$ Sol. $\left.101,352 \mu \mathrm{g} \cdot \mathrm{mL}^{-1}\right)$

\section{Incerteza da preparação da solução de trabalho}

Grandezas de entrada: incerteza da solução estoque, volume pipetado da solução estoque individual para preparação da solução mista de trabalho e volume final da solução mista de trabalho. 
Componentes de incertezas:

$\mathrm{u}\left(\mathrm{C}_{\text {sol. } \text { trabalho }}\right)=0,000703298 \mu \mathrm{g} \cdot \mathrm{mL}^{-1}$

$\mathrm{u}\left(\mathrm{V}_{\mathrm{i} \_ \text {sol. trabalho }}\right)=0,000600002 \mathrm{~mL}$

calibração $=0,000519615$

repe $=0,0003$

$\Delta \mathrm{t}=1,73205 \mathrm{E}-06$

$\mathrm{u}\left(\mathrm{V}_{\text {final }}\right)=0,001760767 \mathrm{~mL}$

calibração $=0,001732051$

repe $=0,000316228$

$\Delta \mathrm{t}=1,73205 \mathrm{E}-05$

Incerteza combinada

$\mathrm{u}_{\mathrm{c}}\left(\beta-\mathrm{BHC}_{\text {sol_trabalho }}\right)=0,021125412 \mu \mathrm{g} \cdot \mathrm{mL}^{-1}\left(\right.$ Sol. $\left.10,1352 \mu \mathrm{g} \cdot \mathrm{mL}^{-1}\right)$

\section{Incerteza da preparação das soluções de calibração para a curva} analítica.

Grandezas de entrada: incerteza da solução de trabalho, volume pipetado da solução de trabalho e volume dos balões usados para a diluição das soluções.

Incerteza de volume pipetado para cada solução da curva

$\mathrm{u}(\mathrm{V} 1$ _sol. curva analítica $)=0,000173498 \mathrm{~mL}$

calibração $=0,000173205$

repe $=0,00001$

$\Delta \mathrm{t}=1,21244 \mathrm{E}-06$

$\mathrm{u}(\mathrm{V} 2$ _sol. curva analítica $)=0,000433744 \mathrm{~mL}$

calibração $=0,000433013$

repe $=0,000025$

$\Delta \mathrm{t}=3,03109 \mathrm{E}-06$

$\mathrm{u}(\mathrm{V} 3$ _sol. curva anal'tica $)=0,000293036 \mathrm{~mL}$

calibração $=0,000288675$

repe $=0,00005$

$\Delta \mathrm{t}=6,06218 \mathrm{E}-06$ 


$$
\begin{aligned}
& u(V 4 \text { sol. curva analítica })=0,000439554 \mathrm{~mL} \\
& \text { calibração }=0,000433013 \\
& \text { repe }=0,000075 \\
& \Delta t=9,09327 \mathrm{E}-06 \\
& u(V 5 \text { sol. curva analítica })=0,000586072 \mathrm{~mL} \\
& \text { calibração }=0,00057735 \\
& \text { repe }=0,0001 \\
& \Delta t=1,21244 E-05 \\
& \text { Incerteza do vial de } 1 \mathrm{~mL} \\
& u\left(V \_1 \mathrm{~mL}\right)=0,00586072 \mathrm{~mL} \\
& \text { calibração }=0,005773503 \\
& \text { repe }=0,001 \\
& \Delta t=0,000121244
\end{aligned}
$$

Incerteza combinada para cada uma das soluções da curva $\mathrm{u}_{\mathrm{c}}\left(\beta-\mathrm{BHC} C \mathrm{C} 1_{\text {sol_curva }}\right)=0,001868034$ (solução $0,1014 \mu \mathrm{g} \cdot \mathrm{mL}^{-1}$ ) $\mathrm{u}_{\mathrm{c}}\left(\beta-\mathrm{BHC} \_\mathrm{C} 2_{\text {sol_curva }}\right)=0,004670085$ (solução $0,2534 \mu \mathrm{g} \cdot \mathrm{mL}^{-1}$ ) $\mathrm{u}_{\mathrm{c}}\left(\beta-\mathrm{BHC} \_\mathrm{C} 3_{\text {sol_curva }}\right)=0,004330964$ (solução $0,5068 \mu \mathrm{g} \cdot \mathrm{mL}^{-1}$ ) $\mathrm{u}_{\mathrm{c}}\left(\beta-\mathrm{BHC} \_\mathrm{C} 4_{\text {sol_curva }}\right)=0,006496446$ (solução $0,7601 \mu \mathrm{g} \cdot \mathrm{mL}^{-1}$ ) $\mathrm{u}_{\mathrm{c}}\left(\beta-\mathrm{BHC}{ }_{\mathrm{C}} 5_{\text {sol_curva }}\right)=0,008661928$ (solução $1,0135 \mu \mathrm{g} \cdot \mathrm{mL}^{-1}$ )

Os cálculos até aqui apresentados podem ser aplicados às duas matrizes (Caieiras e Franco da Rocha), uma vez que as grandezas de entrada não envolvem as respostas das amostras. A seguir são descritas individualmente as incertezas calculadas para as curvas analíticas e a recuperação de cada matriz.

\section{MATRIZ CAIEIRAS}

\section{Incerteza da curva analítica}

Grandezas de entrada: área da amostra, área do branco, soluções da curva (C1 a C5), áreas referentes às soluções da curva. 
Incerteza combinada da curva analítica

$\mathrm{u}_{\mathrm{c}}(\beta-\mathrm{BHC}$ curva analítica $)=0,0086 \mu \mathrm{g} \cdot \mathrm{mL}^{-1}$

\section{Incerteza da recuperação}

Grandezas de entrada: concentração da solução padrão e resultado da concentração encontrada.

$$
\begin{aligned}
& \text { Incerteza combinada da recuperação } \\
& \mathrm{u}_{\mathrm{c}}(\beta-\mathrm{BHC} \text { recuperação })=0,0061 \mu \mathrm{g} \cdot \mathrm{mL}^{-1} \\
& \mathrm{u}\left(\mathrm{C}_{\text {real }}\right)=0,002503803 \mu \mathrm{g} \cdot \mathrm{mL}^{-1} \\
& \mathrm{u}\left(\mathrm{C}_{\text {encontrado }}\right)=0,005616427 \mu \mathrm{g} \cdot \mathrm{mL}^{-1}
\end{aligned}
$$

\section{MATRIZ FRANCO DA ROCHA}

\section{Incerteza da curva analítica}

Grandezas de entrada: área das amostras, área do branco, soluções da curva (C1 a C5), áreas referentes às soluções da curva.

Incerteza combinada da curva analítica

$$
\mathrm{u}_{\mathrm{C}}\left(\beta-B H C_{\text {curva analítica }}\right)=0,0118 \mu \mathrm{g} \cdot \mathrm{mL}^{-1}
$$

\section{Incerteza da recuperação}

Grandezas de entrada: concentração da solução padrão e resultado da concentração encontrada.

Incerteza combinada da recuperação

$\mathrm{u}_{\mathrm{c}}(\beta-\mathrm{BHC} \mathrm{recuperação})=0,0067 \mu \mathrm{g} \cdot \mathrm{mL}^{-1}$

$\mathrm{u}\left(\mathrm{C}_{\text {real }}\right)=0,002503804 \mu \mathrm{g} \cdot \mathrm{mL}^{-{ }^{\prime}}$

$\mathrm{u}\left(\mathrm{C}_{\text {encontrado }}\right)=0,005671872 \mu \mathrm{g} \cdot \mathrm{mL}^{-1}$ 


\section{CÁLCULO DE INCERTEZAS PARA O Y-BHC}

\section{Incerteza da preparação da solução padrão estoque.}

Grandezas de entrada: pureza do padrão u(P) e volume final da solução estoque $\mathrm{u}(\mathrm{V})$.

Componentes de incertezas

$\mathrm{u}(\mathrm{P})=0,005773503$

$\mathrm{u}(\mathrm{V})=0,058543431 \mathrm{~mL}$

Incerteza combinada

$\mathrm{u}_{\mathrm{c}}\left(\mathrm{\gamma}-\mathrm{BHC}_{\text {sol. padrão }}\right)=0,00070 \mu \mathrm{g} \cdot \mathrm{mL}^{-1}$

\section{Incerteza da preparação da solução de trabalho}

Grandezas de entrada: incerteza da solução estoque, volume pipetado da solução estoque individual para preparação da solução mista de trabalho e volume final da solução mista de trabalho.

Componentes de incertezas

$\mathrm{u}\left(\mathrm{C}_{\text {sol. trabalho }}\right)=0,000699591 \mu \mathrm{g} \cdot \mathrm{mL}^{-1}$

$\mathrm{u}\left(\mathrm{V}_{\mathrm{i} \_ \text {sol. trabalho }}\right)=0,000600002 \mathrm{~mL}$

calibração $=0,000519615$

repe $=0,0003$

$\Delta \mathrm{t}=1,73205 \mathrm{E}-06$

$\mathrm{u}\left(\mathrm{V}_{\text {final }}\right)=0,00586072 \mathrm{~mL}$

calibração $=0,005773503$

repe $=0,001$

$\Delta \mathrm{t}=0,000121244$

Incerteza combinada

$\mathrm{u}_{\mathrm{c}}\left(\mathrm{Y}-\mathrm{BHC}_{\text {sol_estoque }}\right)=0,00070 \mu \mathrm{g} \cdot \mathrm{mL}^{-1}$ (Sol. $\left.10,098 \mu \mathrm{g} \cdot \mathrm{mL}^{-1}\right)$

3. Incerteza da preparação das soluções de calibração para a curva analítica

Grandezas de entrada: incerteza da solução de trabalho, volume pipetado da solução de trabalho e volume dos balões usados para a diluição das soluções. 
Incerteza de volume pipetado para cada solução da curva

$$
\begin{aligned}
& \mathrm{u}(\mathrm{V} 1 \text { _sol. calibração })=0,000173498 \mathrm{~mL} \\
& \text { calibração }=0,000173205 \\
& \text { repe }=0,00001 \\
& \Delta \mathrm{t}=1,21244 \mathrm{E}-06 \\
& \mathrm{u}(\mathrm{V} 2 \text { _sol. calibração })=0,000433744 \mathrm{~mL} \\
& \text { calibração }=0,000433013 \\
& \text { repe }=0,000025 \\
& \Delta \mathrm{t}=3,03109 \mathrm{E}-06 \\
& \mathrm{u}\left(\mathrm{V} 3_{\text {_sol. calibração }}\right)=0,000293036 \mathrm{~mL} \\
& \text { calibração }=0,000288675 \\
& \text { repe }=0,00005 \\
& \Delta \mathrm{t}=6,06218 \mathrm{E}-06 \\
& \mathrm{u}(\mathrm{V} 4 \text { _sol. calibração })=0,000439554 \mathrm{~mL} \\
& \text { calibração }=0,000433013 \\
& \text { repe }=0,000075 \\
& \Delta \mathrm{t}=9,09327 \mathrm{E}-06 \\
& \mathrm{u}(\mathrm{V} 5 \text { _sol. calibração })=0,000586072 \mathrm{~mL} \\
& \text { calibração }=0,00057735 \\
& \text { repe }=0,0001 \\
& \Delta \mathrm{t}=1,21244 \mathrm{E}-05
\end{aligned}
$$

Incerteza do vial de $1 \mathrm{~mL}$

$$
\begin{aligned}
\mathrm{u}\left(\mathrm{V}_{\text {_ }} 1 \mathrm{~mL}\right)= & 0,00586072 \mathrm{~mL} \\
& \text { calibração }=0,005773503 \\
& \text { repe }=0,001 \\
& \Delta \mathrm{t}=0,000121244
\end{aligned}
$$

Incerteza combinada para cada uma das soluções da curva $\mathrm{u}_{\mathrm{c}}\left(\mathrm{Y}-\mathrm{BHC} \_\mathrm{C} 1_{\text {sol_curva }}\right)=0,001861178$ (solução $0,1010 \mu \mathrm{g} \cdot \mathrm{mL}^{-1}$ ) 


$$
\begin{aligned}
& \mathrm{u}_{\mathrm{c}}\left(\mathrm{Y} \text {-BHC_C2} 2_{\text {sol_curva }}\right)=0,004652944 \text { (solução } 0,2525 \mu \mathrm{g} \cdot \mathrm{mL}^{-1} \text { ) } \\
& \mathrm{u}_{\mathrm{c}}\left(\mathrm{Y}-\mathrm{BHC} \_\mathrm{C} 3_{\text {sol_curva }}\right)=0,004315068 \text { (solução } 0,5049 \mu \mathrm{g} \cdot \mathrm{mL}^{-1} \text { ) } \\
& \mathrm{u}_{\mathrm{c}}\left(\mathrm{\gamma}-\mathrm{BHC} \_\mathrm{C} 4_{\text {sol_curva }}\right)=0,006472602 \text { (solução } 0,7574 \mu \mathrm{g} \cdot \mathrm{mL}^{-1} \text { ) } \\
& \mathrm{u}_{\mathrm{c}}\left(\mathrm{\gamma}-\mathrm{BHC} \_\mathrm{C} 5_{\text {sol_curva }}\right)=0,008630135 \text { (solução } 1,0098 \mu \mathrm{g} \cdot \mathrm{mL}^{-1} \text { ) }
\end{aligned}
$$

Os cálculos até aqui apresentados podem ser aplicados às duas matrizes (Caieiras e Franco da Rocha), uma vez que as grandezas de entrada não envolvem as respostas das amostras. A seguir são descritas individualmente as incertezas calculadas para as curvas analíticas e a recuperação de cada matriz.

\section{MATRIZ CAIEIRAS}

\section{Incerteza da curva analítica}

Grandezas de entrada: área da amostra, área do branco, soluções da curva (C1 a C5), áreas referentes às soluções da curva.

Incerteza combinada da curva analítica

$\mathrm{u}_{\mathrm{c}}\left(\mathrm{\gamma}-\mathrm{BHC}_{\text {curva analítica }}\right)=0,0072 \mu \mathrm{g} \cdot \mathrm{mL}^{-1}$

\section{Incerteza da recuperação}

Grandezas de entrada: concentração da solução padrão e resultado da concentração encontrada.

Incerteza combinada da recuperação

$$
\begin{aligned}
& \mathrm{u}_{\mathrm{c}}\left(\mathrm{\gamma}-\mathrm{BHC} \mathrm{C}_{\text {recuperação }}\right)=0,0063 \mu \mathrm{g} \cdot \mathrm{mL}^{-1} \\
& \mathrm{u}\left(\mathrm{C}_{\text {real }}\right)=0,002503803 \mu \mathrm{g} \cdot \mathrm{mL}^{-1} \\
& \mathrm{u}\left(\mathrm{C}_{\text {encontrado }}\right)=0,004939159 \mu \mathrm{g} \cdot \mathrm{mL}^{-1}
\end{aligned}
$$

\section{MATRIZ FRANCO DA ROCHA}

\section{Incerteza da curva analítica}

Grandezas de entrada: área das amostras, área do branco, soluções da curva (C1 a C5), áreas referentes às soluções da curva.

Incerteza combinada da curva analítica

$$
\mathrm{u}_{\mathrm{C}}\left(\mathrm{\gamma}-\mathrm{BHC}_{\text {curva analítica }}\right)=0,0162 \mu \mathrm{g} \cdot \mathrm{mL}^{-1}
$$




\section{Incerteza da recuperação}

Grandezas de entrada: concentração da solução padrão e resultado da concentração encontrada.

$$
\begin{aligned}
& \text { Incerteza combinada da recuperação } \\
& \mathrm{u}_{\mathrm{c}}(\mathrm{\gamma}-\mathrm{BHC} \text { recuperação })=0,0063 \mu \mathrm{g} \cdot \mathrm{mL}^{-1} \\
& \mathrm{u}\left(\mathrm{C}_{\text {real }}\right)=0,002503803 \mu \mathrm{g} \cdot \mathrm{mL}^{-1} \\
& \mathrm{u}\left(\mathrm{C}_{\text {encontrado }}\right)=0,004939159 \mu \mathrm{g} \cdot \mathrm{mL}^{-1}
\end{aligned}
$$

\section{CÁLCULO DE INCERTEZAS PARA O ס-BHC}

\section{Incerteza da preparação da solução padrão estoque}

Grandezas de entrada: pureza do padrão $u(P)$ e volume final da solução estoque $\mathrm{u}(\mathrm{V})$.

Componentes de incertezas

$\mathrm{u}(\mathrm{P})=0,005773503$

$\mathrm{u}(\mathrm{V})=0,058543431 \mathrm{~mL}$

Incerteza combinada

$\mathrm{u}_{\mathrm{c}}\left(\delta-\mathrm{BHC}_{\text {sol. padrão }}\right)=0,00070 \mu \mathrm{g} \cdot \mathrm{mL}^{-1}$

\section{Incerteza da preparação da solução de trabalho}

Grandezas de entrada: incerteza da solução estoque, volume pipetado da solução estoque individual para preparação da solução mista de trabalho e volume final da solução mista de trabalho.

Componentes de incertezas

$$
\begin{aligned}
& \mathrm{u}\left(\mathrm{C}_{\text {sol. trabalho }}\right)=0,000699591 \mu \mathrm{g} \cdot \mathrm{mL}^{-1} \\
& \mathrm{u}\left(\mathrm{V}_{\mathrm{i} \text { _trabalho }}\right)=0,000600002 \mathrm{~mL} \\
& \text { calibração }=0,000519615 \\
& \text { repe }=0,0003 \\
& \Delta \mathrm{t}=1,73205 \mathrm{E}-06 \\
& \mathrm{u}\left(\mathrm{V}_{\text {final }}\right)=0,001760767 \mathrm{~mL} \\
& \text { calibração }=0,001732051 \\
& \text { repe }=0,000316228 \\
& \Delta \mathrm{t}=1,73205 \mathrm{E}-05
\end{aligned}
$$


Incerteza combinada

$\mathrm{u}_{\mathrm{c}}\left(\delta-\mathrm{BHC}_{\text {sol_trabalho }}\right)=0,020635175 \mu \mathrm{g} \cdot \mathrm{mL}^{-1}\left(\right.$ Sol. $\left.9,9 \mu \mathrm{g} \cdot \mathrm{mL}^{-1}\right)$

\section{Incerteza da preparação das soluções de calibração para a curva analítica}

Grandezas de entrada: incerteza da solução de trabalho, volume pipetado da solução de trabalho e volume dos balões usados para a diluição das soluções.

\section{Incerteza de volume pipetado para cada solução da curva}

$\mathrm{u}(\mathrm{V} 1$ _sol. curva analítica $)=0,000173498 \mathrm{~mL}$

calibração $=0,000173205$

repe $=0,00001$

$\Delta \mathrm{t}=1,21244 \mathrm{E}-06$

$\mathrm{u}(\mathrm{V} 2$ _ sol. curva analítica $)=0,000433744 \mathrm{~mL}$

calibração $=0,000433013$

repe $=0,000025$

$\Delta \mathrm{t}=3,03109 \mathrm{E}-06$

$\mathrm{u}(\mathrm{V} 3$ _sol. curva analítica $)=0,000293036 \mathrm{~mL}$

calibração $=0,000288675$

repe $=0,00005$

$\Delta \mathrm{t}=6,06218 \mathrm{E}-06$

$\mathrm{u}(\mathrm{V} 4$ _sol. curva analítica $)=0,000439554 \mathrm{~mL}$

calibração $=0,000433013$

repe $=0,000075$

$\Delta \mathrm{t}=9,09327 \mathrm{E}-06$

$\mathrm{u}(\mathrm{V} 5$ _sol. curva analítica $)=0,000586072 \mathrm{~mL}$

calibração $=0,00057735$

repe $=0,0001$

$\Delta \mathrm{t}=1,21244 \mathrm{E}-05$ 


$$
\begin{aligned}
& \text { Incerteza do vial de } 1 \mathrm{~mL} \\
& \mathrm{u}\left(\mathrm{V}_{1} 1 \mathrm{~mL}\right)=0,00586072 \mathrm{~mL} \\
& \text { calibração }=0,005773503 \\
& \text { repe }=0,001 \\
& \Delta t=0,000121244
\end{aligned}
$$

Incerteza combinada para cada uma das soluções da curva

$\mathrm{u}_{\mathrm{c}}\left(\delta\right.$-BHC_C1 $\left.1_{\text {sol_curva }}\right)=0,001824684$ (solução $0,0990 \mu \mathrm{g} \cdot \mathrm{mL}^{-1}$ )

$\mathrm{u}_{\mathrm{c}}\left(\delta\right.$-BHC_C2 $\left.2_{\text {sol_curva }}\right)=0,00456171$ (solução $0,2475 \mu \mathrm{g} \cdot \mathrm{mL}^{-1}$ )

$\mathrm{u}_{\mathrm{c}}\left(\delta\right.$-BHC_C $\left.3_{\text {sol_curva }}\right)=0,004230459$ (solução $0,4950 \mu \mathrm{g} \cdot \mathrm{mL}^{-1}$ )

$\mathrm{u}_{\mathrm{c}}\left(\delta\right.$-BHC_C4 $\left.4_{\text {sol_curva }}\right)=0,006345688$ (solução $0,7425 \mu \mathrm{g} \cdot \mathrm{mL}^{-1}$ )

$\mathrm{u}_{\mathrm{c}}\left(\delta\right.$-BHC_C5 $\left.5_{\text {sol_curva }}\right)=0,008460917$ (solução $0,9900 \mu \mathrm{g} \cdot \mathrm{mL}^{-1}$ )

Os cálculos até aqui apresentados podem ser aplicados às duas matrizes (Caieiras e Franco da Rocha), uma vez que as grandezas de entrada não envolvem as respostas das amostras. A seguir são descritas individualmente as incertezas calculadas para as curvas analíticas e a recuperação de cada matriz.

\section{MATRIZ CAIEIRAS}

\section{Incerteza da curva analítica}

Grandezas de entrada: área da amostra, área do branco, soluções da curva (C1 a C5), áreas referentes às soluções da curva.

Incerteza combinada da curva analítica

$\mathrm{u}_{\mathrm{c}}\left(\delta-\mathrm{BHC}_{\text {curva analitica }}\right)=0,0112 \mu \mathrm{g} \cdot \mathrm{mL}^{-1}$

\section{Incerteza da recuperação}

Grandezas de entrada: concentração da solução padrão e resultado da concentração encontrada.

Incerteza combinada da recuperação

$\mathrm{u}_{\mathrm{c}}\left(\delta-\mathrm{BHC}_{\text {recuperação }}\right)=0,0065 \mu \mathrm{g} \cdot \mathrm{mL}^{-1}$

$\mathrm{u}\left(\mathrm{C}_{\text {real }}\right)=0,002503804 \mu \mathrm{g} \cdot \mathrm{mL}^{-1}$

$\mathrm{u}\left(\mathrm{C}_{\text {encontrado }}\right)=0,004405319 \mu \mathrm{g} \cdot \mathrm{mL}^{-1}$ 


\section{MATRIZ FRANCO DA ROCHA}

\section{Incerteza da curva analítica}

Grandezas de entrada: área das amostras, área do branco, soluções da curva (C1 a C5), áreas referentes às soluções da curva.

Incerteza combinada da curva analítica

$\mathrm{u}_{\mathrm{C}}\left(\delta-\mathrm{BHC}_{\text {curva analítica }}\right)=0,0170 \mu \mathrm{g} \cdot \mathrm{mL}^{-1}$

\section{Incerteza da recuperação}

Grandezas de entrada: concentração da solução padrão e resultado da concentração encontrada.

$$
\begin{aligned}
& \text { Incerteza combinada da recuperação } \\
& \mathrm{u}_{\mathrm{c}}(\delta-\mathrm{BHC} \text { recuperação })=0,0065 \mu \mathrm{g} \cdot \mathrm{mL}^{-1} \\
& \mathrm{u}\left(\mathrm{C}_{\text {real }}\right)=0,002503804 \mu \mathrm{g} \cdot \mathrm{mL}^{-1} \\
& \mathrm{u}\left(\mathrm{C}_{\text {encontrado }}\right)=0,004405319 \mu \mathrm{g} \cdot \mathrm{mL}^{-1}
\end{aligned}
$$

\section{CÁLCULO DE INCERTEZAS PARA O HEPTACLORO}

1. Incerteza da preparação da solução padrão estoque.

Grandezas de entrada: pureza do padrão $u(P)$ e volume final da solução estoque $\mathrm{u}(\mathrm{V})$.

Componentes de incertezas

$\mathrm{u}(\mathrm{P})=0,018475209$

$\mathrm{u}(\mathrm{V})=0,058543431 \mathrm{~mL}$

Incerteza combinada

$\mathrm{u}_{\mathrm{c}}($ Heptacloro sol. padrão $)=0,00072 \mu \mathrm{g} \cdot \mathrm{mL}^{-1}$

\section{Incerteza da preparação da solução de trabalho}

Grandezas de entrada: incerteza da solução estoque, volume pipetado da solução estoque individual para preparação da solução mista de trabalho e volume final da solução mista de trabalho. 
Componentes de incertezas

$\mathrm{u}\left(\mathrm{C}_{\text {sol. trabalho }}\right)=0,000720991 \mu \mathrm{g} \cdot \mathrm{mL}^{-1}$

$\mathrm{u}\left(\mathrm{V}_{\mathrm{i}_{\text {_t }} \text { trabalho }}\right)=0,000600002 \mathrm{~mL}$

calibração $=0,000519615$

repe $=0,0003$

$\Delta \mathrm{t}=1,73205 \mathrm{E}-06$

$\mathrm{u}\left(\mathrm{V}_{\text {final }}\right)=0,001760767 \mathrm{~mL}$

calibração $=0,001732051$

repe $=0,000316228$

$\Delta \mathrm{t}=1,73205 \mathrm{E}-05$

Incerteza combinada

$\mathrm{u}_{\mathrm{c}}($ Heptacloro sol_trabalho $)=0,020378392 \mu \mathrm{g} \cdot \mathrm{mL}^{-1}\left(\right.$ Sol. $\left.9,7768 \mu \mathrm{g} \cdot \mathrm{mL}^{-1}\right)$

\section{Incerteza da preparação das soluções de calibração para a curva analítica}

Grandezas de entrada: incerteza da solução de trabalho, volume pipetado da solução de trabalho e volume dos balões usados para a diluição das soluções.

Incerteza de volume pipetado para cada solução da curva

$\mathrm{u}(\mathrm{V} 1$ _sol. curva analítica $)=0,000173498 \mathrm{~mL}$

calibração $=0,000173205$

repe $=0,00001$

$\Delta \mathrm{t}=1,21244 \mathrm{E}-06$

$\mathrm{u}(\mathrm{V} 2$ _sol. curva analítica $)=0,000433744 \mathrm{~mL}$

calibração $=0,000433013$

repe $=0,000025$

$\Delta \mathrm{t}=3,03109 \mathrm{E}-06$

$\mathrm{u}(\mathrm{V} 3$ _sol. curva analítica $)=0,000293036 \mathrm{~mL}$

calibração $=0,000288675$

repe $=0,00005$

$\Delta \mathrm{t}=6,06218 \mathrm{E}-06$ 


$$
\begin{aligned}
& \mathrm{u}(\mathrm{V} 4 \text { _sol. curva analítica })=0,000439554 \mathrm{~mL} \\
& \text { calibração }=0,000433013 \\
& \text { repe }=0,000075 \\
& \Delta t=9,09327 \mathrm{E}-06 \\
& \mathrm{u}(\mathrm{V} 5 \text { _sol. curva analítica })=0,000586072 \mathrm{~mL} \\
& \text { calibração }=0,00057735 \\
& \text { repe }=0,0001 \\
& \Delta \mathrm{t}=1,21244 \mathrm{E}-05 \\
& \text { Incerteza do vial de } 1 \mathrm{~mL} \\
& \mathrm{u}\left(\mathrm{V} \_1 \mathrm{~mL}\right)=0,00586072 \mu \mathrm{gg} \cdot \mathrm{mL}^{-1} \\
& \text { calibração }=0,005773503 \\
& \text { repe }=0,001 \\
& \Delta t=0,000121244
\end{aligned}
$$

Incerteza combinada para cada uma das soluções da curva

$$
\begin{aligned}
& \mathrm{u}_{\mathrm{c}}\left(\text { Heptacloro_C1 } 1_{\text {sol_curva }}\right)=0,001801977 \text { (solução 0,0978 } \mu \mathrm{g} \cdot \mathrm{mL}^{-1} \text { ) } \\
& \mathrm{u}_{\mathrm{c}} \text { (Heptacloro_C2 } \text { sol_curva }_{\text {a }}=0,004504942 \text { (solução } 0,2444 \mu \mathrm{g} \cdot \mathrm{mL}^{-1} \text { ) } \\
& \mathrm{u}_{\mathrm{c}}(\text { Heptacloro_C3 } \text { sol_curva })=0,004177813 \text { (solução } 0,4888 \mu \mathrm{g} \cdot \mathrm{mL}^{-1} \text { ) } \\
& \mathrm{u}_{\mathrm{c}}\left(\text { Heptacloro_C4} 4_{\text {sol_curva }}\right)=0,00626672 \text { (solução } 0,7333 \mu \mathrm{g} \cdot \mathrm{mL}^{-1} \text { ) } \\
& \mathrm{u}_{\mathrm{c}}\left(\text { Heptacloro_C5} 5_{\text {sol_curva }}\right)=0,008355626 \text { (solução } 0,9777 \mu \mathrm{g} \cdot \mathrm{mL}^{-1} \text { ) }
\end{aligned}
$$

Os cálculos até aqui apresentados podem ser aplicados às duas matrizes (Caieiras e Franco da Rocha), uma vez que as grandezas de entrada não envolvem as respostas das amostras. A seguir são descritas individualmente as incertezas calculadas para as curvas analíticas e a recuperação de cada matriz.

\section{MATRIZ CAIEIRAS}

\section{Incerteza da curva analítica}

Grandezas de entrada: área da amostra, área do branco, soluções da curva (C1 a C5), áreas referentes às soluções da curva. 
Incerteza combinada da curva analítica

$\mathrm{u}_{\mathrm{c}}($ Heptacloro curva analítica $)=0,0108 \mu \mathrm{g} \cdot \mathrm{mL}^{-1}$

\section{Incerteza da recuperação}

Grandezas de entrada: concentração da solução padrão e resultado da concentração encontrada.

\section{Incerteza combinada da recuperação}

$\mathrm{u}_{\mathrm{c}}($ Heptacloro recuperação $)=0,0067 \mu \mathrm{g} \cdot \mathrm{mL}^{-1}$

$\mathrm{u}\left(\mathrm{C}_{\text {real }}\right)=0,002503805 \mu \mathrm{g} \cdot \mathrm{mL}^{-1}$

$\mathrm{u}\left(\mathrm{C}_{\text {encontrado }}\right)=0,00623365 \mu \mathrm{g} \cdot \mathrm{mL}^{-1}$

\section{MATRIZ FRANCO DA ROCHA}

\section{Incerteza da curva analítica}

Grandezas de entrada: área das amostras, área do branco, soluções da curva (C1 a C5), áreas referentes às soluções da curva.

Incerteza combinada da curva analítica

$\mathrm{u}_{\mathrm{C}}\left(\right.$ Heptacloro $\left._{\text {curva analítica }}\right)=0,0224 \mu \mathrm{g} \cdot \mathrm{mL}^{-1}$

\section{Incerteza da recuperação}

Grandezas de entrada: concentração da solução padrão e resultado da concentração encontrada.

Incerteza combinada da recuperação

$\mathrm{u}_{\mathrm{c}}($ Heptacloro recuperação $)=0,0131 \mu \mathrm{g} \cdot \mathrm{mL}^{-1}$

$\mathrm{u}\left(\mathrm{C}_{\text {real }}\right)=0,002503805 \mu \mathrm{g} \cdot \mathrm{mL}^{-1}$

$\mathrm{u}\left(\mathrm{C}_{\text {encontrado }}\right)=0,012953695 \mu \mathrm{g} \cdot \mathrm{mL}^{-1}$

\section{CÁLCULO DE INCERTEZAS PARA O HEPTACLORO EPÓXIDO CIS}

\section{Incerteza da preparação da solução padrão estoque}

Grandezas de entrada: pureza do padrão $u(P)$ e volume final da solução estoque $\mathrm{u}(\mathrm{V})$. 
Componentes de incertezas

$\mathrm{u}(\mathrm{P})=0,008660254$

$\mathrm{u}(\mathrm{V})=0,03786159 \mathrm{~mL}$

Incerteza combinada

$\mathrm{u}_{\mathrm{c}}($ Hept_Ep_Cis sol. padrão $)=0,00114 \mu \mathrm{g} \cdot \mathrm{mL}^{-1}$

\section{Incerteza da preparação da solução de trabalho}

Grandezas de entrada: incerteza da solução estoque, volume pipetado da solução estoque individual para preparação da solução mista de trabalho e volume final da solução mista de trabalho.

\section{Componentes de incertezas}

$\mathrm{u}\left(\mathrm{C}_{\text {sol. } \text {. trabalho }}\right)=0,001140984 \mu \mathrm{g} \cdot \mathrm{mL}^{-1}$

$\mathrm{u}\left(\mathrm{V}_{\mathrm{i} \text { _trabalho }}\right)=0,000600002 \mathrm{~mL}$

calibração $=0,000519615$

repe $=0,0003$

$\Delta \mathrm{t}=1,73205 \mathrm{E}-06$

$\mathrm{u}\left(\mathrm{V}_{\text {final }}\right)=0,001760767 \mathrm{~mL}$

calibração $=0,001732051$

repe $=0,000316228$

$\Delta \mathrm{t}=1,73205 \mathrm{E}-05$

Incerteza combinada

$u_{c}($ Hept_Ep_Cis sol. trabalho $)=0,022863426 \mu \mathrm{g} \cdot \mathrm{mL}^{-1}\left(\right.$ Sol. $\left.10,9689 \mu \mathrm{g} \cdot \mathrm{mL}^{-1}\right)$

\section{Incerteza da preparação das soluções de calibração para a curva analítica}

Grandezas de entrada: incerteza da solução de trabalho, volume pipetado da solução de trabalho e volume dos balões usados para a diluição das soluções.

Incerteza de volume pipetado para cada solução da curva

$\mathrm{u}\left(\mathrm{V} 1_{\text {_sol. curva analitica }}\right)=0,000173498 \mathrm{~mL}$

calibração $=0,000173205$ 
repe $=0,00001$

$\Delta \mathrm{t}=1,21244 \mathrm{E}-06$

$\mathrm{u}(\mathrm{V} 2$ _sol. curva analítica $)=0,000433744 \mathrm{~mL}$

calibração $=0,000433013$

repe $=0,000025$

$\Delta \mathrm{t}=3,03109 \mathrm{E}-06$

$\mathrm{u}(\mathrm{V} 3$ _sol. curva analítica $)=0,000293036 \mathrm{~mL}$

calibração $=0,000288675$

repe $=0,00005$

$\Delta \mathrm{t}=6,06218 \mathrm{E}-06$

$\mathrm{u}(\mathrm{V} 4$ _sol. curva analítica $)=0,000439554 \mathrm{~mL}$

calibração $=0,000433013$

repe $=0,000075$

$\Delta \mathrm{t}=9,09327 \mathrm{E}-06$

u(V5_sol. curva analítica $)=0,000586072 \mathrm{~mL}$

calibração $=0,00057735$

repe $=0,0001$

$\Delta \mathrm{t}=1,21244 \mathrm{E}-05$

Incerteza do vial de $1 \mathrm{~mL}$

$\mathrm{u}\left(\mathrm{V} \_1 \mathrm{~mL}\right)=0,00586072 \mathrm{~mL}$

calibração $=0,005773503$

repe $=0,001$

$\Delta \mathrm{t}=0,000121244$

Incerteza combinada para cada uma das soluções da curva

$\mathrm{u}_{\mathrm{c}}\left(\right.$ Hept_Ep_Cis_C1 $1_{\text {sol_curva }}$ ) $=0,002021706$ (solução 0,1097 $\mu \mathrm{g} \cdot \mathrm{mL}^{-1}$ )

$\mathrm{u}_{\mathrm{c}}$ (Hept_Ep_Cis_C2 sol_curva) $=0,005054264$ (solução $0,2742 \mu \mathrm{g} \cdot \mathrm{mL}^{-1}$ )

$u_{c}\left(\right.$ Hept_Ep_Cis_C3 sol_curva $_{\text {) }}=0,004687247$ (solução $0,5484 \mu \mathrm{g} \cdot \mathrm{mL}^{-1}$ )

$\mathrm{u}_{\mathrm{c}}\left(\right.$ Hept_Ep_Cis_C4 $\left.4_{\text {sol_curva }}\right)=0,007030871$ (solução $0,8227 \mu \mathrm{g} \cdot \mathrm{mL}^{-1}$ )

$\mathrm{u}_{\mathrm{c}}($ Hept_Ep_Cis_C5 sol_curva $)=0,009374495$ (solução 1,0969 $\mu \mathrm{g} \cdot \mathrm{mL}^{-1}$ ) 
Os cálculos até aqui apresentados podem ser aplicados às duas matrizes (Caieiras e Franco da Rocha), uma vez que as grandezas de entrada não envolvem as respostas das amostras. A seguir são descritas individualmente as incertezas calculadas para as curvas analíticas e a recuperação de cada matriz.

\section{MATRIZ CAIEIRAS}

\section{Incerteza da curva analítica}

Grandezas de entrada: área da amostra, área do branco, soluções da curva (C1 a C5), áreas referentes às soluções da curva.

\section{Incerteza combinada da curva analítica \\ $\mathrm{u}_{\mathrm{c}}($ Hept_Ep_Cis curva analítica $)=0,0079 \mu \mathrm{g} \cdot \mathrm{mL}^{-1}$}

\section{Incerteza da recuperação}

Grandezas de entrada: concentração da solução padrão e resultado da concentração encontrada.

$$
\begin{aligned}
& \text { Incerteza combinada da recuperação } \\
& \mathrm{u}_{\mathrm{c}}(\text { Hept_Ep_Cis recuperação })=0,0057 \mu \mathrm{g} \cdot \mathrm{mL}^{-1} \\
& \mathrm{u}\left(\mathrm{C}_{\text {real }}\right)=0,002503815 \mu \mathrm{g} \cdot \mathrm{mL}^{-1} \\
& \mathrm{u}\left(C_{\text {encontrado }}\right)=0,005298724 \mu \mathrm{g} \cdot \mathrm{mL}^{-1}
\end{aligned}
$$

\section{MATRIZ FRANCO DA ROCHA}

\section{Incerteza da curva analítica}

Grandezas de entrada: área das amostras, área do branco, soluções da curva (C1 a C5), áreas referentes às soluções da curva.

Incerteza combinada da curva analítica

$\mathrm{u}_{\mathrm{C}}($ Hept_Ep_Cis recuperação $)=0,0126 \mu \mathrm{g} \cdot \mathrm{mL}^{-1}$ 


\section{Incerteza da recuperação}

Grandezas de entrada: concentração da solução padrão e resultado da concentração encontrada.

Incerteza combinada da recuperação

$\mathrm{u}_{\mathrm{c}}($ Hept_Ep_Cis recuperação $)=0,0057 \mu \mathrm{g} \cdot \mathrm{mL}^{-1}$

$\mathrm{u}\left(\mathrm{C}_{\text {real }}\right)=0,002503815 \mu \mathrm{g} \cdot \mathrm{mL}^{-1}$

$\mathrm{u}\left(\mathrm{C}_{\text {encontrado }}\right)=0,005298724 \mu \mathrm{g} \cdot \mathrm{mL}^{-1}$

\section{CÁLCULO DE INCERTEZAS PARA O HEPTACLORO EPÓXIDO TRANS}

\section{Incerteza da preparação da solução padrão estoque}

Grandezas de entrada: pureza do padrão $u(P)$ e volume final da solução estoque $\mathrm{u}(\mathrm{V})$.

Componentes de incertezas

$u(P)=0,005773503$

$\mathrm{u}(\mathrm{V})=0,03786159 \mathrm{~mL}$

Incerteza combinada

$\mathrm{u}_{\mathrm{c}}($ Hept_Ep_Trans sol. padrão $)=0,00113 \mu \mathrm{g} \cdot \mathrm{mL}^{-1}$

\section{Incerteza da preparação da solução de trabalho}

Grandezas de entrada: incerteza da solução estoque, volume pipetado da solução estoque individual para preparação da solução mista de trabalho e volume final da solução mista de trabalho.

Componentes de incertezas

$\mathrm{u}\left(\mathrm{C}_{\text {sol. estoque }}\right)=0,001133657 \mu \mathrm{g} \cdot \mathrm{mL}^{-1}$

$\mathrm{u}\left(\mathrm{V}_{\text {i_estoque }}\right)=0,000600002 \mathrm{~mL}$

calibração $=0,000519615$

repe $=0,0003$

$\Delta \mathrm{t}=1,73205 \mathrm{E}-06$

$\mathrm{u}\left(\mathrm{V}_{\text {final }}\right)=0,001760767 \mathrm{~mL}$

calibração $=0,001732051$

repe $=0,000316228$ 


$$
\Delta \mathrm{t}=1,73205 \mathrm{E}-05
$$

Incerteza combinada

$\mathrm{u}_{\mathrm{c}}($ Hept_Ep_Trans sol_estoque $)=0,021671232 \mu \mathrm{g} \cdot \mathrm{mL}^{-1}\left(\right.$ Sol. $\left.10,3969 \mu \mathrm{g} \cdot \mathrm{mL}^{-1}\right)$

\section{Incerteza da preparação das soluções de calibração para a curva analítica}

Grandezas de entrada: incerteza da solução de trabalho, volume pipetado da solução de trabalho e volume dos balões usados para a diluição das soluções.

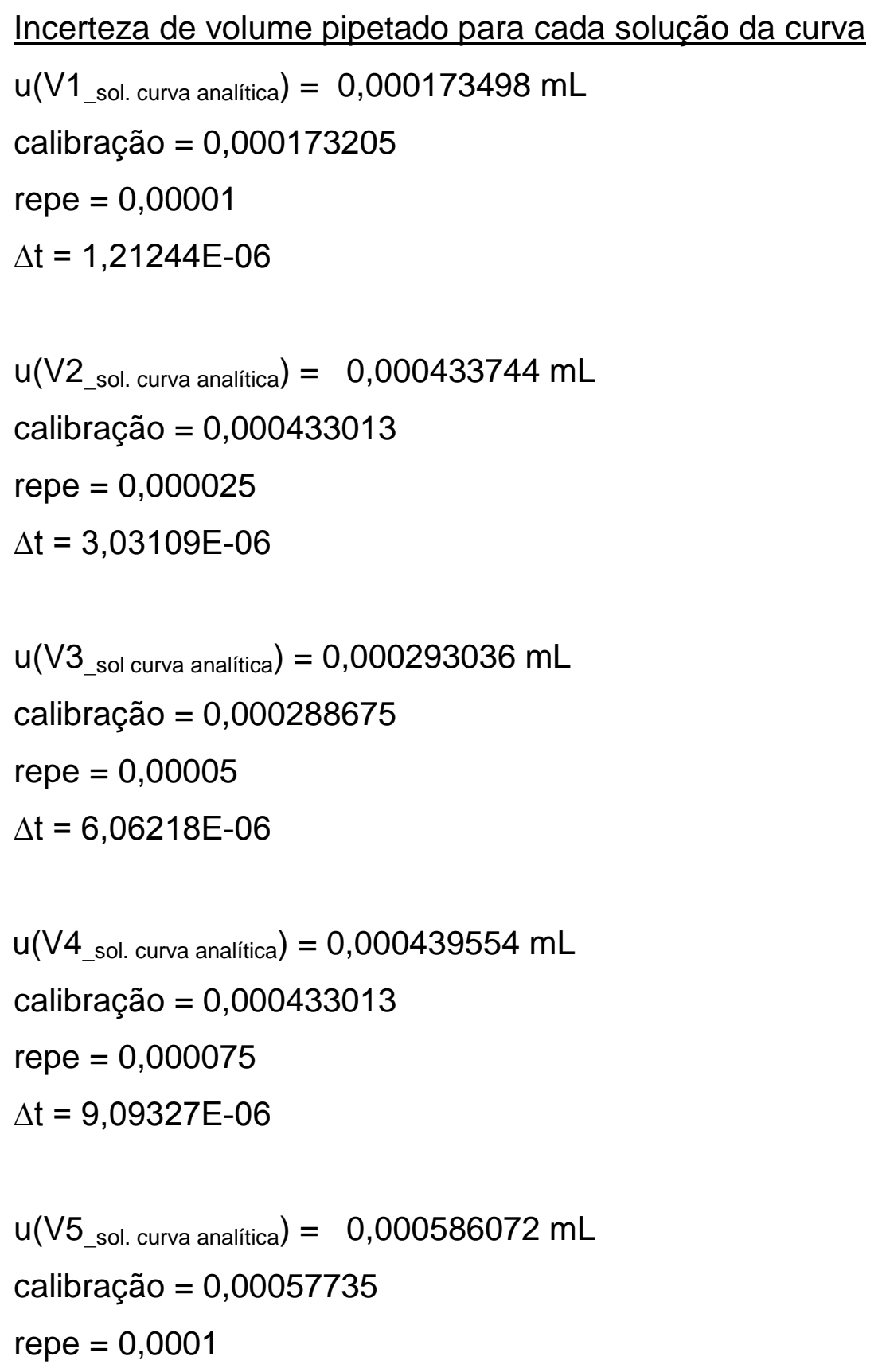




$$
\Delta \mathrm{t}=1,21244 \mathrm{E}-05
$$

Incerteza do vial de $1 \mathrm{~mL}$

$\mathrm{u}\left(\mathrm{V} \_1 \mathrm{~mL}\right)=0,00586072 \mathrm{~mL}$

calibração $=0,005773503$

repe $=0,001$

$\Delta \mathrm{t}=0,000121244$

Incerteza combinada para cada uma das soluções da curva

$\mathrm{u}_{\mathrm{c}}\left(\right.$ Hept_Ep_Trans_C1 $\left.1_{\text {sol_curva }}\right)=0,001916283$ (sol. 0,1040 $\mu \mathrm{g} \cdot \mathrm{mL}^{-1}$ )

$\mathrm{u}_{\mathrm{c}}\left(\right.$ Hept_Ep_Trans_C2 $\left.2_{\text {sol_curva }}\right)=0,004790708$ (sol. 0,2599 $\left.\mu \mathrm{g} \cdot \mathrm{mL}^{-1}\right)$

$\mathrm{u}_{\mathrm{c}}\left(\right.$ Hept_Ep_Trans_C3 $\left.3_{\text {sol_curva }}\right)=0,00444283$ (sol. 0,5198 $\mu \mathrm{g} \cdot \mathrm{mL}^{-1}$ )

$\mathrm{u}_{\mathrm{c}}\left(\right.$ Hept_Ep_Trans_C4 $\left.4_{\text {sol_curva }}\right)=0,006664245$ (sol. 0,7798 $\mu \mathrm{g} \cdot \mathrm{mL}^{-1}$ )

$\mathrm{u}_{\mathrm{c}}($ Hept_Ep_Trans_C5 sol_curva $)=0,008885659$ (sol. 1,0397 $\left.\mu \mathrm{g} \cdot \mathrm{mL}^{-1}\right)$

Os cálculos até aqui apresentados podem ser aplicados às duas matrizes (Caieiras e Franco da Rocha), uma vez que as grandezas de entrada não envolvem as respostas das amostras. A seguir são descritas individualmente as incertezas calculadas para as curvas analíticas e a recuperação de cada matriz.

\section{MATRIZ CAIEIRAS}

\section{Incerteza da curva analítica}

Grandezas de entrada: área da amostra, área do branco, soluções da curva (C1 a C5), áreas referentes às soluções da curva.

Incerteza combinada da curva analítica

$\mathrm{u}_{\mathrm{c}}($ Hept_Ep_Trans curva analítica $)=0,0081 \mu \mathrm{g} \cdot \mathrm{mL}^{-1}$

\section{Incerteza da recuperação}

Grandezas de entrada: concentração da solução padrão e resultado da concentração encontrada.

Incerteza combinada da recuperação

$\mathrm{u}_{\mathrm{c}}\left(\right.$ Hept_Ep_Trans recuperação $=0,0059 \mu \mathrm{g} \cdot \mathrm{mL}^{-1}$ 


$$
\begin{aligned}
& \mathrm{u}\left(\mathrm{C}_{\text {real }}\right)=0,002503818 \mu \mathrm{g} \cdot \mathrm{mL}^{-1} \\
& \mathrm{u}\left(\mathrm{C}_{\text {encontrado }}\right)=0,005563628 \mu \mathrm{g} \cdot \mathrm{mL}^{-1}
\end{aligned}
$$

\section{MATRIZ FRANCO DA ROCHA}

\section{Incerteza da curva analítica}

Grandezas de entrada: área das amostras, área do branco, soluções da curva (C1 a C5), áreas referentes às soluções da curva.

Incerteza combinada da curva analítica

$\mathrm{u}_{\mathrm{C}}($ Hept_Ep_Trans curva analitica $)=0,0127 \mu \mathrm{g} \cdot \mathrm{mL}^{-1}$

\section{Incerteza da recuperação}

Grandezas de entrada: concentração da solução padrão e resultado da concentração encontrada.

Incerteza combinada da recuperação

$\mathrm{u}_{\mathrm{c}}($ Hept_Ep_Trans recuperação $)=0,0059 \mu \mathrm{g} \cdot \mathrm{mL}^{-1}$

$\mathrm{u}\left(\mathrm{C}_{\text {real }}\right)=0,002503818 \mu \mathrm{g} \cdot \mathrm{mL}^{-1}$

$\mathrm{u}\left(\mathrm{C}_{\text {encontrado }}\right)=0,005563628 \mu \mathrm{g} \cdot \mathrm{mL}^{-1}$

\section{CÁLCULO DE INCERTEZAS PARA O CLORDANO CIS}

\section{Incerteza da preparação da solução padrão estoque}

Grandezas de entrada: pureza do padrão $u(P)$ e volume final da solução estoque $\mathrm{u}(\mathrm{V})$.

Componentes de incertezas

$\mathrm{u}(\mathrm{P})=0,005773503$

$\mathrm{u}(\mathrm{V})=0,03786159 \mathrm{~mL}$

Incerteza combinada

$\mathrm{u}_{\mathrm{c}}($ Clord_Cis sol. padrão $)=0,00113 \mu \mathrm{g} \cdot \mathrm{mL}^{-1}$ 


\section{Incerteza da preparação da solução de trabalho}

Grandezas de entrada: incerteza da solução estoque, volume pipetado da solução estoque individual para preparação da solução mista de trabalho e volume final da solução mista de trabalho.

\section{Componentes de incertezas}

$$
\begin{aligned}
& u\left(C_{\text {sol. trabalho }}\right)=0,001133657 \mu \mathrm{g} \cdot \mathrm{mL}^{-1} \\
& \mathrm{u}\left(\mathrm{V}_{\mathrm{i}_{\text {_ sol. trabalho }}}\right)=0,000600002 \mathrm{~mL} \\
& \text { calibração }=0,000519615 \\
& \text { repe }=0,0003 \\
& \Delta \mathrm{t}=1,73205 \mathrm{E}-06 \\
& \mathrm{u}\left(\mathrm{V}_{\text {final }}\right)=0,001760767 \mathrm{~mL} \\
& \text { calibração }=0,001732051 \\
& \text { repe }=0,000316228 \\
& \Delta \mathrm{t}=1,73205 \mathrm{E}-05
\end{aligned}
$$

Incerteza combinada

$\mathrm{u}_{\mathrm{c}}($ Clord_Cis sol_estoque $)=0,022286149 \mu \mathrm{g} \cdot \mathrm{mL}^{-1}\left(\right.$ Sol. $\left.10,692 \mu \mathrm{g} \cdot \mathrm{mL}^{-1}\right)$

\section{Incerteza da preparação das soluções de calibração para a curva analítica}

Grandezas de entrada: incerteza da solução de trabalho, volume pipetado da solução de trabalho e volume dos balões usados para a diluição das soluções.

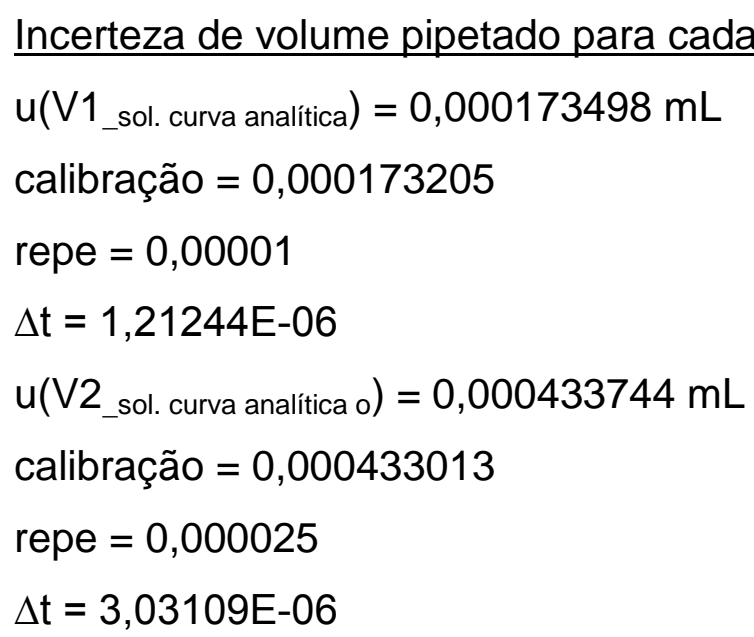




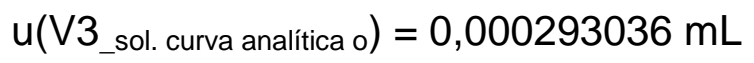

calibração $=0,000288675$

repe $=0,00005$

$\Delta \mathrm{t}=6,06218 \mathrm{E}-06$

$\mathrm{u}(\mathrm{V} 4$ _sol. curva analítica $)=0,000439554 \mu \mathrm{g} \cdot \mathrm{mL}^{-1}$

calibração $=0,000433013$

repe $=0,000075$

$\Delta \mathrm{t}=9,09327 \mathrm{E}-06$

$\mathrm{u}(\mathrm{V} 5$ _sol. curva analitica $)=0,000586072 \mathrm{~mL}$

calibração $=0,00057735$

repe $=0,0001$

$\Delta \mathrm{t}=1,21244 \mathrm{E}-05$

Incerteza do vial de $1 \mathrm{~mL}$

$\mathrm{u}\left(\mathrm{V} \_1 \mathrm{~mL}\right)=0,00586072 \mathrm{~mL}$

calibração $=0,005773503$

repe $=0,001$

$\Delta \mathrm{t}=0,000121244$

Incerteza combinada para cada uma das soluções da curva

$\mathrm{u}_{\mathrm{c}}\left(\right.$ Clord_Cis_C1 1 sol_curva) $=0,001970659$ (sol. 0,1069 $\mu \mathrm{g} \cdot \mathrm{mL}^{-1}$ )

$\mathrm{u}_{\mathrm{c}}($ Clord_Cis_C2 sol_curva $)=0,004926647$ (sol. 0,2673 $\mu \mathrm{g} \cdot \mathrm{mL}^{-1}$ )

$\mathrm{u}_{\mathrm{c}}$ (Clord_Cis_C3 sol_curva $)=0,004568897$ (sol. 0,5346 $\mu \mathrm{g} \cdot \mathrm{mL}^{-1}$ )

$\mathrm{u}_{\mathrm{c}}\left(\right.$ Clord_Cis_C4 $\left.4_{\text {sol_curva }}\right)=0,006853346$ (sol. 0,8019 $\mu \mathrm{g} \cdot \mathrm{mL}^{-1}$ )

$\mathrm{u}_{\mathrm{c}}\left(\right.$ Clord_Cis_C5 $\left.5_{\text {sol_curva }}\right)=0,009137794$ (sol. 1,0692 $\mu \mathrm{g} \cdot \mathrm{mL}^{-1}$ )

Os cálculos até aqui apresentados podem ser aplicados às duas matrizes (Caieiras e Franco da Rocha), uma vez que as grandezas de entrada não envolvem as respostas das amostras. A seguir são descritas individualmente as incertezas calculadas para as curvas analíticas e a recuperação de cada matriz. 


\section{MATRIZ CAIEIRAS}

\section{Incerteza da curva analítica}

Grandezas de entrada: área da amostra, área do branco, soluções da curva (C1 a C5), áreas referentes às soluções da curva.

\section{Incerteza combinada da curva analítica}

$\mathrm{u}_{\mathrm{c}}($ Clord_Cis curva analifica $)=0,0076 \mu \mathrm{g} \cdot \mathrm{mL}^{-1}$

\section{Incerteza da recuperação}

Grandezas de entrada: concentração da solução padrão e resultado da concentração encontrada.

\section{Incerteza combinada da recuperação}

$\mathrm{u}_{\mathrm{c}}($ Clord_Cisisecuperação $)=0,0058 \mu \mathrm{g} \cdot \mathrm{mL}^{-1}$

$\mathrm{u}\left(\mathrm{C}_{\text {real }}\right)=0,002503816 \mu \mathrm{g} \cdot \mathrm{mL}^{-1}$

$\mathrm{u}\left(\mathrm{C}_{\text {encontrado }}\right)=0,005529537 \mu \mathrm{g} \cdot \mathrm{mL}^{-1}$

\section{MATRIZ FRANCO DA ROCHA}

\section{Incerteza da curva analítica}

Grandezas de entrada: área das amostras, área do branco, soluções da curva (C1 a C5), áreas referentes às soluções da curva.

Incerteza combinada da curva analítica

$\mathrm{u}_{\mathrm{C}}\left(\right.$ Clord_Cis $\left.{ }_{\text {curva analitica }}\right)=0,0115 \mu \mathrm{g} \cdot \mathrm{mL}^{-1}$

\section{Incerteza da recuperação}

Grandezas de entrada: concentração da solução padrão e resultado da concentração encontrada.

Incerteza combinada da recuperação

$\mathrm{u}_{\mathrm{c}}($ Clord_Cis recuperação $)=0,0058 \mu \mathrm{g} \cdot \mathrm{mL}^{-1}$

$\mathrm{u}\left(\mathrm{C}_{\text {real }}\right)=0,002503816 \mu \mathrm{g} \cdot \mathrm{mL}^{-1}$

$\mathrm{u}\left(\mathrm{C}_{\text {encontrado }}\right)=0,005529537 \mu \mathrm{g} \cdot \mathrm{mL}^{-1}$ 


\section{CÁLCULO DE INCERTEZAS PARA O CLORDANO TRANS}

\section{Incerteza da preparação da solução padrão estoque.}

Grandezas de entrada: pureza do padrão u(P) e volume final da solução estoque $\mathrm{u}(\mathrm{V})$.

Componentes de incertezas

$\mathrm{u}(\mathrm{P})=0,005773503$

$\mathrm{u}(\mathrm{V})=0,03786159 \mathrm{~mL}$

Incerteza combinada

$\mathrm{u}_{\mathrm{c}}($ Clord_Trans sol. padrão $)=0,00113 \mu \mathrm{g} \cdot \mathrm{mL}^{-1}$

\section{Incerteza da preparação da solução de trabalho}

Grandezas de entrada: incerteza da solução estoque, volume pipetado da solução estoque individual para preparação da solução mista de trabalho e volume final da solução mista de trabalho.

Componentes de incertezas

$\mathrm{u}\left(\mathrm{C}_{\text {sol. estoque }}\right)=0,001133657 \mu \mathrm{g} \cdot \mathrm{mL}^{-1}$

$\mathrm{u}\left(\mathrm{V}_{\text {i_estoque }}\right)=0,000600002 \mathrm{~mL}$

calibração $=0,000519615$

repe $=0,0003$

$\Delta \mathrm{t}=1,73205 \mathrm{E}-06$

$\mathrm{u}\left(\mathrm{V}_{\text {final }}\right)=0,001760767 \mathrm{~mL}$

calibração $=0,001732051$

repe $=0,000316228$

$\Delta \mathrm{t}=1,73205 \mathrm{E}-05$

Incerteza combinada

$\mathrm{u}_{\mathrm{c}}($ Clord_Trans sol_estoque $)=0,023932806 \mu \mathrm{g} \cdot \mathrm{mL}^{-1}\left(\right.$ Sol. $\left.11,482 \mu \mathrm{g} \cdot \mathrm{mL}^{-1}\right)$ 


\section{Incerteza da preparação das soluções de calibração para a curva analítica}

Grandezas de entrada: incerteza da solução de trabalho, volume pipetado da solução de trabalho e volume dos balões usados para a diluição das soluções.

Incerteza de volume pipetado para cada solução da curva

u(V1_sol. curva analítica $)=0,000173498 \mathrm{~mL}$

calibração $=0,000173205$

repe $=0,00001$

$\Delta \mathrm{t}=1,21244 \mathrm{E}-06$

u(V2_sol. curva analítica $)=0,000433744 \mathrm{~mL}$

calibração $=0,000433013$

repe $=0,000025$

$\Delta \mathrm{t}=3,03109 \mathrm{E}-06$

u(V3_sol. curva analítica $)=0,000293036 \mathrm{~mL}$

calibração $=0,000288675$

repe $=0,00005$

$\Delta \mathrm{t}=6,06218 \mathrm{E}-06$

$\mathrm{u}(\mathrm{V} 4$ _sol. curva analítica $)=0,000439554 \mathrm{~mL}$

calibração $=0,000433013$

repe $=0,000075$

$\Delta \mathrm{t}=9,09327 \mathrm{E}-06$

u(V5_sol. curva analítica o $)=0,000586072 \mathrm{~mL}$

calibração = 0,00057735

repe $=0,0001$

$\Delta \mathrm{t}=1,21244 \mathrm{E}-05$

Incerteza do vial de $1 \mathrm{~mL}$

$\mathrm{u}\left(\mathrm{V}_{\text {_1 }} \mathrm{mL}\right)=0,00586072 \mathrm{~mL}$

calibração $=0,005773503$ 


$$
\begin{aligned}
& \text { repe }=0,001 \\
& \Delta t=0,000121244
\end{aligned}
$$

Incerteza combinada para cada uma das soluções da curva

$\mathrm{u}_{\mathrm{c}}\left(\right.$ Clord_Trans_C1 $\left.1_{\text {sol_curva }}\right)=0,002116268$ (sol. 0,1148 $\left.\mu \mathrm{g} \cdot \mathrm{mL}^{-1}\right)$

$\mathrm{u}_{\mathrm{c}}\left(\right.$ Clord_Trans_C2 $\left.2_{\text {sol_curva }}\right)=0,005290671$ (sol. 0,2871 $\mu \mathrm{g} \cdot \mathrm{mL}^{-1}$ )

$\mathrm{u}_{\mathrm{c}}\left(\right.$ Clord_Trans_C3 $\left.3_{\text {sol_curva }}\right)=0,004906487$ (sol. 0,5741 $\mu \mathrm{g} \cdot \mathrm{mL}^{-1}$ )

$\mathrm{u}_{\mathrm{c}}\left(\right.$ Clord_Trans_C4 $\left.4_{\text {sol_curva }}\right)=0,007359731$ (sol. 0,8612 $\mu \mathrm{g} \cdot \mathrm{mL}^{-1}$ )

$\mathrm{u}_{\mathrm{c}}($ Clord_Trans_C5 sol_curva $)=0,009812975$ (sol. 1,1482 $\mu \mathrm{g} \cdot \mathrm{mL}^{-1}$ )

Os cálculos até aqui apresentados podem ser aplicados às duas matrizes (Caieiras e Franco da Rocha), uma vez que as grandezas de entrada não envolvem as respostas das amostras. A seguir são descritas individualmente as incertezas calculadas para as curvas analíticas e a recuperação de cada matriz.

\section{MATRIZ CAIEIRAS}

\section{Incerteza da curva analítica}

Grandezas de entrada: área da amostra, área do branco, soluções da curva (C1 a C5), áreas referentes às soluções da curva.

Incerteza combinada da curva analítica

$\mathrm{u}_{\mathrm{c}}($ Clord_Trans curva analitica $)=0,0093 \mu \mathrm{g} \cdot \mathrm{mL}^{-1}$

\section{Incerteza da recuperação}

Grandezas de entrada: concentração da solução padrão e resultado da concentração encontrada.

Incerteza combinada da recuperação

$$
\begin{aligned}
& \mathrm{u}_{\mathrm{c}}(\text { Clord_Trans } \\
& \mathrm{u}\left(\mathrm{C}_{\text {real }}\right)=0,002503813 \mu \mathrm{g} \cdot \mathrm{mL}^{-1} \\
& \mathrm{u}\left(\mathrm{C}_{\text {encontrado }}\right)=0,0005019823 \mu \mathrm{g} \cdot \mathrm{mL}^{-1}
\end{aligned}
$$




\section{MATRIZ FRANCO DA ROCHA}

\section{Incerteza da curva analítica}

Grandezas de entrada: área das amostras, área do branco, soluções da curva (C1 a C5), áreas referentes às soluções da curva.

Incerteza combinada da curva analítica

$\mathrm{u}_{\mathrm{C}}\left(\right.$ Clord_Trans $\left.\mathrm{curva}_{\text {analítica }}\right)=0,0089 \mu \mathrm{g} \cdot \mathrm{mL}^{-1}$

\section{Incerteza da recuperação}

Grandezas de entrada: concentração da solução padrão e resultado da concentração encontrada.

Incerteza combinada da recuperação

$\mathrm{U}_{\mathrm{c}}($ Clord_Trans recuperação $)=0,0055 \mu \mathrm{g} \cdot \mathrm{mL}^{-1}$

$\mathrm{u}\left(\mathrm{C}_{\text {real }}\right)=0,002503813 \mu \mathrm{g} \cdot \mathrm{mL}^{-1}$

$\mathrm{u}\left(\mathrm{C}_{\text {encontrado }}\right)=0,005019823 \mu \mathrm{g} \cdot \mathrm{mL}^{-1}$ 


\section{BIBLIOGRAFIA}

1. ABNT (Associação Brasileira de Normas Técnicas); Solo - Determinação do teor de matéria orgânica por queima a $440^{\circ} \mathrm{C}$ (NBR 13600), 1996.

2. Agency for Toxic Substance Substances and Disease Registry - ATSDR. Departament of Health and Human Services, Public Health Service. Heptachlor e Heptachlor Epoxide., 2007.

3. ALMEIDA, F. V.; CENTENO, A. J.; BISINOTI, M. C.; JARDIM, W. F. Substâncias Tóxicas Persistentes (STP) no Brasil. Quim. Nova, Vol. 30, p. 1976-1985, 2007.

4. ANASTASSIADES, M.; LEHOTAY, S. J. Fast and Easy Multiresidue Method Employing Acetonitrile Extraction / Partitioning and "Dispersive Solid-Phase Extraction" for the Determination of Pesticide Residues in Produce. Journal of AOAC International, v. 86, p. 412-431, 2003.

5. ANASTASSIADES, M.; SCHERBAUM, E.; TASDELEN, B.; STAJNBAHER, D. Crop protection, public health, environmental safety. Wilei-VCH, 2007.

6. ANVISA (Agência Nacional de Vigilância Sanitária); Resolução RE no899, de 29/05/2003.

7. ASAMOTO, B. FT-ICR MS: Analytical Applications of Fourier Transform Íon Cyclotron Resonance Mass Spectrometry, VCH, 1991.

8. ASHCROFT, A. E. lonization methods in organic mass spectrometry. The Royal Society of Chemistry, 1997.

9. AUGUSTO, F.; ANDRADE, J. C.; CUSTÓDIO, R.;. Disponível em: $<$ http://www.chemkeys.com> Acesso em 13/03/2010.

10. BARBER, M.; BORDOLI, R.S; SEDGWICK, R. D.; TYLER, A. N. J. Chem. Soc. Chem. Commum., v. 7, p.325, 1981.

11. BARKER, S. A. Application of matrix solid-phase dispersion in food analysis. Journal of chromatography A, v. 63, p. 880, 2000.

12. BARROS NETO, B.; PIMENTEL, M. F.; ARAÚJO, M. C. Quim. Nova, v. 25, p. 856, 2002.

13. BARROS NETO, B.; SCARMINIO, I. S.; BRUNS, R. E. Como Fazer Experimentos: Pesquisa e Desenvolvimento na Ciência e na Indústria. Editora da Unicamp, 2001.

14. BENN F. R.; McAULIFFE, C. A. Química e Poluição. São Paulo, Editora da USP, 1981.

15. BEYNON J. H.; MORGAN, R. P. The development of mass spectroscopy: an historical account. Int. J. Mass Spectrom. Ion Phys., v. 27, pp.1, 1978.

16. BOX, G. E. P.; HUNTER, W. G.; HUNTER, J. S. Statistics for Experimenters. Wiley, 1987. 
17. BRASIL, Supremo Tribunal Federal. Portaria n. 329 de 2 de setembro de 1985. Ementa da portaria do Diário Oficial da República Federativa do Brasil, Brasília, v. 123, n. 168, p. 12941, Seção I, 1985.

18. BRITO, N. M.; JUNIOR, O. P. M.; POLESE, L.; RIBEIRO, M. L. Validação de Métodos Analíticos: estratégia e discussão. Ecotoxicol. E Meio Ambiente, v. 13, p. 129-146, 2003.

19. BUOSI, D.; FELFILI, J. M. Recuperação de áreas contaminadas por pesticidas organoclorados na cidade dos meninos, município de Duque de Caxias, RJ. Sociedade de Investigações Florestais (SIF), v. 28, p. 465470, 2004.

20. BURNS, D. T.; DANZER, K.; TOWNSHEND, A. Use of the term "recovery" and "apparent recovery" in analytical procedures Pure Appl. Chem., v. 74, p. 2201, 2002

21. BUSTILLOS, O. V.; SASSINE, A.; MARCH, R.; A espectrometria de massas quadrupolar, $1^{a}$ ed., Scortecci: São Paulo, Brasil (2003).

22. CAMEL, $V$. Supercritical fluid extraction as a useful method for pesticides determination. Journal of Chromatography A; v. 26, p.99, 1998.

23. CASCAES, J. M. Ocorrência de PCBs, PBDEs e pesticidas organoclorados em Prionace glauca da costa sul brasileira. Dissertação de Mestrado. Universidade de São Paulo, 2009.

24. CAVALCANTI, J. E. A década de 90 é dos resíduos sólidos. Revista Saneamento Ambiental, ํㅜ 54, p. 16-24, nov./dez. 1998.

25. CAVERO, E. S. Manual de Inseticidas e acaricidas: aspectos toxicológicos. Pelotas. Editora Aimara, 1976.

26. CDER (Center of Drug Evaluation and Research). United States Food and Drug Administration. General Principles of Validation, Rockville, 1987.

27. CDER (Center of Drug Evaluation and Research). United States Food and Drug Administration. Review Guide: Validation of Chromatography Methods, Rockville, 1993.

28. CETESB - GTS (Companhia de Tecnologia de Saneamento Ambiental). Guia de Amostragem de Solo, 1999.

29. CETESB (Companhia de Tecnologia de Saneamento Ambiental). Documento técnico informativo: 0005/09/CLS de 13/01/2009.

30. CETESB (Companhia de Tecnologia de Saneamento Ambiental). Projeto GTZ. Lista Holandesa de Valores de Qualidade do solo e da água subterrânea - Valores STI, 1999.

31. CHALLONER, J. 1001 Invenções que mudaram o mundo. Sextante, 2010.

32. CICT/FIOCRUZ - Centro de Informação Científica e Tecnológica/FIOCRUZ (1998). Sistema Nacional de Informações Tóxico-Farmacológicas 
(SINITOX). Estatística Anual de Casos de Intoxicações e Envenenamento: Brasil, 1996.

33. CICT/FIOCRUZ - Centro de Informação Científica e Tecnológica/FIOCRUZ (2000). Sistema Nacional de Informações Tóxico-Farmacológicas (SINITOX). Estatística Anual de Casos de Intoxicações e Envenenamento: Brasil 1999.

34. CIENFUEGOS, F.; VAITSMAN, D. Análise Instrumental. Interciência, 2000.

35. CIOLA, R. Fundamentos da Cromatografia a Gás. Edgar Blucher, 1985.

36. COCKERMAN, G. L. Basic environmental toxicology. Boca Raton, Flórida: CRC Press, 1994.

37. Codex Alimentarius Commission on Methods of Analysis and Sampling; Criteria for Evaluating Acceptable Methods of Analysis for Codex.

38. CONAMA (Conselho Nacional do Meio Ambiente). Resolução 420/2009.

39. CORREIA M.; DELERUE-MATOS, C.; ALVES, A. Development of a SPME-GC-ECD methodology for selected pesticides in must and wine samples. Fresenius' Journal of Analitycal Chemistry, 369-647, 2001.

40. COTTA, J. A. O. Diagnóstico ambiental do solo e sedimento do parque estadual turístico do Alto Ribeira (PETAR). Dissertação de Mestrado. Universidade de São Paulo (São Carlos), 2003.

41. CUADROS-RODRÍGUEZ, L.; GÁMIZ-GRACIA, L.; ALMANSA-LÓPEZ, E. M; BOSQUE-SENDRA, J. M.; Trends Anal. Chem., v. 20, p. 620, 2001,

42. DEAN, J. R.; XIONG, G. Extration of organic pollutants from environmental matrices: selection of extraction technique. Trends in analytical chemistry, v. 19, n. 9, 2000.

43. Declaration on the elimination of Persistent Organic Polluants (POPs). Stockholm Declaration, 2001. Acesso em: 09/04/2010. Disponível em: $<$ http:// www.geogiastrait .org/Articles\% 202001/ stockholm.htm>

44. DEMPSTER, A. J. Phys. Rev., V. 18, p. 415, 1921.

45. DOLE, M.; MACK, L. L.; HINES, R. L.; MOBLEY, R. C..; FERGUSON, L. D.; ALICE, M. B. J. Chem. Phys., v. 49, p. 2240, 1968.

46. DOMINGUEZ, L. A. E. Determinação de focos secundários de contaminação por hexaclorociclo-hexano no solo da cidade dos meninos, Duque de Caxias (RJ). Dissertação de Mestrado. Escola Nacional de Saúde Pública Fundação Oswaldo Cruz, 2001.

47. DORIGATTI, A. Aplicação de Cromatografia Gasosa em Estudos de Dissipação de Herbicida em Solos Brasileiros. Dissertação de Mestrado. Unicamp, 1987.

48. EPA (Environmental Protection Agency); Regional Screening Levels for Chemical Contaminants at Superfund Sites June 20, 2008. Disponível em: $<$ http://www.calscience.com/PDF/PRG Table.pdf $>$. Acesso em 12 fev. 2010. 
49. ESB (2006). Escola Superior de Biotecnologia - Universidade Católica Portuguesa. Poluentes Orgânicos Persistentes. Acesso em: 14 mar. 2009. Disponível em: <http://www.esb.ucp.pt/gea/myfiles/pops>

50. ETO. M. Chemistry of plant protection. Berlin: Spring-Verlag, 1990.

51. FALCH, F.; RICCI, A.; WOLLFF, M. S.; GODBOLD, J.; DECKERS, P. Pesticides and polychlorinated biphenyl residues in human breast lipids and their relation to breast cancer. Archives of Environmental Health, v. 47, p. $143-146,1992$.

52. FELIX, F. F.; NACKIENE, S.; DÓREA, H. S. Poluentes Orgânicos Persistentes (POPs) como Indicadores da Qualidade do Solo. Fapese, v.3, p. 39-62, 2007.

53. FERNíCOLA, N. A. G. G. Toxicologia de los inseticidas organoclorados. Boletim Santel Panama, v. 98, p. 1-6, 1985.

54. FERRACINI, V. L.; PESSOA M. C. Y. P.; SILVA, A. S.; SPADOTTO C. A. Análise de risco de contaminações das águas subterrâneas e superficiais da região de Petrolina - PE e Juazeiro - BA. Ecotoxicol e Meio Ambiente. v. 11, p. 1-16, 2001.

55. FILHO, E.S. Grau de exposição a praguicidas organoclorados em moradores de aterro a céu aberto. Revista de Saúde Pública / Journal of Public Health, v. 37, n. 4, p. 515-522, 2003.

56. FLORES, A. V.; RIBEIRO, J. N.; NEVES, A. A.; QUEIROZ, E. L. R. Organoclorados: um problema de saúde pública, Rev. Ambiente \& Sociedade (ANPPAS), v. VII, ำ2, 2004.

57. FURUSAWA, H. A. Validação de Ensaios Químicos. São Paulo, IPENCNEN/SP, 2007 (adaptação eletrônica baseada no documento DOQCGCRE-008 de 01 mar. 2003 do INMETRO).

58. GARP (Associação Grupo de Analistas de Resíduos de Pesticidas); Manual de Resíduos de Pesticidas em Alimentos (apostila), 1999.

59. Google Earth, disponível em: <http//maps.google.com/maps>. Acesso em 18 mar. 2010.

60. GOTTLIEB, O. R.; Introdução à espectrometria de massa das substâncias orgânicas, USPCQ: Rio de Janeiro, 1968.

61. GUEDES, R. N. C.; Toxicologia dos inseticidas. Ed. Universidade Federal de Viçosa, 1999.

62. GUERRA, M. S.; SAMPAIO, D. P. A. Receituário agronômico. 2. Ed. São Paulo: Editora Globo, 1991.

63. GUIA EURACHEM. Determinando a incerteza na medição analítica. 2ed. Versão Brasileira, 2002.

64. HILDERBRAND, D. L. Int. J. Mass Spectrom., v. 197, p.237, 2000.

65. HODGES, L. Environmental pollution. $2^{\mathrm{a}} \mathrm{ed}$. New York:Holt, 1977.

66. HOLSTEGE, D. M.; SCHARBERG, D. L.; TOR E. R.; HART, L. C.; GALEY, F. D. A rapid multiresidue screen for organophosphorous, organochlorine, and $\mathrm{N}$-methyl carbamate insectides in plant and animal 
tissues. Journal of the Association of Oficial Analytical Chemists, v. 77, p. 1263, 1994.

67. HORNING, E. C.; CARROL, D. I., DZIDIC, I.; HAEGELE, K. D.; HORNING, M. G.; STILLWELL, R. N. J. Chromatogr Sci., v. 12, p.725, 1974.

68. HORNING. E. C.; HORNING, M. G.; CARROL, D. I.; DZIDIC, I.; STILLWELL, R. N. Anal. Chem., v. 45, p. 936, 1973.

69. HORWITZ, W.; ALBERT, R. The Horwitz ratio (HorRat): a useful index of method performance with respect to precision. Journal of AOAC International, v. 89, n. 4, 2006.

70. HUBER, L.; LC-GC Int., v. 11, p. 96, 1998.

71. HUSSAIN, M. T.; SAEEd, A.; RAMA, N. H. J. Chem. Soc. Pak., v. 42, p. 23, 2001.

72. HYOTLAINEN, T.; TUUTIJARVI, T.; KUOSMANEN, K.; RIEKKOLA, M. L. Determination of pesticides residues in red wines with microporous membrane liquid-liquid extraction and gas chromatography. Analytical and Bioanalytical Chemistry, p. 372-732, 2002.

73. Instituto Brasileiro de Geografia e Estatística - IBGE. Censo Populacional 2010.

$$
\text { Disponível }
$$

em:

$<$ http://www.ibge.gov.br/home/estatistica/populacao/censo2010/calendario .shtm>. Acesso em 29 nov. 2010.

74. Instituto Nacional de Metrologia, Normalização e Qualidade Industrial (INMETRO); Orientações sobre Validação de Métodos Analíticos, DOQCGCRE-008, 2010.

75. International Conference on Harmonisation (ICH); Validation of Analytical Procedures: Definitions and Terminology, Q2A (CPMP/ICH/381/95), 1995.

76. International Conference on Harmonisation (ICH); Validation of Analytical Procedures: Definitions and Terminology, Q2A (CPMP//CH/381/95), 1995.

77. International Standard Organization; General Requirements for the Competence of Testing and Calibration Laboratories, ISO/IEC 17025, 1999.

78. International Standard Organization; Statistics-Vocabulary and SymbolsPart 1: Probability and General Statistical Terms, ISO 3534-1, 1993.

79. JAVARONI, R. C. A.; LANDGRAF, D.; REZENDE, M. O. Comportamento dos herbicidas atrazina e alaclor aplicados em solo preparado para 0 cultivo de cana-de-açucar. Química Nova, v. 22, p. 58-64, 1999.

80. KIM, J.; SMITH, A. Distribution of organochlorine pesticides in soil from South. Chemosphere, v. 43, p. 137-140, 2001.

81. KONRADSEN, F.; VAN DER HOEK, W.; AMERASINGUE, F. P.; MUTERO, C.; BOELEE, E. Engineering and malaria control: learning from the past 100 years. Acta Tropica, v. 89, p. 99-108, 2004. 
82. KRAMER, B. K.; RYAN, P. B. Soxhlet and microwave extration in determining the bioaccessibility of pesticides from soil and model solids. Conference on Hazardous Waste Research, p. 196-210, 2000.

83. KRULL, I.; SWARTZ, M.; LC-GC, v. 16, p. 464, 1998.

84. LANÇAS, F. M. Validação de Métodos Cromatográficos de Ensaio. São Carlos: RiMa, 2004. 62 p.

85. LEHOTAY, S. J.; MASTOVSKA, K.; LIGHTFIELD, A. R. Use of Buffering and Other Means to Improve Results of Problematic Pesticides in a Fast and Easy Method for Residue Analysis of Fruits and Vegetables. Journal of the Association of Official Analytical Chemists,v. 88, p.615, 2005.

86. LEITE, F. Validação em Análise Química, 4 a ed., Ed. Átomo: Campinas, 2002.

87. LESUEUR, C.; GARTNER, M.; MENTLER, A.; FUERHACKER, M. Comparison of four extraction methods for the analysis of 24 pesticides in soil samples with gas chromatography - mass spectrometry and liquid chromatography - ion trap - mass spectrometry. Talanta, v.75, p.284 293, 2008.

88. LING, Y. C.; TENG, H. C. Supercritical fluid extraction and clean-up of organochlorine pesticides and polychlorinated biphenyls in mussels. Journal of Chromatography A., p.790:153, 1997.

89. MAGGS, J. R.; JOYNES, P. L.; DAVIES, A. J.; LOVELOCK, J. E. The Electron Capture Detector - A New Mode of Operation. 1971.

90. MALLIAROS, C.; GUITONAS, A. Pré-treatment and elimination systems of toxic industrial waste and sludges. The case study of the department of Attika. Wat. Sci. Tech., v.36, p. 91-100, 1997.

91. MARCH, R. E. J. Mass Spectrom., v. 32, p. 351, 1997.

92. MARICONI, F. A. M. Inseticidas e seu emprego no combate as pragas. 7. Ed. São Paulo. Distribuidora, 1985.

93. MARICONI, L. A.; MIZUBUTI, E. S. G.; Fitopatologia x sociedade. Ação Ambiental, v. 2, p. 9-12, 1999.

94. MARONI, M.; COLSIO, C.; FERIOLI, A; FAIT, A. Introduction Toxicology, v. 143 , p. 5-8, 2000.

95. MARTINS, E. A. J. Estimativa da incerteza em Ensaios Químicos. São Paulo, IPEN-CNEN/SP, 2010 (adaptação eletrônica baseada no documento EURACHEM/CITAC Guide.Second Edition, 2000).

96. MATUO, Y. K.; LOPES, J. N. C.; MATUO, T. Contaminação do leite humano por organoclorados DDT, BHC e ciclodienos. Ed. FUNEP, 1990.

97. MILLER, J. C.; MILLER, J. N.; Statistics for Analytical Chemistry, $2^{\mathrm{a}}$ ed., Ellis Horwood: Chichester, 1988. 
98. MOREIRA, L. F.; CRUZ, J. C. S. Uso correto e seguro de fitossanitários. Viçosa, MG: EMATTER, DETEC; Departamento Técnico. Não paginado, 1996.

99. MUNSON, M. S. B.; FIELD, F. H. J. Am. Chem. Soc., v. 88, p. 2621, 1966.

100. MUSUMECI, M. R. Defensivos agrícolas e sua interação com a microbiota do solo, In: TSAI, S. M.; NEVES, M. C. P. (org) Microbiologia do solo, Campinas: Sociedade Brasileira do Sol, 1992, p. $341-360$.

101. NAKAGAWA, L M.; ANDREA, M. M. Efeitos de alterações nas características do solo sobre a degradação de hexaclorobenzeno. Bras. Ci. Solo, v. 30, p. 575-582, 2006.

102. NAKAGAWA, L. E.; ANDREA, M. M. Liberação de resíduos não-extraíveis ou ligados do herbicida atrazina em solo e sua absorção por plantas. Pesq. Agropec. Brás., v. 35, p. 1517-1522, 2000.

103. NIER, A. O. Rev. Sci. Instrum., v. 18, p.398, 1947.

104. O'CONNOR, C. S. S. Price, S. D. Int. J. Mass Spectrom. , v. 11, p. 184, 1999.

105. O'CONNOR, C. S. S.; Price, S. D. Int. J. Mass Spectrom. , v. 119, p. 177, 1998.

106. OLIVEIRA, W.; ADEODATO, S. O. O bairro que respira veneno. Globo Ciência, v. 6, p. 48-51, 1997.

107. OPAS/OMS (1991). HENAO, S. \& COREY,G. - Plaguicidas Inhibidores de las Colinesterasas. Serie Vigilancia n. 11. Centro Panamericano de Ecologia Humana y Salud. Programa de Salud Ambiental. Mepetec. México.

108. OPAS/OMS (1996). Manual de Vigilância da Saúde de Populações Expostas a Agrotóxicos. Brasília. Representação do Brasil.

109. OSTWALD, E. O.; ALBRO, P. W.; MCKINNEY, J. D. J. Chromatogr.; v. 98, p. 363, 1974.

110. OTTAWAY, J. H. Bioquímica da Poluição. São Paulo. Editora da USP, 1982. PINHEIRO, A. C. B. F.; MONTEIRO, A. L. F. B. P. A. Ciências do Ambiente - ecologia, poluição e impacto ambiental. São Paulo: Editora Makron, 1992.

111. OVCHARENKO, V. V. SHAIKHUTDINOV, A.; PIHLAJA, K, STÁJER, G.; J. Am. Soc. Mass Spectrom., v. 12, p. 1049, 2003.

112. PAPADAKIS, E. N.; VRYSAS, Z.; PAPADOPOULOU-MOURKIDOU, E. Rapid Method for the determination of 16 organochlorine pesticides in sesame seeds by microwave-assisted extraction and analysis of extracts by gas chromatography-mass spectrometry. Journal of Chromatography A, v. 6, p.1127, 2006.

113. PAULA, J. L.; DUARTE, M. N. Manual de métodos de análise de solo EMBRAPA. Ed. UFV, 2ed, 1997. 
114. PERES, F. É. Veneno ou é Remédio? Os Desafios da Comunicação Rural sobre Agrotóxicos. Dissertação de Mestrado. ENSP/FIOCRUZ. Rio de Janeiro, 1999.

115. PINHEIRO, A. C. F. B.; MONTEIRO, A. L. F. B. P. A. Ciências do ambiente - ecologia, poluição e impacto ambiental. São Paulo: Editora Makron, 1992.

116. PINTO, C.G.; LAESPADA, M. E. F.; MARTÍN, S.H.; FERREIRA, A. M. C.; PAVÓN, J. L.; CORDERO, B. M. Simplified QuEChERS approach for the extraction of chlorinated compounds from soil samples. Talanta, v. 81, 385391, 2010.

117. PRATA, F. Comportamento do Glifosato no solo e deslocamento miscível de Atrazina. Tese de Doutorado, Universidade de São Paulo, 2002.

118. PRESTES, O. D.; ADAIME, M. B.; ZANELLA, R. QuEChERS: possibilidades e tendências no preparo de amostra para determinação multirresíduo de pesticidas em alimentos. Scientia Chromatographica; vol. 1, 51-64. 2011.

119. QUINETE, N. S. Extração de poluentes organoclorados persistentes em fragmentos remanescentes da mata atlântica, RJ: comparação de métodos. Dissertação de Mestrado. Universidade Federal Fluminense, 2005.

120. RAMOS, L.; KRISTENSON, E.M.; BRINKMAN, A. U. T. Current use of pressurised liquid extraction and subcritcal water extraction in environmetal analysis. Journal of Chromatography A, v. 5, p. 397, 2002.

121. RIBANI, M.; BOTTOLI, C. B. G.; COLLINS, C. H.; JARDIM, I. C. S. F.; MELO, L. F. C. Validação em métodos cromatográficos e eletroforéticos. Química. Nova, v. 27, n. 5, p. 771-780, 2004.

122. RIGITANO, R. L. O.; BARBOSA, T. M. L. Influência da classe e profundidade do solo na degradação do inseticida-nematicida aldicarb.

Pesquisa Agropecuária Brasileira, v. 29, p. 955-960, 1994.

123. RISSATO, S. R.; LIBÂNIO, M.; GIAFFERIS, G. P.; GERENUTTI, M. Determinação de pesticidas organoclorados em água de manancial, água potável e solo na região de Baurú (SP). Química Nova, v. 27, p. 739-743, 2004.

124. SALEH, M.; KAMEL, A.; RAGAB, A.; EL-BAROTY, G.; EL-SEBAE, A. K. Regional distribution of organochlorine enseticide residues in human milk from Egypt. Journal Environmental Science Health, v. B31, p. 241-255, 1996.

125. SASSINE, A. Determinação de Pesticidas piretróides em leite bovino por meio da cromatografia a gás acoplada à espectrometria de massas de armadilha iônica- GC/ITMS ("ín trap"). Dissertação de mestrado. Instituto de Pesquisas Energéticas e Nucleares (IPEN), 2002.

126. ŠEVČíK, J. Detectors in gas chromatography. Elsevier Scientific Publishing Company ,1976.

127. SILVERSTAIN, R.M.; BASSLER, G. C.; MORRILL, T.C. Spectrometric identification of organic compounds, Koogan, 1963. 
128. SKOOG, D. A.; HOLLER, F. J.; NIEMAN, T. A. Principles of Instrumental Analysis. Saunders College Publishing, 1998.

129. SMITH, R. M.; BUSCH, K. L.; Understanding Mass Spectra-A Basic Approach, Wiley: New York, 1999.

130. SNYDER, L. R. ; KIRKLAND, J. J.; GLAJCH, J. L.; Practical HPLC Method Development, 2 a ed., Wiley: New York, 1997.

131. SOLOMONS, T. W. G. Organic Chemistry, $4^{a}$ ed. Wiley, New York, EUA, 1968.

132. SOUZA, R. R. Desenvolvimento e validação de metodologia analítica para determinação de disruptores endócrinos resultantes de atividades entrópicas nas águas da região do Rio Paraíba do Sul, SP. Dissertação de Mestrado. Instituto de Pesquisas Energéticas e Nucleares, 2011.

133. SSEBUGERE, P.; WASSWA, J.; MBABAZI, J.; NYANZI, S. A.; KIREMIRE, B. T.; MARCO, J. A. M. Organochlorine pesticides in soils from southwestern Uganda. Chemosphere, v. 78, p. 1250-1255, 2010.

134. SUBRAMANIAN, A.; OHTAKE, M.; KUNISUE, T.; TANABE, S. High levels of organochlorines in mother's milk from Chennai (Madras) city, India. Chemosphere, v. 68, p. 928-939, 2007.

135. SWARTZ, M. E.; KRULL, I. S.; Pharm. Technol., v. 2, p. 12, 1998.

136. SYKES, P. Guia de Mecanismos da Química Orgânica. RJ, Brasil, 1969.

137. TAKAYAMA, M. Int. J. of Mass Spectrom. Ion Processes, v. 144, p.199, 1995.

138. THOMPSON, M.; ELLISON, S. L. R.; FAJGELJ, A.; WILLETTS, P.; Wood, R.; Pure Appl. Chem., v. 71, p. 337, 1999.

139. THOMPSON, M.; ELLISON, S. L. R.; WOOD, R.; Pure Appl. Chem., v. 74, p. 835, 2002.

140. TORGESON, D. F.; SKOWRONSKI, R. P.; MACFARLANE, R. D. Biochem. Biophys. Res. Commun., v. 60, p. 616, 1974.

141. TURK, J. Introduction to environmental studies. 3. Ed. New York: Saunders College, 1989.

142. UNEP - United Nations Environment Programme. Disponível em: $<$ http://www.unep.org/gef >. Acesso em 12jul. 2010.

143. United States Pharmacopeia Convention; US Pharmacopeia 24, Validation of Compendial Methods <1225>, Rockville, 1999.

144. US-FDA (United States Food and Drug Administration), Center for Drug Evaluation and Research (CDER); Review Guide: Validation of Chromatographic Methods, Rockville, 1993.

145. US-FDA (United States Food and Drug Administration), Center for Drug Evaluation and Research (CDER); General Principles of Validation, Rockville, 1987. 
146. US-FDA (United States Food and Drug Administration); Reviewer Guidance, Validation of Chromatographic Methods, 1994.

147. VALENTIM, L. S. O. Sobre a produção de bens e males nas cidades Estrutura urbana e cenários de risco à saúde em áreas contaminadas da Região Metropolitana de São Paulo. Tese de Doutorado. Universidade de São Paulo, 2010.

148. VALSAMAKI, V. I.; BOTI, V.I.; SAKKAS, V. A.; ALBANIS, T. A. Determination of organochlorine pesticides and polychlorinated biphenyls in chicken eggs by matrix solid phase dispersion. Analytica Chimica Acta, p. 195-573, 2006.

149. VANDER HEYDEN, Y.; NIJHUIS, A.; SMEYERS-VERBEKE, J.; VANDEGINSTE, B. M. G.; MASSART, D. L. Guidance for robustness/ruggedness test in method validation. J. pharmaceutical and biomedical analysis, v. 24, p. 723 - 753, 2001.

150. VIEIRA, E. O. Efeito da irrigação na movimentação no solo de inseticidas de tratamento de sementes de milho (Zea mays L.). Dissertação de Mestrado. Universidade de Viçosa - MG, 1996.

151. VIM (Vocabulário Internacional de Metrologia). Conceitos Fundamentais e Gerais e Termos Associados. Instituto Nacional de Metrologia, Normalização e Qualidade Industrial (INMETRO). Versão Brasileira, 2008.

152. WHO (World Health Organization Expert Committee on Specifications for Pharmaceutical Preparations); Thirty-second report, Technical Report Series, n‥823, Geneva, 1992.

153. YAMASHYTA, M.; FENN, J. B.; Phys. Chem.,v. 88, p. 4451, 1984.

154. ZHANG, L.; DONG, L.; SHI, S.; ZHOU, L.; ZHANG, T.; HUANG, Y. Organochlorine pesticides contamination insurface soils from two pesticide factories in southeast China. Chemosphere, v. 77, p. 628-633, 2009. 